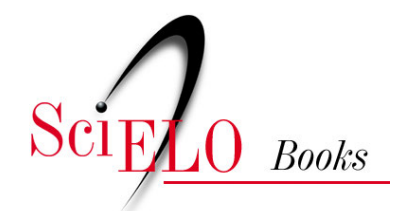

\title{
Epidemiologia e saúde dos povos indígenas no Brasil
}

\author{
Carlos E. A. Coimbra Jr. \\ Ricardo Ventura Santos \\ Ana Lúcia Escobar \\ (orgs.)
}

COIMBRA JR., CEA., SANTOS, RV and ESCOBAR, AL., orgs. Epidemiologia e saúde dos povos indígenas no Brasil [online]. Rio de Janeiro: Editora FIOCRUZ; Rio de Janeiro: ABRASCO, 2005. 260 p. ISBN: 85-7541-022-9. Available from SciELO Books <http://books.scielo.org>.

\section{(1) (1)(2)}

All the contents of this work, except where otherwise noted, is licensed under a Creative Commons Attribution-Non Commercial-ShareAlike 3.0 Unported.

Todo o conteúdo deste trabalho, exceto quando houver ressalva, é publicado sob a licença Creative Commons Atribuição Uso Não Comercial - Partilha nos Mesmos Termos 3.0 Não adaptada.

Todo el contenido de esta obra, excepto donde se indique lo contrario, está bajo licencia de la licencia Creative Commons Reconocimento-NoComercial-CompartirIgual 3.0 Unported. 


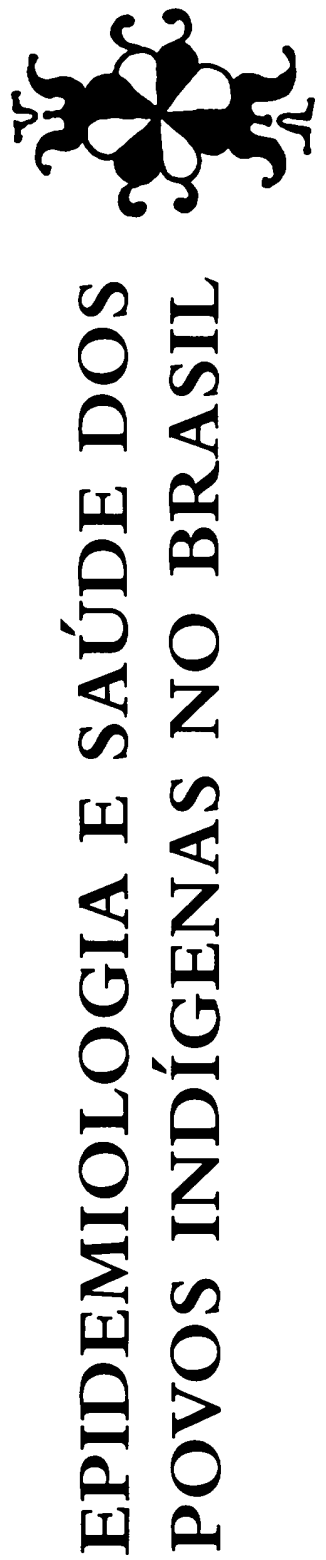


\section{FUNDAÇÃO OSWALDO CRUZ}

Presidente

Paulo Marchiori Buss

Vice-Presidente de Desenvolvimento

Institucional, Informação e Comunicação

Paulo Gadelha

\section{EDITORA FIOCRUZ}

\section{Coordenador}

Paulo Gadelha

Conselho Editorial

Carlos E. A. Coimbra Jr.

Carolina M. Bori

Charles Pessanha

Jaime L. Benchimol

José da Rocha Carvalheiro

José Rodrigues Coura

Luis David Castiel

Luiz Fernando Ferreira

Maria Cecília de Souza Minayo

Miriam Struchiner

Paulo Amarante

Vanize Macedo

\section{Coordenador Executivo}

João Carlos Canossa P. Mendes 


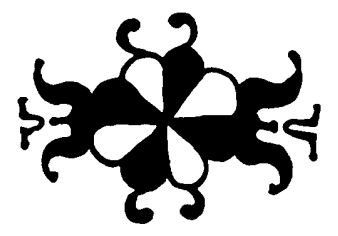

Carlos E. A. Coimbra Jr. Ricardo Ventura Santos Ana Lúcia Escobar organizadores

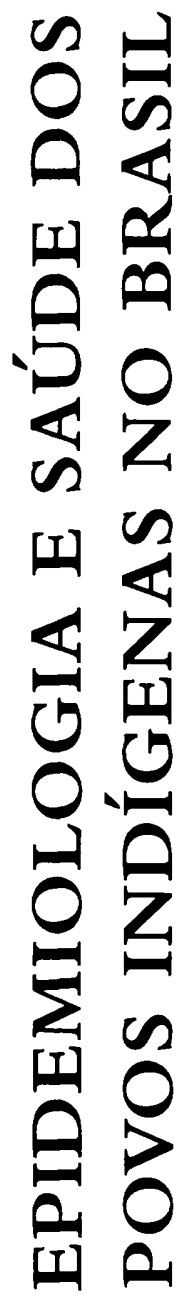


Copvright is: 20103 dos alutores

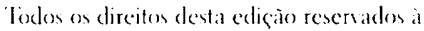

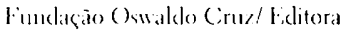

ISBN: $55-75+1-(1) 2-9$

Projetos grafico: Dinnowski Design I tcla

Ilustração de capa e viuhetas de abertura dos capítulos a partir de descrolio de (:uido Boggiani em "O) ("eduveo". Biblisteca Histórica do Brasil, volume. XIV, I ivararia

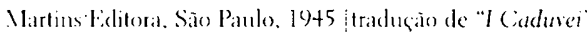
Mhava o (iuncuril. Viagoi dun Artista nell America Meridionale". Roma, 1595!.

Revisào e copiedespae: I eandro (amalho e Itamar ()liveira Esta publicacion foi possicel através de aporo da Fundacăo Ford. por meio do projeto Saude Indígena em Rondônia. evecutarlo pelo (éntro de Éstudos em Sinte do Inelio de Rondonia - (ZS.SIR i comênio I Iniversidade feederal de Ronclonia/ Fencola Nacional de Santede Priblical.

Caltalogaçàio na fonte

Centro de Informaçăo (ientifical e Teconologrica

Bibliotecal lincolu de Freitas Filho

$(: 6-5)$

Coimbra Jr. Cartos E. A torg. I

Pipidemiologia e sanide dos poros indigenas no Brasil /

(oganizado por (arlos t. A Coimbra Jr. Rio de Janciro:

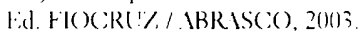

261) p.. tab). graff, malpass

1. Indion Sul- Anericaness. 2. Perfis Lipidemiotógicos. 3. Sande.

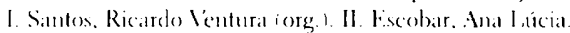

(:I)I $-20.0 \mathrm{~d} \cdot 950 .+1098 \mathrm{l}$

20113

Fititora FIOC:RI $1 \%$

A: Brasil t(1)36, l" anclar, sala 112, Manguinhos

21(1)+0.361. Rio de Jancion RJ

ted : 211 is $82-90139$ c $3852-90+1$

fax $: 21 ;$ is $\$ 2.9006$ e $3852-900$

(-11ail: editorarufocruz.br

lıt|p//\%wu fiocruz.br/editora

Anociaçäo Brasileira de Pós-(iraduaçào

(min Satide Colctiala ABRASC()

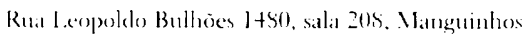

$210+1-210$. Rio de Janciro RJ

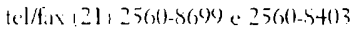

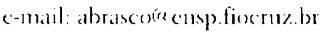

hetp//awww abrascosorg.br 


\section{AUTORES}

\section{Aline F. Rodrigues}

Centro de Estudos em Saúde do Índio de Rondônia, Universidade Federal de Rondônia, Porto Velho.

\section{Ana Felisa Hurtado Guerrero}

Centro de Pesquisa Leônidas \& Maria Deane.

Fundação Oswaldo Cruz, Manaus.

Ana Lúcia Escobar (organizadora)

Nícleo de Saúde e Centro de Estudos em Saúde do Índio de Rondônia, Universidade Federal de Rondônia, Porto Velho.

\section{Andrey M. Cardoso}

Equipe Multidisciplinar de Saúde Indígena, Pólo-Base Angra dos Reis, Angra dos Reis.

Carlos E. A. Coimbra Jr. (organizador) Escola Nacional de Saúde Pública, Fundação Oswaldo Cruz, Rio de Janeiro.

Cristiano L. M. Alves

Centro de Estudos em Saúde do Índio de Rondônia, Universidade Federal de Rondônia, Porto Velho.

\section{Dulce Lopes Barboza Ribas}

Centro de Ciências Biológicas e da Saúde, Universidade Federal de Mato Grosso do Sul. Campo Grande.

\section{Eliana E. Diehl}

Centro de Ciências da Saúde, Universidade Federal de Santa Catarina, Florianópolis.

\section{Evelyne Marie Therese Mainbourg} Centro de Pesquisa Leônidas \& Maria Deane, Fundação Oswaldo Cruz, Manaus.

\section{Inajara Rodrigues}

Secretaria de Estado da Saúde do Rio Grande do Sul, Porto Alegre.

\section{Inês E. Mattos}

Escola Nacional de Saúde Pública,

Fundação Oswaldo Cruz, Rio de Janeiro.

Ivone Menegolla

Secretaria de Estado da Saúde do Rio Grande do Sul, Porto Alcgre.

\section{Jesem D. Y. Orellana}

Centro de Estudos em Saúde do Índio de Rondônia, Universidade Federal de Rondônia, Porto Velho.

José Camilo Hurtado Guerrero Instituto Nacional de Pesquisas da Amazônia, Manaus.
Juberty Antonio de Souza

Centro de Ciências Biológicas e da Saúde, Universidade Federal de Mato Grosso do Sul, Campo Grande.

Luiz Carlos Brandão

Núcleo de Estudos de Saúde Pública/Projeto RASI, Universidade Federal do Amazonas, Manaus.

\section{Luiza Garnelo}

Centro de Pesquisa Leônidas \& Maria Deane,

Fundação Oswaldo Cruz e Departamento de Saúde Coletiva, Universidade Federal do Amazonas, Manaus.

Maria Clara V. Weiss

Instituto de Saúde Coletiva, Universidade Federal de Mato Grosso, Cuiabá.

Maria de Lourdes Drachler

Universidade do Vale do Rio dos Sinos

c Universidade de Caxias do Sul, Rio Grande do Sul.

Marilda Kohatsu

Secretaria de Saúde, Prefeitura Municipal de Londrina, Londrina.

Marlene de Oliveira

Secretaria de Ação Social, Prefeitura Municipal de Londrina, Londrina.

Maurício Soares Leite

Escola Nacional de Saúde Pública,

Fundação Oswaldo Cruz, Rio de Janeiro.

Regina M. de Carvalho Erthal

LACED, Museu Nacional, Universidade Federal do Rio de Janeiro, Rio de Janeiro.

Ricardo Ventura Santos (organizador) Escula Nacional de Saúde Pública, Fundação Oswaldo Cruz e Museu Nacional, Universidade Federal do Rio de Janeiro, Rio de Janeiro.

Rosalina J. Koifman

Escola Nacional de Saúde Pública,

Fundação Osualdo Cruz, Rio de Janeiro.

Rui Arantes

Escola Nacional de Saúde Pública, Fundação Oswaldo Cruz, Rio de Janeiro.

Silvia Angela Gugelmin Instituto de Nutrição,Universidade do Estado do Rio de Janeiro, Rio de Janeiro.

Sonia Tucunduva Philippi

Faculdade de Saúde Pública,

Universidade de São Paulo, São Paulo. 


\section{SUMÁRIO}

8

13

49

73

89

105

127

\section{APRESENTAÇÃO}

Carlos E. A. Coimbra Jr., Ricardo Ventura Santos

\& Ana Lúcia Escobar

CENÁRIOS E TENDÊNCIAS DA SAÚDE

E DA EPIDEMIOLOGIA DOS POVOS INDÍGENAS

NO BRASIL

Ricardo Ventura Santos \& Carlos E. A. Coimbra Jr.

SAÚDE BUCAL DOS POVOS INDÍGENAS

NO BRASIL: PANORAMA ATUAL E PERSPECTIVAS

Rui Arantes

ASPECTOS ALIMENTARES E NUTRICIONAIS

DE MÃES E CRIANÇAS INDÍGENAS TERÉNA, MATO GROSSO DO SUL

Dulce Lopes Barboza Ribas \& Sonia Tucunduva Philippi

CONDIÇÃO NUTRICIONAL DE UM GRUPO DE IDOSOS INDÍGENAS NO DISTRITO SANITÁRIO LESTE DE RORAIMA

Ana Felisa Hurtado Guerrero, Evelyne Marie Therese

Mainbourg \& José Camilo Hurtado Guerrero

PERFIS DE SAÚDE INDÍGENA, TENDÊNCIAS

NACIONAIS E CONTEXTOS LOCAIS: REFLEXÕES

A PARTIR DO CASO XAVÁNTE, MATO GROSSO

Maurício Soares Leite, Silvia Angela Gugelmin,

Ricardo Ventura Santos \& Carlos E. A. Coimbra Jr.

CAUSAS DE INTERNAÇÃO HOSPITALAR INDÍGENA EM RONDÔNIA. O DISTRITO SANITÁRIO

ESPECIAL INDÍGENA PORTO VELHO (1998-2001)

Ana Lúcia Escobar, Aline F. Rodrigues, Cristiano L. M. Alves, Jesem D. Y. Orellana, Ricardo Ventura Santos \& Carlos E. A. Coimbra Jr. 
O USO DE BEBIDAS ALCOÓLICAS NAS SOCIEDADES INDÍGENAS: ALGUMAS REFLEXÕES SOBRE OS KAINGÁNG DA BACIA DO RIO TIBAGI, PARANÁ Juberty Antonio de Souza, Marlene de Oliveira \& Marilda Kohatsu

PREVALÊNCIA DE DIABETES MELLITUS E DA SÍNDROME DE RESISTÊNCIA INSULÍNICA NOS ÍNDIOS GUARANÍ DO ESTADO DO RIO DE JANEIRO Andrey M. Cardoso, Inês E. Mattos \& Rosalina J. Koifman

CONTATO INTERÉTNICO, PERFIL SAÚDE-DOENÇA E MODELOS DE INTERVENÇÃO EM SAÚDE INDÍGENA: O CASO ENAWENÊ-NAWÊ, MATO GROSSO Maria Clara V. Weiss

A FORMAÇÃO DO AGENTE DE SAÚDE INDIGENA TIKÚNA NO ALTO SOLIMÕES:

UMA AVALIAÇÃO CRÍTICA

Regina M. de Carvalho Erthal

FINANCIAMENTO E ATENÇÃO À SAÚDE NO DISTRITO SANITÁRIO ESPECIAL INDÍGENA INTERIOR SUL Eliana E. Diehl, Maria de Lourdes Drachler, Ivone Menegolla \& Inajara Rodrigues

AVALIAÇÃO PRELIMINAR DO PROCESSO DE DISTRITALIZAÇÃO SANITÁRIA INDÍGENA NO ESTADO DO AMAZONAS

Luiza Garnelo \& Luiz Carlos Brandão 


\section{APRESENTAÇÃO}

O momento atual da saúde dos povos indígenas no Brasil caracteriza-se por intensas transformações, que englobam desde aceleradas mudanças nos perfis epidemiológicos até a reestruturação do sistema de atenção à saúde indígena. Não obstante, mesmo que transbordem evidências quanto às condições de marginalização sócio-econômica, com amplos impactos sobre o perfil saúde/doença, muito pouco se conhece sobre a saúde dos povos indígenas, ainda mais se considerarmos a enorme diversidade sócio-cultural e de experiências históricas de interação com a sociedade nacional.

No Brasil e em outras partes do mundo, as doenças infecciosas ocupam um locus diferenciado na história dos povos indígenas. É desnecessário reiterar a magnitude da desestruturação demográfica e sócio-cultural a elas associada, o que fez com que se tornassem elementos cruciais no processo de subjugação frente ao expansionismo ocidental. Ainda que as doenças infecciosas continuem a ocupar um papel proeminente no perfil epidemiológico indígena no país, há evidências de que a expressão das doenças crônicas não transmissíveis, como obesidade, hipertensão e diabetes mellitus, está se ampliando. A sobreposição de perfis epidemiológicos também se verifica na população brasileira em geral, mas é possível que seja mais intensa entre os povos indígenas. As consequiências dessa sobreposição (para os indivíduos, as comunidades e os serviços de saúde) são amplas, ainda que seja difícil caracterizá-las no contexto atual da saúde indígena no Brasil.

Desde 1999, aconteceram importantes mudanças no sistema de saúde voltado para os povos indígenas com a implantação dos Distritos Sanitários Especiais Indígenas (DSEIs), de norte a sul do país (ver Mapa). Há de se aguardar a acumulação de dados e experiências antes de ser possível aquilatar a extensão dos impactos associados a essa reestruturação. Como enfatizam vários autores neste volume, um dos grandes desafios a se enfrentar na implementação desse novo modelo de assistência é consolidá-lo (envolvendo centenas de milhares de usuários e agências governamentais e não governamentais), sem perder de vista a imensa sociodiversidade indígena, bem como a heterogeneidade de perfis epidemiológicos. Tal coadunação é o denominador comum do modelo, e também uma das facetas de mais difícil implementação.

A presente coletânea é constituída de uma seleção de textos e experiências que foram discutidos durante a primeira oficina de trabalho sobre o tema 
"Saúde e Epidemiologia das Populações Indígenas no Brasil" realizada durante um congresso promovido pela Associação Brasileira de Pós-Graduação em Saúde Coletiva - ABRASCO. A oficina aconteceu nos dias 23 e 24 de março de 2002, no campus da Pontifícia Universidade Católica (PUC), Curitiba, durante o V Congresso Brasileiro de Epidemiologia. Os tópicos abordados na oficina incluíram as doenças infecciosas, saúde bucal, situação nutricional de crianças, adultos e idosos, alcoolismo e a emergência das doenças crônicas não transmissíveis, bem como a formação de agentes indígenas de saúde, financiamento da saúde indígena, sistema de informação em saúde indígena, geração de indicadores epidemiológicos e a avaliação do processo de distritalização.

A realização da oficina de trabalho em Curitiba concretizou os esforços do primeiro ano de atuação do Grupo de Trabalho (GT) Saúde Indígena da ABRASCO, cujas principais metas foram assentadas por ocasião de reunião realizada na cidade de Manaus, em dezembro de 2000.1 Na ocasião, foram destacados dois objetivos principais a serem cumpridos pelo GT: (a) fomentar discussões acerca do estado atual das pesquisas sobre saúde indígena, prioritariamente nas áreas de epidemiologia e antropologia da saúde e (b) identificar lacunas do conhecimento, propor linhas de investigação e formas de articulação das instituições de pesquisa e ensino com os serviços de saúde e as comunidades indígenas.

A oficina de trabalho contou com a participação de trinta e três pessoas, resultando em um grupo que incluiu profissionais com formação nas mais diversas disciplinas constitutivas do campo da saúde coletiva, em especial antropologia, biologia, enfermagem, farmácia, medicina, nutrição e odontologia. Em relação à procedência, a distribuição dos participantes, segundo regiões do Brasil, foi a seguinte: Norte (6), Centro-Oeste (8), Sul e Sudeste (18) e Nordeste (1). Finalmente, em relação à inserção profissional, aproximadamente um terço dos participantes eram vinculados a órgãos/agências (governamentais ou não) prestadores de serviços de saúde às populações indígenas. Os demais participantes eram professores universitários e pesquisadores vinculados em quase sua totalidade a instituições públicas.

Várias pessoas e instituições apoiaram as atividades do GT de Saúde Indígena em 2001 e 2002, que culminaram com a publicação deste volume. Em especial, gostaríamos de reconhecer o apoio da Diretoria da ABRASCO, em particular de seu diretor, o Prof. José Carvalho de Noronha. Também foi imprescin- 
dível o suporte dado pela comissão organizadora do V Congresso Brasileiro de Epidemiologia, em especial de seu presidente, o Prof. Moisés Goldbaum. Péricles Silveira da Costa, então secretário-geral da ABRASCO, foi um grande estimulador da criação do GT Saúde Indígena e da realização da primeira oficina. As reuniões do GT Saúde Indígena, realizadas nesse período, foram apoiadas pela Escola Nacional de Saúde Pública e pelo Centro de Pesquisas Leônidas e Maria Deane, da Fundação Oswaldo Cruz. A realização da oficina de trabalho contou com o importante apoio da Fundação Nacional de Saúde, em especial dos técnicos José Carlos Matos e Alba Figueroa, que estiveram presentes em Curitiba. A publicação deste volume não teria sido possível sem o suporte financeiro da Fundação Ford, através do projeto Saúde Indígena em Rondônia, executado pelo Centro de Estudos em Saúde do Índio de Rondônia - CESIR (convênio Universidade Federal de Rondônia/Escola Nacional de Saúde Pública).

Os organizadores

\footnotetext{
I O GT Saúde Indígena da ABRASCO é integrado pelos seguintes membros, em ordem alfabética: Ana Lúcia Escobar (Universidade Federal de Rondônia, Porto Velho), Carlos E.A. Coimbra Jr. (Escola Nacional de Saúde Pública/FIOCRUZ, Rio de Janeiro), Esther Jean Langdon (Universidade Federal de Santa Catarina, Florianópolis), Dulce Lopes B. Ribas (Universidade Federal de Mato Grosso do Sul, Campo Grande), Luiza Garnelo (Centro de Pesquisas Leônidas e Maria Deane/FIOCRUZ, Manaus), Regina M. de Carvalho Erthal (Museu Amazônico, Manaus), Ricardo Ventura Santos (Escola Nacional de Saúde Pública/FIOCRUZ e Museu Nacional, Rio de Janeiro) e Roberto G. Baruzzi (Escola Paulista de Medicina/UNIFESP, São Paulo).
} 


\section{Localização dos Distritos Sanitários Especiais Indígenas (DSEIs)}

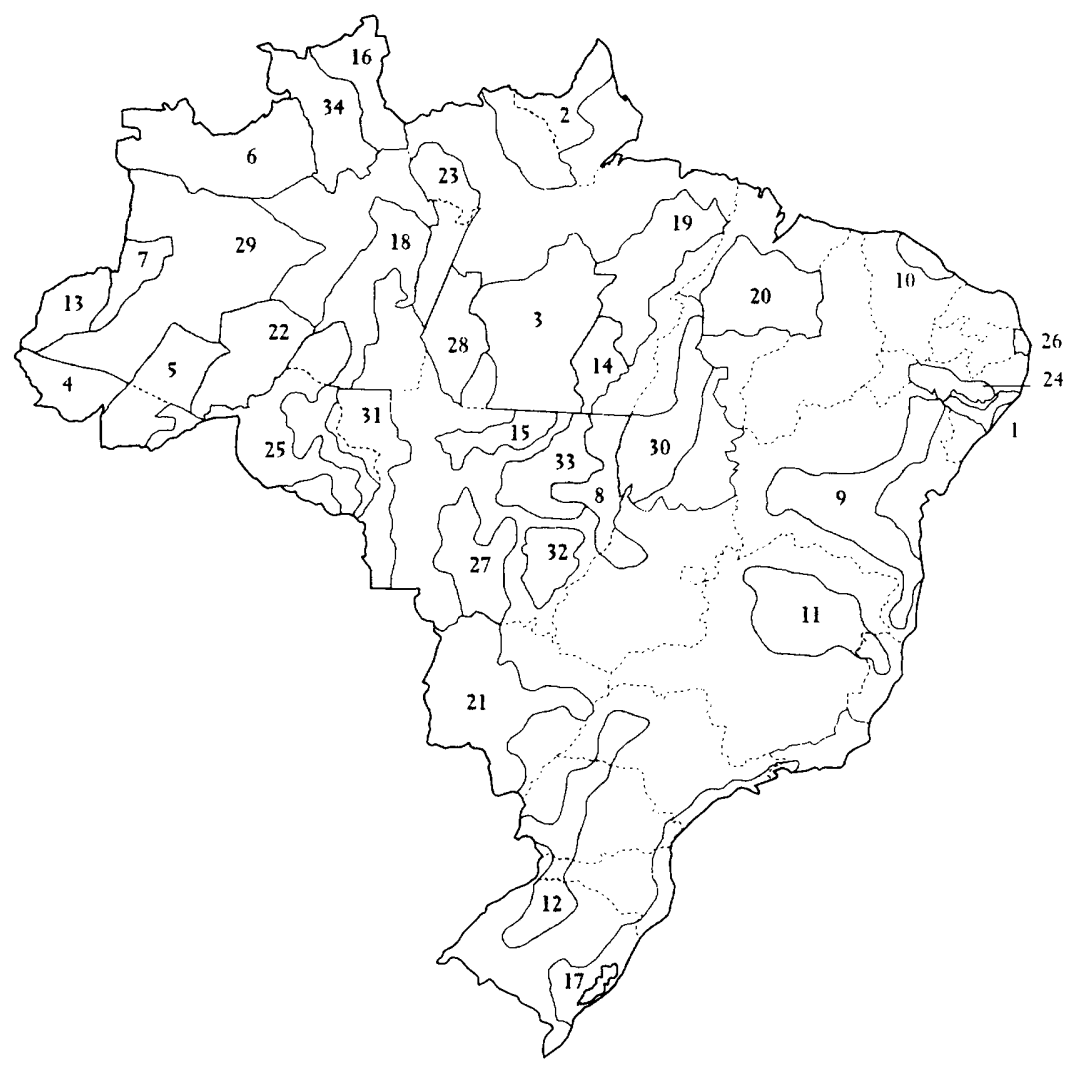

1. I)SFil de Alagoas c Sergipe

2. DSEI do Amapá c Nortc do Pará

3. ISSFi de Altamira

4. DSFI do Alto Rio Juruá

5. LSEI do Alto Rio Purus

6. DSEI do Alto Rio Negro

7. DSEI do Alto Rio Solimóes

8. ISSFI do Araguaia

9. DSEI da Baliia

10. DSEI do Ceará

11. DSFI de Minas Gerais

e Espírito Santo

12. ISSEI do Interior Sul
13. DSEL do Vale do javari

14. ISSEI de Kavapó - PA

15. IDSFi de Kayapó - MII

16. DSEI do I este de Roraina

17. ISSEI do Litoral Sul

18. DSEI de Manaus

19. DSEI de ('uamá-Tocantins

20. DSEI do Maranhão

21. IDSEI do Mato Grosso do Sul

22. I)SFi do Médio Rio Purús

23. DSEl de Parintins

2t. DSF, de Pernambuco
25. DSEI de Porto Velho

26. DSEI Potiguara

27. DSEI de Cuiabá

28. LSEI do Rio 'Tapajós

29. DSHi do Médio Rio Solimões

e Afluentes

30. DSEI do Tocantins

31. DSFI de Vilhena

32. DSFI Xavante

33. DSFI do Parque Indigena

do Xingú

34. DSEL Yanomani

Fonte: Fundação Nacional de Saúde (http:/www.funasa.gov.br) 


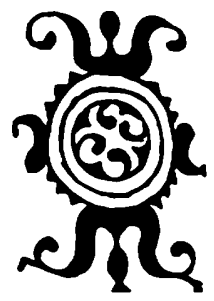

CENÁRIOS E TENDÊNCIAS DA SAÚdE

E DA EPIDEMIOLOGIA DOS POVOS

INDÍGENAS NO BRASIL

Ricardo Ventura Santos, Carlos E. A. Coimbra Jr.

Os povos indígenas no Brasil apresentam um complexo c dinâmico quadro de saúde, diretamente relacionado a processos históricos de mudanças sociais, econômicas e ambientais atreladas à expansão e à consolidação de frentes demográficas c econômicas da sociedade nacional nas diversas regiōes do país. Ao longo dos séculos, tais frentes excrceram importante influência sobre os determinantes dos perfis da saúde indígena, quer seja por meio da introdução de novos patógenos, ocasionando graves cpidemias; usurpação de territórios, dificultando ou inviabilizando a subsistência; c/ou a perseguição e morte de indivíduos ou mesmo comunidades inteiras. No presente, emergem outros desafios à saúde dos povos indígenas, que incluem doenças crônicas não-transmissíveis. contaminação ambiental e dificuldades de sustentabilidade alimentar, para citar uns poucos exemplos.

(O) perfil epidemiológico dos poros indígenas é muito pouco conhecido, o) que decorre da exigüiidade de investigações, da ausência de inquéritos e censos, assim como da precariedade dos sistemas de informações sobre morbidade e mortalidadc. Qualquer discussão sobre o processo saúde/docnça dos povos indígenas precisa levar em consideração, além das dinânicas epidemiológica e demográfica, a cnorme sociodiversidade existente. São centenas de ctnias, falantes de centenas de línguas distintas, que têm experiências de interação com a sociedade nacional as mais diversas. I Iá desde alguns poucos grupos vivendo ainda relativamente isolados na Amazônia, até outros com significativas parcelas de sulas populações vivendo em cidades como Manaus, Campo Grande, São Paulo c outros centros de médio a grande porte.

Com base nos dados disponiveis, não é possivel traçar de forma satisfatória o perfil epidemiológico dos povos indígenas, dado que estão ausentes os clcmentos quantitativos necessários para embasar análises abrangentes e sofisticadas. Fim geral, é difícil ir além da compilação de estudos de casos específicos, muitos dos qua is oriundos da Amazônia. Não obstante, restann poucas clúvidas de que as condições de saúde dos poros indígenas são precérias, colocando-os 
em uma posição de desvantagem em relação a outros segmentos da sociedade nacional (Coimbra Jr. \& Santos, 2000; Coimbra Jr. et al., 2002; FUNASA, 2002; Santos \& Coimbra Jr., 1994; Santos \& Escobar, 2001). Tal situação de marginalidade é recorrente em diversas outras regiões das Américas (Coimbra Jr., 1998; OPAS, 1998). Corroborando esse diagnóstico, um recente documento do Ministério da Saúde (MS), intitulado Política Nacional de Atenção aos Povos Indígenas, não somente explicita a condição de ausência de dados, como também aponta para a magnitude das desigualdades entre a saúde dos povos indígenas e de outros segmentos da sociedade nacional: "Não se dispõe de dados globais fidedignos sobre a situação de saúde... [dos povos indígenas], mas sim de dados parciais, gerados pela FUNAI, pela FUNASA e diversas organizações não-governamentais ou ainda por missões religiosas que, por meio de projetos especiais, têm prestado senviço de atenção à saúde dos povos indígenas. Embora precários, os dados disponiveis indicam, em diversas situações, taxas de morbidade e mortalidade três a quatro vezes maiores que aquelas encontradas na população brasileira geral. $O$ alto número de óbitos sem registro ou indexados sem causas definidas confirmam a pouca cobertura e baixa capacidade de resolução dos serviços disponiveis" (FUNASA, 2002:10).

Nosso objetivo neste capítulo é apresentar um panorama geral da saúde indígena no Brasil, enfocando as articulações com processos de mudanças sociais, econômicas e ambientais nas quais estão envolvidos. A literatura sobre o tema é bastante extensa e o intuito não é o de realizar uma revisão exaustiva, mas sobretudo delinear um quadro geral e, na medida do possível, apontar tendências. Dentre as várias fontes de informação utilizadas, lançamos mão da literatura produzida com base em atividades de pesquisas científicas, que em geral tem sido pouco explorada nas discussões sobre saúde dos povos indígenas, como demonstra a própria citação acima. Frisamos que uma melhor compreensão do complexo e dinâmico quadro da saúde indígena é fundamental para o planejamento e a avaliação de programas e serviços de saúde destinados ao atendimento dessas populações.

\section{DEMOGRAFIA}

A situação demográfica dos povos indígenas na atualidade está estreitamente relacionada com os amplos impactos causados pela interação com a sociedade nacional, cuja profundidade temporal se estende até a chegada dos colonizadores 
europeus no século XVI. Se na atualidade estão longe de alcançar a cifra de um milhão de pessoas, o contingente populacional indígena que vivia na região que atualmente compreende o território brasileiro talvez chegasse a seis milhões ou mais em 1500 (Cunha, 1992; Denevan, 1976). Como em outras regiões das Américas, epidemias de doenças infecciosas, massacres e trabalho escravo foram os principais fatores de depopulação (Larsen \& Milner, 1994; Verano \& Ubelaker, 1992).

Até a década de 1970, foram correntes prognósticos sombrios sobre o futuro dos povos indígenas no Brasil (Davis, 1978; Ribeiro, 1977, entre outros). No final da década de 1980, já emergiam vozes mais otimistas. Segundo Mércio Gomes (1988:16-17), “...o que surge como mais surpreendente e extraordinário nas relações entre os índios e o Brasil é a possível reversão histórica na demografia indígena. Certamente seria temerário afirmar que os índios, afinal, sobreviveram, $e$ que esta é uma realidade concreta e permanente... Mas o fato é que há fortes indícios de que as populações indígenas sobreviventes vêm crescendo nas últimas três décadas, surpreendendo as expectativas alarmantes... de tempos atrás". Na década de 1990, essa percepção se consolidou, como indicou Carlos Alberto Ricardo (1996:xii): “... [foi] afastada a hipótese de desaparecimento físico dos índios no Brasil..., portanto, não estamos diante de uma 'causa perdida' como se chegou a dizer anos atrás". A reversão do quadro de pessimismo quanto ao futuro dos povos indígenas fundamentou-se na constatação de contínuo crescimento populacional ao longo de um período amplo de tempo (Azevedo, 2000; Coimbra Jr. et al., 2002; Pagliaro, 2002). Confirmando essa tendência, Marta Azevedo (2000: $80)$ notou recentemente: “... se constata que a maioria dos povos indígenas tem crescido, em média, 3,5\% ao ano, muito mais do que a média de 1,6\% estimada para o período de 1996 a 2000 para a população brasileira em geral"l.

Apesar desse dinâmico quadro de transformação, que se expressa em elevado crescimento populacional, permanecem desconhecidos os mais básicos indicadores demográficos para a ampla maioria das etnias indígenas. Estatísticas vitais, tais como coeficiente de mortalidade infantil, esperança de vida ao nas-

\footnotetext{
1 Ainda segundo Azevedo (2000), do ponto de vista demográfico, a questão primordial já não é se o contingente populacional indígena está crescendo ou não - em seu conjunto, sem dúvida está - , mas sim quais são os fatores que explicam o crescimento acelerado (queda da mortalidade, aumento da fecundidade ou uma combinação de ambos). Considerando a sociodiversidade existente, um outro desafio é caracterizar a multiplicidade de experiências demográficas das centenas de etnias indígenas no país.
} 
cer e taxas brutas de natalidade e mortalidade, essenciais para compreender a dinâmica demográfica, para monitorar o perfil de saúde/doença e para plancjar ações de saúde e educação, raramente são disponíveis. Quando disponíveis, como salicnta Ricardo (1996:v), “... |os dados| são bastante heterogêneos quanto à sua origem, data e procedimento de coleta ... Mesmo quando são dados resultantes de contagem direta, via de regra os recenseadores não dominam a língua, não entendem a organização social nem a dinâmica espacial e sazonal das sociedades indigenas, produzindo, portanto, informações inconsistentes e totais errados, para mais ou para menos".

Coimbra Jr. \& Santos (2000) chamam a atenção para as implicações do que denominam uma "danosa imvisibilidade demográfica e epidemiológica". Fsstatísticas vitais não somente são uíteis para situar demograficamente os povos indígenas no contexto sociopolítico nacional contemporâneo, como também apresentam a potencialidade de lançar luzes sobre a trajetória histórica dessas socicdades ao longo do processo de interação com a sociedade envolvente. Como veremos adiante, ainda que o processo de distritalização da saúde indígena en curso tenha na montagem de sistemas de informação um objetivo central, na prática informações confiáveis e consistentes continuam escassas.

É importante indicar como tem sido "produzida" a ausência de dados demográficos para os povos indígenas. Ainda que por longa data tenha sido atribuição institucional da Fundação Nacional do Índio (FUNAI) coletar e sistematizar dados demográficos, na prática os mesmos inexistiam por completo ou não se revestiam de confiabilidade, por não serem coletados e atualizados de forma sistemática. Tamanha carência de dados está longe de ser remediada mesmo após a introdução da categoria "indígena" no quesito "cor ou raça” a partir do censo de 1991. Nos censos anteriores, quando levados em conta, os índios eram contabilizados en categorias como "pardo" ou "amarelo" - Além de dificuldades na classificação, pois, obviamente, "indígena” não é cor, inúmeros outros problemas têm sido apontados (Azevedo, 1997; Coimbra Jr. \& Santos, 2000; Silva, 1994). Por exemplo, no censo de 1991, somente foram recenseadas as pessoas vivendo próximas dos postos indígenas ou cm missões religiosas, excluindo da confagem un contingente desconhecido, mas certannente significativo, de indiví-

\footnotetext{
Z As categorias de "cor ou raça" adotadas pelo IBC SF, são as seguintes: branco, preto, annarelo, pardo e indígena. Sobre os povos indigenas nos censos nacionais no Brasil, ver Aycredo (20010) e ()liveira (1997).
} 
duos residentes em aldeias sem a presença de agentes governamentais ou de missionários. Além disso, no censo predomina um "conceito de índio genérico", haja vista que não são disponibilizadas informações sobre grupos étnicos específicos (Xavánte, Kayapó, Yanomámi, etc.).

Mesmo com essas limitações, a inclusão da categoria "indígena" no censo é uma iniciativa de grande importância, sobretudo considerando a escassez de dados existentes. Desde já os resultados dos dois censos que incluíram a categoria "indígena" (1991 e 2000) impõem desafios interpretativos de grande magnitude. Por exemplo, os totais de pessoas que se autodeclararam "indígena" nos censos de 1991 e 2000 foram de, respectivamente, 294.148 e 701.462, ou seja, um crescimento de mais de $100 \%$ em menos de uma década (Tabela 1 ). $\mathrm{O}$ aumento foi bastante desigual, variando de $61,2 \%$ na Região Norte a $410,5 \%$ na Região Sudeste. As razões que explicam esse notável incremento são desconhecidas e demandarão um intenso esforço de análise nos próximos anos. Azevedo \& Ricardo (2002) sugerem algumas possibilidades: crescimento demográfico real das etnias; aumento da porcentagem de indígenas urbanizados que optaram pela categoria "indígena" (que talvez se classificaram na categoria "pardo" em censos anteriores); dupla contagem de indígenas nas cidades e nas terras indígenas, devido a constante mobilidade em algumas etnias; aparecimento de um contingente de pessoas que, ainda que não se identificando com etnias específicas, se classificaram genericamente como "indígenas"3.

O Instituto Socioambiental (ISA) disponibiliza dados populacionais sobre os povos indígenas no Brasil, com desagregação segundo etnia. Os dados do ISA derivam de levantamento feitos nas comunidades por antropólogos, indigenistas e outros profissionais. Segundo Ricardo (2000), há aproximadamente 216 povos indígenas, totalizando cerca de 350 mil indivíduos, menos de $0,5 \%$ da população nacional brasileira (ver http://www.socioambiental.org). Quanto ao contingente populacional segundo etnia, a maioria (aproximadamente 68\%) é composta por menos de mil indivíduos. As seis etnias com mais de 10 mil indivíduos (Guaraní, Kaingáng, Makuxí, Guajajára, Teréna e Tikúna) somam conjunta-

\footnotetext{
3 Para além dos fatores explicativos desse crescimento, o trabalho de Pereira et al. (2002), que é uma análise preliminar das características censitárias básicas em 1991 e 2000 da população residente em terras indígenas, aponta para alguns dos desafios metodológicos e teóricos envolvidos na interpretação dos dados dos censos decenais no tocante aos indígenas.
} 
Tabela 1

Número de pessoas que se autoclassificaram como "indígenas", segundo os censos de 1991 e 2000, por inacrorregiões geográficas.

\begin{tabular}{lcc}
\hline Macrorregiões & Censo 1991 & Censo 2000 \\
\hline Norte & 124.618 & 200.934 \\
Nordeste & 55.854 & 166.500 \\
Centro-Oeste & 52.750 & 127.003 \\
Sudeste & 30.584 & 156.134 \\
Sul & 30.342 & 50.891 \\
Total & 294.148 & 701.462 \\
\hline
\end{tabular}

Fonte: IBGE (http://w'ww.sidra.ibge.gov.br, acessado em 20 de maio de 2003).

mente em torno de 130 mil pessoas, o que equivale a $38-40 \%$ dos indígenas no país (Ricardo, 2000). Portanto, predominam as "microssociedades", mas uma parcela importante do contingente indígena total concentra-se em um número reduzido de etnias.

Apenas umas poucas etnias foram estudadas de forma mais detalhada do ponto de vista da demografia. Mesmo essas investigações apresentam limitações importantes, como os curtos intervalos de tempo analisados. Entre os estudos produzidos na última década, podem ser citados Baruzzi et al. (1994), Coimbra Jr. et al. (2002), Early \& Peters (1990), Flowers (1994), Pagliaro (2002) e Souza $\&$ Santos $(2001)^{4}$. Analisar comparativamente os resultados apresentados nesses trabalhos e em outros realizados sobre os povos indígenas é uma tarefa difícil, devido a diferenças nas metodologias de coleta de dados, períodos cobertos, estatísticas vitais reportadas, agrupamentos etários e assim por diante. Não obstante, tende a haver uma consistência quanto a apontar para um padrão caracterizado por populações jovens (em muitos casos com $50 \%$ das pessoas com menos de 15 anos) e por elevadas taxas de mortalidade e de fecundidade (Tabela 2$)^{5}$.

Um estudo demográfico recentemente realizado entre os Xavánte de Sangradouro, em Mato Grosso, exemplifica esses pontos (Souza \& Santos,

\footnotetext{
4 Ver também o conjunto de estudos de casos incluído no volume organizado por Adams \& Price (1994). Pagliaro (2002) apresenta uma informativa revisão dos estudos sobre demografia indígena no Brasil.
} 
Tabela 2

\begin{tabular}{|c|c|c|c|c|c|c|c|}
\hline Fonte & $\begin{array}{l}\text { Etnia } \\
\text { (localização) }\end{array}$ & $\begin{array}{l}\text { Período } \\
\text { de referência }\end{array}$ & (X:Ml & I'BM & $c_{x}$ & IBN & 'TFT \\
\hline $\begin{array}{l}\text { Coimbra Jr. } \\
\text { et al. i200211 }\end{array}$ & $\begin{array}{l}\text { Xaránte - Pimentel } \\
\text { Barbosa (NI) }\end{array}$ & $1972-1990$ & 102.0 & 10.0 &. & 511.5 & 7.9 \\
\hline $\begin{array}{l}\text { Early \& Peters } \\
(1990)\end{array}$ & $\begin{array}{l}\text { Yanomámi } \\
\text { (AM e RR! }\end{array}$ & 1958.1987 & $1+0,0$ & 23,4 & 38.9 & +9.9 & 7.9 \\
\hline Pagliaro $(200) 2)=$ & Kayabi iNTt & $1970-1909$ & 32.8 & 8,1 & $+8,5-66,4$ & 53,1 & $5,-9.5$ \\
\hline Picchi (1994) & Bakairi (MT) & $1979-1981$ & - & 10,4 & - & 45.1 & 5.4 \\
\hline $\begin{array}{l}\text { Sollza \& Santos } \\
(2001)\end{array}$ & $\begin{array}{l}\text { Xavánte - } \\
\text { Sangradouro (NT) }\end{array}$ & $1903-1997$ & 87.1 & 9,1 & $\ldots$ & 57.7 & 8.6 \\
\hline
\end{tabular}

CNI = coeficiente de mortalidade infantil ipor 1.000$)$; TBM = taxa brutia de mortalidade (por 1.00)(: $e_{x}=$ esperança de vida ao nascer (em anosi; TBX - taxa bruta de natalidade (por l. $(600)$;

T'FT = taxa de fecundidade total.

1 Em Coimbra Jr. et al (2002), (XII e TFI referem-se ao período 1977-1990.

2 Pagliaro (2002) apresenta os valores de ex segundo períodos de cinco anos e de T'F I' segundo períodos de der anos. (Os valores inclúdos na tabela acima são os mínimos e os máximos reportados pela autora.

2001). lim uma comunidade que totalizava 825 indivíduos, o estudo revelou altas taxas brutas de mortaliclade $(9,1$ por mil), superiores às médias nacionais $(6,7$ por mil em 1996) e inclusive acina das cifras mais elevadas do país, que são as da Região Nordeste (7,8 por mil cm 1996). F́ necessário, contudo, proceder a comparação de valores de taxas brutas com cautela, pois as mesmas são particularmente influenciadas pela composição etária que, no caso dos Xavánte, difere bastante daquela da população brasilcira. Pouco mais da metade da população Xavánte (56\%) era constituída por menores de 15 anos de idade (mediana de 13 anos). Para o país como um todo, a porcentagem era de aproximadamente $30 \%$ em 1991.

O coeficiente de mortalidade infantil (CMI) para os Xavánte (87,1 por mil) no período 1993-1997 apresentou-se muito mais elevado do que a cifra para

\footnotetext{
5 Mclchior et al. (2002) analisaram a mortalidade indígena no norte do Paraná. N'o tocante à mortalidade infantil, concluíram que os níveis são bastante mais clevados que os que se verificam na âmbito regional e nacional e que a tendência ao longo dos anos 1990 foi de aumento, revelando uma piora do nivel de saúde indígena.
} 
o Brasil (37,5 por mil em 1996). A maior parte das mortes (55\%) foi de crianças menores de um ano, que correspondiam a aproximadamente $5 \%$ da população total. A elevadíssima mortalidade nos primeiros anos de vida faz com que somente $86 \%$ das crianças Xavánte sobrevivam até o décimo ano de vida (Souza \& Santos, 2001).

A taxa de fecundidade total (TF') calculada para os Xavánte de Sangradouro foi de 8,6 filhos. Tal padrão de alta fecundidade, com TFTs da ordem de 7-8 ou mais filhos, tem sido observado em diversas outras populações indígenas no país (Early \& Peters, 1990; Flowers, 1994; Meireles, 1988; Pagliaro, 2002; Picchi, 1994; Werner, 1983) e está associado a intervalos intergenésicos (i.e., entre os partos) curtos, combinados com a iniciação da fase reprodutiva no início da segunda década de vida, por volta dos 13-14 anos, que se estende não raro até os 40-45 anos. As TFTs reportadas para diferentes grupos indígenas, incluindo os Xavánte, mostram-se invariavelmente mais elevadas que aquela da população brasileira. E.m 1996, por exemplo, a T'F T para o Brasil era de 2,3.

Souza \& Santos (2001) argumentam que os elevados níveis de mortalidade verificados entre os Xavánte o que parece ser uma situação difundida em muitos outros grupos indígenas no Brasil, tomando-se por base os estudos de casos disponíveis, exemplifica a condição de marginalidade socioeconômica a que estão relegados, onde uma das facetas se manifesta por meio das precárias condições de saneamento de suas aldeias e inadequados serviços de saúde, comprometendo principalmente a saúde e a sobrevivência das crianças ${ }^{6}$.

\section{SUBSISTÊNCIA, SUSTENTABILIDADE ALIMENTAR E ESTADO NUTRICIONAL}

No passado, os povos indígenas dependiam, em menor ou maior grau, da agricultura, caça, pesca e coleta para a subsistência. A interação com as frentes de

\footnotetext{
6 Dois estudos recentes baseiam-se em dados demográficos coletados ao longo de períodos mais amplos. O trabalho de Heloisa Pagliaro (2002) é uma minuciosa investigação das tendências de crescimento, de mortalidade e de fecundidade da população Kayabi do Parque Indígena do Xingu, com base na análise de dados coletados pela equipe de Roberto G. Baruzzi e colaboradores ao longo de várias décadas. Coimbra Jr. et al. (2002) apresentam uma análise da dinâmica populacional dos Xavánte de Pimentel Barbosa com foco na crise demográfica que se seguiu ao contato.
} 
expansão, ocasionando a instalação de novos regimes econômicos e a diminuição dos limites territoriais, entre outros fatores, levaram a drásticas alterações nos sistemas de subsistência, ocasionando, via de regra, empobrecimento e carência alimentar. Além das etnias com parcelas expressivas de suas populações vivendo em áreas urbanas, portanto não mais produzindo diretamente os alimentos consumidos, há atualmente outras habitando áreas nas quais as pressões populacionais, aliadas a ambientes degradados, comprometem a manutenção da segurança alimentar. Há de se mencionar também a utilização da mão-deobra indígena em muitas regiões, como no corte manual da cana-de-açúcar no Sudeste ou a extração de borracha nativa na Amazônia, em troca de pagamentos ínfimos que não garantem a aquisição de alimentos em quantidade e qualidade satisfatórias.

Para os povos indígenas, a garantia da posse da terra extrapola a subsistência propriamente dita, representando elo fundamental na continuidade sociocultural. Ainda que certamente imbricadas, as relações entre posse da terra e condições nutricionais das populações indígenas são muito pouco conhecidas no Brasil. Um dado importante é que $40 \%$ dos indígenas vivem nas regiões Nordeste, Sudeste e Sul, nas quais estão situadas somente cerca de $2 \%$ da extensão das terras indígenas demarcadas no país. Nas regiões Centro-Oeste e Norte, localizam-se $98 \%$ da extensão das reservas, e $60 \%$ do contingente indígena (Ricardo, 1999). Não surpreendentemente, levantamento realizado em meados da década de 90 revelou que havia graves problemas de sustentação alimentar em pelo menos um terço das terras indígenas do país, acometendo sobretudo grupos localizados no Nordeste, Sudeste e Sul (Verdum, 1995).

Sabe-se muito pouco sobre a situação nutricional dos povos indígenas. Por exemplo, as três principais pesquisas nacionais que incluíram a coleta de dados sobre o estado nutricional no país ao longo das últimas décadas - o Estudo Nacional de Despesa Familiar (ENDEF), realizado em 1974-1975, a Pesquisa Nacional sobre Saúde e Nutrição (PNSN), em 1989, e a Pesquisa Nacional sobre Demografia e Saúde (PNDS), em 1996 - não incluíram as populações indígenas como segmento de análise específico. Essas são as principais fontes que têm permitido análises sobre as transformações no perfil nutricional do país no final do século XX (Monteiro, 2000). O desconhecimento acerca da situação nutricional dos povos indígenas é preocupante, uma vez que, em decorrência das transformações socioeconômicas que atravessam, relacionadas inclusive à garantia da posse da terra e segurança alimentar, há uma conjuntura de fatores propiciadores do surgimento de quadros de má-nutrição (Santos, 1993, 1995). 
A avaliação da situação nutricional de crianças é um instrumento bastante útil na aferição das condições de vida da população em geral. Isso porque há uma íntima associação entre alimentação, saneamento e assistência à saúde, dentre outros fatores. Com relação à ocorrência de desnutrição energética-protéica em crianças indígenas, o que se sabe advém de inquéritos antropométricos realizados em algumas poucas comunidades, a maior parte das quais localizadas na Amazônia. Em geral, os resultados apontam para elevadas frequiências de déficits para o indicador estatura para idade (abaixo de -2 escores $\mathrm{z}$ das medianas da referência do National Center for Health Statistics - NCHS -, recomendada pela Organização Mundial da Saúde - OMS), o que é interpretado como indicativo de desnutrição crônica. Na maioria dos estudos de casos, as freqüências de baixa estatura para idade superam os valores reportados para crianças não-indígenas no Brasil (10,5\% em 1996, segundo Monteiro, 2000) (Tabela 3). Vale salientar que há uma discussão em curso na literatura acerca da validade de utilizar os pontos de corte preconizados por organismos internacionais, como as recomendações da OMS em relação à adoção das curvas do NCHS, na avaliação nutricional de crianças indígenas (ver Santos, 1993; Stinson, 1996).

A anemia constitui grave problema nutricional nas populações indígenas, afetando, sobretudo, crianças e mulheres em idade reprodutiva. Além da ingestão insuficiente de determinados nutrientes, como o ferro, a ocorrência de anemia nas populações indígenas também deve estar associada à presença de parasitoses endêmicas, como a ancilostomose e a malária. Mais uma vez, a maioria dos estudos sobre o tema foi conduzida na região amazônica. Já nas décadas de 60 e 70, inquéritos apontavam para elevadas freqüências de anemia entre os Xavánte (Neel et al., 1964), os Krenakaróre (ou Panará) (Baruzzi et al., 1977) e nas populações do Alto Xingu (Fagundes Neto, 1977). Investigações mais recentes também constataram uma ampla disseminação dessa carência nutricional. Entre os Tupí-Mondé, por exemplo, cerca de $60 \%$ das crianças de 0,5-10 anos de idade e 65\% da população geral estavam anêmicas (Coimbra Jr., 1989; Santos, 1991). Entre os Xavánte, Leite (1998) reportou a ocorrência de ancmia em $74 \%$ das crianças de $0-10$ anos e em $53 \%$ do total da população. Nos Estados do Rio de Janeiro e São Paulo, Serafim (1997) detectou 69\% de anemia nas crianças Guaraní entre 0-65 meses, alcançando $82 \%$ naquelas entre 6-24 meses.

Não há inquéritos sobre a ocorrência de hipovitaminose A entre as populações indígenas. Contudo, deve ser um problema comum em diversas etnias, dado que acomete com frequiência populações não-indígenas, como aquelas vi- 
Freqüência de crianças indígenas com baixa estatura para idade $(\leq-2$ escores $\mathrm{z}$ das medianas da referência do NCHS), reportadas em alguns estudos conduzidos entre povos indígenas no Brasil publicados a partir de 1990 .

\begin{tabular}{|c|c|c|c|c|}
\hline Fonte & $\begin{array}{l}\text { Etnia } \\
\text { (localização) }\end{array}$ & $\begin{array}{l}\text { Ano de coleta } \\
\text { dos dados }\end{array}$ & Faixa etária & $\begin{array}{l}\%(\leq-2 \\
\text { escores } z)\end{array}$ \\
\hline Coimbra Jr. \& Santos (1991) & Suruí (RO) & 1987 & $0-9$ anos & 46,3 \\
\hline Coimbra Jr. et al., (2002) & $\begin{array}{l}\text { Xavánte - Pimentel } \\
\text { Barbosa (MT) }\end{array}$ & 1995 & $0-48$ meses & 27,7 \\
\hline Capelli \& Koifman (2001) & Parakatejé (PA) & 1994 & $0-60$ meses & 10,0 \\
\hline Leite et al., (neste volume) & $\begin{array}{l}\text { Xavánte - } \\
\text { Sangradouro (MT) }\end{array}$ & 1997 & $0-5$ anos & 28,3 \\
\hline Martins \& Menezes (1994) & Parakanã (PA) & 1991 & $0-5$ anos & 50,6 \\
\hline Morais et al., (2003) & Alto-Xingu (MT) & 1992 & $0-60$ meses & 20,4 \\
\hline Santos (1991) & Tupí-Mondé (MT e RO) & 1990 & $0-10$ anos & 55,4 \\
\hline Ribas et al., (2001) & Teréna (MS) & 1999 & $0-60$ meses & 16,0 \\
\hline Weiss (neste volume) & Enawenê-Nawê (MT) & 1990 & $0-60$ meses & 50,0 \\
\hline
\end{tabular}

" Faixa etária conforme indicada pelos autores.

vendo em zonas rurais das regiões Norte e Nordeste (Prado et al., 1995; Santos et al., 1996), nas quais estão também localizadas inúmeras etnias indígenas.

Quanto a outras carências nutricionais, vale chamar a atenção para o relato de Vieira Filho et al. (1997) acerca da ocorrência de beribéri entre os Xavánte, que esses autores associaram a uma dieta baseada quase que unicamente em arroz beneficiado. Tal registro é particularmente importante, pois sinaliza para os graves impactos nutricionais que podem advir de mudanças na dieta de grupos indígenas (devido à diminuição da diversidade alimentar).

Essa breve revisão evidencia importantes lacunas no conhecimento sobre a alimentação e a nutrição de povos indígenas, ao mesmo tempo em que sinaliza para situações preocupantes. $O$ pouco que se sabe deriva de estudos realizados, sobretudo, na Amazônia. É provável que vários problemas nutricionais sejam particularmente graves em grupos vivendo nas regiões Nordeste, Sudeste e Sul, entre os quais tendem a ser maiores as dificuldades de sustentação alimentar devido à reduzida extensão de suas terras, e mesmo em decorrência de uma inserção socioeconomicamente marginal na periferia de centros urbanos. 


\section{DOENÇAS INFECTO-PARASITÁRIAS E SAÚDE AMBIENTAL}

Historicamente, o perfil de morbi-mortalidade indígena no Brasil tem sido dominado pelas doenças infecciosas e parasitárias. Até um passado recente, epidemias de viroses, como gripe e sarampo, chegavam a dizimar milhares de indivíduos num curto intervalo de tempo, exterminando aldeias inteiras ou reduzindo drasticamente o número de habitantes, o que comprometia a continuidade cultural e social dos grupos atingidos (ver a clássica análise de Darcy Ribeiro, 1956). A raridade de tais eventos no presente não elimina o peso exercido pelas doenças infecciosas no cotidiano da grande maioria dos povos indígenas. Infelizmente, a inexistência de um sistema de informação impede uma análise minimamente detalhada acerca da epidemiologia das doenças infecciosas e parasitárias nas populações indígenas, como também limita tentativas de avaliação de programas de controle das principais endemias. Até mesmo os dados de cobertura vacinal são de difícil obtenção.

A tuberculose destaca-se como uma das principais endemias que acomete os povos indígenas. Sua importância deve-se não somente a seu papel histórico como fator de depopulação, como também pela ampla distribuição no presente (Baruzzi et al., 2001; Buchillet \& Gazin, 1998; Costa, 1986; Escobar et al., 2001; Sousa et al., 1997). Por exemplo, durante a primeira metade da década de 1990 foram registrados pela Secretaria da Saúde de Rondônia 329 novos casos de tuberculose em indígenas. Essa cifra representa aproximadamente $10 \%$ do total de casos notificados em todo o Estado no período, apesar do contingente indígena não alcançar $1 \%$ da população total de Rondônia (Escobar et al., 1999, 2001). Do total de casos de tuberculose em indígenas, $30 \%$ ocorreram em crianças com menos de 15 anos de idade. O fato de apenas $39 \%$ dos casos terem sido confirmados bacteriologicamente revela importantes lacunas nos serviços de saúde oferecidos a essas populações em Rondônia, o que possivelmente também se aplica para outras regiões do país.

A relevância da malária no perfil epidemiológico da população indígena é inquestionável (Ianelli, 2000). Grupos vivendo em certas áreas da Amazônia e no Centro-Oeste, em especial aquelas sob a influência de fluxos migratórios, atividades de mineração ou de implantação de projetos de desenvolvimento, são particularmente vulneráveis. Nesses contextos, elevadas taxas de morbidade e mortalidade devido à malária têm sido observadas. Considerando-se o impacto de inúmeros fatores ambientais e socioeconômicos que operam localmente, assim como a diversidade sociocultural e de acesso a serviços de saúde, não é difí- 
cil entender o porquê da distribuição desigual da malária em povos indígenas da Anazônia, notando-se discrepâncias importantes mesmo entre árcas contíguas ou muito próximas. Segundo Barata (1995), as áreas indígenas no Brasil apresentam incidência variável ou, como sintctizado por Ianclli (2000:366), “... ao mesmo tempo em que é possível se observar epidemias ... também se encontram populações indígenas com alta resposta imune-humoral ao P. falciparum na vigência de baixa parasitemia e aparente ausência de sinais elou sintomas compativeis com a doença".

A título de exemplo, um olhar sobre as estatísticas geradas na Casa de Saúde do Índio de Guajará-Mirim, em Rondônia, destinada ao atendimento da população indígena que habita as bacias dos rios Guaporé e Mamoré, revela que durante a primeira metade da década de 90 cerca de $40 \%$ dos atendimentos foram ocasionados pela malária. Durante o mesmo período, $12 \%$ das internações na Casa de Saúde do Índio de Porto Velho também foram devidas a essa parasitose (Escobar \& Coimbra Jr., 1998) (ver também Sá, 2003).

O caso Yanomámi é particularmente ilustrativo de uma epidemia de malária que se originou a partir da invasão do território indígena por centenas de garimpeiros, o que ocorreu na segunda metade dos anos 80 e início da década de 90. Esses invasores não somente alteraram profundamente o ambiente, criando condições propiciadoras para a transmissão da malária, mas também introduziram cepas do parasito (em especial de P. falciparum) resistentes aos cuimioterápicos usuais. Segundo Pithan et al. (1991), durante a pior fase da epidemia, cerca de 40\% dos óbitos registrados entre os Yanomámi internados na Casa do Índio de Boa Vista foram devidos à malária. Não há estatísticas confiávcis sobre o impacto da malária nas comunidades Yanomámi mais isoladas, mas sabe-se que muitas pessoas morreram sem qualquer atendimento.

Outras árcas indígenas nas quais a malária é endêmica e para as quais há estudos epidemiológicos são: o leste do Pará c Baixo Rio Xingu, incluindo as ctnias Arará, Kayapó e Parakanã (Arruda et al., 1989; Martins \& Menezes, 199+b); o leste e nordeste de Mato Crosso, em regiōes do Parque do Xingu (Baruzzi. 1992; Burattini ct al., 1993; Spindel, 1995) e en áreas Xavánte (Ianclli, 1997); no ocste do Amazonas, entre os grupos que habitam o vale do Rio Jaara (Sampaio ct al., 1996).

Pouco se sabe sobre a ecologia dos vetores da malária e sulas relaçōes com as populações humanas em áreas indígenas. Os cstudos realizados têm identificado o Anopheles darlingi como principal vetor, que parece exibir comportamento predominantemente exofílico, ou seja, as picadas ocorrem fora dos domi- 
cílios (Ianelli et al., 1998; Lourenço-de-Oliveira, 1989; Moura et al., 1994; Sá, 2003). A presença diária e nos mais variados horários de famílias indígenas às margens de cursos d'água no entorno das aldeias, inclusive nos momentos de pico da atividade anofélica, expõe indivíduos de ambos os sexos e de todas as idades ao risco de infecção.

Mas há também certos aspectos das culturas indígenas que parecem atuar como fatores de proteção contra a malária. Ainda que não se possa generalizar, há casos (ex., Xavánte, Waimirí-Atroarí) nos quais a arquitetura da habitação tradicional indígena parece não ser favorável à penetração pelos anofelinos (Ianelli et al., 1998; Moura et al., 1994). Com base em estudo realizado entre os Xavánte, Ianelli et al. (1998) questionaram a eficácia da utilização de métodos convencionais para o controle da malária - baseados na instalação de barreiras físicas e/ou químicas que visam a impedir o contato intradomiciliar humanomosquito - em contextos nos quais as populações são predominantemente expostas a picadas no ambiente extradomicilar.

Uma característica marcante da grande maioria das áreas indígenas é a precariedade das condições de saneamento. Raramente os postos indígenas onde convivem funcionários administrativos, agentes de saúde, escolares e visitantes, dentre outros, dispõem de infra-estrutura sanitária adequada. É comum também a ausência de infra-estrutura destinada à coleta dos dejetos e a inexistência de águla potável nas aldeias. Nesse cenário, não é de surpreender que as parasitoses intestinais sejam amplamente disseminadas?

Dentre as investigações mais recentes sobre parasitismo intestinal estão aquelas que focalizam os Guaraní, em São Paulo e no Rio de Janeiro (Serafim, 1997), os Parakanã no Pará (Miranda et al., 1998), os Pakaanóva (Warí), Karitiána e diversos grupos Tupí-Mondé em Rondônia e Mato Grosso (Coimbra Jr. \& Santos, 1991a, 1991b; Escobar \& Coimbra Jr., 1998; Ferrari et al., 1992), os Xavánte (R. V. Santos et al., 1995; Leite et al., neste volume) e diversas comunidades indígenas em Pernambuco (Carvalho et al., 2001). Em geral, as espécies de helmintos mais prevalentes são Ascaris lumbricoides, Trichuris trichiura, Strongyloides stercoralis e ancilostomídeos e, comumente, mais de 50\% da população encontra-se acometida por mais de uma espécie. Esses estudos também revela-

\footnotetext{
7 Ver Salzano \& Callegari-Jacques (1988) para uma revisão sobre os trabalhos publicados até o final da década de 80 . Mais recentemente, Vieira (2003) apresentou uma revisão detalhada das publicações sobre enteroparasitores $\mathrm{em}$ populações indígenas.
} 
ram prevalências variáveis de infecção por protozoários intestinais, como Giardia lamblia e Entamoeba hystolitica.

As condições ambientais favoráveis à transmissão de helmintos e protozoários intestinais são também aquelas que propiciam a contaminação da água de consumo e dos alimentos por enterobactérias e rotavírus. A presença de diversas cepas patogênicas de enterobactérias e a ocorrência de elevadas taxas de soroprevalência para rotavírus têm sido amplamente reportadas para a população indígena em geral, especialmente na Amazônia (Linhares, 1992; Linhares et al., 1986). Em certas situações, as infecções gastrintestinais chegam a responder por quase metade das internações hospitalares de crianças indígenas e por até $60 \%$ das mortes em crianças menores de um ano, como sugerem dados dos Xavánte (Ianelli et al., 1996).

Chama a atenção a existência de pouquíssimos estudos sobre a epidemiologia das leishmanioses em grupos indígenas, considerando-se que, em sua grande maioria, vivem em áreas endêmicas, e em contextos nos quais podem vir a interferir nos ciclos enzoóticos do parasita. O único registro de epidemia de leishmaniose tegumentar documentado na literatura aconteceu entre os Waurá, no Alto Xingu (Carneri et al., 1963). Outros inquéritos têm apontado para um padrão no qual predominam reatores fortes à intradermoreação com leishmanina, da ordem de 60-70\%, com raríssimos casos de doença (Coimbra Jr. et al., 1996b; Lainson, 1988). Deve-se mencionar que surtos de leishmaniose visceral, de relativa gravidade, têm sido descritos em Roraima, entre os Makuxí e Yanomámi (Castellón et al., 1997).

A oncocercose é outra endemia que, apesar de apresentar uma distribuição na população indígena no Brasil restrita aos Yanomámi e a poucas outras etnias situadas na mesma região, alcança elevada prevalência em algumas áreas (70-80\% dos indivíduos em algumas comunidades), requerendo especial atenção para o seu controle (Coelho et al., 1998; Moraes, 1991; Py-Daniel, 1997; Shelley, 2002).

As hepatites constituem importantes causas de morbidade e mortalidade entre os povos indígenas. Diversos inquéritos têm revelado elevadas prevalências de marcadores sorológicos para hepatite $\mathrm{B}$. Por vezes, a presença de portadores crônicos do vírus é numericamente expressiva (Azevedo et al., 1996; Coimbra Jr. et al., 1996a; A. K. Santos et al., 1995). Nesses casos, não é rara a presença de coinfecção pelo vírus Delta (HDV), ocasionando óbitos devido a quadros graves de hepatite aguda. Por exemplo, entre os Mundurukú, no Pará, onde ocorreram vários óbitos por hepatite, Soares \& Bensabath (1991) relataram que cerca de 50\% 
dos indivíduos que se encontravam $\mathrm{HB}_{\mathrm{A}} \mathrm{Ag}$ positivos também se apresentavam positivos para anticorpos anti-HDV. A cpidemiologia da hepatite C nas populações indígenas ainda não foi investigada sistematicamente.

Coimbra Jr. ct al. (1996a) chamam a atenção para a presença de inúmeras práticas culturais de cunho ritualístico, cosmético ou curativo (escarificações, tatuagens, sangrias, etc.) por meio das quais pode ocorrer a transmissão dos vírus das hepatites B C D cm sociedades indígenas. Tais práticas, aliadas à interação com garimpeiros, militares coutros agentes de frentes de expansão, colocam as populações indígenas (em especial alguns grupos) em condições particularmente vulnerávecis para a transmissão não somente de hepatites, como também de outros vírus veiculáveis pelo sangue como, por exemplo, os retrovírus (ver Black et al., 1994; Ishak et al., 1995; Vallinoto et al., 2002 e Wiik, 2001 para discussões sobre o impacto e a epidemiologia de infecçóes por IIIV c HTLV em populações indígenas).

Apreende-se, portanto, que o contexto geral de mudanças socioculturais, economicas e ambientais no qual se inserem os povos indígenas no Brasil de hoje tem grande potencialidade de influenciar os perfis epidemiológicos. A revisão acima sobre as principais doenças infecciosas e parasitárias presentes nas populações indígenas lista tão somente uns poucos fragmentos de umn quadro mais amplo, complexo e multifacetado, além de, em grande medida, desconhecido. A inexistência de estatísticas confiáveis não pernite ir alćm da revisão de um conjunto relativamente restrito (do ponto de vista geográfico, étnico e epidemiológico) de estudos de casos. Por exemplo, não foram mencionadas importantes doenças para as quais as informações disponíveis não vão muito além de relatos orais, resumos de trabalhos apresentados em congressos ou relatórios preliminares, sc tanto. Dentre as mesmas, sem tentar esgotar a questão, merecem atenção a esquistossomose e o tracoma entre indígenas no Nordeste, a hanseníase na população indígena em geral (sobre a cual não há praticamente informação no que pese essas populações estarem inscridas en contextos sociogeográficos de moderada a alta endemicidade) e a AIISS (de norte a sul do país). O tema da saúde da mulher indigena tem sido poucuíssimo investigado (Coimbra Jr. \& Carnelo, 2003), apesar das clevalas prevalências de infecção ginecológica por papilomavírus e Chlamydia reportadas e'm alguns estudos (Brito et al., 1996; Ishak et al., 1993; Ishak \& Ishak, 2001; 'laborda et al., 200(0).

Outra questão relevante no ecenário da salúcle dos povos indígenas di\% respeito alos impactos das mudanças anubientais decorrentes da construção de barragens e hidrelétricas em suas terras on mas proximidades, atividades cxtrati- 
vistas como o garimpo, ou mesmo a introdução de novas tecnologias agrícolas que envolvam a substituição do sistema de horticultura consorciada tradicional por monoculturas. Koifman (2001) mapeia a localização das principais hidrelétricas no país e sua relação com as terras indígenas, chamando a atenção para os seus possíveis impactos sobre a saúde. Esse autor discute a associação entre exposição contímua aos campos eletromagnéticos gerados pelas redes de transmissão e câncer (veja também Koifman et al., 1998 e Vieira Filho, 1994).

()utro agravo ambiental com consequiências importantes para a saúde indígena decorre da contaminação pelo mercúrio utilizado no garimpo de ouro, principalmente na Amazônia. Fissa questão associa-se ao consumo de pescado, item importante na dieta de muitos grupos indígenas, o que favorece a contaminação disseminada pelo mercúrio de indivíduos dos vários grupos ctários e de ambos os sexos, mesmo nos casos em que os garimpos estejam situados fora da terra indígena propriamente dita. Fintre os Mundurukú no Pará, por exemplo, Brabo et al. (1999) verificaram níveis elevados de metilmercúrio nas espécies de peixes mais frequientemente consumidas. Outros estudos recentes, como entre os Makuxí, Kayapó e Pakaanóva (Warí), confirmam a amplitude do problema de contaminação ambiental por mercúrio em áreas indígenas na bacia amazônica (Barbosa et al., 1998; Santos et al., 2003; Sing ct al., 1996).

\section{MORBI-MORTALIDADE EM TRANSICCÃO}

Una dimensão particulamente pouco conhecida da epidemiologia dos povos indígenas no Brasil, c com amplos impactos no presente e futuro, diz respcito à emergência de doenças crônicas não-transmissiveis, como obesidade, hipertensão arterial, diabetes mellitus tipo II, entre outras. () surgimento desse grupo de doenças como elementos importantes no perfil de morbidade c mortalidade indígena está estreitamente associado a modificações na subsistência, dieta e atividade física, dentre outros fatores, acopladas às mudanças socioculturais e econômicas resultantes da interação com a sociedade nacional. No bojo dessas mudanças, verifica-se que, concomitante à cmergência de doenças crônicas não-transmissíveis, há um crescente número de relatos sobre a ocorrência de transtornos psiquiátricos que, não raro, impactam sobre as commidades de forma disseminada, incluindo jovens e adultos de ambos os sexos. A ocorrência de suicídio, alcoolismo e drogadicção vem sendo reportada em diferentes etnias em crescente númcro (Firthal, 2001; I angdon, 1999; Meihy, 1994; Morgado, 1991; Poz, 2000); 
Souza et al., neste volume). Observa-se também aumento importante das mortes por causas externas, sejam essas ocasionadas por acidentes automobilísticos e uso de maquinário agrícola, como também por violência - em muitos dos casos, assassinatos e mesmo massacres perpetrados por madeireiros, garimpeiros e outros invasores de terras indígenas (CIMI, 1996, 1997).

O conhecimento do perfil epidemiológico em transição dos povos indígenas, considerando a grande diversidade étnica e regional na qual se inserem, reveste-se de suma importância para orientar a organização, planejamento e melhoria da qualidade dos serviços de assistência à saúde. Em geral, esses serviços encontram-se voltados para lidar com determinados grupos de doenças, sobretudo as infecciosas e parasitárias, que, historicamente, têm (ou tiveram) maior peso na morbi-mortalidade indígena.

A literatura sobre saúde das populações indígenas situadas nas Américas, em particular aquelas localizadas no Canadá e nos Estados Unidos, aponta para a emergência da obesidade, hipertensão e diabetes mellitus, dentre outras, como sérios problemas de saúde pública ao longo das últimas décadas, não raro sobrepujando-se às doenças infecciosas e parasitárias (Narayan, 1996; Szathmary, 1994; West, 1974; Young, 1993). Ainda que esta não seja a situação epidemiológica dos povos indígenas no Brasil, há indícios claros de uma transição em curso.

Povos indígenas vivendo sob regimes de subsistência "tradicionais" (no que se refere à ecologia e alimentação) têm atraído o interesse de epidemiólogos e de antropólogos devido aos baixos níveis tensionais que apresentam em comparação àqueles verificados nas populações urbanas não-indígenas. Inúmeros estudos destacam a ausência da clássica associação entre idade e elevação dos níveis tensionais em populações indígenas, além da raridade de indivíduos portadores de doenças cardiovasculares (Fleming-Moran \& Coimbra Jr., 1990; Mancilha-Carvalho et al., 1989; Page, 1974; Vaughan, 1978). As explicações mais comumente apresentadas enfocam a ausência ou baixa exposição a conhecidos fatores de risco associados à gênese desse grupo de doenças. Contudo, esse perfil tende a mudar rapidamente conforme os grupos indígenas intensificam seus contatos com a sociedade nacional, quando ocorre a introdução do sal, de bebidas alcoólicas destiladas, de gorduras saturadas em quantidade, associados à redução dos níveis de atividade física. Pesquisas conduzidas em várias regiões do mundo têm documentado a rápida emergência de hipertensão arterial em populações nativas passando por mudanças em seus estilos de vida (McGarvey \& Schendel, 1986; Page, 1974; Sinnett et al. 1992; Vaughan, 1978). 
Pouco se sabe acerca da cpideniologia da hipertensão em populações indígenas no Brasil. A maioria dos estudos sobre níveis tensionais foi realizada cm grupos que ainda se mantinham relativamente isolados (Fleming-Moran \& Coimbra Jr., 1990; Crews \& Mancilha-Carvalho, 1993; Lima, 1950; Oliver et al., 1975). Poucos trabalhos foram conduzidos sobre o tema visando a avaliar os impactos das mudanças socioculturais e ambientais em curso sobre os níveis tensionais (Cardoso et al., 2001; Coimbra Jr. et al., 2001; Fleming-Moran et al., 1991).

O caso dos Xavánte da aldeia de Etéñitépa (ou Pimentel Barbosa), em Mato Grosso, ilustra bem esse processo (Coimbra et al., 2001, 2002). No início dos anos 60, os Xavánte foram estudados por uma equipe constituída por médicos e antropólogos (Neel et al., 1964). Cerca de 30 anos depois, o mesmo grupo foi reestudado e os resultados apontam claramente para uma tendência de aumento dos níveis tensionais sistólicos e diastólicos ('labela 4). Em 1962, as pressões sistólicas c diastólicas estavann na faixa de $94-126$ e 48-80 $\mathrm{mmH} \mathrm{g}$, respectivamente, e não foram obscrvados casos de hipertensão. lim 1990, as médias sistólicas e diastólicas mostraram-sc mais elcvadas em ambos os sexos e foram detectados casos de hipertensão. Ainda cm 1990, notou-se também uma correlação positiva cntre pressão sistólica e idade, inexistente anteriormente. Coimbra Jr. e associados argumentam que, no curso de quase 50 anos de contato com a socicdade nacional, aconteceram mudanças no estilo de vida que predispuseram os Xavánte à hipertensão e a outras doenças cardiovasculares. Por exemplo, houve significativo aumento nas médias do índice de massa corporal (IMC) dos adultos, bem como redução da atividade física (Santos et al., 1997; Cugelmin \& Santos, 2001 ). Atualmente, o arroz. constitui a base da alimentação e o sal é usado diariamente. Além disso, parcela expressiva dos homens fuma, o que não era o caso no passado.

A obesidade ć um problema de saúde em ascensão cm povos indígenas nas mais diversas regiões do mundo, em particular na América do Norte, Oceania e Polinésia (Kunitz, 1994; Young, 1993). Km relação aos povos indígenas no Brasil, referências à ocorrência de obesidade são incomuns. No que tange aos problemas nutricionais, revisões sobre o estado nutricional de populações indígenas publicadas até o início dos anos 90 enfatizaram sobretudo a ocorrência da desnutrição energético-proteica crônica e seus efeitos sobre o crescimento físico de crianças (Dufour, 1992; Santos, 1993). Ainda que não sejam disponíveis dados epidemiológicos confiáveis para caracterizar a ocorrência e a distribuição de obesidade nas populações indígenas no Brasil de forma satisfatória, de alguns anos para cá tem surgido um número crescente de estudos que chamam a aten- 


\begin{tabular}{|c|c|c|c|c|}
\hline & \multicolumn{2}{|c|}{ Masculino } & \multicolumn{2}{|c|}{ Feminino } \\
\hline & $N$ & Média & $N$ & Média \\
\hline \multicolumn{5}{|c|}{ Estatura (cm) } \\
\hline 1962 & 13 & 169,3 & 12 & 155,3 \\
\hline 1990 & 25 & 168,1 & 26 & 154,0 \\
\hline \multicolumn{5}{|l|}{ Peso $(\mathrm{kg})$} \\
\hline 1962 & 13 & 68.3 & 12 & 53.3 \\
\hline 1990 & 25 & 72,9 & 26 & 60,05 \\
\hline \multicolumn{5}{|c|}{$\operatorname{IMC}(\mathbf{k g} / \mathrm{m} 2)$} \\
\hline 1962 & 13 & 23.8 & 12 & 22,0 \\
\hline 1990 & 25 & 25,8 & 26 & 25,2 \\
\hline \multicolumn{5}{|c|}{ Sistólica (mmHg) } \\
\hline 1962 & 13 & 114,0 & 12 & 106,7 \\
\hline 1990 & 26 & 120,9 & 27 & 120,6 \\
\hline \multicolumn{5}{|c|}{ Diastólica $(\mathbf{m m H g})$} \\
\hline 1962 & 13 & 63.5 & 12 & 66,2 \\
\hline 1990 & 26 & 76,5 & 27 & 75,0 \\
\hline
\end{tabular}

Fontes: Coimbra Jr. et al. (2001, 2002).

ção para a ocorrência da obesidade em diferentes grupos, como os Boróro e Xavánte em Mato Grosso (Leite, 1998; Vieira Filho, 1996, 2000), os Teréna no Mato Grosso do Sul (Ribas \& Phillipi, neste volume), os Suruí em Rondônia (Santos \& Coimbra Jr., 1996, 1998) e os Gavião-Parakatejé no Pará (Capelli \& Koifman, 2001; Tavares et al., 1999).

Dois casos ilustrativos das inter-relações entre mudanças socioeconômicas e ambientais e suas influências sobre o estado nutricional e composição corporal de adultos são aqueles dos Suruí (Santos \& Coimbra Jr., 1996) e dos Xavánte (Gugelmin \& Santos, 2001). No final da década de 80 , inquérito antropométrico em adultos Suruí mostrou que aqueles indivíduos que já não estavam diretamente envolvidos em atividades de subsistência "tradicionais" consumiam uma dieta que combinava alimentos industrializados pobres em fibras, com ele- 
vados teores de gorduras e/ou açúcares e também apresentavam menores níveis de atividade física. Esses indivíduos exibiam médias de peso bem mais elevadas que a população adulta Suruí em geral. As diferenças alcançavam $7,6 \mathrm{~kg}$ entre as mulheres e $5,7 \mathrm{~kg}$ entre os homens. Os autores concluíram que o segmento da população Suruí que ganhou mais peso foi aquele mais diretamente envolvido em determinadas atividades econômicas recém-introduzidas, que levaram à rápida capitalização (por meio do cultivo de café e comércio de madeira), ocasionando mudanças importantes na dieta e nos padrões de atividade física. Gugelmin \& Santos (2001) compararam duas comunidades Xavánte com diferentes trajetórias de contato e alterações em seus sistemas de subsistência. Verificaram médias de peso e do IMC significativamente mais elevadas naquela onde as mudanças foram mais intensas (ver também Leite et al., neste volume).

Segundo diversos autores, o diabetes mellitus tipo II era desconhecido entre povos indígenas até a primeira metade do século XX. Sobretudo na América do Norte, tornou-se um dos mais sérios problemas de saúde em diversas sociedades, por vezes apresentando prevalências que superam aquelas reportadas para a população em geral (Ghodes, 1986; Narayan, 1996; Szathmáry, 1994; West, 1974; Young, 1993). Mudanças na dieta e em estilos de vida são considerados os principais fatores associados à emergência de diabetes em populações indígenas. Referindo-se a grupos da América do Norte, Szathmáry (1994:470) comenta: “...em geral, a possível seqüência de mudanças [que levam à emergência do diabetes mellitus não-insulino-dependente em populações indígenas da América do Norte] pode ter sido a sedentarização, redução da atividade física, aumento na ingestão calórica elou de algum nutriente específico, mudanças na distribuição da gordura corporal e desenvolvimento de obesidade".

Durante as décadas de 1970 e 1980, a imagem de índios obesos sofrendo de diabetes era estranha para a maioria dos antropólogos e médicos brasileiros. A equipe médica da Escola Paulista de Medicina liderada por Roberto Baruzzi, que por várias décadas tem realizado pesquisas e provido assistência às populações xinguanas, conduziu vários inquéritos que não detectaram casos de diabetes (Baruzzi \& Franco, 1981; Franco, 1981, 1992). Diversos outros estudos sobre metabolismo de glicose foram realizados em grupos indígenas que aderiam a dietas tradicionais e mantinham níveis de atividade física relativamente altos. Nenhuma dessas pesquisas encontrou qualquer indicação de diabetes (Bloch et al., 1993; Spielman et al., 1982; Vieira Filho, 1975).

A primeira referência ao diabetes mellitus em grupos indígenas no Brasil data dos anos 70, e diz respeito aos Karipúna e Palikúr no Amapá (Vieira Fi- 
lho, 1977). Desde então, casos têm sido reportados em diversos outros grupos indígenas da Amazônia e Centro-Oeste, como os Gavião, Boróro, Xavánte e Teréna (Cardoso et al., neste volume; Tavares et al., 1999; Vieira Filho, 1981, 1996; Vieira Filho et al., 1983, 1984).

No presente, não há informações epidemiológicas detalhadas e consistentes que permitam mapear a ocorrência de diabetes em indígenas no Brasil. Contudo, os poucos relatos e estudos de casos disponíveis na literatura sugerem fortemente tratar-se de problema de saúde em franca emergência (ver Cardoso et al. neste volume). Por exemplo, Vieira Filho (1996:61) sumariza da seguinte maneira suas observações clínico-epidemiológicas, resultantes de duas décadas de interação com os Xavánte: “Quando iniciei minhas visitas anuais aos índios Xavantes de Sangradouro e São Marcos, há 20 anos, observei que eram delgados e com atividade física intensa, não havendo nenhum caso com sintomatologia de diabetes melito... Nos últimos anos, têm ocorrido casos de diabetes com sintomatologia exuberante entre os Xavantes que se tornaram obesos". Segundo dados da equipe de saúde da Fundação Nacional de Saúde (FUNASA), em Barra do Garças, responsável pelo atendimento médico à população Xavánte, no final da década de 1990 havia 72 casos de diabetes que estavam sendo acompanhados mensalmente pelo serviço de saúde (Coimbra Jr. et al., 2002). Há uma notável concentração em apenas três terras indígenas (São Marcos, Parabubure e Sangradouro), que juntas representam $94,4 \%$ do total.

Portanto, a transição epidemiológica que se observa nos povos indígenas no Brasil no presente, com a rápida emergência de doenças crônicas não-transmissíveis em vários grupos, é um tema que tenderá a ganhar maior visibilidade no futuro próximo, face à intensidade das mudanças sócio-culturais, comportamentais e ambientais e seus impactos sobre os perfis de morbi-mortalidade.

\section{COMENTÁRIOS FINAIS}

Até o final da década de 1990, os serviços de saúde destinados ao atendimento dos povos indígenas eram geridos pela FUNAI. Em larga medida, baseavam-se em atuações eminentemente curativas. A continuidade da atenção básica à saúde nas áreas indígenas não ocorria de forma satisfatória. Mesmo nas décadas de 1960 e 1970, quando já se dispunham de vacinas, antibióticos e outros recursos, não se conseguiu evitar que epidemias de malária, tuberculose ou mesmo de sarampo dizimassem centenas de indígenas recém-contatados no Brasil-Central e 
Amazônia. Isso aconteceu sobretudo em áreas sob influência de rodovias em construção como a Transamazônica, assim como em regiões sujeitas aos impactos de frentes de expansão agropastoril, como nos casos de Rondônia e Roraima. Mesmo em contextos outros em que as crises decorrentes de epidemias, salvo exceções, vitimaram diversos indígenas, os serviços prestados pela FUNAI tendiam a ser desorganizados e, em muitas áreas, esporádicos.

A partir de 1999, a responsabilidade pela provisão de serviços de saúde aos povos indígenas passou para a FUNASA, vinculada ao Ministério da Saúde (FUNASA, 2002), concretizando a implantação de um serviço de saúde voltado para os povos indígenas e estruturado segundo divisão territorial em distritos (os chamados "Distritos Sanitários Especiais Indígenas" ou DSEIs), vinculados ao Sistema Único de Saúde (SUS). No presente há 34 distritos implantados em todo o país, em diferentes graus de estruturação 8 .

No âmbito das estratégias de reestruturação do sistema de saúde destinado aos povos indígenas, merece destaque a implantação de um sistema de informação. Segundo a própria FUNASA (2002:19), “... o acompanhamento e avaliação ... [da política de atenção à saúde indígena] terá como base o Sistema de Informação da Atenção à Saúde Indígena - SIASI... Os aspectos a serem acompanhados e avaliados incluirão a estrutura, o processo $e$ os resultados da atenção à saúde dos povos indígenas. O SIASI deverá subsidiar os órgãos gestores e de controle social quanto à indispensável compatibilidade entre o diagnóstico situacional dos problemas de saúde identificados e as prioridades estabelecidas nos níveis técnico, social e político, visando a coerência entre ações planejadas e efetivamente executadas". Vale mencionar que, no presente, após mais de três anos do início do processo de distritalização, o SIASI ainda não disponibiliza dados demográficos e epidemiológicos de forma ampla. Espera-se que muito em breve essa situação seja revertida, e que sejam iniciadas análises aprofundadas para monitorar e avaliar as condições de saúde dos povos indígenas no âmbito da nova política de atenção à saúde.

A implementação de um sistema de informação em saúde indígena é de vital importância nas mais diversas esferas. Vimos ao longo deste capítulo quão precários são os conhecimentos disponíveis sobre o perfil de saúde/doença dos

\footnotetext{
8 Sobre o processo de distritalização da saúde indígena, ver, entre outros, Athias \& Machado (2001), Garnelo \& Sampaio (2003), Langdon (2000), bem como outros capítulos neste volume, como os de Diehl e colaboradores e de Garnelo \& Brandão.
} 
povos indigenas no Brasil. Desnecessário enfatizar que a existência de registros epidemiológicos sistemáticos será de grande valia para fins do planejamento, implementação e avaliação de serviços e de programas de saúde. Informações confiáveis são também imprescindíveis para viabilizar análises sobre as múltiplas e complexas interelaçoes entre desigualdades sociais, processo saúde-doença e etnicidade. Como tivemos a oportunidade de salientar anteriormente sobre os poros indígcnas, “... coeficientes de morbi-mortalidade mais altos... fome e desnutrição, riscos ocupacionatis e violência social são apenas algums dos múltiplos reflexos sobre a sazide, decorrentes da persistência de desigualdades" (Coimbra Jr. \& Santos, $20(0): 131)$. Tais conhecimentos, gerados con base em parcerias entre pesquisadores, lideranças indígenas e provedores de serviços de saúde, são fundamentais para o embasamento de atuações políticas, inclusive por parte das comunidades indígenas, e de intervenções na área da saúde. Fispera-se ainda que, a partir da crescente participação indígena nos vários segmentos do sistema de saúde, futuramente eles próprios venham a farer uso crescente dessas informações com vistas a definir prioridades e implementar estratégias mais adequadas de atuação dos serviços de saúde junto às suas comunidades. 


\section{Referências}

ADA.HS, K. \& PRICE, D. (eds.), 1994. 'The Demograplyy of Sinall-Scale Societies: Case Studies from I owland South America. South American Indian Studies, 4 (mímero temático).

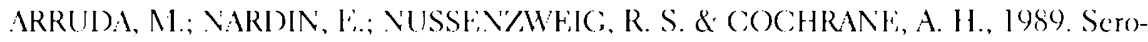
epidemiological studies of malaria in Indian tribes and monkeys of the Amazon basin of Brazil. American Journal of Tropical Medicine and Hygiene, 41:379-385.

AT'HIAS, R. \& . MAC.HADO ), M., 20()l. A saúde indígena no processo de implanta(cão dos Distritos Sanitários: 'Temas críticos e propostas para um diálogo interdisciplinar. (iatdernos de Saude Pública, 17:425-431.

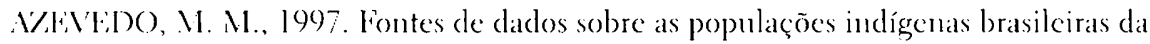
Amazônia. Cadernos de Lstudos Sociais, 13:163-177.

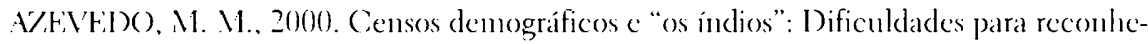
cer c contar. In: Povos Indigenas no Brasil 1996/2000) (C. A. Ricarclo, org.), pp. 7983, São Paulo: Instituto Socioambicutal.

ALEVEDO, N1. N. \& RICARI)O, F., 2002. Censo 2000 do IBCF Revela Contingente "Indígena" Pouco (onhecido. 14 . Naio de $2002<$ http://www.socioambiental.org $>$.

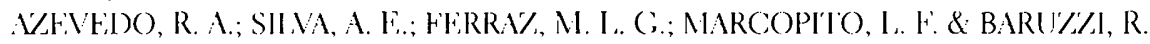
(i., 1996. Prevalência dos marcadores sorológicos dos vírus da hepatite B e I) em crianças das tribos Caiabi e Txucarranãe do Parque Indígena do Xingu, Brasil Central. Revista da Sociedade Brasileira de Medicina 'Tropical, 29:431-439.

BARATA, R. B., 1995. Malária no Brasil: Panorana epidemiológico na última década. Cadernos de Saúde Pública, 11:128-136.

BARBOSA, A. C.; SIL, A, S. R. \& IOORFA, J. C,., 1998. Concentration of mercury in hair of indigenous mothers and infants from the Anazon Basin. Archives of Emvirommental Contamination and Toxicology, 3+:100)-105.

BARIIZZI, R. (;., 1992. Nalária e populações indígenas. Revista da Sociedade Brasileira de Medicina l'ropical, 25:23-26.

BARUI\%I, R. (;; BARROS, V. L.; ROI)RI(;UIS, D).; SOU/A, A. L. M. \& PI.ACIARO, 11., 200) Saúde e doença em índios Panará (Krecn-Akarôre) após vinte e cinco anos de contato com o nosso mundo, com ênfase na ocorrência de tuberculose (Brasil Central). Cademos de Saúde Pública, 17:407-412.

BARUY\%I, R. (;. \& FRANCO), I. J., 1981. Amerindians of Brazil. In: Westem I)iseases: Their Fimergence and Prevention (H. C. Trowell \& I). P. Burkitt. eds.), pp. $138-153$, I ondon: lidward Arnold.

BARUYZI, R. (;.; MARCOPITO, I.. F.; SFRRA, M. L. (., SOU\%A, F. A. A. \& SIABII.F, (., 1977. The Kren-Akorore: A recently contacted indigenous tribe. In: Health and Disease in 'Tribal Societies (K. Villiot \& J. Whelan, eds.), pp. 179-211, Amsterdam: Filscrier.

BARUYZI, R. (;.; PACLIARO, II.; SIINA, S. S.; SCHIVARTCHF, V. \& MVZIARA, II., 1994. ()s indios Panará: $A$ busca pela sobrevivencia. In: IX Eincontro Vacional de Fistudos Populacionais, Anais, v. 2, pp. 225-242, Brasília: Associação Brasilcira de Fistudos Populacionais. 
BLACK, F. L.; BIGGAR, R.; NEEL, J. V.; MAL.ONEY, E. M. \& WATERS, D. J., 1994. Endemic transmission of HTLV type II among Kayapó Indians of Brazil. AIDS Research and Human Retrovirus, 10:1165-1171.

BLOCH, K. V.; COUTINHO, E. S. F.; LÔBO, M. E. C.; OLIVEIRA, J. E. P. \& MILECH, A., 1993. Pressão arterial, glicemia capilar e medidas antropométricas em uma população Yanomámi. Cadernos de Saúde Pública, 9:428-438.

BRABO, E. S.; SANTOS, E.; JESUS, I. M.; MASCARENHAS, A. F. \& FAIAL, K. F., 1999. Níveis de mercúrio em peixes consumidos pela comunidade indígena de Sai Cinza, na reserva Mundurukú, Município de Jacarecanga, Estado do Pará, Brasil. Cadernos de Saúde Pública, 15:325-331.

BRITO, E. B.; MENEZES, R. C.; MARTINS, S. J.; BASTOS, M. G. M. \& SOUSA, A., 1996. Estudo preliminar para detecção de cérvico-vaginites e lesões precursoras do câncer de colo uterino em índias da tribo Parakanã. Revista da Associação Médica Brasileira, 42:11-15.

BUCHILLET, D. \& GAZIN, P., 1998. A situação da tuberculose na população indígena do Alto Rio Negro (Estado do Amazonas, Brasil). Cadernos de Saúde Pública, 14 : 181-185.

BURATTINI, M. N.; MASSAD, E.; COUTINHO, F. A. B. \& BARUZZI, R. G., 1993. Malaria prevalence amongst Brazilian Indians assessed by a new mathematical model. Epidemiology and Infection, 111:525-537.

CAPELLI, J. C. S. \& KOIFMAN, S., 2001. Avaliação do estado nutricional da comunidade indígena Parkatêjê, Bom Jesus do Tocantins, Pará, Brazil. Cadernos de Saúde Pública, 17:433-437.

CARDOSO, A. M.; MATTOS, I. E. \& KOIFMAN, R. J., 2001. Prevalência de fatores de risco para doenças cardiovasculares na população Guaraní-Mbyá do Estado do Rio de Janeiro. Cadernos de Saúde Pública, 17:345-354.

CARNERI, I.; NUTELS, N. \& MIRANDA, J. N., 1963. Epidemia de leishmaniose tegumentar entre índios Waurá do Parque Nacional do Xingu (Estado de Mato Grosso, Brasil). Revista do Instituto de Medicina Tropical de São Paulo, 5:271-272.

CARVALHO, E. F.; FONTBONNE, A. K.; SÁ, G. A. \& CESSE, E. P., 2001. Fatores de risco para poliparasitismo intestinal em urna comunidade indígena de Pernambuco, Brasil. Cadernos de Saúde Pública, 17:367-373.

CASTELlÓN, E. G.; GUERRA, J. O. \& COSTA, Y. C., 1997. A leishmaniose visceral (calazar) no Estado de Roraima. In: Homem, Ambiente e Ecologia no Estado de Roraima (R. I. Barbosa, E. J. Ferreira \& E. G. Castellón, orgs.), pp. 157-179, Manaus: Instituto Nacional de Pesquisas da Amazônia.

CIMI (Conselho Indigenista Missionário), 1996. A Violência Contra os Povos Indígenas no Brasil: 1994-1995. Brasília: CIMI.

CIMI (Conselho Indigenista Missionário), 1997. A Violência Contra os Povos Indígenas no Brasil - 1996. Brasília: CIMI.

COELHO, G. E.; VIEIRA, J. B. F.; GARCIA-ZAPATA, M. T. A. \& SCHUERTZ, J. C. M., 1998. Identificação de áreas de estratificação epidemiológica no foco de oncocercose na região Yanomámi, Roraima, Brasil. Cadernos de Saúde Pública, 14:607611 . 
COIMBRA Jr., C.. F.. A., 1989. From Shifting Cultivation to Coffee Farming: The Impact of Change on the Ilealth and Ficology of the Surui Indians in the Brazilian Amazon. Ph.I ). Dissertation, Bloomington: Indiand University:

COIMBRA Jr., C. E. A., 1998. Minorías étnico-raciales, designaldad y salud: Consideraciones teóricas preliminares. In: Salud. Cambio Social y Política: Perspectivas desde América Latina (M. ‥ Bronfman \& R. Castro, orgs.), pp. 151-161, México, DF: lidanex.

COMIBRA Jr., (;. F. A.; (.HOR, I).; SANTOS, R. V.\& SALLANO, F. M., 2001. Blood pressure levels in Xavánte adults from the Pimentel Barbosa Indian Reserve, Mato Grosso, Brazil. Fithnicity and Disease, $11: 232-240$

COIMBRA Jr., (.. E. A.; FLOWHES, N. M.; SAVTOS, R. V. \& SALZANO, F. M., 2002. The Xavante in 'Transition: Mealth, Ecology, and Bioanthropology in Central Brazil. Anu Arbor: University of Michigan Press.

COMABRA Jr., C. F.. A. \& (iARNFil.O, L., 2003. Questões de saúde reprodutiva da mulher indigena no Brasil. In: Raça/Etnicidade na América latina: Questões sobre Saúde e Direitos Reprodutivos (S. Monteiro, org.), Rio de Janeiro: Fditora Fiocrur. (no prelo).

COIMBRA Jr., C. E. A. \& SANTOS, R. V., 1991 a. Avaliação do estado nutricional num contexto de mudança sócio-econômica: () grupo indígena Suruí do Fsstado de Rondônia, Brasil. Cademos de Saúde Pública, 7:538-562.

C.OIMBRA Jr.. (.. E. A. \& SAN"IOS, R. V., 1991b. Parasitismo intestinal entre o grupo indígena \%oró, estado de Mato Crosso (Brasil). Cadernos de Saúde Pública, 7: 100)103.

COIMBRA Jr., C. E. A. \& SANT'OS, R. V., 2000). Saúde, minorias e desigualdade: Algumas teias de inter-relações, com ĉnfase nos poros indigenas. Ciência ć Saúde Coletiva, 5:125-132.

COINIBRA Jr., C. F. A.; SAVIOOS, R. V.; FIOWLES, N. M.; YOSHIDA, C.; BAP'IISIA, M. \& VAI.L. A. C. F., 1996a. Hepatitis B epidemiology and cultural practices in Ancrindian populations of Amazonia: 'The Tupí-Mondé and the Xavánte of Rondônia and Mato Grosso. Social Science and Medicine, 42:1738-1743.

COJNBRA Jr., C. F. A.; SANTOS, R. V. \& VAI,LF, A. C. F., 1996b. Cutancous leishmaniasis in 'Tupi-Mondé Amerindians from the Brazilian Anazonia. Acta Tropica, 61: $201-211$.

COSTA, I). (., 1986. Processo Social e Doença: Tuberculose em (Grupos Indigenas Brasileiros. Dissertação de Mestrado, Rio de Janeiro: Universidade Estadual do Rio de Janeiro.

CUNHA. M. C.. 1992. Introdução a uma história indígena. In: História dos Índios no Brasil (M. C. Cunha, org.), pp. 9-24, São Paulo: Companhia das Letras.

CREWS, I). F. \& MANCIL.HA-CARVAIHO, J. J., 1993. Correlates of blood pressure in Yanomami Indians of Northwestern Brazil. Ethnicity and Disease, 3:362-371.

DATASUS (1)epartamento de Informática do SUS), 2000. Indicadores e Dados Básicos, Brasil - 1997.4 Janciro $2000<$ hittp://www. datasus.gov.br/cgi/idb97/matriz.litm>.

DAVIS, S. H., 1978. Vitimas do Milagre: O Desenvolvimento e os Índios do Brasil. Rio de Janciro: 'Jahar. 
I)FWVAN, W. M., 1976. The Native Populations of the Americas in 1492. Madison: The (University of Wisconsin Press.

DUFOUR, D., 1992. Nutritional ecology in the tropical rain forests of Amazonia. American lournal of Human Biology', t:197-2077.

FARI,I. J. D. \& PFIFRS, J. F. 1990. The Population Dynamics of the Macajai Yanomama. San Diego: Academic Press.

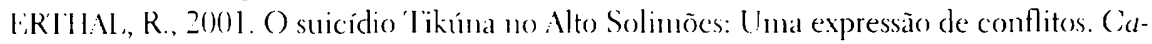
dernos de Saúde Pública, 17:299-311.

FS(,)B.IR, A. L.., 200)1. Epidemiologia da Tuberculose na População Indígena Pakánora (Hari), Fistado de Rondonia. Brasil. 'lése de Doutorado. Fiscola Nacional de Saúde Pública, Fundação (Oswaldo Cruz, Rio de Janeiro.

FSC:OBAR, A. I. \& COIMBRA Jr., C. F. A., 1998. Considerações sobre as Condiçóes de Saúde das Populações das Areas Indigenas Pakaánova (Wari) e do Posto Indígena Cillaporé, Rondônia. Documento de Irabalho n. 1, Porto Vélho: Céntro de Estudos em Saúde do f́ndio de Rondônia, Universidade Federal de Rondônia.

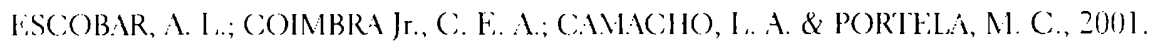
Tuberculose em populaçóes indiggenas de Rondônia, Anazônia, Brasil. Cadernos de Saúde Pública, 17:285-298.

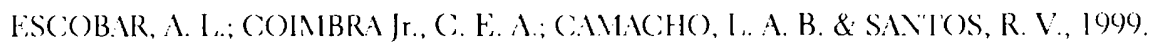
Caracterização dos calsos notificados pelo Programa de Controle da liuberculose, Rondônia, Brasil. II. (impos Indígenas. Revista da Sociedade Brasileira de Medicina Tropical, 32(Sup. 1):131.

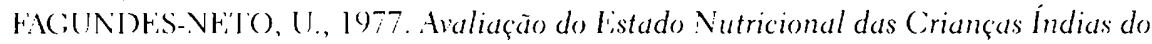
Alo Xingu. Tese de Doutorado, São Paulo: Lscola Paulista de Mecticina.

FFRR IRI, J.: FFRRIIRA, M. 11.: CAMIARC;O, 1. M1. \& FERRFIRA. C. S., 1992. Intestinal parasites among Karitiana Indians from Rondonia state, Brazil. Revista do Instituto de Medicina Tropical de São Paulo, 34:223-225.

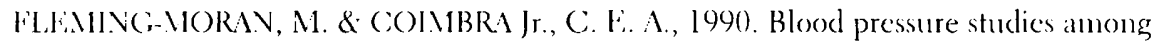
Anlazonian native populations: A revien from an epidemiological perspective. Social Science and Medicine, 31:593-601.

FLWIINC-MORAN, M.; SAN"IOS, R. V. \& C.OINIBRA Jr., C. E. A., 199I. Blood pressure levels of the Surui and \%oró Indians of the Brazilian Amazon: (Froup - and sex-specific effects resulting from body composition, health status, and age. Human Biologs, 63:835-86].

PICWFRS, N. M., 1994. Crise e recuperação demográfica: Os Xavánte de Pimentel Barbosa, Mato Crosso. In: Salide e Poros Indigenas (R. V. Santos \& C. F. A. Coimbra Jr., orgs. ), pp. 213-2+2, Rio de Janeiro: Viditora Fiocruz.

FRIN(C), I. J., 1981. Aspectos Metabólicos da População Indigena do Alto Xingu. 'Tése de Doutorado. São Paulo: liscola Paulista de Nedicina.

FRANC(), I. J., 1992. Diabetes in Brazil: A review of recent survey data. Fithnicity and Disease, 2:158-165.

FUINAS (Fundação Nacional de Saúde), 20)(2). Política Nacional de Atenção à Satide dos Povos Indigenas. 2a Fid. Brasília: FIINASM/Ministério da Saúde.

(AARNEI,(), I. \& SAMPAI(), S., 2003. Basses sócio-culturais do controle social em saúde 
indígena. Problemas e questões na Região Norte do Brasil. Cadernos de Saúde Pública, 19:311-317.

GHODES, D. M.,1986. Diabetes in American Indians: A growing problem. Diabetes Care, 9:609-613.

GOMES, M. P., 1988. Os Índios e o Brasil: Ensaio Sobre um Holocausto e Sobre uma Nova Possibilidade de Convivência. Petrópolis: Vozes.

GUGELMIN, S. A. \& SANTOS, R. V., 2001. Ecologia humana e antropometria nutricional de adultos Xavánte, Mato Grosso, Brasil. Cadernos de Saúde Pública, 17:313322.

GUGELMIN, S. A.; SANTOS, R. V. \& LEITE, M. S., 2001. Crescimento físico de crianças indígenas xavantes de 5 a 10 anos de idade, Mato Grosso. Jornal de Pediatria, 77 : 17-22.

IANELLI, R. V., 1997. Epidemiologia da Malária em uma População Indígena do Brasil Central: Os Xavánte de Pimentel Barbosa. Dissertação de Mestrado, Rio de Janeiro: Escola Nacional de Saúde Pública, Fundação Oswaldo Cruz.

IANELLI, R. V., 2000. Epidemiologia da malária em populações indígenas da Amazônia. In: Doenças Endêmicas: Abordagens Sociais, Culturais e Comportamentais (R. B. Barata \& R. Briceño-León, orgs.), pp. 355-374, Rio de Janeiro: Editora Fiocruz.

IANELLI, R. V.; COIMBRA Jr., C. E. A. \& SANTOS, R. V., 1996. Perfil de morbi-mortalidade entre os índios Xavante de Mato Grosso. Revista da Sociedade Brasileira de Medicina Tropical, 29(Sup. 1):256.

IANELLI, R. V.; HONÓRIO, H. A.; LIMA, D. C.; LOURENÇO-DE-OLIVEIRA, R.; SANTOS, R. V. \& COIMBRA Jr., C. E. A., 1998. Faunal composition and behavior of Anopheline mosquitoes on the Xavánte Indian Reservation of Pimentel Barbosa, Central Brazil. Parasite, 5:37-46.

ISHAK, M. G. \& ISHAK, R., 2001. O impacto da infecção por Chlamydia em populações indígenas da Amazônia brasileira. Cadernos de Saúde Pública, 17:385-396.

ISHAK, M. O. G.; ISHAK, R.; CRUZ, A. C. R.; SANTOS, D. E. M. \& SALGADO, U., 1993. Chlamydial infection in the Amazon region of Brazil. Transactions of the Royal Society of Tropical Medicine and Hygiene, 87:60-62.

ISHAK, R.; HARRINGTON, W. J.; AZEVEDO, V. N.; EIRAKU, N.; ISHAK, M. O. \& HALL, W. W., 1995. Identification of human T cell lymphotropic virus type Ila infection in the Kayapó, an indigenous population of Brazil. AIDS Research and $\mathrm{Hu}$ man Retrovirus, 11:813-819.

KOIFMAN, S., 2001. Geração e transmissão de energia elétrica: Impacto nas nações indígenas do Brasil. Cadernos de Saúde Pública, 17:413-423.

KOIFMAN, S.; FERRAZ, I.; VIANNA, T. S.; SILVEIRA, C. L.; CARNEIRO, M. T.; KOIFMAN, R. J.; FERNANDEZ, C. \& BULCÃO, A. C., 1998. Cancer clusters among young Indian adults living near power transmission lines in Bom Jesus do Tocantins, Pará, Brasil. Cadernos de Saúde Pública, 14(Sup. 3):161-172.

KUNITZ, S. J., 1994. Disease and the destruction of indigenous populations. In: Companion Encyclopedia of Anthropology (T. Ingold, ed.), pp. 297-325, London: Routledge.

LAINSON, R., 1988. Ecological interactions in the transmission of the leishmaniasis. Philosophical Transactions of the Royal Society of London, 321B:389-404. 
1 ANC:DON, F. J., 1999. () que beber, como beber e quando beber: O contexto sociocultural no alcoolismo entre as populações indigenas. In: Saude, Saberes e Ética: Três Conferencias sobre Antropologia da Saúde (F. J. Langdon, org.), pp. 1-17, Florianópolis: Programa de Pós-Graduação cm Antropologia Social, Universidade Federal de Santa Catarina.

I AN(;I)ON, E. J., 2000. Salud y pucblos indígenas: I os desafíos en el cambio de siglo. In: Salud y' Lquidad: (Ina Mirada desde las Ciencias Sociales (R. Briceño-I.cón, M. C. S. Minavo \& (. L. A. Coimbra Jr., orgs.), pp. 107-117, Rio de Janeiro: Fiditora fiocruz.

IARSEN, C. S. \& NIII.NFR, (;. R. (eds.), 1994. In the Wake of Contact: Biological Response to Conquest. New York: Wiley-1,iss.

Li.IT F. . M., 1998. Avaliação do Fistado Nutricional da População Xavánte de São losé, Terra Indigena Sangradouro-Volta Grande, Mato (Grosso. I)issertação de Mestrado, Rio de Janciro: Escola Vacional de Saúde Pública, Fundação Oswaldo Cru\%.

I.INA, P., 1950. Níveis tensionais dos índios Kalapalo e Kamaiurá. Revista Brasileira de Medicina, $7: 787-788$.

LI.NHARES, A. C., 1992. Iipidemiologia das infecções diarréicas entre populações indígenas da Amazônia. Cadernos de Saúde Pública, 8:121-128.

I.INHARES, A. C.; SAI BB, l.. V.; CABBAY, Y. B. \& NAKAU'H, C. M., 1986. Prevalence of rotavirus antibody anong isolated South American Indian communities. American fournal of Eipidemiolog), 123:699-7(19.

I.)URF.N(O)-DE-OLIVEIRA, R., 1989. Some observations on the mosquitoes of Indian settlements in Xingu National Park, Mato ('rosso state, Brazil, with emphasis on malaria vectors. Revista Brasileira de Biologia, 49:393-397.

MAC.ML HîES, E., 2000. O Estado e a Saúde Indígena. A Experiencia do Distrito Sanitário Yanomami. Dissertação de Mestrado, Brasília: Universidade de Brasília.

MIANCILHA-CARVAIHO, J. J.; BARUYZI, R. (;; HOWARD, P. F.; POUITER, N.; IIPERS, M. P.; FRA.VCO, I.. J.; MARCOPIJO, I.. F.; SPOONER, V. J.; I)YFR, A. R.; ELIIOTT, P. \& SIIANLLE, J., 1989. Blood pressure in four remote populations in the IN'IF,RSALT study. Hypertension, 1 t:238-246.

NAR'IINS, S. J. \& MFVE:Z.F.S, R. (.., 1994a. Eolução do estado nutricional de menores de 5 anos em aldeias indígenas da tribo Parakanã, na Amazônia oriental brasileira (1989-1991). Revista de Saúde Pública, 28:1-8.

MAR'TINS, S. J. \& MENE.ZFS, R. C., 1994b. Infecção malárica mista entre os indígenas Parakanã. Revista da Sociedade Brasileira de Medicina Tropical, 27 (Sup. 1):274.

MC (ARVFY, S. T' \& SCHFNDEL, D. E., 1986. Blood pressure of Samoans. In: The ('hanging Samoans: Behavior and Health in Transition (P. 'I'. Baker, J. M. Hama \& T. S. Baker, eds.), pp. 350-393, New York: Oxford University Press.

M.EIHY, J. C. S. B., 1994. A morte como apelo para a vida: O suicídio Kaiowá. In: Saúde e Povos Indigenas ( R. V. Santos \& (. F. A. Coimbra Jr., orgs.), pp. 243-251, Rio de Janciro: Fiditora Fiocruz.

MEIRF,L.F, D. M., 1988. Sugestões para uma análise comparativa da fecundidade em populações indígenas. Revista Brasileira de Listudos Populacionais, 5:1-2().

MHLLCHIOR, S.C.; SOARES, I).A.; ANDRAI)H. S.M. \& KAYOKO, R.M., 2002. Avaliação 
da mortalidade de grupos indígenas do norte do Paraná - 1990 a 1999. Informe Epidemiológico do SUS, 11:61-68.

MIRANDA, R. A.; XAVIER, F. B. \& MENEZES, R. C., 1998. Parasitismo intestinal em uma aldeia indígena Parakanã, sudeste do Estado do Pará, Brasil. Cadernos de Saúde Pública, 14:507-511.

MONTEIRO, C. A., 2000. Evolução da desnutrição infantil nos anos 90. In: Velhos e Novos Males da Saúde no Brasil: A Evolução do País e de suas Doenças (C. A. Monteiro, org.), pp. 375-392, São Paulo: Editora Hucitec.

MORAES, M. A. P., 1991. Oncocercose entre os índios Yanomámi. Cadernos de Saúde Pública, 7:503-514.

MORAIS, M. B.; FAGUNDES NETO, U. L.; MATTOS, A. P. \& BARUZZI, R. G., 2003. Estado nutricional de crianças índias do Alto Xingu em 1980 e 1992 e evolução pondero-estatural entre o primeiro e o quarto anos de vida. Cadernos de Saúde Pública, 19:543-550.

MORGADO, A. F., 1991. Epidemia de suicídio entre os Guaraní-Kaiwá: Indagando suas causas e avançando a hipótese do recuo impossível. Cadernos de Saúde Pública, 7: 585-598.

MOURA, R. C.; FÉ, N. F. \& SOARES, A. R., 1994. Há transmissão intradomiciliar da malária nas habitações indígenas tradicionais na Amazônia? Revista da Sociedade Brasileira de Medicina Tropical, 27(Sup. 1):5.

NARAYAN, K. M. V., 1996. Diabetes mellitus in Native Americans: The problem and its implications. In: Changing Numbers, Changing Needs (G. D. Sandefur, R. R. Rindfuss \& B. Cohen, eds.), pp. 262-288, Washington, DC: National Academy Press.

NEEL, J. V.; SALZANO, F. M.; JUNQUEIRA, P. C.; KEITER, F. \& MAYBURY-LEWIS, D., 1964. Studies on the Xavante Indians of Brazilian Mato Grosso. American Journal of Human Genetics, 16:52-140.

OLIVEIRA, J. P., 1997. Pardos, mestiços ou caboclos: Os índios nos censos nacionais no Brasil (1872-1980). Horizontes Antropológicos, 3:60-83.

OLIVER, W. J.; COHEN, E. L. \& NEEL, J. V., 1975. Blood pressure, sodium intake and sodium related hormones in the Yanomamo Indians, a "no-salt" culture. Circulation, 52:146-151.

OPS (Organización Panamericana de la Salud), 1998. La salud de los pueblos indígenas. In: La Salud en las Américas (OPS, org.), Publicación Científica 569, v. 1, pp. $95-$ 105, Washington, DC: OPS.

PAGE, L., 1974. Hypertension and atherosclerosis in primitive and acculturating societies. In: International Symposium on Hypertension (J. C. Hunt, ed.), pp. 1-12, New York: Health Learning Systems.

PAGLIARO, H., 2002. A Revolução Demográfica dos Povos Indígenas: A Experiência dos Kaiabi do Parque Indígena do Xingu, Mato Grosso (1970-1999). Tese de Doutorado, São Paulo: Faculdade de Saúde Pública, Universidade de São Paulo.

PEREIRA, N. O. M.; FLORIDO, A. C. \& FERNANDES, M. Z., 2002. População residente em terras indígenas: características básicas censitárias - 1991 e 2000. In: XIII Congresso da Associação Brasileira de Estudos Populacionais, Ouro Preto, Minas 
Gerais, ta 8 de novembro. 13 de Junho de $2003<$ http://www.abep.org.br/Xillencontrol Anais_Abep_2(0)2/trabalhos.htmis.

PIC(CHI, I)., 1994. Observations about a central Brazilian indigenous population: The Bakairi. South American Indians Studies, $4: 37-46$.

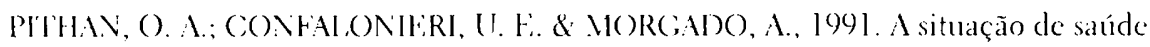
dos indios Yánomami. Ciadernos de Saúde Pública, $7: 563-580$.

P()\%, J. I)., 2000). Crônica de una morte anunciada: Do suicídio entre os Sorowalá. Revista de Antropologia, +3:89-1+4.

PRII)( ), M. S.; MASSIS, A. M.; MARIINS, M. (: NNARE, M. P.; REZLENDF, I. F. B. \&

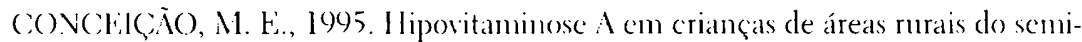
árido baiano. Revista de Sande Pública, 29:209-212.

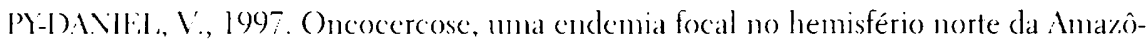
nia. In: Homem, Ambiente e Ecologia no bistado de Roraima (R. I. Barbosa, F.. J. Ferreira \& L.. (;. Castellón, orgs. ), pp. 111-155, Manaus: Instituto Nacional de Pesquisas dà Ana\%ônia.

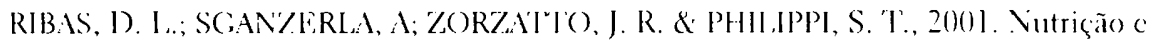
salúde infantil de uma commidade Teréna da região (entro-()este do Brasil. (aadernos de Saúde Pública, 17:323-331.

RIBLIRO, D., 1956. Comvivio e contaminaçion: Efeitos dissociativos da depopulação provocada por epidemias em grupos indigenas. Sociologia, 18:3-50.

RIBri,IRO, D., 1977. (Os Índios e a Civilização: A Integração das Populações Indigenas no Brasil Moderno. Petrópolis: Vozes.

RICARI)(), (. A., 1996. A sociodiversidade nativa contemporânea no Brasil. In: Povos Indígenas no Brasil 1991/1995 (C.. A. Ricardo, org.), pp. i-xii, São Paulo: Instituto So(ioambiental.

RICARI)(). (. A. (org.), 2000). Povos Indigenas no Brasil 1996/2000. São Paulo: Instituto Socioambiental.

SA. 1). R., 2003. Malária em Terras Indigenas Mabitadas pelos Pakaanova (Wari), Fistado de Rondônia, Brasil. Fistudo Eipidemiológico e Fintomológico. Dissertação de Nestrado, Rio de Janciro: Fiscola Nacional de Saúde Pública, Fundação Oswaldo (inuz.

SAIZANO, I. M. \& CALIEGARI-JACQUES, S. M., 1988. South American Indians: A (arse Study in Evolution. ()xford: Clarendon Press.

SAMPAIO, M. R.; 'TURCOITIF, S.; MARTINS, V. F.; (.ARI)OSO, F. M. \& BURAIIIINI, 11. N., 1996. Nalaria in the Indian reservation of "Vale do Javarin", Brasil. Revista do Instituto de Medicina Tropical de São Paulo, 38:59-60.

SAVIOS, A. K.; ISHAK, M. O.; SAVTOS, S. F,; (YIFRREIRO, J. F. \& ISHAK, R., 1995. A possible correlation between the host genetic background in the epidemiology of hepatitis B virus in the Amazon region of Brazil. Memórics do Instituto ()swaldo (ruz, 90:435-441.

SAVIOS, F. C. ().; CAMARA, V. M.; BRUBO, L. S.; I.OURFIRO, L. C. B.; JFSUS, I. M.; FAY , K. \& SACICA, F., 2003. Avaliação dos níveis de exposição ao mercúrio entre indios Pakaanóva, Amazônia, Brasil. Cadernos de Saúde Pública, 19:199-206.

SANTOS, I.. N.; BATISIA FILHO, M. \& DINI/, A. S., 1996. Epidemiologia da carencia 
de vitamina A no Nordeste do Brasil. Boletín de la Oficina Sanitaria Panamericana, 120:525-537.

SANTOS, R. V., 1991. Coping with Change in Native Amazonia: A Bioanthropological Study of the Gavião, Suruí, and Zoró, Tupi-Mondé Speaking Societies from Brazil. Ph.D. Dissertation, Bloomington: Indiana University.

SANTOS, R. V., 1993. Crescimento físico e estado nutricional de populações indígenas brasileiras. Cademos de Saúde Pública, 9(Sup. 1):46-57.

SANTOS, R. V., 1995. Nutrição e povos indígenas. In: Mapa da Fome entre os Povos Indígenas no Brasil (II): Contribuição à Formulação de Políticas de Segurança Alimentar Sustentáveis (INESC, PETI/MN, ANAÍ/BA, Ação da Cidadania Contra a Fome, a Miséria e pela Vida, orgs.), pp. 22-24, Brasília: Instituto de Estudos Sócio-Econômicos.

SANTOS, R. V. \& COIMBRA Jr., C. E. A., 1991. Socioeconomic transition and physical growth of Tupí-Mondê Amerindian children of the Aripuanã Park, Brazilian Amazon. Human Biology, 63:795-820.

SANTOS, R. V. \& COIMBRA Jr., C. E. A. (orgs.), 1994. Saúde e Povos Indigenas. Rio de Janeiro: Editora Fiocruz.

SANTOS, R. V. \& COIMBRA Jr., C. E. A., 1996. Socioeconomic differentiation and body morphology in the Suruí of Southwestern Amazonia. Current Anthropology, 37:851856.

SANTOS, R. V. \& COIMBRA Jr., C. E. A., 1998. On the (un)natural history of the TupíMondé Indians: Bioanthropology and change in the Brazilian Amazonia. In: Toward a Biocultural Synthesis: Political-Economic Perspectives in Biological Anthropology (A. Goodman \& T. Leatherman, eds.), pp. 269-294, Ann Arbor: Michigan University Press.

SANTOS, R. V.; COIMBRA Jr., C. E. A.; FLOWERS, N. M. \& SILVA, J. P., 1995. Intestinal parasitism in the Xavante Indians, Central Brazil. Revista do Instituto de Medicina Tropical de São Paulo, 37:145-148.

SANTOS, R. V. \& ESCOBAR, A. L. (eds.), 2001. Saúde dos povos indígenas no Brasil: Perspectivas atuais. Cadernos de Saúde Pública, 17(2) (número temático).

SANTOS, R. V.; FLOWERS, N. M.; COIMBRA Jr., C. E. A. \& GUGELMIN, S. A., 1997. Tapirs, tractors, and tapes: The changing economy and ecology of the Xavánte Indians of Central Brazil. Human Ecology, 25:545-566.

SERAFIM, M. G., 1997. Hábitos Alimentares e Nivel de Hemoglobina em Crianças Indigenas Guarani, Menores de 5 Anos, dos Estados de São Paulo e do Rio de Janeiro. Dissertação de Mestrado, São Paulo: Escola Paulista de Medicina.

SHELLEY, A. J., 2002. Human onchocerciasis in Brazil: An overview. Cademos de Saúde Pública, 18:1167-1177.

SILVA, M. F., 1994. A demografia e os povos indígenas no Brasil. Revista Brasileira de Estudos Populacionais, 11:261-264.

SING, K. A.; HRYHORCZUK, D.; PASCHAL, D. C. \& CHEN, E. H., 1996. Environmental exposure to organic inercury among the Makuxí in the Amazon Basin. International Joumal of Occupational and Environmental Health, 2:165-171.

SINNETT, P. F.; KEVAU, I. H. \& TYSON, D., 1992. Social change and the emergence of degenerative cardiovascular disease in Papua New Guinea. In: Human Biology in 
Papua New Guinea: The Small Cosmos (R. D. Atemborough \& M. P. Alpers, eds.), pp. 373-386, Oxford: Clarendon Press.

SOARES, M. C. \& BENSABATH, G., 199l. Tribos indígenas da Amazônia Oriental como população de risco para a hepatite D (Delta). Revista do Instituto de Medicina Tropical de São Paulo, 33:241-242.

SOUSA, A. O.; SALEM, J. I.; LEE, F. K.; VERÇOSA, M. C.; CRUAUD, P.; BLOOM, B. R.; LAGRANGE, P. H. \& DAVID, H. L., 1997. An epidemic of tuberculosis with a high rate of tuberculin anergy among a population previously unexposed to tuberculosis, the Yanomami Indians of the Brazilian Amazon. Proceedings of the National Academy of Sciences of the USA, 94:13227-13232.

SOUZA, L. G. \& SANTOS, R. V., 2001. Perfil demográfico da população indígena Xavánte de Sangradouro-Volta Grande, Mato Grosso, Brasil (1993-1997). Cadernos de Saúde Pública, 17:355-365.

SPIELMAN, R. S.; FAJANS, S. S.; NEEL, J. V.; PEK, S.; FLOYD, J. C. \& OLIVER, W. J., 1982. Glucose tolerance in two unacculturated Indian tribes of Brazil. Diabetologia, 23:90-93.

SPINDEL, R., 1995. Avaliação da Efetividade da Vacinação Contra o Sarampo em Crianças das Tribos Indígenas Caiabí e Caiapó, Habitantes de Áreas Malarígenas: Parque Indígena do Xingu, Brasil Central. Dissertação de Mestrado, São Paulo: Escola Paulista de Medicina.

STINSON, S., 1996. Early childhood growth of Chachi Amerindians and Afro-Ecuadorians in Northwest Ecuador. American Joumal of Human Biology, 8:43-53.

SZATHMÁRY, E. J. E., 1994. Non-insulin dependent diabetes mellitus among aboriginal North Americans. Annual Review of Anthropology, 23:457-482.

TABORDA, W.C.; FERREIRA, S.C.; RODRIGUES, D.; STÁVE.LE, J.N. \& BARUZZI, R.G., 2000. Rastreamento do câncer de colo uterino em índias do Parque Indígena do Xingu, Brasil Central. Revista Panamericana de Salud Pública, 7:92-96.

TAVARES, E. F.; VIEIRA FILHO, J. P. B.; ANDRIOLO, A. \& FRANCO, L. J., 1999. Anormalidades de tolerância à glicose e fatores de risco cardiovascular em uma tribo indígena aculturada da região amazônica brasileira. Arquivos Brasileiros de Endocrinologia e Metabologia, 43(Sup. 1):S235.

VALLINOTO, A.C.R.; ISHAK, M.O.G.; AZEVEDO, V.N.; VINCENTE, A.C.P.; OTSUKI, K.; HALL, W.W. \& ISHAK, R., 2002. Molecular epidemiology of human T-lymphotropic virus type II infection in Amerindian and urban populations of the Amazon region of Brazil. Human Biology, 74:633-644.

VAUGHAN, J. P., 1978. A review of cardiovascular diseases in developing countries. Annals of Tropical Medicine and Parasitology, 72:101-109.

VERANO, J. W. \& UBELAKER, D. H. (eds.), 1992. Disease and Demography in the Americas. Washington, DC: Smithsonian Institution Press.

VERDUM, R., 1995. Mapa da fome entre os povos indígenas no Brasil (II). In: Mapa da Fome entre os Povos Indígenas no Brasil (II): Contribuição à Formulação de Políticas de Segurança Alimentar Sustentáveis (INESC, PETI/MN, ANAI/BA, Ação da Cidadania Contra a Fome, a Miséria e pela Vida, orgs.), pp. 7-15, Brasília: Instituto de Estudos Sócio-Econôınicos. 
VIL:IRA, (;. O., 2003. Einteroparasitoses em Populações Indigenas no Brasil: Uma Revisão Sistemática da Produção Científica. Dissertação de Mestrado, Rio de Janciro: Fiscola Vacional de Saúde Pública, Fundação (Oswaldo Crù.

VIl:IRA FII.HO, J. P. B., 1975. Análise das glicemias dos índios das aldeias Suruí, Caviões e Xikrín. Revista da Associação Médica Brasileira, 21:253-5.

VIFIRA FIL.IIO, J. P. B., 1977. () diabetes mellitus e as glicemias de jejum dos índios Caripuna c Palikur. Revista da Associação Médica Brasileira, 23:175-178.

VIKIRA FIL.IIO, J. P. B., 1981. Problemas da aculturação alimentar dos Xavante e Bororo. Revista de Antropologia, 24:37-40.

VIFIRA FII.HO, J. P. B., 1994. Malignant tumors among Gavião Indians. Proximity of eletronagnctic ficlds. Revista da Associação Médica Brasileira, 40:137-139.

VIEIRA FII.HO, J. P. B., 1996. Fmergência do diabetes melito tipo II entre os Xavantes. Revista da Associaçào Médica Brasileira, 42:61.

VIEIRA FILII(), J. P. B. 2000. Cenótipo econômico c produção de insulina. In: Diabetes, Saúde Ǵ Cia), p. 2, São Pauk: Aventis Pharma.

VIFIRA FIL.HO, J. P. B.; OLIVEIRA, A. S. B.; SILVA, M. R. D.; AMARAL, A. L. \& SCIIULTZ, R. R., 1997. Polincuropatia nutricional cntre índios Xavantes. Revista da Associação Médica Brasileira, 43:82-88.

VIEIRA FILIIO, J. P. B.; RUSSO, L.. M. K. \& JUL,IANO, Y., 1984. A hemoglobina glicosilada (I IbAl) dos índios Bororo. Arquivos Brasileiros de Endocrinologia e Metabologia, 28:87-90.

VIEIRA FILHO, J. P. B.; RUSSO, E. M. K. \& . VOVO, N. F., 1983. A hemoglobina glicosilada (HbAl) dos índios Xavante. Arquivos Brasileiros de Endocrinologia e Metabologia, 27:153-155.

WERNFR, 1)., 1983. Fertility and pacification among the Mekranoti of Central Brazil. Human Ecology, 11:227-245.

WF.ST, K. M., 1974. Diabetes in American Indians and other native populations of the New World. I iabetes, 23:841-855.

WIIK, F., 2001. Contato, epidemia e corpo como agentes de transformação: Um estudo sobrc a AIDS entre os índios Xokléng (Jê) de Santa Catarina, Brasil. Cadernos de Saúde Pública, 17:397-406.

YOU.VC, 'I'. K., 1993. Diabetes mellitus among Native Americans in Canada and the United States: An epidemiological review. American Journal of Human Biology, 5:399-413. 



\section{(4) \\ SAÚDE BUCAL DOS POVOS \\ INDÍGENAS NO BRASIL: \\ PANORAMA ATUAL E PERSPECTIVAS \\ Rui Arantes}

É bem conhecido que, com a expansão da sociedade ocidental nas Américas, aconteceram devastadoras e duradouras mudanças na vida dos poros indígenas. (O processo de contato acarretou profundas transformações nos mais diferentes níveis de seus sistemas sócio-culturais, políticos e econômicos, com reflexos nos padrões de subsistências, na demografia e na epiclemiologia, somente para citar algumas dimensões (Coimbra Jr. et al., 200)2; Ribciro, 1956).

No que tange ao perfil epidemiológico, ainda que seja reconhecida a magnitude das transformações experimentadas pelos povos indígenas ao longo dos últimos séculos, permanece pouco conhecido. Mesmo nos dias atuais, não ć possível traçar o perfil epidemiológico dos povos indígenas no Brasil de modo satisfatório. Os órgãos governamentais continuam a não dispor de um sistema de coleta de dados eficiente e contínuo, gerando informações esparsas e não confiáveis. Com exceção de algumas poucas populações, nem os indicadores sociodemográficos básicos, como taxa de mortalidade infantil, esperança de vida ao nascer ou principais causas de morbimortalidade, são disponíveis (Coimbra Jr. \& Santos, 2000).

No que dì respeito à saúdc bucal, o quadro não é muito diferente do apontado acima, sendo marcado por uma escassez de dados que inviabiliza o delineamento de un quadro epidemiológico amplo e robusto, que inclusive leve em consideração a heterogeneidade que certamente existe no âmbito dos povos indígenas. () senso comum é o de que os impactos decorrentes do contato, sobretudo nas formas de subsistência, envolvendo mudanças na dieta com a entrada de alimentos industrializados e do açúcar refinado, repercutiram negativamente na saúde bucal. Na prática, contudo, faltam subsídios epidemiológicos que permitam corroborar com certeza essa tendência. 


\section{A DOENÇA CÁRIE: ASPECTOS EPIDEMIOLÓGICOS E ANTROPOLÓGICOS}

Do ponto de vista epidemiológico, a cárie é a doença bucal mais importante. Sua estreita ligação com a dieta e/ou hábitos alimentares também lhe confere relevância antropológica, uma vez que os meios de produção de alimentos e padrões de consumo de diferentes sociedades humanas fazem-se refletir nas condições de saúde bucal.

Estudos antropológicos bascados na análise de remanescentes esqueletais têm mostrado a evolução da freqüiĉncia de cárie associada a mudanças nas formas de subsistência, parecendo ser particularmente crítico, do ponto de vista da epidemiologia bucaal, a transição de economias baseadas na caça-coleta para agricultura na pré-história (Cassidy, 1984; Meiklejohn et al., 1984; Perzigian ct al., 1984; Roosevelt, 1984). Estudos palcopatológicos demonstram que, antes do advento da agricultura, as populações humanas apresentavam uma menor prevalência de cárie. Fim populações de caçadores e coletores, a cárie ocorria em baixa frequiência (menos de $2 \%$ dos dentes permanentes apresentavam lesões) e cra mais comum em adultos do que em crianças. Já nas economias agrícolas do neolítico, nas quais predominava uma dieta mais rica em carboidratos, a prevalência de cárie podia superar 20\% (Meiklejohn ct al., 1984; Moore \& Corbett, 1971; Perzigian et al., 1984; Scott \& Turner, 1988).

Nessa tendência de aumento da prevalência de cárie ao longo da história humana, as localizações mais frequientes das lesões eram as regiões de fóssulas e fissuras dos molares e pré-molares (Moore \& Corbett, 1973). Na Europa, foi a partir do século XVII que esse padrão começou a mudar, com as lésões passando a atingir, em crescente número, também as superfícies lisas dos dentes. Houve aumento não somente no número de dentes afetados, como também no de lesões por dente, possivelmente ocasionadas pelo rápido aumento do consumo de açúcar de cana.

Segundo Renson (1989), o índice de cárie aumentou continuamente nos séculos XVIII e XIX, quando o consumo de açúcar passou de 10-20 libras para 90 libras per capita/ano. No século XIX, com a popularização do açúcar de cana em todo o mundo ocidental, a cárie passou a assumir características pandêmicas. Até então, populações que não tinham acesso ao açúcar de cana, como os aborígenes australianos, apresentavam baixa prevalência de cárie. A introdução de produtos açucarados alterou significativamente o quadro de saúde bucal de várias dessas populações nlativas, por vezes equiparando ou mesıno sobrepujando os índices verificados em países ocidentais (Newbrun, 1982). 
A etiologia multifatorial da cárie permite uma variedade de interpretações a respeito das mudanças em sua prevalência, tanto nos países desenvolvidos como nos países em desenvolvimento. Essas mudanças estão associadas às alterações nos hábitos alimentares (especialmente referentes ao consumo de açúcar), nos padrões de higiene dental e no aumento de contato com o flúor, seja por ingestão ou por ação local na boca por meio dos dentifrícios. Inúmeros estudos têm demonstrado que, por um lado, o aumento no consumo do açúcar está diretamente relacionado a aumento nos índices de cárie; por outro, a utilização do flúor relaciona-se à redução desses índices (Gustafsson et al., 1954; WHO, 1992).

\section{ESTUDOS EPIDEMIOLÓGICOS EM SAÚDE BUCAL INDÍGENA}

A maior parte dos estudos com populações indígenas situadas no Brasil e regiões vizinhas, no que diz respeito ao campo da saúde bucal, está ligada à morfologia dentária, marcadores fisiológicos como desgaste dentário e defeitos de esmalte, características anatômicas dos elementos dentários, entre outros. Sobretudo, são estudos na área da antropologia física/biológica, mais especificamente sobre antropologia dentária (Scott \& Turner, 1988).

Os estudos em antropologia dentária trazem informações importantes a respeito da economia e da dieta de populações indígenas que habitavam o atual território brasileiro na pré-história. Mendonça-de-Souza et al. (1994) destacam a importância da observação de fatores como perda dentária, abscessos alveolares e desgaste dentário nos estudos comparativos das doenças bucais entre grupos horticultores e caçadores-coletores. Como exemplo, podemos citar o estudo de Rodrigues (1997), que comparou duas séries esqueletais - uma referente a um grupo interiorano do semi-árido pernambucano (Furna do Estrago) e outra a um grupo do litoral de Santa Catarina (Sambaqui de Cabeçuda). No cemitério de Furna de Estrago, o impacto de uma alimentação abrasiva e rica em amido repercutiu na forma de complicações orais severas, com maior taxa de cárie e ocorrência de abcessos ainda na infância. Já a ausência de cáries e baixa ocorrência de processos dento-maxiliares no Sambaqui de Cabeçuda sugerem uma alimentação menos cariogênica. Estudos como o de Rodrigues permitem construir modelos bioculturais passíveis de serem testados com materiais oriundos de outras populações pré-históricas de diferentes partes do território brasileiro.

Os estudos de hipoplasias de esmalte também têm sido utilizados no âmbito da antropologia biológica como parâmetro para avaliar o impacto das 
transformações econômicas, sociais e culturais no passado e no presente (como a emergência da agricultura, o contato entre populações, a ocorrência de estresses fisiológicos em populações contemporâneas devido à exposição a condições ambientais adrersas, cutre outros) (Cohen \& Armelagos, 1984; Goodman et al., 1991). No caso de grupos indígenas no Brasil, podem ser citados os trabalhos de Arantes (1998) e Santos \& Coimbra Jr. (1999), que investigaram a ocorrência de hipoplasias dentárias e suas relaçóes com a história de contato dos Xavánte (Mato Grosso) c'lupí-Mondé (Rondônia e Mato (irosso), respectivanente.

()s estudos epidemiológicos sobre a doença cáric em populações indígenas são ainda escassos no Brasil, o que se verificaa também em outros países das Américas. Na última década, a grande maioria dos trabalhos publicados foi realirada com commidades nativas da Anérica do Vorte (Fistados Unidos e Canadá) (I Iarrison \& Davis, 1993; Jones \& Phipps, 1992; O’Sullivan et al., 1994; Phipps et al., 1991; 'I'itley \& Bedard, 1986). Nessa literatura, nota-se que a cáric rampante (de mamadeira) é um tema recorrente nas pesquisas e sua prevalência ć muito mais alta nas populações indigenas se comparadas às não-indígenas desses países, atingindo cifras de até $50 \%$ nas primeiras (Barnes et al., 1992; Cook et al., 1994; Kaste et al., 1992; Milnes et al., 1903). Pesquisas comparativas entre indígenas e não-indígenas conduzidas na América do Norte indicam que as condições de saúde bucal das princiras são piores que para a população em geral, atingindo una prevalência de cárie quase duas vezes maior (Burt \& Arbor, 1994; (Fim et al., 1994). Fim relação aos idosos, observou-se que a prevalência de edentulismo também é bem maior entre os indígenas (Phipps et al., 1991).

No Brasil, mesmo para os não-indígenas, as informações disponíveis sobré a ocorrência e a distribuição da cárie são nuito limitadas, restringindo-se às populaçoes urbanas e, em grande parte, baseadas em estudos conduzidos entre escolares (MS, 1988; Nommando \& Araújo, 1990; Pinto, 1990, 1992; Vicgas \& Viegas, 1988). Fistudos com populações indígenas são esporádicos, restringindose qualse sempre a trabalhos transversais e com amostras pequenas (Arantes et al., 2001; Detogni, 1994; Rigonatto et al., 2001; 'Tricerri, 1985; 'Tumang \& Piedade, 1968). Desse quadro resulta uma grande escassez de informações qualitativas e quantitativas sobre o estado de saúde bucal dass populações indígenas no Brasil ('labela 1). Não obstante, ć informativo mencionar alguns dos traballos que enfocaram essals populações.

Donnellỵ et al. (1977) conduziram uma análise das condições dé cáric, doença periodontal e placa bacteriana em três aldeias Yanomámi (totalizando 222 indivíduos), localizadas na fronteira do Brasil com a Venezucla, com dife- 
Trabalhos publicados em saúde bucal e antropologia dentária abordando populações indígenas do Brasil (lista não exaustiva).

\begin{tabular}{|c|c|c|}
\hline Autores & Povo & Temas priorizados \\
\hline Oliveira (1948) & Karajá & Análise sobre morfologia dentária e padrões de abrasão \\
\hline Lima (1954) & Tenetehára & Análise de padrões de mutilação dentária \\
\hline Neel et al. (1964) & Xavánte & Inquérito epidemiológico sobre cárie e oclusão \\
\hline Niswander (1967) & Xavánte & $\begin{array}{l}\text { Inquérito epidemiológico sobre cárie, oclusão, morfologia } \\
\text { dentária e higiene bucal }\end{array}$ \\
\hline Niswander (1967) & Bakairí & Inquérito epidemiológico sobre cárie \\
\hline Tumang \& Piedade (1968) & Xingu & $\begin{array}{l}\text { Inquérito epidemiológico sobre cárie, periodontopatias } \\
\text { e higiene bucal }\end{array}$ \\
\hline Baruzzi \& Iones (1970) & Xingu & Inquérito epidemiológico sobre cárie \\
\hline Donnelly et al. (1977) & Yanománi & Inquérito epidemiológico sobre cárie e periodontopatias \\
\hline Ayres \& Salzano (1972) & Kayapó & Inquérito epidemiológico sobre cárie \\
\hline Pereira \& Evans (1975) & Yanomámi & $\begin{array}{l}\text { Inquérito epidemiológico sobre oclusão, abrasão } \\
\text { e morfologia dentária }\end{array}$ \\
\hline Hirata et al. (1977) & Xingu & Inquérito epidemiológico sobre cárie \\
\hline Tricerri (1985) & Alto Solimões & Inquérito epidemiológico sobre cárie \\
\hline Ando et al. (1986) & Xingu & Avaliação de métodos preventivos \\
\hline Araújo (1988) & Tikúna & Formação de agentes indigenas de saúde \\
\hline Santos \& Coimbra Jr. (1999) & Tupí-Mondé & Análise de defeitos de esmalte (hipoplasias) \\
\hline Pose (1993) & Xavánte & Inquérito epidemiológico sobre cárie \\
\hline Detogni (1994) & Xingú/Kayabí & Inquérito epidemiológico sobre cárie \\
\hline Rigonatto et al. (2001) & Xingu & Inquérito epidemiológico sobre cárie \\
\hline Arantes et al. (2001) & Xavánte & $\begin{array}{l}\text { Inquérito epidemiológico sobre cárie, oclusão } \\
\text { e periodontopatias }\end{array}$ \\
\hline Fratucci $(2000)$ & Guaraní & $\begin{array}{l}\text { Inquérito epidemiológico sobre cárie, oclusão } \\
\text { e periodontopatias }\end{array}$ \\
\hline
\end{tabular}

Adaptado de Pose (1993).

rentes graus de interação com a sociedade nacional. Os autores utilizaram o índice CPOD (expressa o número médio de dentes cariados, perdidos e/ou obturados) para medir a experiência de cárie, e verificaram valores mais baixos que para outros grupos examinados na América do Norte e para muitas outras regiões do mundo economicamente mais desenvolvidas (o maior valor de CPOD encontrado foi de 2,4). Entre as três áreas estudadas, aquela com presença de missão religiosa foi a que apresentou maior índice de cárie, e a área mais isolada o menor, indicando a influência da ocidentalização de práticas alimentares sobre a saúde bucal. Uma outra característica interessante foi a diminuição do compo- 
nente cariado no decorrer do tempo, atribuída à atrição acentuada observada nos adultos das três áreas. Enquanto o Streptococus mutans foi isolado com base na placa bacteriana aproximadamente na mesma proporção nas três aldeias, a correlação entre a presença do microorganismo e a de uma ou mais lesões de cárie foi significante somente para uma das aldeias, sugerindo que a presença do $S$. mutans não é suficiente para explicar as disparidades entre os escores de CPOD. Em relação à doença periodontal, os examinados apresentaram abundantes depósitos de placa, acompanhados de marcada inflamação gengival. Contudo, as bolsas periodontais e a perda óssea não foram tão marcantes como reportados para outras populações com pouca higiene oral.

Pereira \& Evans (1975) também realizaram estudo entre os Yanomámi, no qual avaliaram as condições de oclusão e de atrição por meio do Canadian Index e do Índice de Características Oclusais do NIDR (National Institute of Dental Research). Apesar deste trabalho não ter tido o mesmo rigor metodológico do anterior, os autores verificaram alta prevalência de má-oclusão (71\%) e intensa atrição dentária. Segundo os autores, a dieta dos Yanomámi provocava forte atrição dentária com mudanças no plano oclusal, levando a uma relação anterior topo a topo e a uma relação classe III nos grupos mais senis. A eliminação das cúspides por desgaste fisiológico aparentemente não prejudicava a eficiência mastigatória. Puderam também identificar dois grupos segundo os esforços mastigatórios: um primeiro grupo que vivia em área de caça abundante e que tinha abrasão mais intensa e menor quantidade de placa; e um segundo, localizado em região onde a caça era mais escassa e na sua alimentação predominava o consumo de bananas e de alguns tipos de pássaros, com menor abrasão e maior quantidade de placas.

Há vários trabalhos sobre saúde bucal abordando os povos indígenas do Parque do Xingu. É importante destacar, contudo, que a diversidade de metodologias utilizadas e os diferentes agrupamentos por faixa etária, entre outros aspectos, dificultam as comparações e impedem o acompanhamento epidemiológico da cárie e de outros problemas de saúde bucal ao longo do tempo. Apesar da notável diversidade de povos que habitam a região, alguns trabalhos não apresentam os dados segundo etnia.

Tumang \& Piedade (1968) investigaram a prevalência de cárie no Alto Xingu e realizaram comparações com uma amostra de não-indígenas da mesma faixa etária da cidade de Piracicaba, São Paulo. Uma limitação do trabalho é que não define as faixas etárias, agrupando os resultados de acordo com dentição decídua, mista e permanente. Além da cárie, foram avaliadas também a situação 
periodontal usando-se o Índice Periodontal de Russel (1956), e a higiene oral pelo Índice de Higiene Oral Simplificado (IHOS) (Greene \& Vermillion, 1964). Em comparação com as crianças de Piracicaba, para as alto-xinguanas foram observados índices inferiores na dentição decídua e permanente, e superiores na dentição mista. Em relação às doenças periodontais e ao IHOS, os autores encontraram uma situação pior para os indígenas, e observaram uma correlação positiva e estatisticamente significante entre higiene oral e presença de doenças periodontais.

Uma outra investigação conduzida no Alto Xingu foi a de Hirata et al. (1977), que realizou um estudo de prevalência de cárie em crianças entre 3-14 anos de idade empregando os índices ceos (para dentição decídua) e CPOS (índice semelhante ao CPOD, mas que utiliza como unidade de observação as superfícies dentárias e não o elemento dentário). O objetivo principal foi efetuar um levantamento da doença cárie no intuito de subsidiar a implantação de programa preventivo. Os autores observaram um "súbito aumento do número de superfícies cariadas" (Hirata et al., 1977:193) para a dentadura decídua, quando confrontados com os dados de Tumang \& Piedade (1968). Comparações entre a dentição mista e a permanente não foram possíveis devido aos diferentes agrupamentos etários utilizados. Hirata et al. (1977) concluíram que a prevalência de cárie no Alto Xingu mostrou-se alta para a dentição decídua e baixa para a permanente. Além disso, observaram um acentuado aumento da prevalência de cárie nas meninas após o "período de reclusão" (fase quando as meninas púberes ficam reclusas em suas casas como parte do processo de iniciação à vida adulta), o que possivelmente decorre de práticas alimentares vigentes nesse período.

Ando et al. (1986) realizaram uma investigação epidemiológica no Alto Xingu com o objetivo de verificar a efetividade de um programa preventivo baseado na aplicação tópica de flúor gel implantado entre 1977 e 1982. O levantamento, realizado em 1982, incluiu 351 crianças e os resultados foram comparados com os de Hirata et al. (1977). Foi observada uma redução média de 16,5\% nos valores do CPOS após cinco anos do programa. Este trabalho tem o mérito de ser o único referente à avaliação de um programa preventivo implantado em área indígena no Brasil. Entretanto, algumas observações em relação à sua metodologia devem ser mencionadas. Quanto à comparação dos dados de $1977 \mathrm{e}$ 1982, não é explicitado se foram ou não investigados os mesmos indivíduos e/ou comunidades nos dois momentos. Além disso, não há a apresentação dos resultados segundo etnia e os autores não conduziram testes estatísticos para avaliar se a redução encontrada foi, de fato, estatisticamente significativa. 
Detogni (1994) realizou um estudo entre os Kayabí do Parque do Xingu, onde um dos focos foi discutir a possibilidade de implantação de programas de saúde bucal para comunidades isoladas e a importância da formação de agentes de saúde. Os dados epidemiológicos reportados pela autora, coletados em 1992, por meio de um levantamento do índice CPOD, fornecem importantes informações sobre o perfil da doença cárie na população, mostrando valores elevados para todas as idades.

O mais recente trabalho sobre a experiência de cárie no Xingu é o de Rigonatto et al. (2001), no qual foram investigadas quatro comunidades (Yawalapití, Awetí, Mehináku e Kamayurá), totalizando 288 indivíduos. Foram empregados os seguintes índices: CPOD, "ceo" e o "índice de cuidados" ou "care index" (Walsh, 1970). Este último verifica a porcentagem de dentes obturados em relação ao CPOD total. Os resultados não são apresentados segundo etnia, o que é justificado pelos autores devido ao reduzido número de indivíduos de cada uma delas. $\mathrm{O}$ índice CPOD indicou altos níveis de cárie para todos os grupos etários (5,9 para a faixa etária 11-13 anos) e baixa taxa de incorporação de serviços de atenção à saúde bucal (verificada pelo "índice de cuidados"). A comparação com os dados de Detogni (1994) indicou que as condições de saúde das etnias localizadas no Médio Xingu (Kayabí) são piores que as de etnias do Alto Xingu, o que é explicado pelos autores como decorrente de diferenças na dieta e em práticas culturais e de higiene. Além disso, as diferenças também devem estar associadas às atividades de educação em saúde e aplicação de flúor gel na região do Alto Xingu pela Universidade de São Paulo, entre 1977 e 1982, bem como às atividades desenvolvidas pelo programa da organização Medicin du Monde, que manteve um odontólogo por quase quatro anos na região do Alto Xingu no final da década de 1980 .

Os Xavánte do leste de Mato Grosso constituem um outro povo que foi investigado quanto às condições de saúde bucal por vários autores. Os primeiros dados foram coletados pela equipe de James Neel em 1962, no Posto Indígena São Domingos (Neel et al., 1964) e revelaram uma ausência quase total da doença cárie. Alguns anos depois, Niswander (1967) realizou investigação entre os Xavánte e os Bakairí que viviam no Posto Indígena Simões Lopes, quando avaliou a ocorrência de cárie, doenças periodontais, padrões de oclusão e maturação dentária, entre outros aspectos. Niswander observou índices relativamente baixos de CPOD (1,6 para os homens e 3,2 para as mulheres) e 33\% de indivíduos livres de cáries. A diferença nas prevalências de cárie entre São Domingos e Simões Lopes já era significativa e foi explicada como conseqüência do contato 
com o posto do Serviço de Proteção aos Índios (SPI), que introduziu o açúcar de cana na comunidade indígena. Niswander (1967) não observou problemas periodontais sérios, uma vez que na maior parte dos indivíduos apenas gengivite foi encontrada, possivelmente indicando pequena reação periodontal em relação à pobre higiene bucal apresentada. Este fato pode ser indicativo de uma "maior resistência aos fatores irritantes locais, aos efeitos benéficos da estimulação gengival provocados por uma dieta mais dura, ou ainda a outros fatores não investigados" (Niswander, 1967:550). No que diz respeito à oclusão, os Xavánte apresentavam arcadas largas e quase perfeitamente alinhadas; quase a totalidade dos indivíduos examinados (95\%) apresentavam oclusão ideal (oclusão em classe I, dentes bem alinhados, sem apinhamentos).

Na década de 90, outros estudos foram conduzidos entre os Xavánte. Utilizando dados primários e secundários, Pose (1993) realizou uma investigação comparativa sobre a saúde bucal de diferentes comunidades, incluindo prevalência de cárie, oclusão e higiene oral. Mais recentemente, Arantes et al. (2001) realizaram um estudo na mesma comunidade Xavánte investigada por Neel et al. (1964) e Pose (1993). Arantes et al. (2001) avaliaram a prevalência de cárie, de periodontopatias, de má-oclusão e de necessidades de tratamento (ver também Arantes, 1998).

Há uma notável carência de estudos sobre as condições de saúde bucal de grupos indígenas urbanizados, sendo Fratucci (2000) uma exceção. Essa autora investigou indígenas Guaranis que vivem na periferia da cidade de São Paulo. Apesar das precárias condições de vida, com pouco acesso a programas preventivos e assistenciais, o estudo revelou que as condições de saúde bucal são mais satisfatórias que o esperado (ver abaixo).

\section{A MULTIPLICIDADE DE PADRÕES EPIDEMIOLÓGICOS}

Em linhas gerais, nota-se uma trajetória comum na saúde bucal dos povos indígenas uma vez em contato permanente com sociedades ocidentais. As mudanças sócio-econômicas e culturais decorrentes deste processo interferem nas formas de subsistência e introduzem novos tipos de alimentos, particularmente os industrializados, alterando os padrões de saúde bucal. Geralmente, esses grupos partem de uma situação de baixa para alta prevalência de doenças bucais, principalmente de cárie (Arantes et al., 2001; Donnelly et al., 1977; Pose, 1993). Fntretanto, esse padrão não pode ser tomado como regra. Para ilustrar os diferentes 
perfis epidemiológicos em saúde bucal que as populações indígenas podem apresentar, exploramos a seguir três estudos de caso, referentes aos Xavánte e Enawenê-Nawê, ambos do Mato Grosso, e os Guaraní, de São Paulo.

Os Xavánte filiam-se linguiisticarnente ao tronco Macro-Jê, família Jê e seu território se localiza no planalto central brasileiro, no leste do Estado do Mato Grosso. Atualmente, estão distribuídos em seis terras indígenas e os dados aqui apresentados dizem respeito aos Xavánte da Aldeia Pimentel Barbosa (também conhecida como Etéñitépa), localizada na Terra Indígena de mesmo nome. Os Xavánte estão em contato permanente com a sociedade nacional desde a década de 1940 (Coimbra Jr. et al., 2002; Flowers, 1983; Lopes-da-Silva, 1992; Maybury-Lewis, 1984). Tradicionalmente, tinham sua dieta baseada na coleta de frutos e raízes silvestres, caça e horticultura, principalmente do milho (Flowers, 1983; Giaccaria \& Heide, 1972; Maybury-Lewis, 1984). Atualmente, devido a uma série de modificações sócio-econômicas, culturais e ambientais resultantes do contato com a sociedade nacional, a base da dieta passou a ser o arroz (Flowers, 1983; Gugelmin, 1995; Santos et al., 1997). Ainda que os alimentos tradicionais continuem a ocupar importante espaço na dieta dos Xavánte de Pimentel Barbosa, o consumo de alimentos industrializados vem aumentando significativamente nas últimas décadas (Coimbra Jr. et al., 2002; Gugelmin, 1995; Santos et al., 1997). Referente às práticas de higienização bucal preconizadas pela odontologia, os Xavánte não praticam, de forma generalizada, a escovação dentária. A água consumida pela população é oriunda de cursos d'água e de um poço, não sendo artificialmente fluoretada.

Dados epidemiológicos colhidos entre os Xavánte de Pimentel Barbosa revelam uma clara tendência de alteração nas condições de saúde bucal ao longo do tempo, algo esperado à luz da história recente do grupo (Tabelas 2 e 3). Na pesquisa realizada em 1962, Neel et al. (1964) observaram uma freqüência mínima de cárie (CPOD de 0,3 para a faixa etária de 13-19 anos e 0,7 para 20-34 anos) (Pose, 1993). Naquela época, o grupo mantinha sua dieta baseada na caça e coleta de frutos e raízes silvestres, complementados pela agricultura baseada no milho, feijão e abóbora. Segundo Neel et al. (1964), os níveis de cárie observados por ocasião da pesquisa nos anos 60 , eram próximos aos reportados para aborígines australianos que ainda não tinham sido expostos à dieta européia. Três décadas depois, Pose (1993), com base em dados coletados em 1991, revelou um quadro distinto, caracterizado por valores mais elevados do CPOD em praticamente todas as faixas etárias. Os valores do CPOD encontrados por esta autora oscilaram entre 0,3 (aos 6-12 anos) a 13,8 (45 ou mais). Para a faixa etária 
Tabela 2

Médias do índice $(P() \mid$ resultantes de levantamentos epidemiológicos realizados entre Xavánte em diferentes ocasiōes, segundo idade, sexos combinados. Commidade de Pimentel Barbosa (Fiténitépa), Mato Cirosso.

\begin{tabular}{|c|c|c|c|c|c|c|}
\hline \multirow[t]{2}{*}{ Idade (anos) } & \multicolumn{2}{|c|}{1962} & \multicolumn{2}{|c|}{1991} & \multicolumn{2}{|c|}{1997} \\
\hline & n & média & 11 & média & 11 & méclia \\
\hline $06-12$ & 14 & 0,21 & 35 & 0.37 & 60 & 1,08 \\
\hline $13-19$ & 21 & 0,30 & 25 & 1,16 & 37 & 4,54 \\
\hline $20-34$ & 17 & 0.71 & 23 & 8,13 & 46 & 9,72 \\
\hline $35+4$ & 5 & $2 .+40$ & 10 & 9.10 & $2 t$ & $1+.25$ \\
\hline $45011+$ & 3 & 3,60 & 18 & 13,78 & 16 & 17,75 \\
\hline
\end{tabular}

Nota: Valores para 1962 e 1991 obtidos de Pose 119931 . e para 1997 de Arantes et al. (2001).

Tabela 3

Nédias e desvios-padrão (DP) do índice ceo resultantes de levantamentos epidemiológicon realizados entre Xaránte em diferentes ocasiós. segundo idade, sevos combinados. Commidade de Pincntel Barbosa (Liténitépa), Mato (irosso.

\begin{tabular}{|c|c|c|c|c|c|c|}
\hline \multirow{2}{*}{$\begin{array}{l}\text { Idade (anos) } \\
\end{array}$} & \multicolumn{3}{|c|}{1991} & \multicolumn{3}{|c|}{1997} \\
\hline & 11 & média & $\mathrm{DP}$ & 11 & média & $\mathrm{DP}$ \\
\hline 2 & - & - & - & 6 & 0.50 & 0.84 \\
\hline 3 & - & - & - & 9 & 2.11 & 4,51 \\
\hline+ & - & -- & - & 16 & +.75 & 3.23 \\
\hline 5 & .. & - & - & $1+$ & +.57 & 3.69 \\
\hline 6 & 5 &,+ 00 & 3.54 & 13 & 5,61 & +15 \\
\hline 7 & 3 & 1.00 & 1.00 & 10) & 3,80 & 2,15 \\
\hline 8 & $s$ & 1,87 & 2.48 & 8 & 5.25 & 3.02 \\
\hline 9 & 3 & 3.00 & 5.20 & 7 & $2,+3$ & 1,81 \\
\hline 10 & 6 & 1.50 & $0.8 t$ & 10 & 2.60 & 2.01 \\
\hline 11 & & - & - & + & 1.50 & 1.91 \\
\hline 12 & - & - & $\ldots$ & 8 & 0.12 & 0.35 \\
\hline
\end{tabular}

Votil: Valores para 1991 obtidos de Pose 19993 , e para 199\% de Arantes et al 12001 . 
20-34 anos, o valor do CPOD) aumentou numa magnitude de 11 vezes (de 0,7 para 8,1) entre 1962 e 1991 . Portanto, a comparação dos dados de Neel et al. (1964) e Pose (1993) evidencia uma marcada deterioração das condições de saúde bucal, certamente influenciada pelas mudanças ocorridas na dieta e hábitos alimentares experimentados pelos Xavánte.

Tal tendência é confirmada pelos resultados derivados de outro inquérito realizado em 1997, na mesma comunidade de Pimentel Barbosa (Arantes, 1998; Arantes et al., 2001). Him relação aos estudos anteriores, os valores de (CPOD mostraram-se mais clevados cm todas as faixas ctárias ('Tabela 2). Em 1997, os valores de (PPOD variavam de 1,1 (6-12 anos) a 17,7 (45 ou mais). A mesma tendência pode ser observada em relação à dentição decídua (Tabela 3). ()s resultados deste estudo apontan claramente para um quadro de deterioração das condições de saúde bucal ao longo do tempo, da doença cárie em particular, em praticamente todas as faixas ctárias. (Os autores destacam a ocorrência entre os Xavánte de uma tendência inversa ao que se tem obscrvado em estudos epidemiológicos confocando não-indígenas conduzidos em várias regiões do Brasil, nas quais os indices de cárie vêm apresentando uma tendência de queda ao longo do tempo (Dini et al., 1999; Frevsleben ct al., 2000; MS, 1996; Narvai, 2000).

Un outro aspecto importante observado por Pose (1993) diz respeito à variação nos padrões de saúde bucal cutre as comunidades Xavánte. Fssa autora dividiu os Xavánte em três grupos seguindo critérios antropológicos, que levaram em consideração a intensidade e as características do contato, continuidade ou não nos territórios originalmente ocupados e os agentes de contato (entidades governiamentais ou missões religiosas). As comparações mostraram que o grupo cuja subsistência e estilo de vida estavam mais próximos do padrão "tradicional" Xavánte apresentara uma prevalência de cárie significativamente mais baixa que os demais ('Tabela 4). Pose conclui que as diferenças na forma e na velocidade de contato cutre os grupos os expuscram a diferentes determinantes, produzindo níveis mais altos de prevalência da doenç̧a cáric nos grupos que tiveram um maior contato e mudanças mais intensas em seu estilo de vida e de dieta.

Fi importante indicar, contudo, que há cvidências que sugerem que tempo de contato e fatores associados não são determinantes que expliquem, na totalidade, a trajetória de transformação da saúde bucal indígena. Análise comparativa de clados coletados com base em pespuisas conduzidas entre os Xavánte, Linawenê-Nawê e Guaraní de São Paunlo, ilustra esse ponto.

Se comparados aos Xavánte, o contato do finawenê-Nawê ć bastante recente, una ver que acontecen em meados da clécarda de 1970. Falantes da lín- 


\begin{tabular}{lrrrrrrrrr} 
Médias e desvios-padrão (DP) do índice CPOD para três conjuntos de grupos Xavánte, Mato Grosso. \\
\hline Idade (anos) & \multicolumn{3}{c}{$\begin{array}{c}\text { Xavánte l } \\
\text { média }\end{array}$} & DP & n & $\begin{array}{c}\text { Xavánte } \\
\text { média }\end{array}$ & DP & n & Xavánte 3 \\
média & DP \\
\hline $6-12$ & 35 & 0,37 & 0,77 & 273 & 3,49 & 2,86 & 265 & 4,26 & 3,97 \\
$13-19$ & 25 & 1,16 & 1,60 & 195 & 7,8 & 5,49 & 197 & 10,93 & 5,48 \\
$20-34$ & 23 & 8,13 & 6,00 & 174 & 14,42 & 6,88 & 222 & 14,61 & 6,36 \\
$35-44$ & 10 & 9,10 & 5,70 & 70 & 16,19 & 8,51 & 61 & 17,92 & 7,77 \\
$450 u+$ & 18 & 13,78 & 7,68 & 92 & 19,94 & 8,02 & 116 & 20,28 & 7,31 \\
\hline
\end{tabular}

Adaptado de Pose (1993).

gua Aruák e localizados em Mato Grosso, sua subsistência é baseada na caça, coleta, pesca e no cultivo da mandioca e milho. A coleta está relacionada principalmente à castanha-do-Brasil, buriti, bacaba, pequi e pequiá, bem como alguns tipos de insetos, cogumelos e mel. A pesca tem grande importância na economia do grupo. Mingaus de mandioca e de milho adocicados, geralmente com mel, são parte importante da dieta dos Enawenê-Nawê. Detogni (1995) destaca que os hábitos alimentares tradicionais dos Enawenê-Nawê são altamente cariogênicos, envolvendo uma alimentação adocicada, pastosa, rica em amido. Os alimentos sólidos geralmente são partidos em pedaços antes de serem levados à boca, diminuindo a possibilidade de auto limpeza dos dentes. Este padrão dietético resultou em péssimas condições de saúde bucal mesmo antes do contato.

Como mostram as Tabelas 5 e 6, que comparam os índices CPOD e "ceo" médios dos Xavánte de Pimentel Barbosa e dos Enawenê-Nawê, existem diferenças marcantes em todas as faixas etárias. Os valores são duas ou até três vezes maiores para os Enawenê-Nawê. Os Xavánte de Pimentel Barbosa, apesar de estarem em contato permanente com a sociedade nacional há mais de meio século, ainda apresentam uma dieta que inclui vários componentes oriundos das atividades de horticultura, caça e coleta, muitos deles duros e pouco cariogênicos. Não obstante, como já apontado, mesmo entre os Xavánte, o consumo de alimentos industrializados, e do açúcar em particular, já se faz refletir nos índices de cárie (Arantes et al., 2001).

A situação dos Guaraní do Estado de São Paulo, que vivem em pequenas áreas litorâneas e também na periferia da capital, é bastante precária. Com uma agricultura frágil, em parte devido à ausência de áreas de cultivo, depen- 
Tabela 5

Médias do índice CPOD para os Xavánte de Pimentel Barbosa (Etéñitépa)

e para os Enawenê-Nawê segundo idade, sexos combinados. Mato Grosso.

\begin{tabular}{|c|c|c|c|c|}
\hline \multirow[t]{2}{*}{ Idade (anos) } & \multicolumn{2}{|c|}{ Xavánte } & \multicolumn{2}{|c|}{ Enawenê-Nawê } \\
\hline & $n$ & média & $\mathrm{n}$ & média \\
\hline $2-5$ & 45 & 0,04 & 39 & 0,02 \\
\hline $6-11$ & 52 & 0,84 & 47 & 3,59 \\
\hline $12-14$ & 20 & 3,70 & 26 & 9,07 \\
\hline $15-19$ & 25 & 4,60 & 26 & 14,84 \\
\hline $20-29$ & 39 & 8,54 & 32 & 19,21 \\
\hline $30-39$ & 20 & 15,05 & 18 & 28,00 \\
\hline $40-49$ & 17 & 14,29 & 5 & 29,00 \\
\hline 50 o11 + & 10 & 19,60 & 22 & 31,09 \\
\hline
\end{tabular}

Nota: Valores para os Xavánte obtidos de Arantes et al. (2001), e para os Enawenê-Nawê de Detogni (1995).

Tabela 6

Médias do índice CPOD para os Guaraní, segundo idade, sexos combinados.

Comnunidade Morro da Saudade, São Paulo.

\begin{tabular}{lcc}
\hline Idade (anos) & $\mathbf{n}$ & média \\
\hline $2-5$ & - & - \\
$6-11$ & 77 & 1,33 \\
$12-14$ & 43 & 3,00 \\
$15-19$ & 25 & 5,76 \\
$20-24$ & 15 & 9,73 \\
$25-34$ & 15 & 15,67 \\
$35-44$ & 5 & 18,20 \\
$45-60$ & 3 & 20,33 \\
\hline
\end{tabular}

Nota: Valores obtidos de Fratucci (2000). 
dem da venda de artesanato e de palmito, bem como da mendicância nos centros urbanos próximos às suas áreas. Notícias recentes publicadas pela imprensa e reunidas pelo Instituto Socioambiental (ISA, 2000) relatam a luta para a demarcação de algumas áreas e as tentativas de auto-organização em curso.

Fratucci (2000) conduziu um levantamento das condições de saúde bucal na aldeia Guarani Morro da Saudade, Distrito de Parelheiros, na periferia da capital paulista. Essa aldeia, fundada em 1958, possui aproximadamente 400 moradores. Utilizando os critérios da Organização Mundial da Saúde (OMS), a autora enfocou o índice de cárie (CPOD), as condições periodontais (utilizando o "Índice Periodontal Comunitário" - IPC), as oclusopatias (usando o "Índice Estético Dentário" - IED) e a fluorose. Concluiu que a situação em Morro da Saudade apresentava uma severidade menor que a observada em estudos realizados no Município de São Paulo e também no Estado de São Paulo. Entre os Guaraní, o índice CPOD aos 12 anos foi de 2,2, e 44\% das crianças estavam livres de cárie (Tabelas 6 e 7). Em relação às oclusopatias, 85,7\% apresentou oclusão normal aos 12 anos, segundo o IED. Apesar das crianças Guaranis de 12 anos estarem dentro das metas da OMS-FDI para o ano 2000 (CPOD $<3,0$ aos 12 anos), o componente cariado correspondeu a $86,8 \%$ do índice CPO, indicando a falta de acesso aos serviços e uma tendência de acúmulo de necessidades com o aumento da idade. Em termos comparativos, dados levantados pela Secretaria Estadual de Saúde do Estado de São Paulo em crianças não-indígenas apontam para índices mais elevados tanto em residentes em municípios de pequeno porte sem água fluoretada (CPOD de 4,8 aos 12 anos), como para o estado como um todo (CPOD de 3,7 aos 12 anos) (FSP-USP, 1997; SES-SP/FSP-USP, 1999). É surpreendente que as condições de saúde bucal dos Guaraní de São Paulo apresentem-se como mais satisfatórias que o de outros segmentos populacionais do mesmo município e do Estado, dadas às condições sócio-econômicas e de saúde a que estão expostos.

A breve análise comparativa acima, que envolveu exemplos dos Xavánte, Enawenê-Nawê e Guaraní, revela que existem grandes variações epidemiológicas nas condições de saúde bucal entre os povos indígenas, e mesmo internamente a eles. Procurou-se enfatizar que tempo de contato, tomado isoladamente, é uma variável pouco satisfatória para explicar a trajetória das mudanças na saúde bucal. As diferenças resultam de influências de determinantes sócio-econômicos, ambientais e culturais altamente complexos e diversificados, que assumem contornos particulares a depender da etnia indígena. 
Médias do indice ceo para os Xavánte de Pimentel Barbosa (Etéñitépa), os Enawenê-Nawê e os Guaraní (Morro da Saudade), segundo idade, sexos combinados. Mato Grosso e São Paulo.

\begin{tabular}{lrrrrrr}
\hline Idade (anos) & \multicolumn{2}{c}{ Xavánte } & \multicolumn{2}{c}{ Enawenê-Nawê } & \multicolumn{2}{c}{ Guaraní } \\
& $\mathbf{n}$ & média & $\mathbf{n}$ & média & n & média \\
\hline 2 & 6 & 0,50 & 6 & 3,00 & 7 & - \\
3 & 9 & 2,11 & 10 & 4,50 & 8 & 2,63 \\
4 & 16 & 4,75 & 5 & 9,20 & 13 & 3,69 \\
5 & 14 & 4,57 & 18 & 8,44 & 18 & 3,28 \\
6 & 13 & 5,61 & 6 & 10,33 & 17 & 4,35 \\
7 & 10 & 3,80 & 10 & 9,50 & 7 & 3,00 \\
8 & 8 & 5,25 & 12 & 8,66 & 15 & 3,53 \\
9 & 7 & 2,43 & 8 & 3,25 & 12 & 2,58 \\
10 & 10 & 2,60 & 4 & 3,00 & 12 & 2,75 \\
11 & + & 1,50 & 7 & 1,14 & 14 & 1,29 \\
12 & 8 & 0,12 & 15 & 0,47 & 21 & 0,48 \\
13 & 4 & - & 4 & 0,50 & - & - \\
\hline
\end{tabular}

Nota: Valores para os Xavánte obtidos de Arantes et al. (2001), para os Enawenê-Nawê de Detogni (1995) e para os Guaraní de Fratucci (2000).

\section{ORGANIZAÇÃO E COBERTURA DOS SERVIÇOS DE SAÚDE BUCAL}

O processo de formulação de uma política nacional para saúde do índio vem sendo discutido de forma mais específica desde a I Conferência Nacional de Proteção à Saúde do Índio, que ocorreu em 1986. Os caminhos apontados pelas I e II Conferências Nacionais de Saúde para os Povos Indígenas consolidaram-se somente em 1999, com a criação dos Distritos Sanitários Especiais Indígenas (DSFIs). Esta proposta foi oficializada em 1999 pela Lei 9.836, cujo projeto foi apresentado pelo Deputado Sérgio Arouca em 1994. Baseia-se nos princípios gerais do relatório final da II Conferência Nacional de Saúde para os Povos Indígenas (1993), e determina que o modelo adotado para a atenção de saúde do índio "deve se basear em uma abordagem diferenciada e global, contemplando aspectos da assistência à saúde, saneamento básico, nutrição, habitação, meio ambiente, demarcação de terras, educação sanitária e integração institucional" (Pellegrini, 2000:141). Além disso, estabelece que o Estado deve proporcionar os meios ne- 
cessários para as comunidades indígenas melhorar e exercer o controle sobre sua saúde, e não meramente fornecer serviços médicos.

O DSEI é uma unidade organizacional de responsabilidade da Fundação Nacional de Saúde (FUNASA), estabelecida com base em uma ou mais etnias e territórios definidos por critérios sócio-culturais, geográficos, epidemiológicos e de acesso aos serviços. Essa unidade organizacional deve contar com uma rede própria de serviços nas terras indígenas, capacitada para ações básicas à saúde e articulada com a rede regional para procedimentos de média e alta complexidade. A participação indígena é garantida pelos Conselhos Distritais de Saúde, de composição paritária entre usuários indígenas, prestadores de serviços e profissionais de saúde.

Para viabilizar o funcionamento dos DSEIs, foram firmados convênios com organizações não-governamentais, associações indígenas, universidades e municípios. A FUNASA tem se deparado com muitas dificuldades para colocar em funcionamento o modelo proposto. Além das dificuldades de recrutamento de pessoal com perfil adequado para atuação em contextos interculturais, o que gera grande rotatividade profissional e interrupção das ações, a pouca capacidade administrativa por parte das convenentes também tem dificultado a implantação efetiva dos DSEIs.

Para facilitar a sistematização da atenção à saúde bucal nos DSEIs, a FUNASA, utilizando-se do DESAI (Departamento de Saúde do Índio), promoveu ao longo de 1999 e 2000 várias oficinas das quais participaram odontólogos dos 34 distritos sanitários, quando foram discutidas as diretrizes para os serviços de saúde bucal dos povos indígenas. Pode-se dizer que as ações propostas estão em consonância com a Norma Operacional Básica (NOB/96) e a Norma Operacional de Assistência à Saúde (NOAS/01), e estão divididas em procedimentos coletivos e individuais.

Os procedimentos coletivos, segundo as diretrizes do DESAI, são aqueles que visam a promoção e a prevenção em saúde bucal. São de baixa complexidade, podem ser executados pelo agente indígena de saúde (AIS), pelo atendente de consultório dentário (ACD) ou pelo técnico de higiene dental (THD) e compreendem as seguintes atividades: educação em saúde bucal, atividades com flúor, higiene bucal supervisionada e levantamento coletivo de necessidades. Este último item é colocado "a título de sugestão", tendo o objetivo de se constituir em "instrumento de vigilancia epidemiológica e deve ser utilizado com a finalidade de planejamento das ações de odontologia, subsidiando o agendamento para atendimento individual e orientando a freqüência da participação nos procedi- 
mentos coletivos" (DESAI, 2000). Depreende-se que não se trata de um levantamento epidemiológico no sentido estrito, uma vez que não é necessariamente conduzido por odontólogos.

Os procedimentos individuais estão divididos em três níveis. O primeiro tem por objetivo o "controle da infecção intra bucal", incluindo algumas atividades que podem ser realizadas pelo pessoal auxiliar (remoção de tártaro e aplicação de selantes), enquanto outras exclusivamente pelo cirurgião dentista, como exodontias, tratamento restaurador atraumático e pulpotomias. No segundo, o objetivo é a reabilitação funcional e social do paciente por meio da reconstituição estética com resinas, próteses unitárias, próteses parciais ou totais. O terceiro consiste na definição de um sistema de referência e contra referência para as especialidades.

As diretrizes para atenção à saúde bucal nos DSEI colocam a sistematização das informações como meta de trabalho, incluindo a organização de um fluxo de informações relacionadas à qualidade dos serviços, à produtividade, ao controle e à vigilância epidemiológica. Indica-se que essas ações devem ser realizadas no âmbito das atividades de atenção à saúde e não de forma paralela. Os dados resultantes alimentarão o SIASI (Sistema de Informação de Atenção à Saúde Indígena) com base em cada DSEI. Propõe-se que os dados deverão ser coletados diariamente "na rotina dos serviços, através de formulários e processos padronizados para a aplicação de indicadores de avaliação do programa odontológico" (Oliveira-Sá, 2000:2). Segundo Oliveira-Sá (2000), o DESAI não pretende planejar e executar um levantamento epidemiológico nacional de saúde bucal enfocando os povos indígenas. A intenção é alimentar o SIASI por meio dos dados coletados na "rotina dos serviços". Há aqui uma questão importante a se considerar: a rotina dos serviços não possibilita um conhecimento adequado das realidades epidemiológicas de cada comunidade, já que o conjunto de indivíduos que buscam os serviços não reflete as reais condições de saúde bucal da coletividade. Além disso, geralmente não constituem amostras representativas no que tange à idade e gênero, dentre outros atributos.

Como enfatizado ao longo deste trabalho, há uma notável carência de dados que permitam, mesmo em linhas gerais, uma aproximação das condições de saúde bucal dos povos indígenas no Brasil. É de fundamental importância que condições locais sejam minimamente caracterizadas para a implantação de um programa de saúde bucal. Sem o conhecimento prévio da situação de saúde bucal não é possível estabelecer metas para os programas e, conseqüentemente, não é possível avaliar a efetividade dos mesmos. As metas a serem alcançadas pe- 
lo programa de saúde bucal de um determinado DSEI provavelmente não serão as mesmas de outro, com contingente populacional distinto, apresentando diferentes composições etárias, hábitos alimentares e formas de inserção no mercado regional, entre outros. Os estudos de caso Xavánte, Enawenê-Nawê e Guaraní ilustram esse ponto.

Uma outra questão fundamental na implementação dos programas de saúde bucal nos DSEIs é a necessidade de priorizar a dimensão preventiva, principalmente propiciando acesso aos dentifrícios fluoretados de forma sistemática e à fluorterapia por meio do uso tópico do flúor. Existem atualmente cerca de 150 odontólogos contratados pelos 34 DSEIs no Brasil, responsáveis pelo atendimento de uma população de aproximadamente 350 mil pessoas, com uma demanda acumulada por trabalhos curativos muito grande. Somente com um programa preventivo eficaz será capaz de diminuir a demanda a médio e longo prazo. Para tal, a dimensão preventiva deverá estar intimamente acoplada a ações educacionais. Para serem bem sucedidos, programas comunitários de saúde e educação deverão levar em consideração o contexto sociocultural, político e econômico de cada comunidade, algo que demanda cuidadoso planejamento e continuidade das ações ao longo do tempo.

Apesar de todas as dificuldades envolvidas na implantação e no funcionamento dos DSEIs, modificações importantes têm sido observadas em relação à atenção à saúde bucal dos povos indígenas, como maior esforço de organização, criação de um serviço mínimo de atenção à saúde bucal, aumento do quadro de profissionais e estabelecimento de um sistema de informações. Este conjunto de fatores tem trazido novas perspectivas para a saúde bucal dos povos indígenas, mas há ainda muito a se trilhar.

\section{Referências}

ANDO, T.; HIRATA, M. J.; MORI, M.; RIBEIRO, F. C. \& RIGONATTO, D. D., 1986. Atuação odontológica no Parque Indígena do Xingu - dados de 5 anos de prevenção de cárie com aplicação de flúor gel. En iclopédia Brasileira de Odontologia, 4:597-608. ARANTES, R., 1998. Saúde Bucal de uma Comunidade Indígena Xavánte do Brasil Central: Uma Abordagem Epidemiológica e Bioantropológica. Dissertação de Mestrado. Rio de Janeiro: Escola Nacional de Saúde Pública, Fundação Oswaldo Cruz.

ARANTES, R.; SANTOS, R. V. \& COIMBRA Jr., C. E. A., 2001. Saúde bucal na população indígena Xavánte de Pimentel Barbosa, Mato Grosso, Brasil. Cadernos de Saúde Pública 17:375-384. 
ARAÚJO, M. A. G., 1988. Treinamento de monitores indígenas em saúde bucal: Uma experiência de trabalho com os Ticuna. Suúde em Debate, Janeiro:42-44.

AYRE.S, M. \& SALZANO, F. M., 1972. Health of Brazilian Cayapo Indians. Tropical and Geographical Medicine, 24:178-185.

BARNES, G. P.; PARKER, W. A.; LYON Jr., 'T. C.; DRUM, M. A. \& COLEMAN, G. C., 1992. Ethnicity, location, age and fluoridation factors in baby bottle tooth decay and caries prevalence of head start children. Public Health Reports, 107:167-173.

BARUZZI, R. G. \& IONES, M., 1970. Levantamento das Condições de Saúde das Tribos Indígenas do Alto Xingu. Aplicação de Medidas Médico-Profiláticas para sua Preservação. Parque Nacional do Xingu. São Paulo: Departamento de Medicina Preventiva, Escola Paulista de Medicina. (mimeo.)

BURT, B. A. \& ARBOR, A., 1994. Trends in caries prevalence in North American children. International Dental Joumal, 44:41)3-413.

CASSIDY, C. M., 1984. Skeletal evidence for prehistoric subsistence adaptation in the central Ohio River Valley. In: Paleopathology at the Origins of Agriculture (M. N. Cohen \& G. J. Armelagos, ed.), pp. 307-345, New York: Academic Press.

COHEN, M. N. \& ARMELAGOS, G. J. (ed.), 1984. Paleopathology at the Origins of Agriculture. New York: Academic Press.

COIMBRA Jr., C. E. A. \& SANTOS, R. V., 2000. Saúde, minorias e desigualdades: Algumas teias de inter-relações, com ênfase nos povos indígenas no Brasil. Ciência 6 Saúde Coletiva, 5:125-132.

COIMBRA Jr., C. E. A.; Fl.OWERS, N. M.; SALZANO, F. M. \& SANTOS, R. V., 2002. The Xavánte in Transition: Health, Ecology, and Bioanthropology in Central Brazil. Ann Arbor: University of Michigan Press.

COOK, H. W.; DUNCAN, W. K.; DE BALL, S. \& BERG, B., 1994. The cost of nursing caries in a native American Head Start population. Joumal of Clinical Pediatric Dentistry, 18:139-142.

DESAI (Departamento de Saúde do Índio), 2000. Diretrizes para o Serviço Odontológico nos DSEIs. Brasília: Fundação Nacional de Saúde. (mimeo.)

DETOGNI, A., 1994. De volta às origens. Revista da Associação Brasileira de Odontologia, 2:138-148.

DF.TOGNI, A., 1995. Relatório Final da Situação de Saúde Bucal do Grupo Indígena Enawene-Nawe, MT e Proposta para um Programa de Saúde Bucal para esta População. Projeto BRA/94/006. Cuiabá: Prograına das Nações Unidas para o Desenvolvimento. (mimeo.)

DINI, E. L.; FOSCHINI, A. L. R.; BRANDÃO, I. M. G. \& SILVA, S. R. C., 1999. Changes in caries prevalence in 7-12-years old children from Araraquara, São Paulo, Brasil: 1989-1995. Cadernos de Saúde Pública, 15:617-621.

DONNELLY, C. J.; THOMSON, L. A.; STILES, H. M.; BREWER, C.; NEEL, J. V. \& BRUNELLE, J. A., 1977. Plaque, caries, periodontal diseases, and acculturation among Yanomami Indians, Venezuela. Community Dentistry and Oral Epidemiology, 5:30-39.

FL.OWERS, N. M., 1983. Seasonal factors in subsistence, nutrition, and child growth in a central Brazilian Indian community. In: Adaptive Response of Native Amazonians (R. B. Hames \& W. H. Vickers, ed.), pp. 357-390, New York: Academic Press. 
FRATUCCI, M. V. B., 2000. Alguns Aspectos das Condições de Saúde Bucal de uma População Indígena Guarani Mbyá no Município de São Paulo. Dissertação de Mestrado, São Paulo: Faculdade de Saúde Pública, Universidade de São Paulo.

FREYSLEBEN, G. R.; PERES, M. A. A. \& MARCENES, W., 2000. Prevalência de cárie e CPO-D médio em escolares de doze a treze anos de idade nos anos de 1971 e 1997, Região Sul, Brasil. Revista de Saúde Pública, 34:304-308.

FSP-USP (Faculdade de Saúde Pública, Universidade de São Paulo), 1997. Levantamento Epidemiológico da Cárie Dentária, Oclusopatias e Fluorose Dentária em Crianças de 5 a 12 Anos de Idade em Escolas Públicas e Privadas do Município de São Paulo, em 1996. São Paulo: Núcleo de Estudos e Pesquisas de Sistemas de Saúde, Faculdade de Saúde Pública, Universidade de São Paulo.

GIACCARIA, B. \& HEIDE, A., 1972. Xavánte: Povo Autêntico. São Paulo: Editora Salesiana Dom Bosco.

GOODMAN, A. H.; MARTINEZ, C. \& CHAVEZ, A., 1991. Nutritional supplementation and the development of linear enamel hypoplasias in children from Tezonteopan, Mexico. American Joumal of Clinic Nutrition, 53:773-781.

GREENE, J. C. \& VERMILLION, J. R., 1964. The simplified oral hygiene index. Journal of American Dental Association, 68:7-13.

GRIM, C. W.; BRODERICK, E. B.; JASPER, B. \& PHIPPS, K. R., 1994. A comparison of dental caries experience in Native American and Caucasian children in Oklahoma. Journal of Public Health Dentistry, 54:220-227.

GUGELMIN, S. A., 1995. Nutrição e Alocação de Tempo dos Xavántes de Pimentel Barbosa, Mato Grosso: Um Estudo em Ecologia Humana e Mudanças. Dissertação de Mestrado, Rio de Janeiro: Escola Nacional de Saúde Pública, Fundação Oswaldo Cruz.

GUSTAFSSON, B. E.; QUENSEL, C. E.; LANKE, L. S.; LUNDQVIST, C.; GRAHNÉN, H.; BONOW, B. E. \& KRASSE, B., 1954. The Vipeholm dental caries study. 'The effect of different levels of carbohidrate intake on caries activity in 436 individuals observed for five years. Acta Odontologica Scandinavica, 11:232-364.

HARRISON, R. L. \& DAVIS, D. W., 1993. Caries experience of Native children of British Columbia, Canada, 1980-1988. Community Dentistry and Oral Epidemiology, 21:102-107.

HIRATA, J.; BERGAMASCHI, O.; OLIVEIRA, A.; LAZARO, A.; MARTINS, C.; BOSCO, L. \& ANDO, T., 1977. Estudo de prevalência de cárie em crianças indígenas do Parque Nacional do Xingu. Revista da Faculdade de Odontologia de São Paulo, 15:189198.

ISA (Instituto Socioambiental), 2000. Povos Indígenas no Brasil - 1996-2000. São Paulo: ISA.

JONES, D. B. \& PHIPPS, K. R., 1992. An oral health survey of Head Start children in Alaska: oral health status, treatment needs, and cost of treatment. Joumal of Public Health Dentistry, 52:86-93.

KASTE, L. M.; MARIANOS, D.; CHANG, R. \& PHIPPS, K. R., 1992. The assessment of nursing caries and its relationship to high caries in the permanent dentition. Joumal of Public Health Dentistry, 52:64-68. 
LIMA, P. E., 1954. Deformações tegumentares e mutilação dentária entre os índios Tenetehará. Boletim do Museu Nacional, 16.

LOPES-DA-SILVA, A., 1992. Dois séculos e meio de história Xavánte. In: História dos Índios no Brasil (M. C. Cunha, org.), pp. 357-378, São Paulo: Companhia das Letras. MAYBURY-LEWIS, D., 1984. A Sociedade Xavánte. Rio de Janeiro: Francisco Alves Editora. MEIKLEJOHN, C.; SCHENTAG, C.; VENEMA, A. \& KEY, P., 1984. Socioeconomic change and patterns of pathology and variation in the Mesolithic and Neolithic of Western Europe: Some suggestions. In: Paleopathology at the Origins of Agriculture (M. N. Cohen \& G. J. Armelagos, ed.), pp. 75-100, New York: Academic Press.

MENDONÇA-DE-SOUZA, S.; ARAÚJO, A. J. G. \& FERREIRA, L. F., 1994. Saúde e doença em grupos indígenas pré-históricos do Brasil: paleopatologia e paleoparasitologia. In: Saúde e Povos Indígenas (R. V. Santos \& C. E. A. Coimbra Jr., org.), pp.21-42, Rio de Janeiro: Editora Fiocruz.

MILNES, A. R.; RUBIN, C. W.; KARPA, M. \& TATE, R., 1993. A retrospective analysis of the costs associated with the treatment of nursing caries in a remote Canadian aboriginal preschool population. Community Dentistry and Oral Epidemiology, 21:253260.

MS (Ministério da Saúde), 1988. Levantamento Epidemiológico em Saúde Bucal: Brasil, Zona Urbana. Brasília: Secretaria Nacional de Programas Especiais de Saúde, Divisão Nacional de Saúde Bucal, MS.

MS (Ministério da Saúde), 1996. Levantamento Epidemiológico em Saúde Bucal. Brasília: Secretaria Nacional de Programas Especiais de Saúde, Divisão Nacional de Saúde Bucal, MS.

MOORE, W. J. \& CORBETT, M. E., 1971. The distribution of dental caries in ancient British populations - I. Anglo-Saxon period. Caries Research, 5:151.

MOORE, W. J. \& CORBETT, M. E., 1973. The distribution of dental caries in ancient British populations - II. Iron Age, Romano-British and Medieval period. Caries Research, 7:139.

NARVAl, P. C., 2000. Cárie dentária e flúor: Uma relação do século XX. Ciência ๔ Saúde Coletiva, 5:381-392.

NEEL, J. V.; SALZANO, F. M.; JUNQUEIRA, P. C.; KEITER, F. \& MAYBURY-LEWIS, D., 1964. Studies on the Xavánte Indians of the Brazilian Mato Grosso. American Journal of Human Genetics, 16:52-140.

NEWBRUM, E., 1982. Sugar and dental caries: A review of human studies. Science, 217:418-423.

NISWANDER, J. D., 1967. Further studies on Xavánte Indians. VII. The oral status of the Xavántes of Simões Lopes. American Journal of Human Genetics, 19:543-533.

NORMANDO, A. D. C. \& ARAÚJO, I. C., 1990. Prevalência de cárie dental em uma população de escolares da regiāo amazônica. Revista de Saúde Pública, 24:294-299.

O'SULLIVAN, D. M.; CHAMPANY, R.; EBERLING, S.; TETREV, S. \& TINANOFF, N., 1994. Dental caries and treatment among Navajo preschool children. Journal of Public Health Dentistry, 54:139-144.

OLIVEIRA-SÁ, E. M., 2000. O quadro epidemiológico em saúde bucal dos povos indígenas. Brasília: Departamento de Saúde Indígena (Desai)/ FUNASA. Mimeo. 
OLIVEIRA, H. C., 1948. Sobre os dentes dos Karajás de Santa Isabel. Revista do Museu Paulista, 2:170-174.

PELLEGRINI, M., 2000. Povos indígenas e a conquista da cidadania no campo da saúde. In: Povos Indígenas no Brasil (C. A. Ricardo, org.), pp. 139-142, São Paulo: Instituto Socioambiental.

PEREIRA, C. \& EVANS, H., 1975. Occlusion and attrition of the primitive Yanomami Indians of Brazil. Dental Clinics of North America, 19:485-498.

PERZIGIAN, A. J.; TENCH, P. A. \& BRAUN, D. J., 1984. Prehistoric health in the Ohio River Valley. In: Paleopathology at the Origins of Agriculture (M. N. Cohen \& G. J. Armelagos, ed.), pp. 347-366, New York: Academic Press.

PHIPPS, K. R.; REIFEL, N. \& BOTHWELL, E., 1991. The oral health status, treatment needs, and dental utilization patters of Native American elders. Journal of Public Health Dentistry, 51:228-233.

PINTO, V. G., 1990. Saúde Bucal. Panorama Internacional. Brasília: Secretaria Nacional de Programas Especiais de Saúde, Ministério da Saúde.

PINTO, V. G., 1992. Saúde Bucal. Odontologia Social e Preventiva. São Paulo: Livraria Santos Editora.

POSE, S. B., 1993. Avaliação das Condições de Saúde Oral dos Índios Xavántes, Brasil Central. Dissertação de Mestrado, Rio de Janeiro: Escola Nacional de Saúde Pública, Fundação Oswaldo Cruz.

RENSON, C. E., 1989. Global changes in caries prevalence and dental manpower requirements: 3. The effects on manpower needs. Dental Update, 16:382-389.

RIBEIRO, D., 1956. Convívio e contaminação. Efeitos dissociativos da população provocada por epidemias em grupos indígenas. Sociologia, 18:3-50.

RIGONATTO, D. L.; ANTUNES, J. L. \& FRAZÃO, P., 2001. Dental caries experience in Indians of the upper Xingu, Brasil. Revista do Instituto de Medicina Tropical de São Paulo, 43:93-98.

RODRIGUES, C. D., 1997. Patologias e Processos Dento-Maxilares em Remanescentes Esqueletais de Dois Sítios Pré-Históricos no Brasil: O Cemitério de Furna de Estrago (PE) e o Sambaqui de Cabeçuda (SC). Dissertação de Mestrado, Rio de Janeiro: Escola Nacional de Saúde Pública, Fundação Oswaldo Cruz.

ROOSEVELT, A. C., 1984. Population health, and the evolution of subsistence: conclusions from the Conference. In: Paleopathology at the Origins of Agriculture (M. N. Cohen \& G. J. Armelagos, ed.), pp. 559-583, New York: Academic Press.

RUSSEL, A. L., 1956. A system of classification and scoring for prevalence surveys of periodontal disease. Joumal of Dental Research, 35:350:359.

SANTOS, R. V. \& COIMBRA Jr., C. E. A., 1999. Hardships of contact: Assessment of defects of dental enamel in permanent anterior teeth of Tupí-Mondé Amerindians from Brazilian Amazonia. American Joumal of Physical Anthropology, 109:111-127.

SANTOS, R. V.; FLOWERS, N. M.; COIMBRA Jr., C. E. A. \& GUGELMIN, S. A., 1997. Tapirs, tractors, and tapes: the changing economy and ecology of the Xavánte Indians of Central Brazil. Human Ecology, 25:545-566.

SCOTT, G. R. \& TURNER, C. G., 1988. Dental Anthropology. Annual Review of Anthropology, 17:99-126. 
SES-SP (Secretaria de Estado da Saúde de São Paulo)/FSP-USP (Faculdade de Saúde Pública - Universidade de São Paulo), 1999. Levantamento Epidemiológico em Saúde Bucal - Estado de São Paulo, 1988. São Paulo: Núcleo de Estudos e Pesquisas de Sistemas de Saúde, Faculdade de Saúde Pública, Universidade de São Paulo.

TITLEY, K. C. \& BEDARD, D. H., 1986. An evaluation of a dental care program for Indian children in the community of Sandy Lake. Sioux lookout zone, 1973-1983. Journal of the Canadian Dental Association, 11:923-928.

TRICERRI, F. J., 1985. Breve passagem odontológica entre índios do Alto Solimões, Amazônia, Brasil. Revista da Fundação SESP, 30:151-160.

TUMANG, J. A. \& PIEDADE, E. F., 1968. Cárie dental, doenças periodontais e higiene oral em indígenas brasileiros. Boletín de la Oficina Sanitaria Panamericana, 64:103109.

VIEGAS, Y. \& VIEGAS, A. R., 1988. Prevalência de cárie dental em Barretos, SP, Brasil, após dezesseis anos de fluoretação da água de abastecimento público. Revista de Saúde Pública, 22:25-35.

WALSH, J., 1970. International patterns of oral health care - the example of New Zealand. New Zealand Dentistry Joumal, 66:143-152.

WHO (World Health Organization), 1991. Levantamento Epidemiológico Básico de Saúde Bucal. São Paulo: Livraria Santos Editora.

WHO (World Health Organization), 1992. Avances Recientes en Salud Bucodental. Série Informes Técnicos 826. Genebra: WHO. 


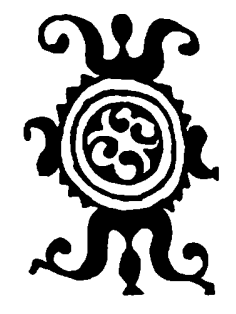

\section{ASPECTOS ALIMENTARES \\ E NUTRICIONAIS DE MÃES \\ E CRIANÇAS INDÍGENAS TERÉNA, MATO GROSSO DO SUL}

\section{Dulce Lopes Barboza Ribas, Sonia Tucunduva Philippi}

As transformações no perfil de saúde apresentam peculiaridades e sofrem mudanças em espaços de tempo relativamente curtos, como as identificadas em comunidades indígenas, nas quais o aumento das taxas de natalidade e a elevada incidência de doenças infecciosas na infância coexistem com o aumento das doenças crônicas não transmissíveis, alcoolismo e violência. As comunidades indígenas são afetadas ainda por problemas de contaminação ambiental, esgotamento de recursos naturais, comprometimento das atividades de subsistência e dependência por produtos industrializados (Ribas, 2001).

O registro e a análise dessas modificações são de grande importância para o entendimento dos determinantes do processo saúde-doença nessas comunidades. As dificuldades e as limitações para tal se inserem na complexidade dos fenômenos sociais em que vivem as sociedades indígenas, somadas à existência de informações parciais e fragmentadas, muitas vezes indisponíveis para análise.

Os estudos epidemiológicos voltados para a análise dos determinantes de mudanças mostram como modificações nos padrões econômicos e sociais interferem nos perfis de mortalidade e morbidade na população, tendo efeito sobre doenças infecciosas e também sobre doenças crônicas não transmissíveis. Em consonância com a transição epidemiológica e demográfica, estão ocorrendo mudanças nos padrões alimentares e nutricionais das populações indígenas, revelando a complexidade dos modelos de consumo e de seus fatores determinantes, onde déficits nutricionais e obesidade coexistem, marcados por alterações nos níveis de atividade física e composição da dieta (Oliveira \& ThébaudMony, 1997).

Este estudo aborda o estado nutricional de crianças menores de cinco anos e suas mães, relacionando condições socioeconômicas, ambientais e o atual estilo de vida em comunidades Teréna do Mato Grosso do Sul. 


\section{POPULAÇÃO E MÉTODOS}

\section{Os Teréna}

A população estudada pertence ao subgrupo Guaná-Txané, remanescentes da família Aruák. Guimarães Rosa (1985:93-95), grande escritor brasileiro, descreveu os Teréna por meio da língua: "Conversa pouca. A surpresa que deram foi ao escutá-los coloquiar entre si, em seu rápido, ríspido idioma. Uma língua não propriamente gutural, não guarani, não nasal, não cantada; mas firme, contida, oclusiva e sem molezas - língua para gente enérgica e terra fria. Respeitei-a, pronto respeitei seus falantes, como se representasse alguma cultura velhissima (....) Toda língua são rastros de velho mistério".

Agricultores, com áreas cultivadas ao redor da aldeia, plantavam mandioca, abóbora, batata doce, pimenta, milho e feijões. A terra não gerava renda; basicamente servia para instalar moradias e produzir alimentos de subsistência. A unidade econômica era a família extensa, com atividades de plantio de roças, coleta de raízes e frutos silvestres, combinadas com a caça e a pesca (Oberg, 1949). A divisão do trabalho reservava ao homem a caça, a pesca, o plantio e as atividades guerreiras, deixando à mulher o preparo dos alimentos, a coleta de frutos e raízes silvestres, a cerâmica e a fiação (Silva, 1949).

A terra continua sendo o espaço da sobrevivência e reprodução, onde se realiza a cultura, onde se criou o mundo, onde descansam os antepassados, além de ser um local onde Os Teréna se apropriam dos recursos naturais e garantem sua subsistência física. A apropriação de recursos naturais não se resume em produzir alimentos, mas consiste em extrair matéria-prima para a construção de casas, para produção de enfeites e artesanatos e para a extração de ervas medicinais, que exigem determinadas condições ecológicas para se reproduzirem. É, sobretudo, um espaço simbólico em que as pessoas travam relações entre si, com a natureza e com seus deuses (Fernandes, 1993).

As primeiras reservas indígenas Teréna datam de 1904, como conseqüência da ação de Rondon à frente da Comissão de Linhas Telegráficas. Entende-se por "reserva" uma área territorial destinada ao aldeamento de indígenas, sendo que nem sempre essas áreas coincidiam com as terras tradicionalmente ocupadas pelas respectivas comunidades e muitas vezes ocorria justaposição de grupos, provocando disputas e graves conflitos internos. A formação de reservas próximas de vilarejos evidencia o reconhecimento dos direitos indígenas a um território, ao mesmo tempo em que, ao agrupá-los, libera grandes áreas 
para o povoamento da região e impulsiona a integração à sociedade envolvente (Pauletti, 2000).

Com relação às áreas indígenas analisadas neste estudo, a área Buriti foi demarcada em 23 de dezembro de 1927, com 2.090 hectares, sendo instalada pelo Serviço de Proteção aos Índios (SPI) em 1928 e homologada em 1991. Nela localizam-se atualmente as aldeias Buriti, Água Azul e Córrego do Meio. A área Buritizinho, situada no Município de Sidrolândia, foi demarcada em 9 de julho de 1984 com 10 hectares. Esta área possui apenas uma aldeia, denominada aldeia Tereré.

\section{Coleta de dados}

Foi realizado estudo descritivo e analítico, de caráter transversal, em quatro aldeias Teréna (Buriti, Córrego do Meio, Água Azul e Tereré), localizadas nos municípios de Dois Irmãos do Buriti e Sidrolândia, Mato Grosso do Sul. Foram avaliadas 351 crianças de $0-59$ meses de idade, correspondendo a $98 \%$ da população menor de cinco anos, e suas respectivas mães, num total de 185 mulheres.

Foram analisadas variáveis sócio-econômicas (renda per capita e escolaridade da mãe), ambientais (utilização da terra disponível, existência de roças, pomares e hortas), antropométricas (peso e estatura) e freqüência de alimentos.

A avaliação qualitativa do consumo alimentar foi realizada por meio de questionário de freqüência, que consistia em uma lista de alimentos agrupados segundo a composição nutricional e de uma seção de respostas sobre a freqüência de consumo de cada alimento.

A técnica de antropometria adotada foi baseada em recomendações da Organização Mundial da Saúde (OMS) e no Anthropometric Standardization Reference Manual (Lohman et al., 1988; WHO, 1995).

A coleta de dados foi efetuada entre julho e dezembro de 1999. Os domicílios foram visitados por entrevistadores treinados e um guia indígena, especialmente indicado pelo cacique de cada aldeia, para o acompanhamento dos trabalhos. Foram realizados contatos prévios com lideranças indígenas, com o intuito de obter anuência das comunidades, sendo o projeto aprovado pelo Comitê de Ética da Faculdade de Saúde Pública da Universidade de São Paulo e da Comissão Nacional de Ética em Pesquisa. 


\section{RESULTADOS}

\section{Mudanças nas áreas indígenas}

Em linhas gerais, o atual modo de produção agrícola Teréna consiste na utilização escalonada do ambiente, mas sem a possibilidade de deslocamentos das plantações devido à redução territorial. Os Teréna não atingem altos índices de produção agrícola, mas contam com uma pequena produção que lhes permite manter contatos comerciais com a sociedade regional. Uma roça produtiva que garanta a subsistência é a aspiração de todo Teréna.

Quanto à utilização da terra disponível, foi identificada a existência de $79,5 \%$ de domicílios com roças, $54,8 \%$ com pomar e $8,6 \%$ com hortas. Na última safra, $66,3 \%$ das famílias destinaram a produção exclusivamente para o consumo próprio, $29,5 \%$ comercializaram os produtos e 4,2\% distribuíram-na entre outras famílias da comunidade.

Cada família possuía uma área disponível para o plantio variando de $\mathrm{l}$ a 10 hectares, com predomínio de áreas menores. Não existe delimitação das áreas com cercas, mas todos têm claro os limites e o respeito para com a terra alheia e os produtos do trabalho. Foram observadas áreas comuns, como pomares, trechos de circulação entre as casas e pequenas capoeiras, de onde retiram madeira, taquaras, sementes, corantes, palha e frutos. Além das roças e capoeiras, não há trechos de mata com cobertura vegetal suficiente que permita a caça.

É importante lembrar que, para que um povo indígena possa sobreviver e se reproduzir, necessita mais terra do que a que utiliza simplesmente para plantar. Os Teréna utilizam critérios particulares para classificar o espaço destinado às plantações. As capoeiras são destinadas para o descanso da terra, para reprodução de pequenos animais e para a obtenção de materiais simbólicos utilizados nos rituais e tratamentos de saúde. Todos têm acesso à terra e esse acesso é efetivado por meio do trabalho que cada família desenvolve numa determinada porção do território.

$\mathrm{Na}$ Área Buritizinho, onde se localiza a Aldeia Tereré, não existe a disponibilidade territorial necessária para implementação de roças, uma vez que a área total da aldeia corresponde a 10 hectares. Nesse exíguo espaço estão distribuídos 62 domicílios, casa de reza, escola, centro de reuniões, campo de futebol e horta comunitária.

A organização circular das longas casas de teto arqueado, onde residiam várias famílias, foi substituída pelo alinhamento residencial. Na avaliação da 
densidade familiar, a média de pessoas residentes por domicílio é de 6,8 moradores, com desvio padrão de 2,9.

\section{Trabalho, estudo e sobrevivência}

Homens e mulheres leréna com maior escolaridade trabalham nos municípios vizinhos ou ocupam posições na escola e no serviço de saúde da própria aldeia. Os demais trabalham em scrviços ocasionais. As mulheres constituem mão-dcobra para serviços domésticos ou não possuem qualquer atividade remunerada.

Obscrvam-se baixos níveis de cscolaridade materna em todas as comunidades: 12,3\% não receberam nenhuma instrução escolar, 66,0\% possuíam de 1 a 4 anos de estudo, $19,8 \%$ de 5 a 8 e $1,9 \%$ acima de 8 anos.

Com relação à renda familiar per capita, observa-se baixa renda em todas as comminidades estudadas, onde $87,7 \%$ encontravam-se na faixa de 0 a 0,5 salário mínimo. Vale mencionar que a garantia da sobrevivência para a maioria das famílias estudadas depende do resultado da pequena produção agrícola on de cestas básicas recebidas por programas assistenciais.

\section{Mães e crianças}

A'Tabela 1 apresenta as condições de nascimento das crianças Teréna. Para as 192 crianças que tinham registro do peso ao nascer, observaram-se $12,5 \%$ com baixo peso $(\leq 2.500 \mathrm{~g})$. F́, importante observar que este número pode estar subestimado, considerando que $45,3 \%$ das crianças não possuíam registro do peso ao nascer, sobretudo as nascidas nos donnicílios e que possivelmente apresentavan maior risco.

Com relação à cobertura de assistência ao parto, $28,2 \%$ foram realizados nos domicílios. 1)os partos hospitalares, 15,7\% foram operatórios.

$\Lambda$ idade média das mães foi de 26,1 anos (desvio padrão de 7,3 ), sendo $15,2 \%$ menores de 20 anos e $0,5 \%$ acima de 50 . Quanto ao número de filhos nascidos vivos, observou-se a média de 3,8 (desvio padrão de 2,7). Na história reprodutiva, 13,7\% das mães relataram a ocorrência de abortos, com média de 1,7 (destio padrão de 0,97 ).

Com relação ao peso, as mães apresentaram média de 59,3kg (mińnimo de $37,4 \mathrm{~kg}$ e máximo de $84,+\mathrm{kg}$ ). A estatura média observada foi de 1,53 m (mínimo de 1,41 m e máximo de 1,69 m).

A 'labela 2 apresenta a araliação do estado nutricional de mães e filhos. Por meio da análise do índice de massa corporal (IMC) das mães foram observa- 
Tabela 1

Distribuição das condições de nascimento em crianças Teréna, Mato Grosso do Sul, 1999.

\begin{tabular}{lcc}
\hline Variáveis & $\mathbf{n}$ & $\%$ \\
\hline Peso ao nascer (gramas) & & \\
$\leq 2.500$ & 24 & 12,5 \\
$2.501-3.000$ & 45 & 23,4 \\
$3.001-3.500$ & 75 & 39,1 \\
$3.501-4.000$ & 41 & 3,6 \\
$>4.000$ & 7 & 28,2 \\
& & 71,8 \\
Local do parto & 99 & \\
Domicílio & 252 & 84,3 \\
Hospital & & 15,7 \\
Tipo de parto & & \\
Normal & 296 & 55 \\
Operatório & & \\
\hline
\end{tabular}

dos: $1,6 \%$ de baixo peso (IMC < 18,5), 70,3\% de peso adequado (IMC 18,524,9 ), $18,9 \%$ de pré-obesidade (IMC $25,()-29,9$ ) e $9,2 \%$ de obesidade materna $(\mathrm{IMC} \geq 30,0)$.

Nas crianças, as prevalências de déficits nutricionais ( $<-2$ z-escores) encontradas foram: $4,0 \%$ para o índice peso/idade, $11,1 \%$ para estatura/idade e $1,1 \%$ para peso/estatura. $\mathrm{Na}$ análise da distribuição de déficts segundo sexo, foram observadas maiores prevalências para peso/idade $(4,2 \%)$ e para estatura/idade $(12,2 \%)$ no sexo masculino.

A prevalência de retardo de crescimento, representado por déficits de estatura/idade, é maior na faixa etária de $12-18$ meses de idade $(25,0 \%)$ e naqueles que apresentaram menor peso ao nascer $(25,0 \%)$. A prevalência de déficits é inversamente proporcional à escolaridade da mãe e faixa de renda familiar per capita.

Os resultados deste estudo demonstram elevada prevalência de déficits de estatuta/idade, ultrapassando a frequiência de $2,3 \%$ esperada pela distribuição de referência (NCHS) e indicando desnutrição crônica, possivelmente iniciada ainda no útero materno. 
Distribuição do estado nutricional das crianças Teréna e de suas mães, Mato Grosso do Sul, 1999.

\begin{tabular}{lc}
\hline & Crianças $(\mathbf{n}=351)$ \\
\hline Peso/Estatura & 0,30 \\
$\quad$ Média (z-escore) & 1,1 \\
Prevalência (porcentagem <-2 z-escore) & \\
Peso/ldade & $-0,27$ \\
$\quad$ Média (z-escore) & 4,0 \\
Prevalência (porcentagem <-2 z-escore) & \\
Estatura/Idade & $-0,76$ \\
Média (z-escore) & 11,1 \\
Prevalência (porcentagem <-2 z-escore) & Mães (n $=185)$ \\
\hline & \\
\hline Índice de massa corporal & 25,1 \\
Média & \\
Distribuição (\%) & 1,6 \\
$<18,5$ & 70,3 \\
$18,5-24,9$ & 18,9 \\
$25-29,9$ & 9,2 \\
$\geq 30,0$ & \\
\hline
\end{tabular}

\section{Padrão de alimentação atual}

As análises de consumo alimentar entre os Teréna foram abordadas numa perspectiva qualitativa, identificando as práticas alimentares e a freqüência dos alimentos na dieta.

Das inúmeras variáveis que determinam as transformações dos hábitos alimentares em comunidades Teréna, destacam-se a baixa disponibilidade de alimentos na área indígena e a renda familiar. Alimentos recolhidos nas matas e rios do passado são atualmente raros, o que se explica pela limitação territorial, invasões de terras, contaminação dos rios e, conseqüentemente, dispersão e escassez de caça e pesca. As atividades de caça e pesca, tão apreciadas pelos homens, são realizadas cada vez com menos freqüência e sempre em locais distan- 
tes da reserva, o que acarreta riscos de serem identificados como invasores em outras áreas.

Foi observada a realização de três refeições, relatadas como principais, sem horários rígidos, mas distribuídas ao longo do dia - ao acordar, no meio do dia e no início da noite. Não são deixados restos nos pratos, onde tudo que é servido é consumido. Após as refeições, quando sobram alimentos preparados, eles permanecem nas panelas sobre o fogão, com livre acesso para qualquer pessoa voltar a se servir.

A varanda é o local privilegiado do domicílio, onde as refeições se realizam, recebem as visitas, armam a rede, brincam, contam e ouvem histórias. A casa pode ter um único dormitório, mas nunca deixa de ter varanda.

A primeira refeição do dia é constituída de arroz e mandioca cozida, geralmente sobras da véspera, e ainda café, chá-mate ou simplesmente água com açúcar caramelizado. No almoço e jantar são acrescidos o feijão cozido, macarrão com extrato de tomate e carne frita. Arroz e mandioca são os alimentos mais freqüentes e em maior quantidade nas refeições, sendo muitas vezes os únicos. A farinha de mandioca foi identificada como um complemento da refeição, mais presente na dieta das famílias que a produzem (32\%). Nas refeições intermediárias foram observados o consumo de chá-mate, café, água com açúcar caramelizado, tereré (erva-mate regada à água fria ou gelada, sorvida através de uma bomba), mandioca cozida, caramelos, chicletes, refrescos em pó diluídos, biscoitos recheados, salgadinhos tipo snacks e, em épocas de safra, banana, manga, goiaba e bocaiúva. Entre os jovens e adultos foi observado o consumo em larga escala de tereré, que é tomado em grupo, passando de mão em mão.

A produção de farinha de mandioca é responsabilidade das mulheres de cada grande família, que se reúnem na casa da avó, denominada tronco da família, para a árdua tarefa de descascar, ralar, lavar a massa, espremer, torrar, o que pode levar dias, dependendo da quantidade da matéria-prima. As mulheres só descansam quando toda a mandioca estiver ralada. A farinha produzida é armazenada em sacos de algodão, sendo motivo de orgulho familiar e objeto de permuta ou presente a ser oferecido a parentes e amigos.

A presença da carne bovina é bastante valorizada nas refeições, mas de difícil acesso para a maioria das famílias. Quando presente (39,5\%), trata-se de peças de menor custo, em pequena quantidade e com elevado teor de gordura, como costela e ponta-de-peito. As carnes gordas são consideradas as mais saborosas e as possíveis de serem adquiridas. Quanto à forma de preparo das carnes e ovos, há predomínio de frituras, geralmente em gordura de origem animal. As 
frituras também são utilizadas como meio de conservação. As carnes são fritas quando adquiridas, sendo guardadas em latas, submérsas em gordura animal. $\mathrm{O}$ consumo de aves (geralmente frango) ocorre em ocasiões especiais, como na dieta das mães em resguardo após o parto, tendo sido observadas em apenas 3,7\% das análises. Com relação aos ovos, foram observados em 6,9\% das dietas analisadas. Quanto à criação de animais, 73,6\% das famílias criavam aves (galinhas), 19,8\% suínos e $3,3 \%$ bovinos em pequena escala.

Nas festas é consumida carne bovina espetada em longos espetos de taquara, assada sobre brasas em um buraco escavado no chão e acompanhada de mandioca cozida e "puchero". O puchero é preparado com sobras de carnes, gorduras, ossos com tutano (vértebras) e temperos, cozidos sem pressa em um grande tacho até amolecer bem. É distribuído a todas as famílias da aldeia, sendo considerado iguaria de "sustância".

Quanto ao consumo de vegetais, $2,3 \%$ consumiram verduras, tais como couve, maxixe e tomate. O consumo de legumes e tubérculos foi de $53,5 \%$, representados especialmente por mandioca, batata doce e abóbora. A mandioca é considerada alimento de todas as horas e de todos os dias, acompanhando tudo o que se come. As preparações tradicionais à base de mandioca são cada vez mais raras, restritas às ocasiões especiais, como o lapâpé (beiju), o hîhi (bolo de mandioca cozido na água), xupú (massa de mandioca cozida e socada no pilão) e o pôréo (creme de mandioca).

O consumo de frutas é restrito à disponibilidade das mesmas na área, tendo sido observado apenas $1,4 \%$ de dietas com frutas adquiridas em estabelecimento comercial, nas compras do mês. Os pomares não apresentam demarcações, com livre acesso para todos, fazendo parte da área de circulação e o local preferido das crianças menores para as brincadeiras.

Nas roças familiares foi identificado o cultivo de arroz, feijão, mandioca, banana e milho. Em menores proporções, aparecem batata doce, abóbora, maxixe, quiabo, abacaxi, melancia, amendoim e cana-de-açúcar, variando de acordo com a área e a época do ano.

A diversidade de produtos cultivados não garante o consumo adequado dos mesmos, seja pela reduzida quantidade produzida, pela necessidade de comercializar ou pela ausência de um sistema de armazenamento e conservação dos produtos.

Dentre os alimentos silvestres, destaca-se o buriti, do qual tudo é aproveitado - a polpa como alimento, o tronco na construção das paredes, as folhas para cobertura das casas e produção de enfeites. 
Quanto ao consumo de produtos industrializados, foram identificados açúcar, sal, óleo de soja, goiabada, macarrão, café, farinha de trigo, leite em pó, extrato de tomate, refresco em pó, chá, refrigerantes, erva-mate, lingüiça, caramelo, pão francês e biscoitos. A maioria desses produtos mostrou-se presente na dieta de todas as famílias, uma vez que recebem uma cesta básica do programa de segurança alimentar do Governo do Estado, que é constituída de arroz, feijão, macarrão, açúcar, sal, óleo de soja, goiabada, farinha de trigo, leite em pó, extrato de tomate, erva-mate e charque. Os demais itens apareceram na dieta das famílias que dispunham de aposentadoria ou salário, sendo adquiridos no período de recebimento. Famílias com indivíduos portadores de diabetes, hipertensão e obesidade recebem as cestas com os mesmos itens, que provavelmente agravam ainda mais a doença.

O leite recebido na cesta de alimentos é destinado às crianças. Os demais produtos lácteos foram apontados como alimentos raramente consumidos. Refrigerantes são consumidos nas festas e quando realizam as compras mensais. Foi observada a presença de bebida alcoólica (aguardente), não sendo possível estimar a freqüência de consumo, uma vez que é considerada proibida nas comunidades.

\section{DISCUSSÃO}

Este estudo apresenta restrições no instrumento de avaliação do consumo de alimentos, que fornece apenas indicações da composição da dieta familiar e não da quantidade de alimentos consumidos. Apresenta ainda limitações no tocante à compreensão da riqueza e particularidades da cultura Teréna, repleta de significados sobre o consumo de alimentos.

Os baixos níveis de escolaridade materna tiveram efeito significativo sobre a prevalência de desnutrição infantil. A baixa escolaridade ou as diferenças na sua qualidade não só mantêm as condições que fazem com que a desigualdade social subsista, mas também reproduz e cria diferenças que, com o tempo, perpetuam a pobreza e a exclusão.

A aldeia Tereré apresentou melhor renda, maior número de pessoas com remuneração e maior escolaridade, o que se explica por sua localização no perímetro urbano de Sidrolândia. Nessa aldeia também foram observadas crianças com melhores condições nutricionais. Por outro lado, apresentou espaço territorial irrisório, ausência de plantações, aglomeração dos domicílios, maior número de mães adolescentes e de famílias sem a presença paterna. 
O número médio de filhos nascidos vivos nas famílias estudadas $(3,8)$ é supcrior ao observado no Estado de Mato Grosso do Sul como um todo, onde na região urbana a média é de 2,5 filhos e na região rural 3,1 (IBGH, 1999).

Com relação à cobertura do parto, foram observados $71,8 \%$ de partos hospitalares. A exceção ocorreu na aldeia Tereré, na qual 98,4\% dos partos tiveram assistência hospitalar. No entanto, um fator que poderia ter favorecido as condições de saúde das mulheres que lá residiam pode ter se convertido em prejuízo, uma ver. que 34,4\% desses partos foram operatórios. De acordo com o Ministério da Saúde (1996), a cobertura em nível nacional de partos cm instituições de saúde era de 91,5\% (Maranhão et al., 1999).

Os dados sobre baixo peso ao nascer obtidos nesse estudo (12,5\%) são supcriores aos observados na Pesquisa Nacional sobre Demografia e Saúde (PNDS/1996), onde a incidência de recém-nascidos de baixo peso era de 9,2\%, sendo $11,1 \%$ nas áreas rurais e 8,6\% nas áreas urbanas (BEMFAM, 1996). Esses valores aproximam-se de um nível considerado elevado segundo a classificação internacional (Monteiro, 1992). Cabe ressaltar que pode ter ocorrido subestimação na análise, considerando que não foram obtidas informações de 45,8\% das crianças, constituídas por aquelas nascidas nos domicílios.

A incidência de baixo peso ao nascer evidencia a necessidade imediata de atenção às mães indígenas durante a gravidez, por meio de um programa que considere os valores culturais e as peculiaridades que envolvem concepção, gestação e nascimento em uma comunidade indígena.

Com relação ao estado nutricional infantil, os valores encontrados demonstram elevada prevalência de déficits de estatura/idade (11,1\%), ultrapassando a frequiência de $2,3 \%$ esperada pela distribuição de referência (NCIS) e indicando desnutrição crônica, possivelmente iniciada ainda no útero matemo. Segundo a Pesquisa Nacional sobre Saúde e Nutrição (PNSN/1989), a prevalência de retardo de crescimento linear infantil cra de $8,2 \%$ para a Região Centro Oeste (IBGH, 1992). Na PNDS/1996, foram observados 10,5\% de déficits de estatura/idade para as crianças brasileiras menores de cinco anos (BEMFAM, 1996).

$\Lambda$ prevalência de déficits de estatura/idade foi inversamente proporcional à escolaridade materna e à faixa de renda familiar, c mais frequiente em crianças de baixo peso ao nascer. Crianças nascidas com menos de $2.500 \mathrm{~g}$ apresentaram $25,0 \%$ de déficits de estatura/idade, em contraste com 2,4\% para as crianças nascidas com $3.500 \mathrm{~g}$ ou mais. Fividencia-sc assim a importância do peso ao nascer como um indicador para a vigilância nutricional $\mathrm{em}$ recém-nascidos. Sob o ponto de vista imediato, essas variáveis poderiam ser assumidas como ele- 
mentos de predição de risco e indicação de grupos alvo de programas assistenciais. Esses resultados indicam que ações de recuperação nutricional devem ser rapidamente incorporadas à programação de assistência à saúde indígena, considerando que, em crianças com déficit de crescimento linear, poderá haver reversibilidade do déficit estatural se houver condições adequadas de recuperação, com atendimento que contemple os diversos aspectos envolvidos.

Comparando com estudos realizados em outras comunidades indígenas, a prevalência de desnutrição infantil observada é inferior às reportadas por grupos indígenas da Região Amazônica. Em 1987, entre crianças Suruí menores de cinco anos, a prevalência de retardo de crescimento infantil era de 50,6\% (Coimbra Jr. \& Santos, 1991). Entre crianças Xavánte de 0-4 anos foi encontrada a prevalência de 27,7\% no ano de 1994 e 22,0\% em 1995 (Gugelmin, 1995). Em estudo realizado entre os Enawenê-Nawê foi encontrada prevalência de $50 \%$ de déficits de estatura/idade (Weiss, 1998).

Os resultados observados nas diferentes aldeias estudadas, especialmente as diferenças entre a aldeia Tereré e as deınais, reforçam a origem nas condições de vida a que estão submetidos, uma vez que os integrantes pertencem à mesma etnia, mesma família (parentes consangüíneos) e que lá residiam antes de migrarem em busca de emprego, escola e assistência à saúde. As diferenças encontradas entre as aldeias Teréna são significativas e provavelmente estão relacionadas às melhores condições de vida em Tereré.

Em comunidade indígena Teréna, localizada em perímetro urbano de Campo Grande, Mato Grosso do Sul, que conta com projetos de assistência à saúde, incentivo ao aumento da escolaridade, geração de renda e saneamento básico, a prevalência de retardo de crescimento observada foi de 9,5\% (Ribas et al., 1999). Esta comparação poderia estar indicando a possível ação benéfica de medidas preventivas e assistenciais agindo sobre as condições nutricionais de crianças indígenas.

Cockington (1980) realizou inquérito sobre crescimento em três comunidades aborígenes australianas de diferentes condições sociais, encontrando diferenças significativas nos parâmetros de crescimento relacionados com a melhoria das condições de vida. O estudo mostrou que crianças aborígenes originárias de ambiente similar ao de crianças caucasianas apresentavam crescimento normal, não havendo diferenças significativas entre os grupos.

Pesquisadores têm registrado um contínuo processo de evolução de estatura em diferentes países (Tanner, 1978; Wieringen, 1978). As razões apontadas para explicar essa tendência secular são as melhorias das condições de vida, o desenvolvimento da saúde coletiva e a melhoria do estado nutricional. 
Modelos teóricos apontam para a multicausalidade da desnutrição (Jonsson, 1986; Monteiro \& Benício, 1981). De acordo com Jonsson (1986), o modelo causal da fome é representado por uma rede de fatores hierarquicamente encadeados, tendo origem na forma como a sociedade mobiliza os recursos potenciais para a produção de bens e serviços e como os distribui entre a população. No nível mais imediato, a fome resulta de ingestão inadequada de alimentos e do estado de saúde dos indivíduos, que por sua vez estão relacionados a fatores que refletem o acesso desigual a produtos, serviços e outros recursos como alimentos, moradia, educação, água, esgoto e serviços de saúde. A estrutura sócioeconômica determina o padrão de produção, distribuição e consumo dessas mercadorias e serviços entre os grupos de indivíduos.

Monteiro et al. (2000) analisaram as tendências temporais baseadas na comparação dos resultados de inquéritos antropométricos realizados em âmbito nacional, evidenciando que o padrão de crescimento na infância melhorou nos últimos quinze anos, em todas as regiões do Brasil, sendo que as regiões Norte e Nordeste, que registravam maiores prevalências de desnutrição em 1975, foram as que menos se beneficiaram da redução da desnutrição infantil, ampliando as diferenças regionais. As evidências de redução da desnutrição acompanham a melhoria de indicadores do nível de escolaridade da população e de saneamento ambiental.

Com relação ao estado nutricional das mães, a obesidade excede a desnutrição, demonstrando a substituição do problema de escassez de alimentos pelo excesso e inadequação da dieta entre os adultos. A prevalência de obesidade materna observada neste estudo $(9,2 \%)$ é semelhante à prevalência na população brasileira adulta (9,6\%) em 1989 (Monteiro et al., 2000).

Com relação à freqüência de alimentos, destaca-se o baixo consumo de verduras, frutas, feijão, ovos, leite e derivados e o elevado consumo de carnes gordas, a utilização de frituras no preparo dos alimentos, a elevada freqüência de alimentos ricos em açúcar (água com açúcar, caramelos, refrigerantes, doce em pasta) e ainda extrato de tomate, erva-mate, café e chá. Os dados disponíveis não permitem avaliação do consumo de álcool e sódio, apenas os apontam como elementos presentes na dieta. No caso do sódio, chama a atenção o consumo de carne salgada (charque) e de produtos enlatados recebidos na cesta de alimentos.

Com relação ao comportamento materno, é importante ressaltar o hábito de consumo de chá-mate, café e tereré. O consumo de três ou mais xícaras de café ( $\geq 300 \mathrm{mg}$ de cafeína) por dia pode resultar no aumento da incidência de baixo peso ao nascer (Narod et al., 1991). Rondó et al. (1996) verificaram que o 
consumo de café na gestação, independente da quantidade consumida, é um fator de risco para o retardo de crescimento intra-uterino.

É importante observar que o consumo elevado de gorduras de origem animal acarreta a elevação do consumo de ácidos graxos saturados e colesterol, produzindo efeitos maléficos sobre a saúde dos indivíduos e, provavelmente, aumentando os riscos da incidência de enfermidades crônicas não-transmissíveis.

As poucas famílias que comercializam o produto de suas coletas enfrentavam dificuldades em conseguir preços adlequados e competitivos no mercado, em função de inúmeros fatores. Essas familias dificilmente conseguiam manter estoques de alimentos em quantidades suficientes e tinham poucas oportunidades de desenvolver alternativas que as protegiam em épocas de escassez.

\section{CONSIDERAÇÕES FINAIS}

Os resultados deste estudo indicam que as comunidades Teréna investigadas caracterizam-se por baixo nível sócio-econômico, comprovado pela baixa renda familiar e pela baixa escolaridade. Verificou-se que a extensão das áreas indígenas é insuficiente para satisfazer a necessidade de reprodução da população existente, agravada pelo empobrecimento do solo, desmatamentos sucessivos, crescimento populacional, além de outras razões de ordem sociocultural, que levam os Teréna a buscar trabalho e sobrevivência fora das aldeias.

Nas mulheres estudadas, os percentuais de sobrepeso e obesidade são maiores que os de baixo peso, e o número de filhos por mulher e a incidência de baixo peso ao nascer são superiores aos valores regionais e nacionais. Para as crianças, a desnutrição continua sendo o problema mais relevante, especialmente os déficits de estatura.

Com relação à avaliação qualitativa da dieta, os resultados indicam monotonia e inadequação, onde o consumo de alimentos esteve determinado pela insuficiente produção local e baixa renda disponível, com aquisição de produtos de baixa qualidade e de menor custo. Foram observadas a coexistência de carências nutricionais e inadequações na composição da dieta, com elevada freqüência de alimentos ričos em gordura e açúcar e reduzida freqüência de leite e derivados, frutas e verduras. $O$ contato permanente com comunidades urbanas que circundam as aldeias e o marketing da indústria de alimentos, promove a introdução acelerada de inúmeros produtos inclustrializados de qualidade reduzida em detrimento de alimentos tradicionais. 
A garantia da alimentação de qualidade para as famílias indígenas depende do acesso à terra e de recursos agrícolas, de modo a oferecer suficiente produção doméstica, melhorando os aspectos quantitativos e qualitativos da dieta. A implementação de medidas e melhorias nas condições de vida nessas comunidades depende fortemente da atuação do setor público, ou scja, por meio de políticas efetivas e investimentos específicos, amenizando os efeitos danosos da desigualdade social. A implementação de atividlades educativas na área nutricional deve contemplar a valorização de alimentos tradicionais da cultura 'leréna, dispensando atenção para problemas de déficits nutricionais e também para os problemas decorrentes do sobrepeso. O desafio é de que, por intermédio do conhecimento das condições de vida dos povos indígenas, sejam efetuadas ações que levem melhorias às aldeias e aos seus moradores, sob a égide do princípio da eqüidade.

\section{Agradecimentos}

A Fundação de Apoio ao Desenvolvimento do Finsino, Ciência e Tecnologia do Fistado de Mato (rrosso do Sul pelo financiamento recebido (FUNDEC'T/0017/00).

\section{Referências}

BE.MFAM (Sociedade Civil Bem-Fstar Familiar no Brasil), 1996. Pesquisa Nacional Sobre Demografia e Saúde. Relatório Preliminar. Rio de Janeiro: BE.MFAM.

COCKIVGION, R. A., 1980. (Frowth of Australian aboriginal children related to social circunstance. Australian and New Zealand Joumal of Medicine, 10:199.

COIMBRA Jr., C. F. A. \& SAN'T'OS, R. V., 1991. Avaliação do estado mutricional num contexto de mudanças socioeconomicas: () grupo indígena Suruí do Vistado de Rondônia, Brasil. Cademos de Saúde Pública, 7:538-562.

FFRNANDES, J., 1993. Indio. Fsse Nosso Desconhecido. Cuiabá: Fiditora UFMT.

IBCFE (Fundação Instituto Brasilciro de (Eeografia e Fistatística), 1992. Perfil Estatístico de Crianças e Mães no Brasil. Aspectos de Saúde e Nutrição de Crianças no Brasil, 1989. Rio de Janciro: IBCil:

IBC:F, (Fundação Instituto Brasilciro de (icografia e Estatística), 1999. Pesquisa Nacional por Amostra de Domicílios. Rio de Janeiro: IBC,E.

Gu(j,I.MIII, S. A., 1995. Nutrição e Nocação de Tempo dos Xavantes de Pimentel Barbosa, Mato (Frosso: Ulm Estudo em Fcologia Humana e. Mudanças. Dissertação de Mestrado, Rio de Janciro: Fiscola Nacional de Saúde Pública, Fundação Oswaldo Crmz. 
JONSSON, V., 1986. As causas da fome. In: Fome e Desnutrição: Determinantes Sociais (F. L. S. Valente, org.), pp. 48-65, São Paulo: Cortez.

LOHMAN, T. G.; ROCHE, A. F. \& MARTORELL, R., 1988. Anthropometric Standardization Reference Manual. Urbana: Human Kinetics.

MARANHÃO, A. G. K.; JOAQUIM, M. M. C. \& SIU, C., 1999. Mortalidade perinatal e neonatal no Brasil. Um desafio para os serviços de saúde. Tema Radis, 17:6-17.

MONTEIRO, C. A. \& BENÍCIO, M. H. A., 1981. Epidemiologia da desnutrição proteicocalórica. In: Desnutrição Intra-uterina e Pós-natal (F. J. Nóbrega, org.), pp. 120-129, São Paulo: Panamed.

MONTEIRO, C. A.; BENÍCIO, M. H. A.; GoUveiA, N. C. \& CARDOSO, M. A. A., 2000. Evolução da desnutrição infantil. In: Velhos e Novos Males da Saúde no Brasil (C. A. Monteiro, org.), pp. 93-114, São Paulo: Editora Hucitec.

MONTEIRO, M. F. G., 1992. Baixo peso ao nascer. In: Perfil Estatístico de Crianças e Mães no Brasil. Aspectos de Saúde e Nutrição no Brasil 1989, pp. 11-18, Rio de Janeiro: Fundação Instituto Brasileiro de Geografia e Estatística.

NAROD, S. A.; SANJOSE, S. \& VICTORA, C., 1991. Coffee during pregnancy: A reproductive hazard? American Joumal of Obstetrics and Gynecology, 164:1 109-1114.

OBERG, K., 1949. The Teréna and the Caduveo of Southern Mato Grosso, Brazil. Washington, DC: Institute of Social Anthropology.

OLIVEIRA, S. P. \& THÉBAUD-MONY, A., 1997. Estudo do consumo alimentar: em busca de uma abordagem multidisciplinar. Revista de Saúde Pública, 31:201-208.

PAULETTI, M., 2000. O Direito Indígena no Ordenamento Brasileiro: Uma Responsabilidade da União. Dissertação de Mestrado, Campo Grande: Universidade Católica Dom Bosco.

RIBAS, D. L. B., 2001. Saúde e Nutrição de Crianças Indígenas Teréna, Mato Grosso do Sul, Brasil. Tese de Doutorado, São Paulo: Faculdade de Saúde Pública, Universidade de São Paulo.

RIBAS, D. L. B.; ZORZATTO, J. R. \& PHILIPPI, S. T., 1999. Nutrição de crianças indígenas. In: Congresso Latino-Americano de Nutrição Humana; Resumos, p. 120, Gramado: Conselho Regional de Nutricionistas.

RONDÓ, P.H.; RODRIGUES L.C. \& TOMKINS, A.M., 1996. Coffee consumption and intrauterine growth retardation in Brazil. European Journal of Clinical Nutrition, 50:705-709.

ROSA, J. G., 1985. Ave, Palavra. Rio de Janeiro: Civilização Brasileira.

SILVA, F. A., 1949. Mudança cultural dos Teréna. Revista do Museu Paulista, 3:271-280.

TANNER, J. M., 1978. A concise history of growth studies from Buffon to Boas. In: $\mathrm{Hu}$ man Growth (F. Falkner \& J. M. Tanner, ed.), pp. 515-593, New York: Plenum Press.

WEISS, M. C. V., 1998. Contato Interétnico, Perfil Saúde-doença e Modelos de Intervenção Mínima: O Caso Enawene-Nawe em Mato Grosso. Tese de Doutorado, Rio de Janeiro: Escola Nacional de Saúde Pública, Fundação Oswaldo Cruz.

WIERINGEN, J. C., 1978. Secular growth changes. In: Human Growth (F. Falkner \& J. M. Tanner, ed.), pp. 445-473. New York: Plenum Press.

WHO (World Health Organization), 1995. Physical Status: The Use and Interpretation of Anthropometry. WHO 'Technical Report Series 854. Geneva: WHO. 


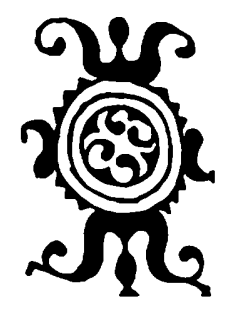

CONDIÇÃO NUTRICIONAL

DE UM GRUPO DE IDOSOS INDÍGENAS

NO DISTRITO SANITÁRIO LESTE

DE RORAIMA

\section{Ana Felisa IIurtado Guerrero, Fvelyne Marie Therese Mainbourg, José Camilo Hurtado Guerrero}

A condição nutricional dos idosos é determinada por vários fenômenos complexos e ć reflexo de fatores sócio-econômicos, geográficos/climáticos, estado da saúde (psíquico e físico), carência de uma atenção específica em saúde e falta de acesso a serviços especializados, cntre outros (Chen, 1986).

() envelhecimento resulta de um processo histórico, fazendo com que o estado nutricional do idoso não dependa somente da disponibilidade de adquirir alimentos, mas também da sua capacidade funcional e das transformações do seu estilo de vida. Dessa maneira, o estado nutricional pode contribuir na instalação, duração ou melhoria de processos mórbidos e, por conscguinte, na qualidade de vida deste segmento populacional (Monsen, 1998). O efeito da nutrição sobre a causa e severidade das doenças na idade avançada, assim como seu papel como elemento ctiológico de doenças crônico-degenerativas, é indiscutível (Kafatos et al., 1993; Peña ct al., 1998).

Fistudos realizados em diversas regiões do Brasil vêm mostrando mudanças na situação sócio-econômica, demográfica, cultural e nutricional de algumas populações indígenas. Essas mudanças refletem-se, principalmente, nas faixas etárias mais vulneráveis (crianças e idosos), fazendo com que apresentem elevadas taxas de morbinortalidade, em geral ligadas à pobreza (Coimbra Jr. \& Santos, 200(); Santos \& Fiscobar, 2001).

Na Amazônia, há escasse\% de estudos que abordem a dimensão ćtnicoracial e suas implicações nos agravos à saúde. As minorias ćtnicas, como as populações indígenas, sobrevivem em situlações de exclusão e desigualdades sociais que as colocam em posição de maior vulncrabilidade frente aos diversos agravos de saúde (Coimbra Jr. \& Santos, 200(0)). $\Lambda$ não satisfação das necessidades básicas dos idosos indígenas (alimentação, vestuário, moradia, etc.) colocam-nos em críticas condições nutricionais, agravadas pela falta de uma vigilância em sańde que resolva os problemas específicos que atingem este segmento populacional.

Segundo dados do Sistema de Informações da Atenção à Saúde lndígena - SLASI, nas nove regiõos que compõem a área Leste de Roraima, existem 
aproximadamente 804 idosos, representando aproximadamente 3,5\% da população total (22.979). Entre os Yanomámi, a esperança de vida ao nascer (38,5 anos homens; 40,5 anos mulheres) é uma das médias mais baixas constatadas para o Brasil e a Venezuela (Early \& Peter, 1990, apud Coimbra Jr. \& Santos, 2000). Pesquisa realizada por Santos \& Coimbra Jr. (1994), no sudoeste da Amazônia, também constatou o reduzido número de idosos entre grupos Tupí-Mondé (Gavião, Suruí, Zoró), situação que pode estar sendo influenciada pelas precárias condições de vida e desigualdades sociais que enfrentam.

Esta pesquisa teve como objetivo avaliar a condição nutricional de um grupo de idosos indígenas procedentes de diferentes etnias do Distrito Sanitário Especial Indígena (DSEI) Leste de Roraima, com o intuito de contribuir para o conhecimento da problemática de saúde do idoso nessa região.

\section{POPULAÇÃO E MÉTODOS}

O DSEI Leste de Roraima situa-se no nordeste do Estado de Roraima, na região de fronteira do Brasil com a Venezuela e a Guiana. Este está composto por nove regiões (Amajari, Baixo Cotingo, Serras, Surumu, Serra da Lua, São Marcos, Taiano, Raposa e Wai-Wai), com 204 comunidades. Essas terras são habitadas por indígenas Makuxí, Wapixána, Taurepáng, Ingarikó, Patamona e Waiwái.

A pesquisa foi conduzida entre abril e junho de 2001 (período de seca). Os dados analisados fazem parte do desdobramento de um estudo transversal denominado Perfil Nutricional das Populações Indígenas do Distrito Sanitário Leste de Roraima. A população investigada foi constituída por um grupo de 68 idosos Makuxí, Wapixána, Taurepáng e outros (com exceção dos Waiwái).

As informações obtidas incluíram: idade, sexo, dosagem de hemoglobina, antropometria (peso, estatura e circunferência braquial) e percentual de gordura corporal. O diagnóstico da anemia foi realizado por meio da dosagem de hemoglobina (Hb) em um hemoglobinometro portátil (HemoCue), utilizando microcuvetas descartáveis (b-hemoglobin, Suécia/Estados Unidos). Para a definição de anemia, foram empregados os valores estabelecidos pela Organização Mundial da Saúde (WHO, 1975) (em mulheres, inferior a 12g/dl e em homens, inferior a $13,0 \mathrm{~g} / \mathrm{dl}$ ). O peso foi obtido em balança de plataforma, da marca Kratos, com precisão de $1,25 \mathrm{~kg}$ e capacidade máxima de $150 \mathrm{~kg}$. A estatura foi obtida utilizando-se um antropômetro, não dobrável, seguindo-se as técnicas recomendadas por Matsudo (2000). O estado nutricional foi estimado por meio do índice 
de massa corporal (IMC) utilizando-se a equação (peso em quilograma)/(estatura em metro ao quadrado). Foram empregados os pontos de corte propostos pela OMS (WHO, 1995), que recomenda a seguinte classificação para idosos (homens e mulheres): desnutrição ou peso abaixo do normal (IMC $<18,5$ ); normal $(18,5<\mathrm{IMC}<25)$; sobrepeso ( $25<\mathrm{IMC}<30$ ); obesidade (IMC $\geq 30$; Grau I 30,0-34,9; Grau II 35,0-39,9 e Grau III $\geq 40,0$ ). A circunferência braquial (CB) foi determinada seguindo-se as recomendações de Guedes \& Guedes (1998). Para tal, utilizou-se uma fita métrica flexível, com precisão de $0,1 \mathrm{~mm}$ e adotaramse os pontos de corte estabelecidos por Jellife (1968). A determinação do percentual de gordura corporal (PGC) foi realizada por meio da técnica Tanita Bia, utilizando-se uma balança modelo TBF-531.

A análise dos dados foi descritiva (média, desvio padrão, porcentagens) e inferencial (correlação de Spearman) (Zar, 1996).

\section{RESULTADOS}

Idosos da etnia Makuxí $(80,9 \%)$ predominaram na amostra, seguidos dos Wapixána $(14,7 \%)$, Taurepáng $(1,5 \%)$ e outras $(2,9 \%)$. A distribuição segundo região apresentou a seguinte composição: Serras (41,2\%), São Marcos (16,2\%), Raposa $(13,2 \%)$, Serra da Lua (10,3\%), Surumu (10,3\%), Amajari $(5,9 \%)$ e Taiano $(2,9 \%)$. Quanto ao sexo, $58,8 \%$ eram do sexo feminino e $41,2 \%$ do masculino. Média e desvio-padrão de idade para os sexos combinados foram $72,1 \pm 8,8$ anos $(73,3 \pm 9,6$ para as mulheres e $70,5 \pm 7,5$ para os homens). Predominância feminina foi encontrada em quase todas as faixas etárias, especialmente na mais avançada.

Algumas variáveis como peso, estatura, $\mathrm{IMC}$ e $\mathrm{CB}$, apresentaram valores médios superiores para os homens. Já para PGC os valores médios são mais elevados no sexo feminino (Tabela l). Os Wapixána apresentaram os maiores valores médios de peso, IMC, PGC e CB (Tabela 2). Os idosos indígenas da região de Surumu apresentaram os valores médios mais baixos de peso, estatura e de PGC. Os valores médios mais baixos de IMC e CB foram encontrados na região da Raposa (Tabela 3).

Com relação ao estado nutricional, $2,9 \%$ dos idosos encontravam-se com desnutrição, $33,8 \%$ com sobrepeso, $1,5 \%$ com obesidade. Aqueles com valores adequados somaram $61,8 \%$. Nas mulheres, evidenciou-se a maior prevalência de baixo peso $(5,0 \%)$. Os homens mostraram uma maior prevalência de sobrepeso $(42,9 \%)$ e de obesidade $(3,6 \%)$ (Tabela 4$)$. A freqüência de valores com- 
Tabela 1

\begin{tabular}{|c|c|c|c|c|c|c|c|c|c|}
\hline \multirow[t]{3}{*}{ Variáveis } & \multirow{2}{*}{\multicolumn{3}{|c|}{ Feminino }} & \multirow{2}{*}{\multicolumn{3}{|c|}{$\begin{array}{c}\text { Sexo } \\
\text { Masculino }\end{array}$}} & \multirow{3}{*}{\multicolumn{2}{|c|}{$\begin{array}{c}\text { Total } \\
(\mathrm{X})\end{array}$}} & \multirow[b]{3}{*}{ (D. P.) } \\
\hline & & & & & & & & & \\
\hline & $n$ & $(\mathrm{X})$ & (D. P.) & $\mathrm{n}$ & $(\mathbf{X})$ & (D. P) & & & \\
\hline Idade (anos) & 40 & 73,30 & 9.56 & 28 & 70,50 & 7,54 & 68 & 72,10 & 8,83 \\
\hline Estatura (m) & 40 & 1,43 & 0,03 & 28 & 1,55 & 0,05 & 68 & 1,48 & 0,07 \\
\hline Massa Corporal (kg) & 40 & 47,59 & 6,93 & 28 & 59,68 & 8,40 & 68 & 52,57 & 9,61 \\
\hline IMC $\left(\mathrm{kg} / \mathrm{m}^{2}\right)$ & 40 & 23,28 & 3,06 & 28 & 24,96 & 3,32 & 68 & 23,97 & 3,25 \\
\hline PGC (\%) & 39 & 23,69 & 8,13 & 28 & 18,86 & 6,46 & 67 & 21,67 & 7,81 \\
\hline $\mathrm{CB}(\mathrm{cm})$ & 40 & 26,06 & 2,65 & 28 & 28,71 & 2,39 & 68 & 27,15 & 2.85 \\
\hline
\end{tabular}

Tabela 2

Estatísticas descritivas (média e desvio-padrão) das variáveis antropométricas segundo etnia em idosos do DSEI Leste, Roraima, Brasil.

\begin{tabular}{|c|c|c|c|c|c|c|c|c|c|c|c|}
\hline \multirow[t]{2}{*}{ Etnia } & \multirow[t]{2}{*}{$\mathbf{n}$} & \multicolumn{2}{|c|}{ Estatura (m) } & \multicolumn{2}{|c|}{$\begin{array}{c}\text { Massa } \\
\text { Corporal (Kg) }\end{array}$} & \multicolumn{2}{|c|}{$\begin{array}{c}\text { IMC } \\
\left(\mathrm{Kg} / \mathrm{m}^{2}\right)\end{array}$} & \multicolumn{2}{|c|}{ PGC (\%) } & \multicolumn{2}{|c|}{$\mathrm{CB}(\mathrm{cm})$} \\
\hline & & $(\mathrm{X})$ & (D. P.). & $(\mathrm{X})$ & (D. P.) & $(\mathrm{X})$ & (D. P.). & $(\mathrm{X})$ & (D. P.). & $(\mathrm{X})$ & (D. P.). \\
\hline Macuxi & 55 & 1,48 & 0,07 & 51,7 & 8,18 & 23,3 & 2,61 & 20,8 & 7,74 & 26,7 & 2,63 \\
\hline Wapixana & 10 & 1,47 & 0.06 & 56,7 & 10,75 & 26,0 & 3,72 & 25,2 & 7,72 & 28,7 & 3,11 \\
\hline Outros" & 3 & 1,51 & 0,05 & 66,3 & 18,40 & 28,9 & 6,17 & 25,0 & 7.86 & 30,0 & 3,46 \\
\hline
\end{tabular}

* Taurepang e outros não identificados.

patíveis com má nutrição, por carência ou por excesso, esteve com os idosos mais longevos (80 e mais anos): desnutrição $(10,0 \%)$ e obesidade $(5,0 \%)$; enquanto que o sobrepeso foi encontrado nos idosos mais jovens, especialmente na faixa etária de 60 a 69 anos (42,9\%) (Tabela 5).

Do total de idosos analisados, 47,8\% mostraram PGC adequados, $26,9 \%$ elevados e $25,4 \%$ baixos. Idosos de sexo feminino mostraram valores elevados $(30,8 \%)$ e baixos $(17,9 \%)$ de PGC, enquanto que o sexo masculino apresentou a maior freqüência de valores baixos $(35,7 \%)$ e elevados $(21,4 \%)$. Vale a pena ressaltar que a grande maioria dos idosos apresentou valores adequados de gordura: 
Tabela 3

Estatísticas descritivas (média e desvio-padrão) das variáveis antropométricas em idosos do DSEI Leste segundo etnia, Roraima, Brasil.

\begin{tabular}{|c|c|c|c|c|c|c|c|c|c|c|c|}
\hline \multirow[t]{2}{*}{ Regiões } & \multirow[t]{2}{*}{$\mathbf{n}$} & \multicolumn{2}{|c|}{ Estatura (m) } & \multicolumn{2}{|c|}{$\begin{array}{c}\text { Massa } \\
\text { Corporal }(\mathrm{Kg})\end{array}$} & \multicolumn{2}{|c|}{$\begin{array}{c}\text { IMC } \\
\left(\mathrm{Kg} / \mathbf{m}^{2}\right)\end{array}$} & \multicolumn{2}{|c|}{$\operatorname{PGC}(\%)^{*}$} & \multicolumn{2}{|c|}{$\mathrm{CB}(\mathrm{cm})$} \\
\hline & & $(\mathrm{X})$ & (D. P.). & $(\mathrm{X})$ & (D. P.). & $(\mathrm{X})$ & (D. P.). & $(\mathrm{X})$ & (D. P.) & $(\mathbf{X})$ & (D. P.). \\
\hline Serras & 28 & 1,48 & 0,07 & 50,8 & 8,67 & 23,1 & 2,68 & 19,9 & 8,70 & 26,7 & 2,84 \\
\hline Raposa & 9 & 1.49 & 0,07 & 50,4 & 7,11 & 22,7 & 2,08 & 21,5 & 6,78 & 26,1 & 2,14 \\
\hline Amajari & 4 & 1,50 & 0,10 & 63,9 & 6,84 & 28,3 & 1,33 & 28,2 & 7,22 & 30,5 & 1,01 \\
\hline Taiano & 2 & 1,47 & 0,04 & 51,1 & 2,75 & 23,7 & 2,67 & 20,7 & 10,25 & 27,2 & 1,76 \\
\hline Serra da Lua & 7 & 1,46 & 0,05 & 53,8 & 15,36 & 24,9 & 5,23 & 23,1 & 7,91 & 27,2 & 3,09 \\
\hline Surumu & 7 & 1,43 & 0,08 & 47,0 & 8,94 & 22,8 & 2,62 & 19,8 & 4,46 & 26,3 & 7,36 \\
\hline São Marcos & 11 & 1,50 & 0,07 & 57,8 & 7,24 & 25,8 & 3,13 & 24,4 & 7,14 & 28,4 & 3,17 \\
\hline Total & 68 & 1,48 & 0,07 & 52,6 & 9,61 & 23.9 & 3,25 & 21,7 & 7,81 & 27,1 & 2,85 \\
\hline
\end{tabular}

Nota: "Corresponde a 67 indivíduos (8 em Raposa).

Tabela 4

Distribuição absoluta e relativa das categorias do índice de massa corporal (IMC), segundo sexo em idosos do DSEI Leste, Roraima, Brasil.

\begin{tabular}{|c|c|c|c|c|c|c|}
\hline \multirow[t]{3}{*}{ Categorias de IMC } & \multicolumn{6}{|c|}{ Estado Nutricional } \\
\hline & \multicolumn{2}{|c|}{ Feminino } & \multicolumn{2}{|c|}{ Masculino } & \multicolumn{2}{|c|}{ Total } \\
\hline & $\mathrm{n}$ & $\%$ & $\mathrm{n}$ & $\%$ & $\mathrm{n}$ & $\%$ \\
\hline Baixo peso & 2 & 5 & 0 & 0,0 & 2 & 2,94 \\
\hline Adequado & 27 & 67,5 & 15 & 53,6 & 42 & 61,76 \\
\hline Sobrepeso & 11 & 27,5 & 12 & 42,9 & 23 & 33,82 \\
\hline Obesidade & 0 & 0,0 & 1 & 3,6 & 1 & 1,47 \\
\hline Total & 40 & 100 & 28 & 100 & 68 & 100 \\
\hline
\end{tabular}


Tabcla 5

Distribuição absoluta e relativa das categorias do indice de massa corporal (IMC), scgundo faixa etária em idosos do DSEI l este. Roraima. Brasil.

\section{Categorias IMC}

$n^{60)-69} \%$

Baixo peso

Adequado

Sobrepeso

Obesidade

Total

$\begin{array}{cc}0 & 0.0 \\ 16 & 57.1 \\ 12 & +2.9 \\ 0 & 0.0 \\ 28 & 100\end{array}$

$51,3 \%$ nas mulheres e $42,9 \%$ nos homens. Os idosos na faixa etária de 80 e mais anos mostraram os valores mais baixos $(40,0 \%)$, enquanto que na faixa ctária de 60 a 69 anos apresentaram os valores mais elevados $(40,7 \%)$.

Foi constatada una associação positiva $\left(\mathrm{r}_{\mathrm{S}}=0,352\right)$, e estatisticamente significativa ( $\mathrm{p}=0,004$, teste t-student) entre IMC e PGC. A anemia apresentou uma associação negativa con IMC $\left(r_{S}=-0,122\right)$, mas essa associação não foi estatisticamente significativa $(\mathrm{p}=0,338)$. Não obstante, a correlação de anemia com PCC ( $\mathrm{r}_{\mathrm{s}}=-(0,277)$ foi estatisticamente significativa $(\mathrm{p}=0,028)$. Observou-se uma associação negativa cntre a idade e as variáveis peso $\left(\mathrm{r}_{\mathrm{S}}=-0,306 ; \mathrm{p}=0,01 \mathrm{l}\right)$, $\operatorname{IMC}\left(r_{S}=-0,277 ; p=0,014\right)$ e estatura $\left(r_{S}=-(), 169 ; p=0,169\right)$ e PGC $\left(r_{S}=-\right.$ $0,219 ; \mathrm{p}=0,075)($ Figura 1$)$.

A média de hemoglobina foi menor nos idosos Wapixána ( $11,7 \mathrm{~g} / \mathrm{dl})$ quando comparada com os Makuxí ( $12,8 \mathrm{~g} / \mathrm{dl})$. No tocante às regiões, os valores médios foram, em ordem crescente: Taiano ( $11,60 \pm 1,2 \mathrm{~g} / \mathrm{dl})$, Raposa $(11,63 \pm 2,07 \mathrm{~g} / \mathrm{dl})$, Surumu ( $11,72 \pm 0,80 \mathrm{~g} / \mathrm{dl})$, Amajari $(1 \mathrm{l}, 82 \pm 2,19 \mathrm{~g} / \mathrm{dl})$ e Serras $(13,45 \pm 1,63 \mathrm{~g} / \mathrm{dl})$.

A maioria dos idosos não apresentou anemia $(71,1 \%$ mulheres c $55,6 \%$ homens). No sexo masculino houve uma maior porcentagem de indivíduos anêmicos $(44,4 \%)$, enquanto que nas mulheres foi de $29,0 \%$. A distribuição da severidade de anemia por faixa etária mostrou maiores porcentagens para a anemia moderada na faixa etária de 60-69 anos (10,7\%) e anemia leve nos idosos de 70$79 \operatorname{anos}(30,0 \%)$ (Figura 2). 
Figura 1

Correlação de Spearman entre algumas variáceis antropontétricas e idade $\mathrm{cm}$ idosos indígenas do Distrito L este de Roraima, Brasil.
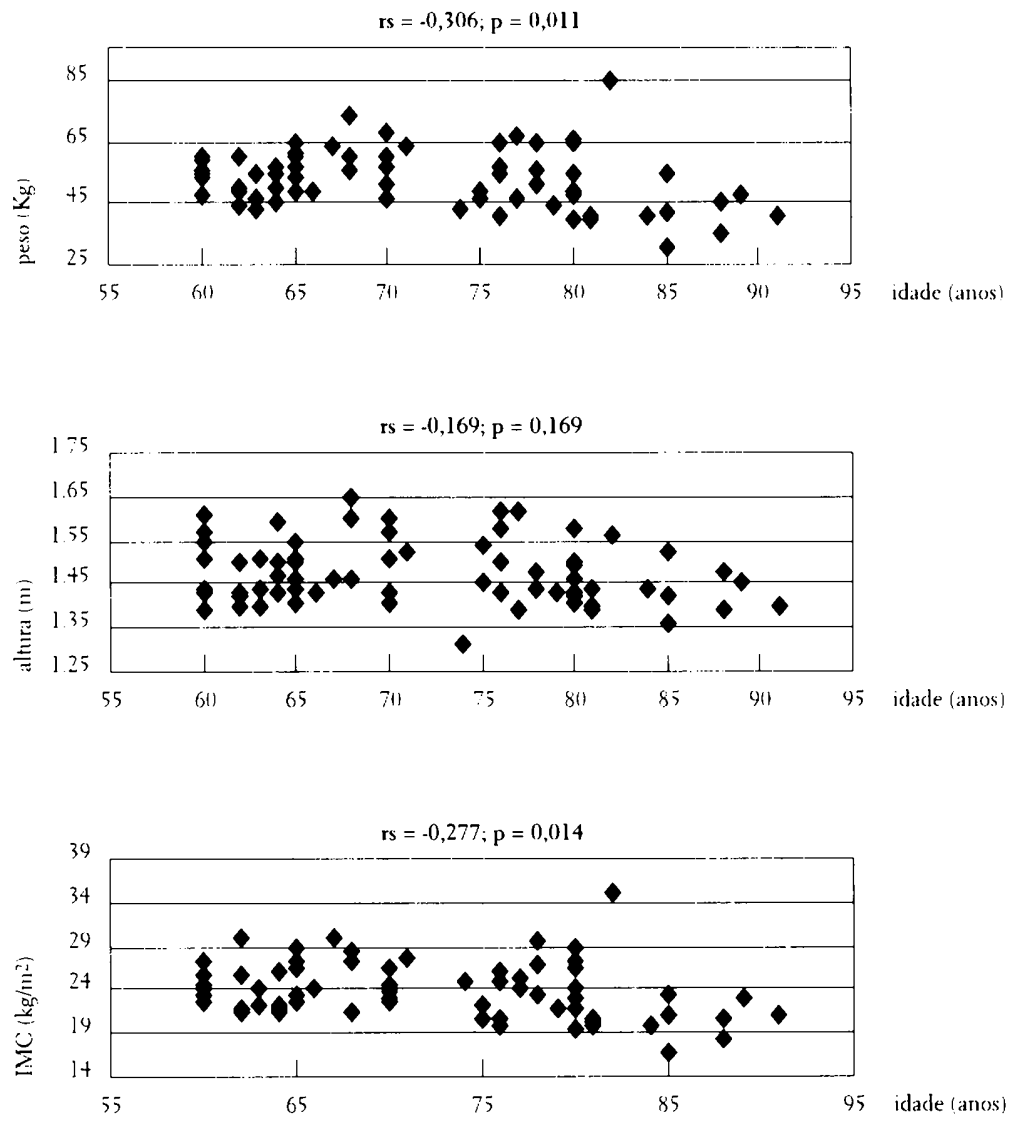

$\mathrm{rs}=-0,219 ; \mathrm{p}=0,075$

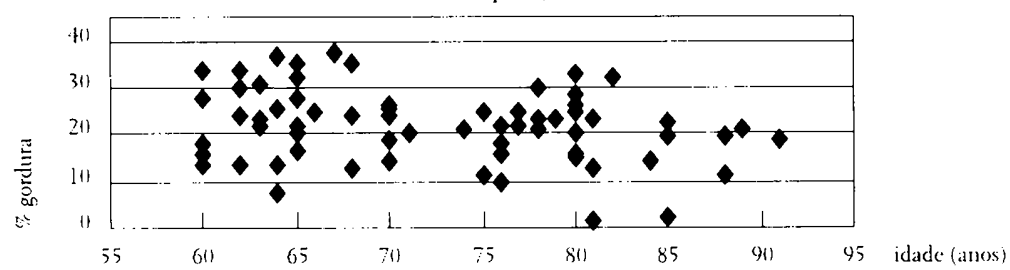


Distribuição relativa da severidade da anemia segındo faixa etária nos idosos indígenas do Distrito Leste de Roraima, Brasil.

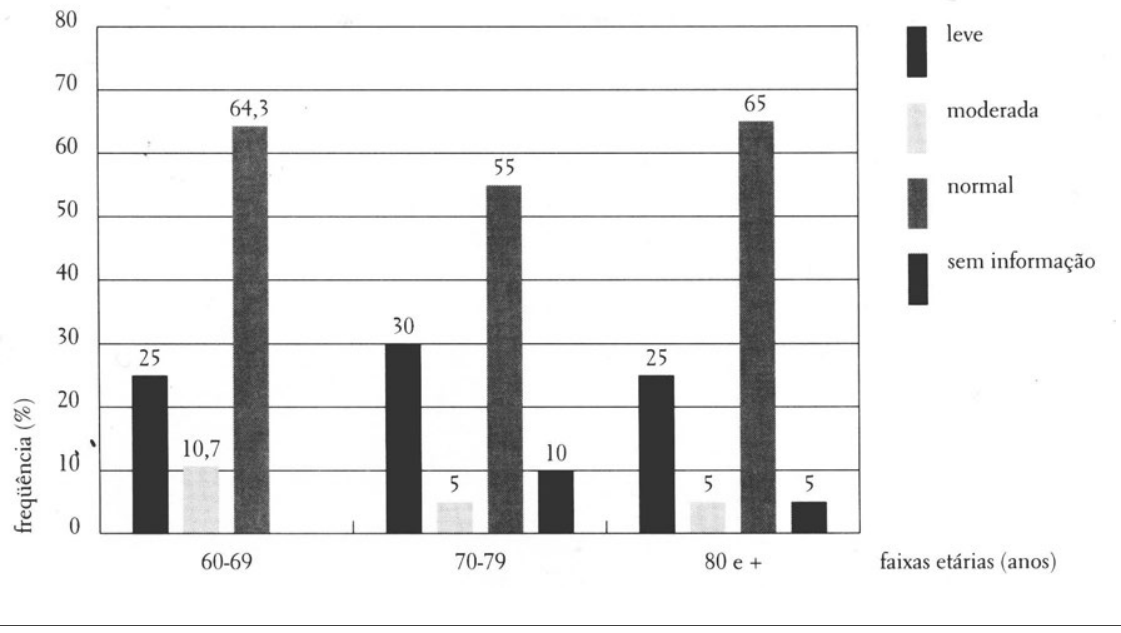

\section{DISCUSSÃO}

$\mathrm{Na}$ população idosa estudada, observou-se uma predominância do sexo feminino, o que coincide com a maioria dos resultados encontrados em outros estudos realizados com idosos no Brasil nas últimas décadas (Tavares \& Anjos, 1999; Veras, 1994). Contudo, esta observação não pode ser generalizada por se limitar a um grupo específico que não representa na sua totalidade a população idosa do DSEI Leste de Roraima.

Os valores médios da estatura mostraram-se bem próximos dos obtidos por Hurtado-Guerrero (2000), em uma população idosa cabocla do Amazonas $(1,55 \pm 0,06 \mathrm{~m}$ no sexo masculino e $1,46 \pm 0,05 \mathrm{~m}$ no feminino). Não obstante, fo-

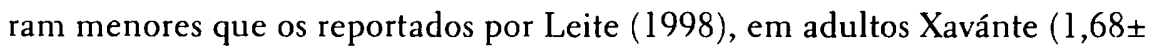
$0,05 \mathrm{~cm}$ e $1,70 \pm 0,02 \mathrm{~cm}$ no sexo masculino, $1,58 \pm 0,05 \mathrm{~cm}$ e $1,49 \pm 0,01 \mathrm{~cm}$ nas mulheres das faixas etárias de 60 a 69 e maiores de 70 anos, respectivamente). Estudo realizado por Faintuch et al. (1983), em uma população idosa do Centro-Sul do país, também reportou estaturas superiores $(1,70 \mathrm{~m}$ nos homens e 
1,58m nas mulheres) àquelas obtidas na presente investigação, do mesmo modo que James \& Schofield (1994), na população idosa brasileira do Nordeste e Sul.

Diversos estudos, tal como o presente, têm demonstrado que, à medida que a idade avança, tanto a estatura como o peso corporal declinam em homens e mulheres (Chumlea \& Baugartner, 1989; Rossman, 1977; Steen, 1988). Pessoas idosas podem sofrer uma perda progressiva de estatura, entre $5-6 \mathrm{~cm}$ a partir dos 65 anos, pela degeneração dos discos vertebrais (MS, 1998).

Há também evidências demonstrando que a estatura dos idosos varia fortemente de um país para outro, e que as condições ambientais e nutricionais durante a infância interagem com o potencial genético do indivíduo para determinar a estatura final. O estudo de Bannerman et al. (1997) constatou que inúmeros fatores podem influenciar os valores antropométricos em idosos maiores de 65 anos, entre os quais as diferenças geográficas ocupam um destaque especial. Portanto, a estatura do adulto é resultado de um processo histórico, relacionado com a satisfação das necessidades sócio-econômicas, assistência à saúde, saneamento e higiene, entre outras (Hurtado-Guerrero, 2000). Pode-se hipotetizar que a baixa estatura na população idosa do Amazonas não está sendo somente influenciada pelas alterações corporais durante a velhice ou devido à questão genética, senão que pode derivar das perpetuadas desigualdades sociais (especialmente carência de alimento) e das condições precárias de saúde em que ainda sobrevivem as populações desta região.

Os valores de peso encontrados no presente estudo mostraram-se próximos daqueles referidos por Hurtado-Guerrero (2000) (59,2 $210,8 \mathrm{~kg}$ no sexo masculino; $53,6 \pm 12,5 \mathrm{~kg}$ no feminino). Contudo, foram divergentes dos reportados por Leite (1998), entre os Xavánte $(68,30 \pm 2,11 \mathrm{~kg}$ e $74,07 \pm 9,74 \mathrm{~kg}$ em homens; $72,62 \pm 5,23 \mathrm{~kg}$ e $63,83 \pm 12,57 \mathrm{~kg}$ nas mulheres da faixa etária de $60-69$ e maiores de 70 anos, respectivamente). Ao compará-los com os dados de James \& Schofield (1994), evidencia-se similaridade com a população do Nordeste e divergência com a do Sul do Brasil.

Os valores mais baixos das diversas variáveis antropométricas foram observados nas regiões mais distantes, como Surumu, enquanto que em regiões mais centrais, como Amajari, foram observados valores mais elevados. Esse padrão parece estar associado à localização das comunidades indígenas em relação aos centros urbanos, embora esta seja uma questão que precise ser analisada mais detalhadamente em futuros estudos.

Fmbora a maioria dos idosos investigados tenha apresentado um estado nutricional adequado, alguns casos de desnutrição e de obesidade foram observa- 
dos. O sexo feminino mostrou maior prevalência de baixo peso, especialmente nas pessoas mais longevas. Estudos como os de Hurtado-Guerrero (2000) e Tavares \& Anjos (1999) também evidenciaram maiores freqüências de desnutrição na população idosa do sexo feminino. Por outro lado, Leite (1998), não observou baixo peso na população feminina Xavánte.

Entre os distúrbios nutricionais mais observados na população idosa, encontra-se a desnutrição protéico-calórica, geralmente relacionada com aumento da morbidade e imunossupressão (Otero et al., 2002). Segundo Ferriolli et al. (2000), o comprometimento do estado nutricional do idoso guarda relação com as funções imunológicas, com a periodicidade e ocorrência de internações e reinternações, evolução/prognóstico da enfermidade, desempenho de atividades da vida diária e qualidade de vida. Silva \& Barros (2002) mostraram que a desnutrição neste segmento populacional continua sendo também um fator de risco significativamente associado a maiores porcentagens de morbidade e mortalidade até no âmbito hospitalar, e que fatores como apoio familiar e nível de escolaridade poderiam contribuir para sua prevenção. A desnutrição geralmente afeta em maior proporção mulheres idosas de países em desenvolvimento e tende a se agravar em períodos de escassez alimentar (Veras, 1994). Na mulher idosa, o gasto energético é significativamente maior que aquele das mulheres adultas jovens (Voorrips et al., 1991).

A prevalência de desnutrição detectada na população investigada pode estar influenciada por aspectos como dependência funcional e/ou comprometimento de saúde, localização geográfica e clima (os críticos períodos de seca, especialmente durante os meses de abril e maio, podem constituir fator importante na oferta de alimentos, assim como favorecer o risco de adoecer). O prazer de alimentar-se também é influenciado por fatores psicossociais. Dessa forma, a presença da família motiva o idoso a alimentar-se nas horas certas, assim como constitui um apoio fundamental no preparo dos alimentos, especialmente, para aqueles que apresentam uma saúde funcional comprometida.

A obesidade constitui uma questão a ser ressaltada, já que geralmente nos idosos indígenas são relatados casos cle má nutrição, caracterizados por carência e não por excesso, o que poderia constituir um sinal de aparecimento de doenças crônico-degenerativas. Esta situação vem sendo encontrada no perfil nutricional de populações indígenas, como os Xavánte (Leite, 1998) e em grupos da América do Norte (Young, 1988).

As mudanças na composição corporal durante o envelhecimento encontram-se relacionadas com a diminuição da massa magra e aumento da gordura 
corporal, processo favorecido pela falta de atividade física (Ioffman, 1993). As mulheres mostraram frequicencias mais clevadas de percentual de gordura. A deposição de gordura corporal nas mulheres pode ser favorecida pela menopausa, que acelera a perda de massa magra e massa mineral óssea, principalmente a partir dos três anos de sula instalação (Aloia et al., 1991; Anselmo et al., 1992). A distribuição de gordura no organismo é de extrenna rclevância, já que é o tecido de fonte direta de energia (Navarro \& Marchini, 200(0) e na desnutrição protéico cnergética a massa corporal magra é utilizada como fonte energética, podendo levar ao óbito quando sua perda alcança entre 30-50\% (Bishop, 1984, apud $\mathrm{Na}$ varro \& Marchini, 2000; Blackburn ct al., 1997, apud Navarro \& Marchini, 2000); Jensen, 1992, apud Navarro \& Marchini, 2000).

() excesso de gordura corporal favorece a instalação de doenças crônicodegenerativas (Navarro \& Marchini, 2000), como hipertensão, hiperlipidcmia, diabetes tipo II e mortalidade prematura, principalmente quando se excede $20 \%$ do peso corporal total (Pauliot et al., 1994, apud Navarro \& Marchini, 2000).

Os homens mostraram-se com maiores frequiências de excesso de peso e menores porcentagens de gordura corporal. Frutuoso \& Conde (200)2), estudando uma população adulta, observaram que apesar do IMC acompanhar as variações de massa gorda, não necessariamente guardam uma relação estreita. 'Tal constatação permite-nos levantar a hipótese de que uma maior quantidade de massa magra possa estar favorecendo o sobrepeso no sexo masculino. Contudo, já que não foram coletadas medidlas antropométricas complementares, não se pode afirmar que esse sobrepeso scja devido a menores porcentagens de gordura corporal encontradas neste sexo.

Constatou-se una frequiência de $33,8 \%$ de sobrepeso nos idosos indígenas estudados, predominando nos homens. Esse resultado é similar ao reportado por Hurtado-Guerrero (2000) em uma população idosa cabocla do Amazonas $(35,8 \%$ ) e por Leite (1998), entre os Xavánte. Porém, os resultados divergem daqueles encontrados para esta mesma faixa etária por Tavares \& Anjos (1999), num estudo da Pesquisa Nacional sobre Saúde e Nutrição (PNSN) para a população brasileira.

Sobrepeso não necessariamente ć sinônimo de excesso de gordura corporal. Por exemplo, cm comunidades rurais este excesso pode ser devido ao aumento de massa muscular, resultado de atividarle física intensa (Lcite, 1998). $\mathrm{Al}$ guns estudos vêm questionando a idéia de que o aumento do peso pode constituir risco de instalação da obesidade, especialnente em populações idosas de zonas urbanas em países desenvolvidos (Kučmarski ct al., 1994). Kista condição 
pode ser relevante em grupos de idosos que realizam pouca atividade física (Hurtado-Guerrero, 2000).

A CB mostrou valores médios superiores para o sexo masculino. No estudo de Leite (1998), foi observada uma situação contrária $(30,10 \pm 1,64 \mathrm{~cm}$ e $30,86 \pm 3,31 \mathrm{~cm}$ nos homens; $32,12 \pm 3,57 \mathrm{~cm}$ e $31,50 \pm 5,22 \mathrm{~cm}$ nas mulheres de 60 69 e 70 e mais anos, respectivamente). Para uma população ribeirinha na Amazônia, Hurtado-Guerrero (2000) mostrou valores médios semelhantes (27,6士 $3,1 \mathrm{~cm}$ nos homens; $27,6 \pm 4,0 \mathrm{~cm}$ nas mulheres). As mulheres idosas apresentam uma prega cutânea tricipital grande, embora relativamente, pequenas medidas de circunferência muscular e área muscular do braço quando comparadas com idosos do sexo masculino (Falciglia, et al., 1988).

Caballero (1992) e Bolzán \& Guimarey (1995) evidenciaram que, em população rural masculina e feminina, a atividade física braçal mais vigorosa favorece o maior desenvolvimento da massa muscular, maior consumo calórico e menor área adiposa, quando comparado com trabalhadores urbanos de melhor condição sócio-econômica e com menor atividade física. Pesquisas da OMS (WHO, 1995), referem que uma perda muscular severa (medida pela circunferência do braço) pode ser um bom indicador de morbi-mortalidade em idosos (Heymsfield et al., 1982).

Apesar da importância epidemiológica da anemia na população indígena, estudos são ainda escassos, especialmente em idosos. A prevalência de anemia neste segmento merece especial atenção por suas implicações na saúde funcional (Arruda, 1990; Batista Filho \& Ferreira, 1996; Mayer, 1991; Szarfarc \& Souza, 1997). Neste estudo, observou-se maior prevalência de anemia em homens, sendo mais elevada na faixa etária de 70-79 anos. Estes resultados são similares aos encontrados em população idosa cabocla no Amazonas (HurtadoGuerrero, 2000), mas divergentes dos reportados por Mainbourg et al. (2002), em populações indígenas do Leste de Roraima e por Leite (1998), entre os Xavánte.

É premente a realização de estudos epidemiológicos sobre a condição nutricional de idosos indígenas, ainda praticamente inexistentes. As informações resultantes serão de grande utilidade na elaboração e implementação de políticas sociais que considerem este segmento populacional, com inpactos nas ações de vigilância nutricional e promoção da saúde. 


\section{Agradecimentos}

Aos idosos do DSEI Leste de Roraima, a Evilene Tomaz (antropóloga), Aldacy de Souza Xavier (chefe de DSEI Yanomámi), Aldemar Marinho de Brito (CIR-Saúde), Paulo Daniel Moraes (Coordenador de Saúde do Convênio CIR/FUNASA) pela colaboração durante o desenvolvimento desta pesquisa. Ao Centro de Pesquisa Leônidas \& Maria Deane/FIOCRUZ, Manaus, Amazonas, pelo apoio financeiro para realização deste estudo.

\section{Referências}

ALOIA, J. F; McGOWAN, D. M.; VASMANI, A. N.; ROSS, P. \& COHN, S. H., 1991. Relationship of menopause to skeletal and muscle mass. American Journal of Clinical Nutrition, 53:1378-1389.

ANSELMO, M. A.; BURINI, R. C.; ANGELELI, A. Y. O.; MOTA, N. G. S. \& CAMPANA, A. O., 1992. Avaliação do estado nutricional de indivíduos adultos sadios de classe média: Ingestão energética e protéica, antropometria, exames bioquímicos do sangue e testes de imunocompetência. Revista de Saúde Pública, 26:46-53.

ARRUDA, I. K. G., 1990. Prevalência de Anemia em Gestantes de Baixa Renda: Algumas Variáveis Associadas e a sua Repercussão no Recém-nascido. Dissertação de Mestrado, Recife: Centro de Ciências da Saúde, Universidade Federal de Pernambuco.

BANNERMAN, E.; REILLY, J.; MACCLENNAN, W.; KIRK, T. \& PENDER, F., 1997. Evaluation of validity anthropometric reference data for assessing nutritional state of elderly people in Edinburg: cross sectional study. BMJ, 615:338-341.

BATISTA FILHO, M. \& FERREIRA, L. O. C., 1996. Prevenção e tratamento da anemia nutricional ferropriva: Novos enfoques e perspectivas. Cadernos de Saúde Pública, 12:411-415.

BOLZAN, A. G. \& GUIMAREY, L. M., 1995. Indicadores braquiales de grasa y músculos de escolares de una comunidad rural según el grupo social (General Lavalle, Buenos Aires, Argentina). Archivos Latinoamearicanos de Nutrición, 45:281-285.

CABALLERO, B., 1992. Nutrición y envejecimiento: Comentario y conclusiones. Archivos Latinoamericanos de Nutrición, 42(Supl. 3):92S-95S.

CHEN, L. H., 1986. Nutritional Aspects of Aging. Boca Raton: CRC Press.

CHUMLEA, W. C. \& BAUMGARTNER, R., 1989. Status of anthropometry and body composition data in the elderly subjects. American Journal Clinical Nutrition, 50:1158-66.

COIMBRA Jr., C. E. A. \& SANTOS, R. V., 2000. Saúde, minorias e desigualdade: Algumas teias de inter-relações, com ênfase nos povos indígenas no Brasil. Ciências $\nleftarrow$ Saúde Coletiva, 5:125-131.

FAINTUCH, J.; PEREIRA, M. L.; FAINTUCH, B. L.; MACHADO, M. C. C. \& PINOTTI, H. W., 1983. Novos parâmetros para avaliação nutricional: Investigação preliminar. Revista do Hospital das Clínicas da Faculdade de Medicina de São Paulo, 38:164166. 
FALCIGLIA, G.; O'CONNOR J. M. \& GEDLING, E. M. A., 1988. Upper arm anthropometric norms in elderly white subjects. Journal of the American Dental Association, 88:569-574.

FERRIOLI, E.; MORIGUTI, J. C.; PAIVA, C. E.; MIRANDA, S. C.; TANNUS, A. F. S.; RIGO, R. \& MARCHINI, J. S., 2000. Aspectos do metabolismo energético e protéico em idosos. Nutrire, 19-20:19-30.

FRUTUOSO, M. F. P. \& CONDE, W. L., 2002. O IMC como expressão da gordura corporal - adultos (1). Livro de resumos (pôster). Revista Brasileira de Epidemiologia, Suplemento Especial:956.

GUEDES, D. P. \& GUEDES, J. E. R., 1998. Controle do Peso Corporal: Composição Corporal, Atividade Física e Nutrição. Londrina: Midiograf.

HEYMSFIELD, S. B.; McMANUS, C.; SMI'T'H, J.; STEVENS, V. \& NIXON, D. W., 1982. Anthropometric measurement of muscle mass: Revised equations for calculating bone-free arm muscle area. American Journal of Clinical Nutrition, 36:680-690.

HOFFMAN, N., 1993. Diet in the elderly. Clinical Nutrition, 77:745-756.

HURTADO-GUERRERO, A. F., 2000. Fatores Determinantes do Estado Nutricional do Idoso de Nova Olinda do Norte - Amazonas, Brasil. Dissertação de Mestrado, Manaus: Universidade do Amazonas.

JAMES, W. P. T. \& SCHOFIELD, E. C.,1994. Necessidades Humanas de Energia: Um Manual para Planejadores e Nutricionistas. Rio de Janeiro: Editora IBGE.

JELLIFE, D. B., 1968. Evaluación del Estado de Nutrición de la Comunidad con Especial Referencia a las Encuestas en las Regiones en Desarrollo. Geneva: Organización Mundial de la Salud.

KAFATOS, A.; DIACATOU, A.; LABADARIOS, D.; KOUNALI, D.; APOSTOLAKI, J.; VLACHONIKOLIS, J.; MAMATAKIS, G. \& MEGREMIS, S., 1993. Nutrition status of the elderly in Anogia, Crete, Greece. Journal American Collaboration Nutrition, 12:685-692.

KUCZMARSKI, R. J.; FLEGAL, K. M.; CAMPBELL, S. M \& JOHNSON, C. L., 1994. Increasing prevalence of overweight among US adults: The National Health and nutrition Examination Surveys, 1990 to 1991. JAMA, 272:353-358.

LEITE, M. S., 1998. Avaliação do Estado Nutricional da População Xavánte de São José, Terra Indígena Sangradouro, Volta Grande. Dissertação de Mestrado, Rio de Janeiro: Escola Nacional de Saúde Pública, Fundação Oswaldo Cruz.

MAINBOURG, E. M. T.; HURTADO-GUERRERO, A. F. \& CAVALCANTE, M. I. A., 2002. Anemia em populações indígenas do Leste de Roraima. Livros de resumos (pôster). Revista Brasileira de Epidemiologia, Suplemento Especial:30.

MATSUDO, S. M. M., 2000. Avaliação do Idoso: Física 6 Funcional. Londrina: Midiograf.

MAYER, E. M. D., 1991. Prévenir et Combattre l'Anémie Ferriprive dans le Cadre des Soins de Santé Primaires. Guide à l'Usage des Administrateurs de la Santé et des Responsables de Programme. Geneva: Organisation Mondiale de la Santé.

MS (Ministério da Saúde), 1998. la Convenção Latino-americana para Consenso em Obesidade. Rio de Janeiro: MS.

MONSEN, E. R., 1998. Nutrition is the first line of defense in disease prevention. Journal of the American Dietetic Association, 98:206-207. 
NAVARRO, A. M. \& MARCHINI, J. S., 2000. Uso de medidas antropométricas para estimar gordura corporal em adultos. Nutrire, 19-20:31-48.

OTERO, U. B.; ROZENFELD, S.; GADELHA, A. M. J. \& CARVALHO, M. S., 2002. Mortalidade por desnutrição em idosos - Região Sudeste, Brasil, 1980-1997. Livros de resumos (pôster). Revista Brasileira de Epidemiologia, Suplemento Especial:1216.

PEÑA, E. P.; LISETI, R. S.; PORTILLO, Z. \& MEERTENS, L. R., 1998. Estado nutricional de adultos mayores institucionalizados, Valencia, Estado de Carabobo, Venezuela. Archivos Latinoamericanos de Nutrición, 48:104-113.

ROSSMAN, I., 1977. Anatomic and body composition changes with aging. In: Handbook of the Biology of Aging (C. E. Finch \& L. Hayflick., eds.). New York: Van Nostrand Reinhold.

SANTOS, R. V. \& COIMBRA Jr., C. E. A., 1994. Contato, mudanças socioeconômicas e a bioantropologia dos Tupí-Mondé da Amazônia brasileira. In: Saúde e Povos Indígenas (R.V. Santos 6. C.E.A. Coimbra Jr., orgs.), pp. 189-210. Rio de Janeiro: Editora FIOCRUZ.

SANTOS, R. V. \& ESCOBAR, A. L., 2001. Saúde dos povos indígenas no Brasil: Perspectivas atuais. Cadernos de Saúde Pública, 17:258-259.

SILVA, M. C. G. B. \& BARROS, A. J. D., 2002. Mortalidade por desnutrição em idosos Região Sudeste, Brasil, 1980-1997. Livro de resumos (pôster). Revista Brasileira de Epidemiologia, Suplemento Especial:1018.

STEEN, B., 1988. Body composition and aging. Nutrition Reviews, 46:45-51.

SZARFARC, C. \& SOUZA, S. B., 1997. Prevalence and risk factors in iron deficiency and anemia. Archivos Latinoamericanos de Nutrición, 47(Sup. 1):35-38.

TAVARES, E. L. \& ANJOS, L. A., 1999. Perfil antropométrico da população idosa brasileira: Resultados da Pesquisa Nacional sobre Saúde e Nutrição. Cadernos de Saúde Pública, 15:759-768.

VERAS, R. P., 1994. País Jovem com Cabelos Brancos: A Saúde do Idoso no Brasil. Rio de Janeiro: Relume Dumará.

VOORRIPS, L. E.; VAN STAVEREN, W. A. \& HAUTVAST, J. G. A. J., 1991. Area physically active women in better nutritional conditions than their sedentary peers? European Joumal Clinical Nutrition, 45:545-552.

WHO (World Health Organization)., 1995. Physical Status: The Use and Interpretation of Anthropometry. Technical Report Series 854. Geneva: WHO.

YOUNG, T. K., 1988. Are Subartic Indians undergoing the epidemiologic transition? Social Science and Medicine, 26:659-671.

WHO (WORLD HEALTH ORGANIZATION), 1975. Control of Nutritional Anaemia with Special Reference to Iron Deficiency. WHO Technical Report Series no. 580. Geneva: WHO.

ZAR, J., 1996. Biostatistical Analysis. 3rd Ed. Upper Saddle River, New Jersey: PrenticeHall. 



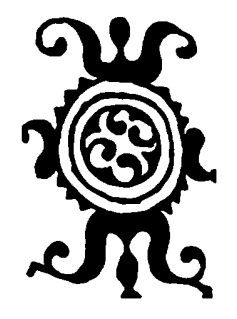

PERFIS DE SAÚDE INDÍGENA, TENDENNCIAS NACIONAIS E CONTEXTOS LOCAIS: REFLEXÕES A PARTIR DO CASO XAVÁNTE, MATO GROSSO

\author{
Maurício Soares Leite, Silvia Angela Gugelmin, \\ Ricardo Ventura Santos, Carlos E. A. Coimbra Jr.
}

Os macrodeterminantes das condições de vida e dos perfis de saúde dos povos indígenas no Brasil são razoavelmente bem conhecidos e se atrelam ao amplo processo de mudanças ocasionadas pela interação com a sociedade nacional. Geralmente envolvem aspectos como restrição territorial, introdução de doenças, mudanças nas relações econômicas e sociais internas e externas aos grupos, acesso diferenciado a serviços de saúde e de educação, dentre outros. Não obstante, observa-se, sob outros prismas, uma notável heterogeneidade. A existência de mais de 200 povos indígenas no país revela uma elevada diversidade sociocultural, política e econômica, reflexo de constituições sociais e trajetórias históricas singulares. Tal diversidade exerce um papel modulador na configuração dos perfis de saúde, por vezes resultando em quadros epidemiológicos bastante distintos segundo etnia. Esse mosaico, no qual se contrabalançam similaridades e singularidades, apresenta importantes implicações teóricas e práticas, com repercussões sobre a concepção, planejamento e implementação de políticas públicas na área da saúde.

Ao longo deste capítulo apresentamos dados epidemiológicos e demográficos relativos aos Xavánte, com ênfase na população localizada na Terra Indígena Sangradouro-Volta Grande. Os registros foram levantados ao longo da década de 1990 e são provenientes de estudos de caso realizados em campo e de análise de fontes secundárias. Serão também apresentadas comparações com informações de outras áreas Xavánte. A título de conclusão, chamamos a atenção para algumas implicações do caso Xavánte no que diz respeito à distritalização da saúde indígena no Brasil.

\title{
OS XAVÁNTE
}

Os Xavánte contam hoje com uma população de aproximadamente 9 mil indivíduos, distribuídos em seis terras indígenas na porção leste do Estado do Mato 
Grosso. Essa região caracteriza-se pelo complexo vegetacional do cerrado. Matas de galeria acompanham os rios de pequeno porte e córregos. É nesses trechos que os Xavánte cultivam suas roças (Coimbra Jr. et al., 2002).

Os primeiros registros históricos sobre os Xavánte datam da segunda metade do século XVIII, quando estavam situados no centro e no norte da então província de Goiás, entre os rios Araguaia e Tocantins. Em decorrência da busca de ouro, a região recebeu um grande contigente de migrantes. Num primeiro momento, os Xavánte e outros grupos viram-se forçados a recuar em seu território. Posteriormente, com a decadência da mineração e a necessidade de diversificar as atividades econômicas, ampliou-se a ocupação dos territórios indígenas pelas frentes de colonização. Alguns grupos indígenas, incluindo os Xavánte, chegaram a ser aldeados. À medida que a colonização avançava, os Xavánte migraram para o oeste, até que se estabeleceram entre os rios Araguaia e das Mortes, onde permanecem até hoje (Coimbra Jr. et al., 2002; Flowers, 1983; Lopesda-Silva, 1992; Maybury-Lewis, 1984; Ravagnani, 1978).

Durante a primeira metade do século $\mathrm{XX}$, foram inúmeras as tentativas de "pacificação" dos Xavánte, tanto por parte do governo quanto de missões religiosas. A despeito de alguns conflitos esporádicos com não-índios e com alguns grupos Karajá e Boróro, os Xavánte permaneceram relativamente isolados até meados da década de 40, quando o interior matogrossense tornou-se alvo da política de Getúlio Vargas de expansão agrícola. Em 1946, no posto de atração São Domingos, foi estabelecido o primeiro contato pacífico com um grupo Xavánte. Devido aos constantes ataques dos colonos e às epidemias de doenças infecciosas, alguns grupos mantiveram-se afastados. Foram necessárias cerca de duas décadas para que toda a população Xavánte se rendesse ao contato permanente. Para alguns grupos, a mediação do contato foi feita por agentes do Serviço de Proteção aos Índios (SPI); para outros, envolveu a participação de missionários católicos ou protestantes. Em alguns casos, as populações conseguiram permanecer nas áreas que ocupavam, enquanto outras foram deslocadas para regiões mais distantes, algumas vezes retornando somente após a demarcação de suas terras. Fruto dessa heterogeneidade, as trajetórias de contato e subseqüentes mudanças foram distintas para os diversos grupos Xavánte (Coimbra Jr. et al., 2002; Flowers 1983; Garfield, 2001; Lopes-da-Silva, 1992; Maybury-Lewis, 1984; Ravagnani, 1978).

No início dos anos 50, os Xavánte que atualmente residem em Sangradouro-Volta Grande estavam situados à margem esquerda do rio Couto de Magalhães, um pouco mais ao norte de sua atual localização. Em 1957, após diversas migrações, perseguições e epidemias, o grupo chegou à Missão Salesiana de 
Sangradouro, que também abrigava índios Boróro (Giaccaria \& Heide, 1972; Menezes, 1984).

A Terra Indígena Sangradouro-Volta Grande compreende atualmente uma área de 100.280 hectares, localizada nos municípios de General Carneiro, Poxoréu e Novo São Joaquim, Mato Grosso. A área é contígua à Missão Salesiana de Sangradouro, tendo como limites o rio das Mortes, a BR-070 e diversas fazendas. Segundo Souza (1999), a população total dessa área era de 920 indivíduos em 1997, distribuídos em sete aldeias. São José é a mais antiga e a principal aldeia, com cerca de $60 \%$ do total da população que vive na área. Em 1998, o número de aldeias havia aumentado para nove. As constantes divisões são reflexo do faccionalismo político dos Xavánte (Coimbra Jr. et al., 2002; Lopes-da-Silva, 1992; Maybury-Lewis, 1984).

As cidades mais próximas de Sangradouro-Volta Grande são Primavera do Leste (50km), General Carneiro (180km) e Barra do Garças (220km). O acesso à terra indígena dá-se através da BR-070. Há diversas estradas interligando as aldeias. Em 1998, São José contava com 59 casas dispostas no formato circular, o que difere da tradicional organização em semicírculo, com a abertura voltada para um curso d'água. Diferentemente das habitações originais, construídas em palha sobre uma armação circular de galhos (Coimbra Jr. et al., 2002), a maior parte das casas em São José possuía paredes de alvenaria com janelas e portas de madeira, embora mantendo a forma circular e a cobertura de palha.

O caso Xavánte oferece uma oportunidade singular para a análise de processos locais de diferenciação epidemiológica. Para isto contribuem algumas características particulares ao grupo. Sua população encontra-se hoje distribuída em diversas terras indígenas, que apresentam realidades por vezes bastante heterogêneas, a despeito de uma base biológica, cultural e social comum. Vale assinalar que os Xavánte encontravam-se, já à época da "pacificação", na década de 40 , divididos em subgrupos, que foram progressivamente alocados nas terras demarcadas. Desde então seguiram trajetórias históricas distintas, em um processo que em parte determinou as formas de relacionamento com a sociedade não-indígena e suas atuais condições de vida e de saúde. Além disso, os Xavánte constituem uma das sociedades indígenas mais intensamente estudadas no Brasil, o que inclui análises biomédicas, antropológicas e históricas (Coimbra Jr. et al., 2002; Garfield, 2001; Graham, 1995; Lopes-da-Silva, 1986; Maybury-Lewis, 1984; entre outros). 


\section{DEMOGRAFIA}

No que diz respeito à composição etária, fecundidade, mortalidade e dinâmica de formação de novas aldeias, Souza (1999) e Souza \& Santos (2001) delinearam o perfil demográfico dos Xavánte de Sangradouro-Volta Grande na década de 1990. As análises foram feitas com base em recenseamentos e registros de eventos vitais relativos ao período de 1993-1997.

Assim como outros grupos indígenas, os Xavánte apresentam uma idade mediana baixa, com mais da metade $(56,3 \%)$ da população abaixo de 15 anos e apenas 2,3\% com mais de 65 anos. A pirâmide populacional apresenta uma base larga, típica de populações com elevadas taxas de natalidade (Figura 1).

Segundo Souza \& Santos (2001), a taxa de crescimento dos Xavánte está em torno de $5 \%$ ao ano, devido principalmente à alta taxa de fecundidade total (média de 8,6 filhos por mulher). Elevadas taxas de fecundidade não são uma particularidade dos Xavánte de Sangradouro-Volta Grande, tendo sido reportadas para vários outros grupos indígenas (Early \& Peters, 1990; Pagliaro, 2002; Werner, 1983). Em relação às taxas específicas de fecundidade, os maiores valores foram constatados na faixa etária de 20-29 anos, com um declínio progressivo até o grupo de 40-49 anos.

A taxa bruta de mortalidade foi de 9,1 mortes por mil indivíduos. A maior parte dos óbitos ocorreu em crianças menores de quatro anos $(84,2 \%)$, e principalmente naquelas menores de um ano (55\%). O coeficiente de mortalidade infantil variou de 62,5 por mil a 116,3 por mil no período de 1993 a 1997 , apresentando o valor médio de 87,1 mortes por mil nascidos vivos. Estes valores são extremamente elevados se comparados às médias nacionais, superando inclusive a média verificada no Nordeste brasileiro, que na mesma época chegava a 60,4 por mil (DATASUS, 2000).

\section{CONDIÇÕES SANITÁRIAS E AMBIENTAIS}

A questão sanitária constitui - não somente para os Xavánte, mas para os povos indígenas de modo geral - importante nó na rede de transformações experimentadas a partir do contato. Essas transformações incluem mudanças nos padrões de assentamento, mobilidade e subsistência, cujos impactos se fazem sentir nos perfis de saúde registrados contemporaneamente nas aldeias Xavánte (Coimbra Jr. et al., 2002). 


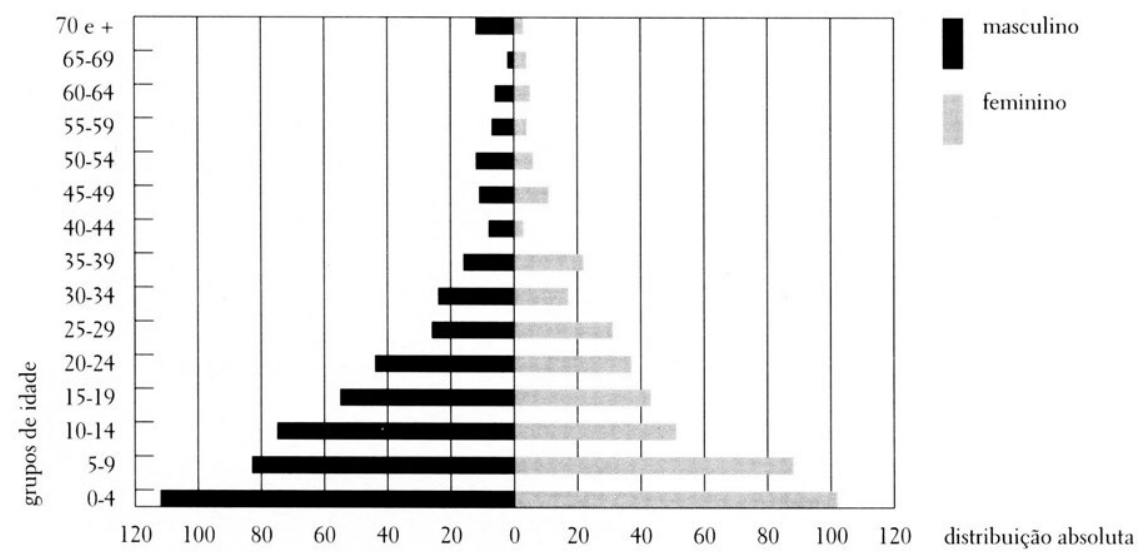

O quadro sanitário observado em São José caracteriza-se pela precariedade. A aldeia está situada no mesmo local há cerca de 40 anos, e não há coleta de lixo e dejetos. Isso favorece a contaminação do solo, dos alimentos e da água disponível na aldeia por enterobactérias, rotavírus e parasitas intestinais. A água para consumo segue encanada, também sem tratamento, de córregos próximos para dois pontos situados no perímetro da aldeia, onde também são lavadas roupas e utensílios. Embora os adultos de modo geral andem calçados, as crianças comumente não o fazem. Diante desse quadro, é significativo que, como veremos mais adiante, as doenças infecciosas e parasitárias constituam componentes importantes do perfil epidemiológico, atingindo particularmente as crianças. As condições sanitárias observadas em São José parecem assemelhar-se àquelas descritas tanto para outras áreas Xavánte, como para grande parte das populações indígenas do país (Coimbra Jr. et al., 2002).

O problema parece ser ainda agravado pela concentração da população na aldeia São José. Dentre os fatores que podem estar concorrendo para tal concentração, estão a proximidade da BR-070, que possibilita o acesso aos centros 
urbanos mais próximos, e a presença dos missionários salesianos. A missão mantém uma enfermaria onde trabalham monitores indígenas de saúde e uma escola que oferece ensino fundamental e médio. Serve também como pólo de atração devido aos postos de trabalho que oferece, como tratorista, motorista, cozinheira e inspetor escolar.

O enteroparasitismo é altamente endêmico em São José. Leite et al. (2002) reportaram os resultados de inquérito coprológico conduzido em 1997 por meio do método de sedimentação de Lutz, quando foram examinadas 364 amostras, incluindo ambos os sexos e todas as faixas etárias. A prevalência geral de parasitismo foi de $78 \%$, com ambos os sexos atingidos de modo semelhante (Tabela 1). Os helmintos mais freqüentes foram Ascaris lumbricoides $(57,7 \%) \mathrm{e}$ ancilostomídeos (44,0\%). Quanto aos protozoários patogênicos mais freqüentes, Entamoeba histolytica e Giardia lamblia apresentaram prevalências de 3,8\% e $4,1 \%$, respectivamente. Dentre os homens, $45,1 \%$ apresentaram-se positivos para duas ou mais espécies de parasitos, enquanto a prevalência de poliparasitismo entre as mulheres foi de $34,4 \%$. Os dados existentes para o conjunto das áreas Xavánte são, de modo geral, semelhantes, revelando prevalências de moderadas a elevadas de enteroparasitismo (Coimbra Jr. et al., 2002; Ianelli et al., 1995; Santos et al., 1995).

\section{ECOLOGIA E SUBSISTÊNCIA}

Outros aspectos relacionados aos padrões de assentamento e à degradação ambiental dizem respeito à disponibilidade e à utilização dos recursos naturais, que também estão intimamente ligados à situação nutricional das populações indígenas. O caso Xavánte parece demonstrar de modo inequívoco que, embora fundamental para a sobrevivência e a continuidade cultural e biológica, a demarcação de terras indígenas não constitui garantia absoluta e suficiente de segurança alimentar.

As atuais estratégias de subsistência dos Xavánte de Sangradouro-Volta Grande apresentam um marcante contraste com os primeiros registros etnográficos sobre o grupo (Coimbra Jr. et al., 2002; Giaccaria \& Heide, 1972; MayburyLewis, 1984). As expedições coletivas de caça e de coleta - que chegavam a durar meses - são agora breves, e mesmo as incursões individuais ou familiares às áreas próximas à aldeia para a coleta de produtos silvestres são cada vez menos freqüentes e produtivas (Leite, 1998). 
Tabela 1

Prevalência de parasitismo segundo faixa etária. Sexos combinados. Aldeia São José,

Terra Indígena Sangradouro-Volta Grande, 1997.

\begin{tabular}{|c|c|c|c|c|c|c|c|c|c|c|c|c|c|c|}
\hline \multirow[t]{3}{*}{ Parasito } & \multicolumn{12}{|c|}{ Faixa etária (anos) } & \multicolumn{2}{|c|}{ Total } \\
\hline & \multicolumn{2}{|c|}{$<5$} & \multicolumn{2}{|c|}{$5-9,9$} & \multicolumn{2}{|c|}{$10-14,9$} & \multicolumn{2}{|c|}{$15-19,9$} & \multicolumn{2}{|c|}{$20-39,9$} & \multicolumn{2}{|c|}{$\geq 40$} & & \\
\hline & $\mathrm{n}$ & $\%$ & $\mathrm{n}$ & $\%$ & $\mathbf{n}$ & $\%$ & $\mathrm{n}$ & $\%$ & $\mathrm{n}$ & $\%$ & $\mathrm{n}$ & $\%$ & $\mathrm{n}$ & $\%$ \\
\hline A. lumbricoides & 49 & 52,7 & 56 & 70,9 & 30 & 65,2 & 21 & 58,3 & 38 & 50,0 & 16 & 47,1 & 210 & 57,7 \\
\hline Ancilostomídeos & 28 & 30,1 & 44 & 55,7 & 23 & 50,0 & 20 & 55,6 & 33 & 43,4 & 12 & 35,3 & 160 & 44,0 \\
\hline H. nana & 10 & 10,8 & 6 & 7,6 & 5 & 10,9 & 2 & 5,6 & 2 & 2,6 & 2 & 5,9 & 27 & 7,4 \\
\hline G. lamblia & 4 & 4,3 & 4 & 5,1 & 3 & 6,5 & 1 & 2,8 & 3 & 3,9 & - & - & 15 & 4,1 \\
\hline E. histolytica & 2 & 2,2 & 2 & 2,5 & 3 & 6,5 & 2 & 5,6 & 4 & 5,3 & 1 & 2,9 & 14 & 3,8 \\
\hline S. stercoralis & 3 & 3,2 & 4 & 5,1 & 2 & 4,3 & 2 & 5,6 & - & - & 1 & 2,9 & 12 & 3,3 \\
\hline T. trichiura & - & - & - & - & 1 & 2,2 & 2 & 5,6 & - & - & 1 & 2,9 & 4 & 1,1 \\
\hline
\end{tabular}

Quando a demarcação e a regularização da Terra Indígena Sangradouro-Volta Grande ocorreram no final da década de 1980, grande parte da cobertura vegetal original já havia sido alterada devido a invasões anteriores por fazendeiros. Além disso, nos anos que se seguiram à demarcação, novas áreas foram destinadas à rizicultura mecanizada, como parte de esforços estatais para tornar as terras indígenas economicamente auto-suficientes (Coimbra Jr. et al., 2002; Lopes-da-Silva, 1992; Santos et al., 1997). Após o abandono das atividades de cultivo em larga escala, a agricultura de subsistência Xavánte, tradicionalmente praticada nas áreas de mata ciliar, passou a encontrar ainda mais restrições para a sua realização. Além disso, a técnica habitualmente utilizada, de corte-e-queima, exige a abertura de novas roças em média a cada três anos, devido à gradual redução da produtividade, à maior ocorrência de pragas e à progressiva invasão pela vegetação secundária. Com o aumento populacional e a crescente demanda por alimentos, juntamente com a menor disponibilidade de terras, as áreas de cultivo têm cada vez menos tempo de descanso até que sejam novamente utilizadas, o que acaba por comprometer a produtividade.

No que se refere à caça, a progressiva escassez de animais nas áreas próximas aos aldeamentos constitui um registro freqüente entre os povos indígenas do país e o caso Xavánte não parece ser uma exceção a este perfil (Coimbra Jr. et al., 2002; Menezes, 1984). Em 1997, não apenas eram freqüentes os relatos de relativo insucesso nas caçadas em São José, como também pareciam ser mais co- 
muns as incursões a fazendas vizinhas à Sangradouro-Volta Grande, onde as atividades eras aparentemente mais produtivas (Leite, 1998).

Outra diferença marcante diz respeito à atual importância do trabalho remunerado em São José quando contrastado com as atividades tradicionais de subsistência. Gugelmin \& Santos (2001) referem que, das atividades de subsistência exercidas por adultos de ambos os sexos durante o ano de 1998,39\% delas diziam respeito a formas de trabalho remunerado, em funções como as de professores, cozinheiras, motoristas e agentes de saúde indígenas, entre outras. Nesse tocante, a comparação com dados coletados em Pimentel Barbosa (também conhecida como Etéñitépa) é elucidativa. Até o início da década de 1980 registrava-se, em Pimentel Barbosa, um progressivo aumento no tempo dedicado à agricultura comercial - com o cultivo de arroz em larga escala - e uma redução significativa do tempo dedicado às atividades tradicionais de subsistência. Nos anos seguintes, contudo, a perspectiva de um crescente envolvimento com o mercado regional e com o trabalho remunerado não veio a se confirmar. Com o fim do projeto de cultivo do arroz promovido pela Fundação Nacional do Índio (FUNAI), inverteu-se a tendência até então observada: no início dos anos 90 , a caça, a pesca e a coleta voltaram a assumir maior importância, e o trabalho remunerado correspondia a apenas $6 \%$ das atividades de subsistência (Coimbra Jr. et al., 2002; Gugelmin, 1995; Santos et al., 1997).

Além de particularidades históricas, as diferenças entre Sangradouro e Pimentel Barbosa parecem derivar, em parte, das condições ecológicas de cada reserva. Vale mencionar que a cobertura vegetal em Pimentel Barbosa encontrava-se relativamente bem preservada, o que não ocorria em Sangradouro-Volta Grande. Além disso, a disponibilidade de terras - e, de certo modo, de recursos naturais - por habitante é significativamente diferenciada entre as duas terras indígenas: Pimentel Barbosa apresentava uma relação de 391,2 hectares por pessoa, enquanto Sangradouro-Volta Grande disponibilizava apenas 115,3 hectares por pessoa (Gugelmin \& Santos, 2001).

\section{ALIMENTAÇÃO E NUTRIÇÃO NO ÂMBITO DAS MUDANÇAS}

Os reflexos desse conjunto de mudanças sobre as práticas alimentares Xavánte são significativos. Embora não tenham sido realizadas análises precisas sobre o consumo alimentar em São José, algumas descrições apontam para uma redução da di- 
versidade alimentar e para o predomínio dos carboidratos, resultando em uma dieta monótona onde o arroz polido constitui a base da alimentação, e onde a carne é um item pouco freqüente (Vieira Filho, 1981; Vieira Filho et al., 1983). Além do arroz, diversos alimentos introduzidos a partir do contato são hoje de uso freqüiente. Como exemplos podem ser mencionados itens como a mandioca e, principalmente, os produtos industrializados, como açúcar, sal de cozinha, óleo de soja e ainda pães, balas, biscoitos e refrigerantes (Leite, 1998; Gugelmin, 2001). O problema da monotonia alimentar assume tal magnitude que já foram registrados diversos casos de polineuropatia nutricional (por deficiência de tiamina) em Sangradouro e em outras comunidades Xavánte (Vieira Filho et al., 1997).

Esta tendência de mudanças nas práticas alimentares, contudo, parece não afetar as diversas comunidades Xavánte na mesma intensidade. Como já mencionamos, é notável o registro em Pimentel Barbosa de itens alimentares resultantes de atividades "tradicionais" de subsistência (caça, pesca e coleta) e, conseqüentemente, uma menor importância dos produtos industrializados em sua dieta (Coimbra Jr. et al., 2002; Santos et al., 1996, 1997).

Entre os Xavánte, como em outras populações, os problemas nutricionais atingem de modo distinto as diversas faixas etárias. Gugelmin (2001) descreve que em Sangradouro-Volta Grande a prevalência de déficit estatural (estatura/idade abaixo de -2 escores z) em 1999 era significativa às crianças menores de dez anos (19,5\%), acentuando-se nos menores de cinco anos (28,3\%). Para o índice massa corporal/idade, os déficits foram de $9,3 \%$ em crianças menores de dez anos e de 15,3\% naquelas menores de cinco anos. Contudo, ao analisar a relação massa corporal/estatura, a prevalência de déficit foi de apenas 1,9\% para ambos os grupos etários, valor inferior ao esperado (2,3\%), considerando-se uma distribuição estatisticamente normal dos valores do índice na população. Isto é, as crianças Xavánte mantêm a proporcionalidade corporal apesar da ocorrência de déficit estatural. Gugelmin (2001) sugere que, além dos problemas de autosustentação, a falta de saneamento e a descontinuidade da atenção básica à saúde interferiam diretamente na determinação do estado nutricional das crianças.

Entre os adultos, a situação observada era radicalmente diferente, não se caracterizando pela ocorrência de desnutrição, mas sim de obesidade. A população adulta de São José apresentava valores médios de massa corporal muito superiores àqueles reportados por Niswander et al. (1967), em um dos primeiros inquéritos de saúde realizados entre os Xavánte. Além disso, Gugelmin (2001) e Gugelmin \& Santos (2001), ao compararem as prevalências de obesidade registradas em Pimentel Barbosa e São José, observaram que, nesta última, 34,2\% dos 
adultos eram obesos, enquanto que em Pimentel Barbosa somente 4\% (índice de massa corporal $\geq 30$ ).

É interessante observar que o perfil descrito para a comunidade de São José guarda certa semelhança com a situação nutricional da população brasileira. Contudo, tanto as prevalências de desnutrição infantil como as de sobrepeso/obesidade em adultos, são extremamente elevadas quando comparadas àquelas verificadas no país como um todo. Dados da Pesquisa Nacional sobre Demografia e Saúde (PNDS), realizada em 1996 (Monteiro, 2000), apontaram para uma prevalência de $10,5 \%$ de baixa estatura para a idade em crianças menores de cinco anos, valor que contrasta com os $28,3 \%$ observados entre os Xavánte de São José. A situação das crianças Xavánte apresenta-se ainda mais desfavorável que das crianças brasileiras não-indígenas que vivem nas áreas rurais do país ( $\mathrm{Fi}$ gura 2). No outro extremo, 9,6\% dos adultos brasileiros de 25 a 64 anos são obesos (Monteiro, 1998), contra os 34,2\% registrados em São José, tornando-se evidentes as disparidades entre indígenas e não-indígenas (Figura 3).

Uma conseqüência adicional das mudanças nas práticas alimentares pode ser percebida na situação de saúde bucal da população Xavánte, avaliada no início da década de 1990 por Pose (1993) e, mais recentemente, por Arantes et al. (2001). Pose assinalou a precariedade do quadro observado no conjunto das aldeias Xavánte, a despeito de alguma heterogeneidade entre as comunidades. Além da ausência de um atendimento odontológico regular para a maior parte da população, a autora refere o caráter "mutilador" dos serviços odontológicos oferecidos, algo evidenciado pela reduzida proporção de restaurações dentárias e de outros procedimentos. Pose (1993) conduziu também uma análise comparativa dos dados de saúde bucal e mostrou que o conjunto de populações Xavánte, no qual se inclui São José, apresentou valores médios do índice CPOD (número de dentes cariados, perdidos ou obturados) bastante superiores $(19,9)$ àqueles registrados em outras áreas, incluindo Pimentel Barbosa $(13,8)$.

A cariogenicidade dos alimentos introduzidos a partir do contato - destacando-se o açúcar refinado - atinge de forma diferenciada os diversos grupos Xavánte. Arantes et al. (2001) mencionam que, em função de um consumo significativo de alimentos tradicionais, a atual dieta dos habitantes de Pimentel Barbosa parece garantir uma situação de saúde bucal razoável, apesar do crescente consumo de produtos industrializados, o que contribui para aumentar a ocorrência de cáries (ver também Arantes, neste volume).

Outro problema de ordem nutricional que alcança uma grande magnitude entre os Xavánte é a anemia. Se um rápido exame da literatura revela um 
Figura 2

Prevalência de déficit mutricional $(\leq-2$ escores $z)$ segundo os índices massa corporal/estatura i MC:/Li, massa corporal/idade ( $\mathrm{MC} / \mathrm{I})$ e estatura/idade ( $\mathrm{S} S \mathrm{~S} \mathrm{I} / \mathrm{I}$ ) em criancas brasileiras não-indígentas e Xavánte, menores de 5 anos. Sexos combinados. Aldeia São José, Terra Indízena Sangradouro-Volta Cirande. Mato (irosso

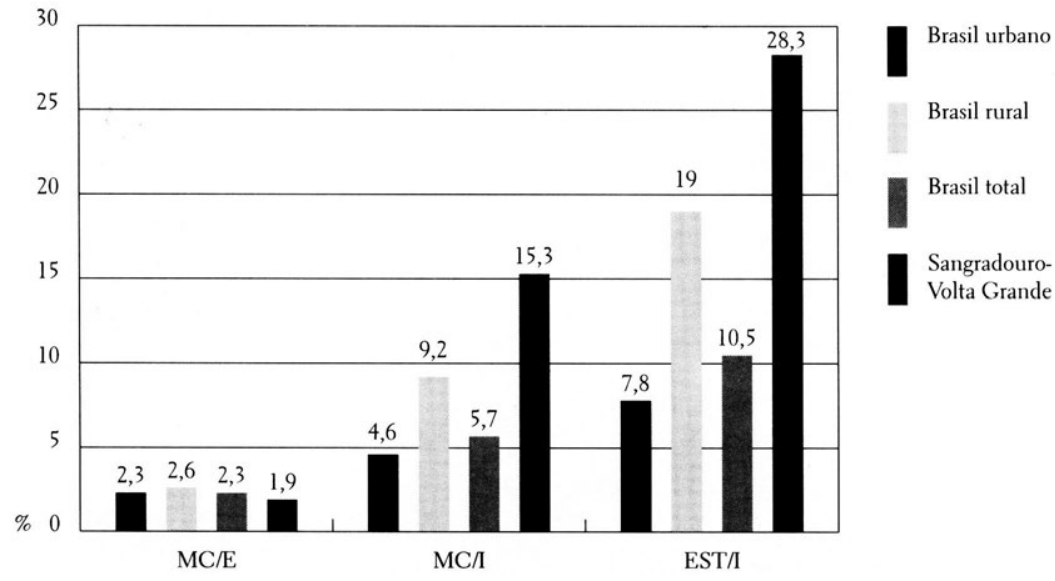

número limitado de estudos sobre alimentação e nutrição entre os povos indígcnas do país (Santos, 1993), a proporção de trabalhos que apresenta entre seus componentes o diagnóstico de anemia é ainda menor. Apesar disso, grande parte dos estudos revela prevalĉncias superiores às observadas em outros segmentos da população brasileira (Baruzzi et al., 1977; Coimbra Jr. \& Santos, 1991; Gugelmin, 1995; Guerrero et al., neste volume; Neel et al., 1964; Santos, 1991). Vale mencionar que, para a população brasileira, cstima-se que as prevalĉncias variem de 22 a $45 \%$ (PAHO/WHO, 1994).

Entre os Xavánte de Sangradouro-Volta Grande o quadro é mais grave: em um inquérito realizado en $1997,48,3 \%$ dos homens e $62,9 \%$ das mulheres examinadas foram diagnosticados com anemia (Leite, 1998; Leite et al., 2002). A prevalência variou significativamente com a idade, sendo mais elevada entre os menores de de\% anos (73,7\%), entre os indivíduos de $10-15$ anos $(63,6 \%$ ) e nas mulheres entre 20-40 anos (54,2\%) (Figura 4). Como esperado, os segmentos mais atingidos pela anemia entre os Xavánte são aqueles representados pelas 
Prevalência de obesidade (IMC $\geq 30 \mathrm{~kg} / \mathrm{m}^{2}$ ) entre adultos brasileiros não-indígenas e Xavánte, segundo o sexo. 'lerras Indígenas Pimentel Barbosa e Sangradouro-Volta Crande, Mato Grosso.

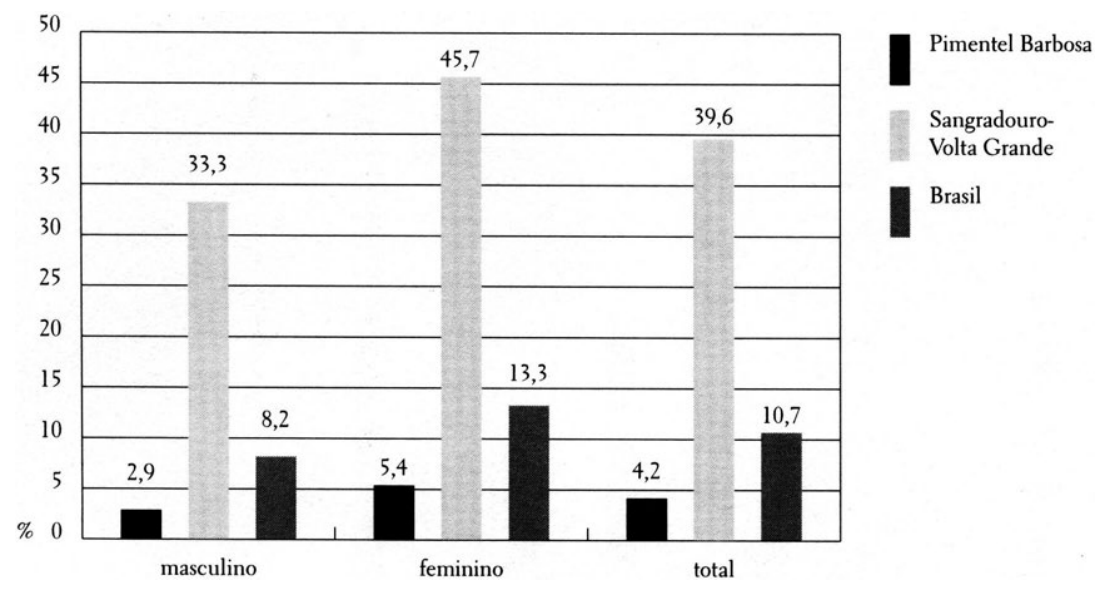

crianças e pelas mulheres em idade reprodutiva. O quadro observado entre as primeiras, contudo, é particularmente grave: $96,6 \%$ dos menores de dois anos estavam anêmicos. Além disso, 37,3\% dos menores de cinco anos apresentavam valores de hemoglobina inferiores a $9,5 \mathrm{gHb} / \mathrm{dl}$. Estas prevalências são de fato alarmantes, considerando-se as evidências que apontam para a associação entre anemia e a menor resistência a infecções, maior risco de mortalidade e retardo do desenvolvimento cognitivo infantil, sem mencionar, no caso dos indivíduos mais velhos, redução da capacidade de trabalho e maior risco de morbi-mortalidade materno-infantil (Allen, 1993; Haas \& Brownlie, 2001; Scrimshaw, 1991; Trowbridge et al., 1993; WHO, 1975; Yip, 1994).

\section{PERFIS DE MORBI-MORTALIDADE}

No que se refere aos perfis de morbidade Xavánte, as análises são bastante dificultadas pela inexistência e inconsistência dos dados epidemiológicos disponí- 
Prevalência de anemia na população Xavánte, segundo sexo e faina etíria. Aldeia São José.

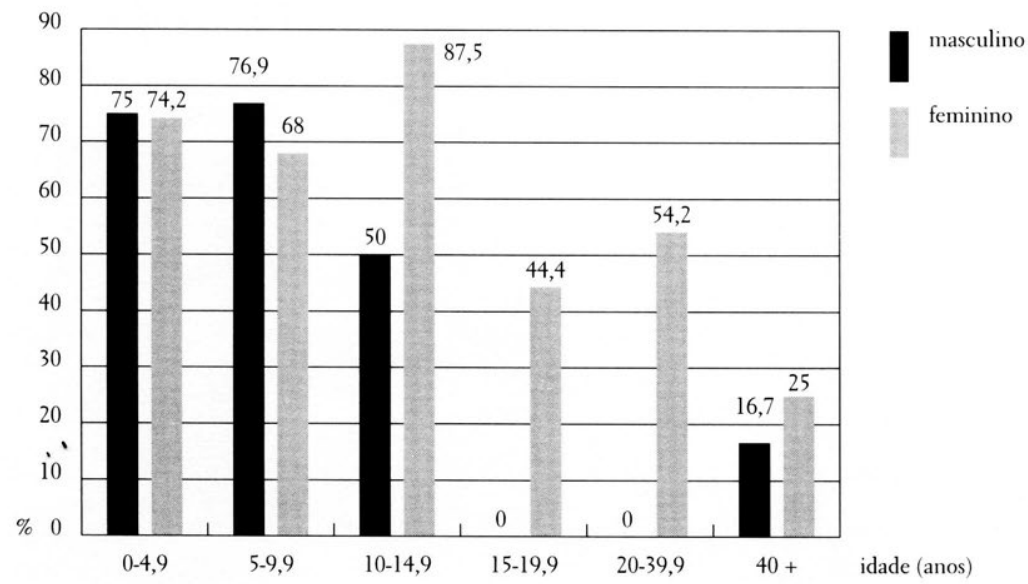

veis. O Relatório Anual de Atividades - Ano 2000 do Distrito Sanitário Fispecial Indígena (DSEI) Xavánte apresenta dados de morbidade sob a forma de um consolidado para toda a população Xavánte (FUNASA, 2000). Infelizmente, não possibilita a desagregação das informações segundo terra indígena/aldcia ou outras variáveis epidemiologicannente relevantes. O relatório cvidencia o predomínio dos atendimentos a menores de cinco anos ( $+5 \%$ do total). No que di\% respeito às causas de morbidade, pneumonias e outras doenças infecciosas e parasitárias constituíram os principais motivos de atendimento, respondendo respectivamente, por 34,8 e $19,5 \%$ das consultas. Fisse quadro é semelhante ao observado para o conjunto das áreas Xavánte (Coimbra Jr. et al., 2002).

A observação de que as doenças cardiovasculares, as neoplasias e os distúrbios metabólico-nutricionais respondan por apenas $0,3,0,1$ e 2,8\% dos atendimentos, respectivanente, parece deixar claro o predomínio absoluto das doenças infecciosas e parasitárias sobre as crônicas não-transmissiveis no perfil de morbidade da população Xavánte. Não obstante, há indícios de mudançàs nesse quadro. O surgimento de casos de diabetes mellitus entre os Xavánte parece 
constituir um exemplo claro deste processo. No início da década de 80, Vieira Filho et al. (1983) não encontraram casos de diabetes em Sangradouro-Volta Grande e São Marcos. Mais recentemente, foi registrada a ocorrência de aproximadamente 70 casos na população Xavánte, sendo que 17 deles (23\%) eram provenientes de Sangradouro-Volta Grande. É notável que cerca de $95 \%$ dos casos encontram-se concentrados em apenas três terras indígenas - Sangradouro-Volta Grande, São Marcos e Parabubure (Coimbra Jr. et al., 2002).

No caso específico de São José, o maior envolvimento em certas funções remuneradas ligadas às atividades da Missão, em lugar de atividades fisicamente exigentes, como a caça e a coleta, freqüentemente resulta em uma redução nos níveis de atividade física. Aliado a esta redução, o consumo de alimentos pobres em fibras vegetais e ricos em carboidratos simples, gorduras saturadas e cloreto de sódio pode favorecer o surgimento de obesidade, diabetes mellitus e de doenças cardiovasculares. Este conjunto de modificações tem sido observado por diversos autores entre grupos indígenas no Brasil, que têm em comum o fato de estarem experimentando profundas alterações em seus sistemas de subsistência, dieta e padrões de atividade física (Capelli \& Koifman, 2001; Cardoso et al., 2001; Ribas \& Philippi, neste volume; Santos \& Coimbra Jr., 1996; Tavares et al., 1999; Vieira Filho, 1977). Esse quadro aponta para uma mudança significativa nos perfis de morbidade e mortalidade dessas populações, a exemplo do que vem ocorrendo entre povos indígenas na América do Norte e em outras partes do mundo (Murphy et al., 1997; West, 1974; Weiss et al., 1984; Young, 1988).

Como esperado, a análise das causas de morte entre os Xavánte apresenta paralelos com o descrito para morbidade. Pneumonia e desnutrição aparecem como as principais causas, tanto para o conjunto da população Xavánte (com 26,3 e 17,5\% dos óbitos, respectivamente) como para o subgrupo atendido no pólo-base de Paranatinga, ao qual pertence Sangradouro-Volta Grande (com 18,8 e 31,3\% dos óbitos), onde chama a atenção a proporção de óbitos atribuídos à desnutrição. Nesse pólo-base, as diarréias foram ainda responsáveis por $12,5 \%$ dos óbitos, o que também reflete as precárias condições sanitárias das aldeias Xavánte. Com relação às doenças crônicas não-transmissíveis, neoplasias e doenças cardiovasculares foram apontadas como responsáveis, respectivamente, por 12,5 e 6,3\% dos óbitos, números que contrastam com a pequena proporção de atendimentos por esse mesmo grupo de doenças (menos de $1 \%$ em ambos os casos). 


\section{ATENÇÃO À SAÚDE}

A partir de meados de 1999, a Fundação Nacional de Saúde (FUNASA, 2002), assumiu a responsabilidade pela assistência à saúde nas terras indígenas e pela estruturação do subsistema de atenção à saúde indígena, articulado con o Sistema Único de Saúde (SUS). Já no final de 2000 havia 34 DSEIs implantados em todo o país, com graus diferenciados de estruturação.

(O DSE. Xavánte abrange todas as terras indígenas Xavánte, além de algumas aldcias Boróro. Fiste aspecto, por um lado, poderia facilitar o plancjamento e a organização dos serviços de saúde, scndo as ações mais facilmente direcionadlas à realidade da população e ao atendimento de suas necessidades. No entanto, na prática, observam-se dificuldades quanto à operacionalização dos serviços. () faccionalisnno político Xavánte gera disputas entre lideranças e comunidades, por vezes ocasionando descontinuidade no provimento dos serviços de saúde e interferindo na rotina do trabalho dos agentes inclígenas de saúde. Por outro lado, a alta rotatividade dos profissionais de sańde dificulta a criação de vínculos entre os profissionais e sulas respectivas equipes $\mathrm{c}$ as comunidades, prejudicando a supervisão continuada dos agentes de saúde, além dos serviços de assistência e prevenção.

() DSEi Xavánte, com sede em Barra do Garças, está subdividido em quatro pólos-base: Campinápolis, que abrange 63 aldeias; Água Boa, com 16 aldcias; Paranatinga, com 21 aldcias e São Marcos, com 20 aldcias. Conta também com três Casas de Saúde, localizadas em Aragarças, Nova Xavantina c Cannpinápolis, bem como postos de saúde em algumas aldeias. As Casas de Saúde recebem e garantem apoio aos pacientes quando encaminhados da aldeia para diagnóstico, tratamento ou supervisão en clínicas e hospitais. Desde novembro de 1999, a execução das ações no DSEI Xavante tem sido realizada por sete equipes de saúcle contratadas pela Sociedade na Defesa da Cidadania (SDC), organi7ação não-governamental conveniada com a FUNASA.

() pólo-base de Paranatinga, que compreende as terras indígenas Sangradouro e Marechal Rondon, dispõe de uma boa infra-cstrutura na aldeia São José. A Missão Salesiana construiu una unidade de saúde composta por ambulatório, consultórios médico e odontológico, enfermaria e farmácia. Lista unidade é referência para outras aldeias da região. No cntanto, apresenta deficiências no que se refere à equipe de saúde. Fimbora conte com a atuação de dois agentes inclígenas de saúde, atualmente há apenas um enfermeiro atuando na unidade, e uma res por scmana um médico cedido por meio de um projeto externo à FUN $A S \Lambda \mathrm{C}$ à $S D C$ p presta assistência médica à comunidade. 


\section{CONSIDERAÇÕES FINAIS}

Apesar da limitação temporal dos dados e das lacunas de comparabilidade, o quadro que emerge é de uma marcante heterogeneidade no perfil epidemiológico dos Xavánte, com diferenças entre os diversos subgrupos que resultam de trajetórias históricas particulares de contato e interação com a sociedade nacional (ver também Coimbra Jr. et al., 2002). Os diversos componentes analisados também apontam para um quadro marcado pela precariedade das condiçôes de saúde, cujos determinantes atrelan-se a condições ecológicas, sócio-econômicas c sanitárias decorrentes de rápido crescimento populacional, degradação ambiental, ausência de saneamento e dificuldades de sustentabilidade alimentar.

Como apontado anteriormente, o alcance das recentes transformações ambientais e sócio-econômicas sobre a saúde Xavánte é amplo. Revela-se por meio de processos tão distintos como a manutenção de elevadas prevalências de doenças infecciosas c parasitárias, concomitantemente com a rápida emergência de doenças crônicas não-transmissíveis. Fissa sobreposição de perfis cpidemiológicos faz-se presente nas diversas áreas Xavánte, mas é particularmente evidente em Sangradouro-Volta Grande. O caso Xavánte demonstra que essas mudanças são, em larga medida, moduladas por contextos locais, que desempenham um papel proeminente na determinação dos perfis epidemiológicos analisados neste capítulo (ver também Coimbra Jr. ct al., 2002 e Santos \& Coimbra Jr., 1994).

Lim termos mais amplos, a trajctória da saúde dos Xavánte guarda proximiclade com discussões na literatura referentes a povos indígenas em outras partes do mundo. Stephen Kunitz (1994), cm seu livro Disease and Social Diversity: The Firopean Impact on the Ilealth of Non-Luropeans, apresenta uma analise comparativa entre os perfis de saúde de populações nativas norte-americanas, polinćsias e australianas, contemplando comparações internacionais macro e microssociais. Esse autor enfatiza que, "ao se refletir sobre as doenças em populações humanas, a importância do conhecimento local não deve ser subestimado" (Kunit $z, 1994: 177$ ), o que pode gerar uma sensibilidade teórico-metodológica com vistas a "compreender em detalhe a miríade de formas como diferentes causas de morbidade e mortalidade... são afetadas por processos sociais" (Kunitz, 1994:5).

Ao longo de uma linha de reflexĩo similar, Coimbra Jr. et al. (2002) propõem que o padrão de tranısição cpideniológica que se observa cntre os Xavánte ć distinto daqueles que têm sido descritos nla literatura (Barreto \& Carmo, 20)00; Frenk et al., 1991). Ao contrário do observado em países como o Brasil, no qual percebe-se mala sobreposição de doenç̧as infecciosas e crônicas não-transminssí- 
veis, num contexto de envelhecimento da população, no caso Xavánte a sobreposição não está se fazendo acompanhar do envelhecimento populacional. Ou seja, um modelo de transição epidemiológica do tipo polarizado, mas sem associação ao envelhecimento. Essses autores enfatizam também que a diversidade de perfis epidemiológicos dos Xavánte apresenta repercussões importantes para a assistência à saúde. Com a emergência das doenças crônicas não-transmissíveis, as diretri\%es de atenção à saúde precisarão ser redefinidas. Como assinalado por Coimbra Jr. et al. (2002:272), “... [atualmente] os serviços de saúde oferecidos para os Xavánte, que aparentemente não são capazes de lidar com as doenças infecciosas, apresentam-se ainda mais deficientes quando confrontados com a crescente carga de doenças crônicas".

A constatação da existência de perfis epidemiológicos significativamente distintos no âmbito de uma mesma etnia, como os Xavánte, apresentando variações importantes entre habitantes de diferentes aldeias, reforça o caráter singular da atenção à saúde de populações indígenas. Tal singularidade assume importância particular na medida em que planos de ação claborados com base em informações agregadas podem se revelar pouco apropriados quando implementados em uma gama de aldeias com realidades e necessidades heterogêneas. Isto não significa, porém, que tendências gerais scjam desprovidas de importância; clas certamente respondem à necessidade de sistematização dos dados em termos progressivamente mais agregados, e possuem uma indiscutível aplicabilidade no que se refere ao delineamento das ações de saúde dirigidas aos povos indígenas.

Consideramos que o caso Xavánte tem implicações significativas para a comprecnsão da dinâmica de sańde dos povos indígenas no Brasil num contexto mais amplo. () que buscamos assinalar foi a notável heterogencidade interna de uma sociedade, resultando cm um mosaico epidemiológico que está longe de ser aleatório, mas fruto de histórias de contato e interação com a sociedade nacional que produziram configuraçôes particulares. Um desafio importante na implantação da distritalização da saúde indígena é contemplar de mancira satisfatória e concomitante as particularidades e as macrotendências de transformação do perfil epidemiológico dos povos indígenas no Brasil. 


\section{Referências}

ALLEN, L. H., 1993. Iron-deficiency anemia increases risk of preterm delivery. Nutrition Reviews, 51:49-52.

ARANTES, R.; SANTOS, R. V. \& COIMBRA Jr., C. E. A., 2001. Saúde bucal na população indígena Xavante de Pimentel Barbosa, Mato Grosso, Brasil. Cadernos de Saúde Pública, 17:375-384.

BARRETO, M. L. \& CARMO, E. H., 2000. Mudanças em padrões de morbimortalidade: Conceitos e métodos. In: Velhos e Novos Males da Saúde no Brasil: A Evolução do Pais e de suas Doenças (C.A. Monteiro, org.), pp. 17-30, São Paulo: Editora Hucitec.

BARUZZI, R. G.; MARCOPITO, L. F.; SERRA, M. L. C.; SOUZA, F. A. A. \& STABILE, C., 1977. The Kren-akarore: A recently contacted indigenous tribe. In: Health and Disease in Tribal Societies (K. Elliot \& J. Whelan, ed.), pp. 179-211, Amsterdam: Elsevier.

CAPPELI, J. C. S. \& KOIFMAN, S., 2001. Avaliação do estado nutricional da comunidade indígena Parkatêjê, Bom Jesus do Tocantins, Pará, Brasil. Cadernos de Saúde Pública, 17:433-437.

CARDOSO, A. M.; MAT”TOS, I. E. \& KOIFMAN, R., 2001. Prevalência de fatores de risco para doenças cardiovasculares na população Guaraní-Mbyá do Esstado do Rio de Janeiro. Cadernos de Saúde Pública, 17:345-354.

COIMBRA Jr., C. E. A. \& SANTOS, R. V., 1991. Avaliação do estado nutricional num contexto de mudança socioeconômica: O grupo indígena Suruí do Estado de Rondônia, Brasil. Cadernos de Saúde Pública, 7:538-562.

COIMBRA Jr., C. E. A.; FLOWERS, N. M.; SALZANO, F. M. \& SANTOS, R. V., 2002. The Xavánte in Transition: Health, Ecology, and Bioanthropology in Central Brazil. Ann Arbor: University of Michigan Press.

DATASUS (Departamento de Informática do SUS), 2000. Indicadores e Dados Básicos, Brasil, 1997. Acesso em 15 de abril de 2003 <http://www.datasus.gov.br.cgi/idb/ matriz.htm>.

EARLY, J. \& PETERS, J., 1990. The Population Dynamics of the Mucajai Yanomama. San Diego: Academic Press.

FLOWERS, N. M., 1983. Forager-Farmers: The Xavante Indians of Central Brazil. Ph.D. 'Thesis, New York: City University of New York.

FRENK, J.; FREJKA, T.; BOBADILLA, J. L.; STERN, C.; LOZANO, R.; SEPULVEDA, J. \& JOSE, M., 1991. La transición epidemiológica en América Latina. Boletín de la Oficina Sanitaria Panamericana, 111:485-496.

FUNASA (Fundação Nacional de Saúde), 2000. Relatório Anual da Atividades da Equipe de Saúde do Distrito Sanitário Xavante, Administração Regional de Barra do Garças. Barra do Garças: FUNASA. (mimeo.)

FUNASA (F'undação Nacional de Saúde), 2002. Atenção à Saúde dos Povos Indígenas. 30 maio $2002<\mathrm{http}: / /$ www.funasa.gov.br/ind/ind00.htm>.

GARFIELD, S. W., 2001. Indigenous Struggle at the Heart of Brazil: State Policy, Frontier Expansion, and the Xavante Indians, 1937-1988. Durham: Duke University Press.

GIACCARIA, B. \& HEIDE, A., 1972. Xavante: Povo Autêntico. São Paulo: Editorial Dom Bosco. 
(;RAHAM, I. R., 1995. Performing Dreams: Discourse of Immortality among the Xavante of Central Brazil. Austin: University of 'Texas Press.

GUCF.I MIN, S. A., 1995. Nutrição e Alocação de lempo dos Xavantes de Pimentel Barbosa, Mato Grosso. I'm Eistudo em Eicologia Humana e Mudanças. Dissertação de Mestrado, Rio de Janeiro: Fundação Oswaldo Cruz.

GUGELMIN, S. A., 200) I. Antropometria Nutricional e Licologia Humana dos Xavante de Sangradouro-Volta Crande, Mato Grosso. Tese de Doutorado, Rio de Janeiro: Fundação Oswaldo Cru\%.

(GUCELAIN, S. A. \& SANTOOS, R. V., 2001. Fcologia humana e antropometria nutricional de adultos Xavantes, Mato Grosso, Brasil. Cademos de Saúde Pública, 17:313322.

HAAS, J. I). \& BROW.ILE, I., 2001. Iron deficiency and reduced work capacity: Joumal of Nutrition, 131:676S-69)S.

IANELLI, R.; SILVA, J. \& AG,OSTINI, S., 1995. Parasitoses intestinais nos índios Xavantes de Parabuburc, Mato Grosso, Brasil. Cadernos de Saude Pública, 11:63().

KUNII\%, S. J., 1994. Disease and Social Diversity: The liuropean Impact on the Health of Non-Europeans. New York: Oxford Iniversity Press.

L,ETTE, M. S., 1998. Avaliação do l'stado Nutricional da População Xavante de São José, Terra Indigena Sangradouro-Volta Crande, Mato Grosso. Disscrtação de Mestrado, Rio de Janciro: Fundação ()swaldo ('nuz.

L.FITL, M. S.; SII.VA, J. P.; COMMBRA Jr., C. F. A. \& SANTOS, R. V., 2002. Anemia parasitismo intestinal em uma população indígena do Brasil Central: Os Xavantes de Sangradouro-Volta (irande, Mato Crosso. Revista Brasileira de Epidemiologia, Suplemento Fispecial:67.

I.OPFS-DA-SILVA, A., 1986. Nomes e Amigos. Da Prática Xavante a uma Reflexão sobre os Jê. São Paulo: Faculdade de Filosofia, I cetras e Ciĉncias Humanas, Universidade de São Paulo.

LOPFS-I A-SIIXA, A., 1992. Dois séculos e meio de história Xavante. In: História dos Índios no Brasil (M. C. Canhla, org.), pp. 357-378, São Paulo: Companlia das l,ctras.

MAYBURY-L.EWIS, D., 1984. A Sociedade Xavante. Rio de Janeiro: Francisco Alves.

MLi.:ZZLS, (;., 1984. Missionários e Índios em Mato Grosso (Os Xavantes da Reserva de São Marcos). 'Tése de Doutorado, São Paulo: Iniversidade de São Paulo.

MONTEIRO, C. A., 1998. Epidemiologia da obesidade. In: Obesidade (A. F. C. Halpern, A. F. (;. Matos, H. I.. Suplicy, M. (. Mancini \& M. 'T' Kanclla, org.), pp. 15-30), São) Paulo: Letmos.

MONTEIRO, C. A., 2000. Prolucão da mutrição infantil nos anos 90. In: Velhos e Novos Males da Saúde no Brasil: A Evolução do País e de suas Doenças (C. A. Monteiro, org.), pp. 375-392, São Paulo: Hucitec.

MURPIY, N.; SCHRIVR, C.; IHFILE, M.; BOYKO, li.; IOO'TY, B. \& IANILR, A., 1997. Hypertension in Alaska Natives: Association with orerweight, glucose intolerance, dict and mechanized activity. lithricity and Health, 2:267-275.

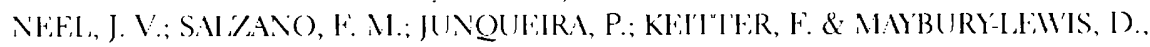


1964. Studies on the Xavante Indians of the Brazilian Mato Grosso. American Journal of Human Genetics, 16:52-140.

NISWANDER, J.; KEITTER, F. \& NEEL, J. V., 1967. Further studies on the Xavante Indians. II. Some anthropometric, dermatoglyphic, and nonquantitative morphological traits of the Xavantes of Simões Lopes. American Journal of Human Genetics, 19:490501.

PAGliarO, H., 2002. A Revolução Demográfica dos Povos Indígenas do Brasil: A Experiência dos Kaiabi do Parque Indígena do Xingu - Mato Grosso, 1970-1990. Tese de Doutorado, São Paulo: Faculdade de Saúde Pública, Universidade de São Paulo.

PAHO (Pan American Health Organization)/WHO (World Health Organization), 1994. Nutritional situation in the anemias. Epidemiological Bulletin, 15:1-6.

POSE, S. B., 1993. Avaliação das Condições de Saúde Bucal dos Índios Xavantes do Brasil Central. Dissertação de Mestrado, Rio de Janeiro: Fundação Oswaldo Cruz.

RAVAGNANI, O. M., 1978. A Experiência Xavante com o Mundo dos Brancos. Tese de Doutorado, São Paulo: Fundação Escola de Sociologia e Política de São Paulo.

SANTOS, R. V., 1991. Coping with Change in Native Amazonia: A Bioanthropological Study of the Gavião, Suruí and Zoró, Tupi-Mondé Speaking Societies from Brazil. Ph.D. 'Thesis, Bloomington: Indiana University.

SANTOOS, R. V., 1993. Crescimento físico e estado nutricional de populações indígenas brasileiras. Cademos de Saúde Pública, 9(Sup. 1):46-57.

SANTOS, R. V. \& COIMBRA Jr., C. E. A., 1994. Contato, mudanças socioeconômicas e a bioantropologia dos Tupí-Mondé da Amazônia Brasileira. In: Saúde e Povos Indígenas (R. V. Santos \& C. E. A. Coimbra Jr., org.), pp. 189-211, Rio de Janeiro: Editora Fiocruz.

SANTOS, R. V. \& COIMBRA Jr., C. E. A., 1996. Socioeconomic differentiation and body morphology in the Suruí of Southwestern Amazonia. Current Anthropology, 37:851856.

SANTOS, R. V.; COIMBRA Jr., C. E. A.; FLOWERS, N. M. \& SILVA, J., 1995. Intestinal parasitism in the Xavante Indians from Central Brazil. Revista do Instituto de Medicina Tropical de São Paulo, 37:145-148.

SANTOS, R. V.; FLOWERS, N. M.; COIMBRA Jr., C. E. A. \& GUGELMIN, S. A., 1996. Human ecology and health in the context of change: The Xavante Indians of Mato Grosso, Brazil. In: Human Ecology and Health: Adaptation to a Changing World (M.-L. Follér \& L. Hanson, ed.), pp. 92-117, Göteborg: Göteborg University.

SANTOS, R.V.; FLOWERS, N. M.; COIMBRA Jr., C. E. A. \& GUGELMIN, S. A., 1997. Tapirs, tractors and tapes: The changing economy and ecology of the Xavánte Indians of Central Brazil. Human Ecology, 25:545-566.

SOUZA, L. G., 1999. Perfil Demográfico dos Xavantes de Sangradouro-Volta Grande, Mato Grosso, 1993-1997. Dissertação de Mestrado, Rio de Janeiro: Fundação Oswaldo Cruz.

SOUZA, L. G. \& SANTOS, R. V., 200l. Perfil demográfico da população indígena Xavante de Sangradouro-Volta Grande, Mato Grosso (1993-1997), Brasil. Cadernos de Saúde Pública, 17:355-365.

SCRIMSHAW, N. S., 1991. Iron deficiency. Scientific American, 265:46-\$2. 
TAVARES, E.; VIEIRA FILHO, J. P. B.; ANDRIOLO, A. \& FRANCO, L., 1999. Anormalidades de tolerância à glicose e fatores de risco cardiovascular em uma tribo indígena aculturada da Região Amazônica brasileira. Arquivos Brasileiros de Endocrinologia e Metabologia, 43(Sup. 1):s235.

TROWBRIDGE, F.; HARRIS, S.; COOK, J.; DUNN, J.; FLORENTINO, R.; KODYAT, B.; MANNAR, M.; TONTISIRIN, K.; UNDERWOOD, B. \& YIP, R., 1993. Coordinated strategies for controlling micronutrient malnutrition: A technical workshop. Journal of Nutrition, 123:775-787.

VIEIRA FILHO, J. P. B., 1977. O diabetes mellitus e as glicemias de jejum dos índios Caripuna e Palikur. Revista da Associação Médica Brasileira, 23:175-178.

VIEIRA FILHO, J. P. B., 1981. Problemas de aculturação alimentar dos Xavantes e Boróros. Revista de Antropologia, 24:37-40.

VIEIRA FILHO, J. P. B.; OLIVEIRA, A.; SILVA, M.; AMARAL, A. \& SCHULTZ, R., 1997. Polineuropatia nutricional entre os índios Xavantes. Revista da Associação Médica Brasileira, 43:82-88.

VIEIRA FILHO, J. P. B.; RUSSO, E. K. \& NOVO, N., 1983. A hemoglobina glicosilada (HbAl) dos índios Xavantes. Arquivos Brasileiros de Endocrinologia e Metabologia, 27:153-155.

WERNER, D., 1983. Fertility and pacification among the Mekranoti of Central Brazil. Human Ecology, 11:227-245.

WEISS, K.; FERRELL, R. \& HANIS, C., 1984. A New World Syndrome of metabolic diseases with a genetic and evolutionary basis. Yearbook of Physical Anthropology, 27:153-178.

WEST, K. M., 1974. Diabetes in American Indians and other native populations of the New World. Diabetes, 23:841-855.

WHO (World Health Organization), 1975. Control of Nutritional Anaemia with Special Reference to Iron Deficiency. WHO Technical Report Series 580. Geneva: WHO.

YIP, R., 1994. Iron deficiency: Contemporary scientific issues and international programmatic approaches. Journal of Nutrition, 124:1479S-1490S.

YOUNG, T. K., 1988. Are subartic Indians undergoing the epidemiologic transition? Social Science and Medicine, 26:659-671. 



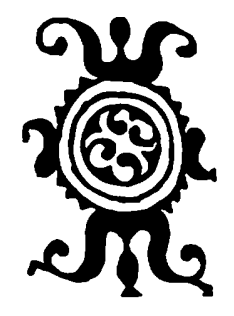

CAUSAS DE INTERNAÇÃO

HOSPITALAR INDÍGENA EM RONDÔNIA.

O DISTRITO SANITÁRIO ESPECIAL

INDÍGENA PORTO VELHO (1998-2001)

Ana Lúcia Escobar, Aline F. Rodrigues,
Cristiano L. M. Alves, Jesem D. Y. Orellana,
Ricardo Ventura Santos, Carlos E. A. Coimbra Jr.

Os povos indígenas de Rondônia atravessam um período singular no que diz respeito ao seu quadro de saúde. Por um lado, as freqüentes e graves epidemias de doenças infecciosas que grassaram por ocasião dos primeiros contatos não parecem mais constituir ameaças a sua sobrevivência. Por outro lado, o processo de mudanças sócio-culturais que se acelerou nos últimos anos vem introduzindo novos agravos (ou riscos de) que incluem, dentre outros, as doenças crônicas não transmissíveis (p. ex., diabetes mellitus, hipertensão arterial), os transtornos mentais e comportamentais (p. ex., alcoolismo), e acidentes ou envenenamentos relacionados ao contato com veículos automotivos, maquinário e defensivos agrícolas (Coimbra et al., 2000; Santos \& Coimbra Jr., neste volume). Além disso, o momento atual envolve a reestruturação do sistema de atenção à saúde, com a implantação dos Distritos Sanitários Especiais Indígenas (DSEIs) a partir da segunda metade de 1999 (Athias \& Machado, 2001; FUNASA, 2002; Langdon, 2000; Santos \& Escobar, 2001).

Infelizmente, com base nas informações demográficas e epidemiológicas disponíveis atualmente no Brasil, não é possível aprofundar análises acerca das condições de saúde dos povos indígenas. No caso de estudos de morbi-mortalidade, bancos de dados de acesso público, como o de Autorizações de Internação Hospitalar (AIHs) ${ }^{1}$, que atualmente representam cerca de 70 a $80 \%$ do total das internações no país, não permitem a identificação do paciente indígena. Soma-se a isso a pouca consistência dos dados eventualmente disponíveis

\footnotetext{
1 Conforme salientam Portela et al. (1997), no que pese o Sistema de Informações Hospitalares do Sistema Único de Saúde (SIH/SUS) não ter sido desenhado com vistas ao controle e avaliação da assistência hospitalar, o mesmo tem possibilitado a geração de informações importantes tanto relativas à morbidade, definida em termos das causas principais de internação, quanto à mortalidade, descrição da assistência e uso de recursos. Infelizmente, esse sistema não permite a desagregação dos dados segundo etnias indígenas.
} 
nos DSEIs, o que resulta em grande dificuldade para se conhecer as causas que levam à hospitalização dos indígenas. Do ponto de vista dos serviços de saúde, a deficiência de informação compromete o planejamento e a avaliação de programas e ações, limitando sobremaneira a aplicabilidade do instrumental epidemiológico na racionalização de recursos. Essas limitações tornam-se mais importantes à medida que os recursos destinados à atenção à saúde desses povos vêm sendo destinados em proporções menores do que aquelas necessárias para que as propostas de intervenção elaboradas com base nas resoluções dos conselhos locais e distritais de saúde indígena sejam contempladas em sua maior parte.

Esse trabalho visa contribuir para o conhecimento da epidemiologia das populações indígenas na Amazônia a partir da análise de causas de internação hospitalar na área de abrangência do DSEI Porto Velho, sediado em Porto Velho, Rondônia. Embora se reconheçam os vários problemas inerentes à qualidade dos dados, incluindo a confiabilidade e a precisão dos registros, considera-se importante esse tipo de estudo por ser uma forma ainda pouco explorada de análise acerca da saúde indígena. Espera-se que o trabalho venha a contribuir para uma melhor compreensão dos problemas que resultam em busca de serviços hospitalares dada a baixa resolutividade da atenção básica que persiste no cenário atual da saúde indígena no Brasil.

\section{POPULAÇ̃̃o E MÉTODOS}

Do ponto de vista gerencial, os serviços de saúde indígena no Estado de Rondônia estão estruturados em dois DSEIs, um dos quais sediado em Porto Velho. A responsabilidade pela operacionalização dos serviços de saúde na área coberta por esse distrito é repassada, através de convênio, da Fundação Nacional de Saúde (FUNASA) para a CUNPIR (Coordenação da União das Nações e Povos Indígenas de Rondônia, Noroeste de Mato Grosso e Sul do Amazonas), uma organização não-governamental.

A população atendida no DSEI Porto Velho contempla cerca de 20 etnias que totalizam, aproximadamente, 6.500 pessoas. Essa população encontrase distribuída em cerca de 80 aldeias localizadas em 10 municípios de Rondônia (Ariquemes, Alta Floresta d'Oeste, Campo Novo de Rondônia, Guajará-Mirim, Ji-Paraná, Jarú, Mirante da Serra, Nova Mamoré, Porto Velho e São Miguel do Guaporé) e um do Amazonas (Humaitá). A rede de atenção básica desse DSEI é 
composta por cinco equipes de saúde localizadas nos pólos-base de Guajará-Mirim, Ji-Paraná, Alta Floresta d'Oeste e Humaitá (ver FUNASA, 2002 para maiores informações).

Foram estudados registros existentes na Casa de Saúde do Índio de Porto Velho (CASAI - Porto Velho) referentes ao período 1998-2001. As CASAIs têm por objetivo facilitar o acesso da população indígena ao atendimento secundário e terciário, servindo de apoio entre a aldeia e a rede de serviços do SUS. ${ }^{2}$ Os dados foram obtidos a partir dos diários de enfermagem da CASAI, nos quais são registradas as internações de indígenas na rede hospitalar da cidade de Porto Velho. Foram coletados os seguintes dados: nome do paciente, sexo, etnia, data de nascimento, data de internação, motivo da internação, data de alta e desfecho. As causas de internação foram agrupadas e classificadas de acordo com a CID-10 (OMS, 1995).

Os dados foram armazenados em bancos de dados estruturados em Excel e as análises realizadas utilizando-se o programa SPSS (versão 9.0).

\section{RESULTADOS}

Foram localizados 499 registros de hospitalização para o período 1998-2001. Desse total, foi possível classificar a causa da internação, segundo os grandes capítulos da CID-10, de 493 (98,8\%).

Indivíduos de 36 etnias foram internados. A ampla maioria dos pacientes é oriunda das seguintes: Karitiána (28,9\%), Kagwahív (Parintintin, Tenharín, Diahói e Júma) (20,8\%), Pakaanóva (Wari’) (10,4\%), Tupí-Mondé (Aruá, Cinta Larga, Gavião, Mekém, Suruí e Zoró) (10,0\%), Urueuwauwáu (6,0\%), Apurinã (4,2\%), Tuparí (3,0\%) e Makuráp (2,8\%). As demais etnias contribuíram com menos de $2 \%$ dos casos cada.

2 Para o cumprimento deste papel, as CASAI devem: a) receber pacientes e seus acompanhantes; b) alojar e alimentar pacientes e seus acompanhantes durante o período de tratamento; c) estabelecer os mecanismos de referência e contra-referência com a rede do SUS; d) prestar assistência de enfermagem aos pacientes pós-hospitalização e em fase de recuperação; e) acompanhar os pacientes para consultas, exames subsidiários e internações hospitalares e f) fazer a contra-referência com os DSEIs e articular o retorno dos pacientes e acompanhantes aos seus domicílios, por ocasião da alta (ver FUNASA, 2003). 
Pacientes de todas as idades foram internados, variando de 0 a 87 anos. Cerca de metade dos registros referem-se a crianças menores de 5 anos $(31,4 \%)$ e entre 5-10 anos (13,8\%). A porcentagem de indivíduos com mais de 50 anos de idade é relativamente pequena ( $12,7 \%)$. Considerando o total de internações, não há diferença entre os sexos ( $51,8 \%$ mulheres; $48,2 \%$ homens). Contudo, nota-se que na faixa etária de 20-50 anos há predomínio de mulheres $(69,0 \%)$. Dentre os pacientes com idades superiores a 50 anos, predominam os homens $(62,5 \%)$ (Tabela 1).

Excluídas as causas de internação classificadas no capítulo XV (relativas a parto, gravidez e puerpério), a distribuição por sexo e idade indica uma predominância de homens $(57,7 \%)$, o que também se aplica para as diversas faixas etárias (Tabela 2).

Agrupando-se os registros segundo três grupos de etnias (Karitiána, Kagwahív e outras), nota-se que há diferenças entre as médias de idade dos pacientes $(16,0,25,7$ e 21,7 anos, respectivamente) $(\mathrm{p}<0,05)$, com uma média geral de 20,8 anos. Ao se excluir as causas obstétricas, a média de idade dos pacientes experimenta ligeira redução (média de 20,0 anos), permanecendo as diferenças entre os três grupos.

As cinco causas de internação mais freqüentes (que totalizam 70,4\%) são: doenças do aparelho respiratório (20,4\%); doenças infecciosas e parasitárias (15,6\%); gravidez, parto e puerpério (15,4\%); contato com serviços de saúde (10,8\%); sintomas e sinais mal definidos $(8,2 \%)$ (ver Tabela 3 e Figura 1). Dentre as causas de internação classificadas no capítulo I (doenças infecciosas e parasitárias), as doenças diarréicas foram as mais freqüentes (41\%), seguidas pela tuberculose (19\%) e a malária (17\%).

Considerando os sexos combinados e excluindo as causas obstétricas, observa-se que, dentre as causas de internação mais freqüentes (mais de 30 ocorrências), as doenças infecciosas e parasitárias e aquelas do aparelho respiratório predominam nas crianças de 0-10 anos. Nota-se também nessa faixa etária o registro de $50 \%$ do total de internações devidas a "sintomas e sinais mal definidos". A categoria "contatos com serviços de saúde" apresenta uma distribuição menos concentrada. Em relação às causas de internação com freqüências intermediárias (entre 10 e 30 ocorrências), enquanto as doenças endócrinas e nutricionais predominam nas crianças, as demais causas (oftalmológicas, digestivas e lesões, envenenamentos e causas externas) ocorrem principalmente em adultos (Tabela 4).

A comparação das causas de internação nos hospitais em Porto Velho, no período de 1998 a 2001, entre a população geral e a indígena, revela vários 
Tabela 1

Distribuição das internações de indígenas em hospitais de Porto Velho, Rondônia, por faixa etária e sexo, 1998-2001.

\begin{tabular}{|c|c|c|c|}
\hline \multirow[t]{2}{*}{ Faixa etária (anos) } & \multicolumn{2}{|c|}{ Sexo } & \multirow[t]{2}{*}{ Total } \\
\hline & Fem & Masc & \\
\hline \multicolumn{4}{|l|}{$00 \vdash 05$} \\
\hline $\mathrm{n}$ & 64 & 75 & 139 \\
\hline$\%$ & 46,0 & 54,0 & 100,0 \\
\hline$\%$ do total & 14,5 & 17,0 & 31,4 \\
\hline \multicolumn{4}{|l|}{$05 \vdash 10$} \\
\hline $\mathrm{n}$ & 26 & 35 & 61 \\
\hline$\%$ & 42,6 & 57,4 & 100,0 \\
\hline$\%$ do total & 5,9 & 7,9 & 13,8 \\
\hline \multicolumn{4}{|l|}{$10 \vdash 20$} \\
\hline $\mathrm{n}$ & 40 & 33 & 73 \\
\hline$\%$ & 54,8 & 45,2 & 100,0 \\
\hline$\%$ do total & 9,0 & 7,5 & 16,5 \\
\hline \multicolumn{4}{|l|}{$20 \vdash 50$} \\
\hline $\mathrm{n}$ & 78 & 35 & 113 \\
\hline$\%$ & 69,0 & 31,0 & 100,0 \\
\hline$\%$ do total & 17,6 & 7,9 & 25,6 \\
\hline \multicolumn{4}{|l|}{$50 \mathrm{e}+$} \\
\hline $\mathrm{n}$ & 21 & 35 & 56 \\
\hline$\%$ & 37,5 & 62,5 & 100,0 \\
\hline$\%$ do total & 4,8 & 7,9 & 12,7 \\
\hline \multicolumn{4}{|l|}{ Total } \\
\hline $\mathrm{n}$ & 229 & 213 & 442 \\
\hline$\%$ & 51,8 & 48,2 & 100,0 \\
\hline$\%$ do total & 51,8 & 48,2 & 100,0 \\
\hline
\end{tabular}


Tabela 2

Distribuição das internações de indígenas em hospitais de Porto Velho, Rondônia, por faixa etária c sexo, 1998-2001, excluídas as causas obstétricas.

\begin{tabular}{|c|c|c|c|}
\hline \multirow[t]{2}{*}{ Faixa ctária (anos) } & \multicolumn{2}{|c|}{ Sexo } & \multirow[t]{2}{*}{ Total } \\
\hline & Fem & Masc & \\
\hline \multicolumn{4}{|l|}{$00 \vdash 05$} \\
\hline$n$ & 62 & 74 & 136 \\
\hline$\%$ & 45,6 & 54,4 & 100,0 \\
\hline$\%$ do total & 17,0 & 20,3 & 37,4 \\
\hline \multicolumn{4}{|l|}{$05 \vdash 10$} \\
\hline$n$ & 26 & 35 & 61 \\
\hline$\%$ & 42,6 & 57,4 & 100,0 \\
\hline$\%$ do total & 7,1 & 9,6 & 16,8 \\
\hline \multicolumn{4}{|l|}{$10 \vdash 20$} \\
\hline n & 14 & 32 & 46 \\
\hline$\%$ & 30,4 & 69,6 & 100,0 \\
\hline$\%$ do total & 3,8 & 8,8 & 12,6 \\
\hline \multicolumn{4}{|l|}{$20 \vdash 50$} \\
\hline 11 & 31 & 35 & 66 \\
\hline$\%$ & 47,0 & 53,0 & 100,0 \\
\hline \% do total & 8,5 & 9,6 & 18,1 \\
\hline \multicolumn{4}{|l|}{$50 e+$} \\
\hline n & 21 & 34 & 55 \\
\hline$\%$ & 38,2 & 61,8 & 100,0 \\
\hline$\%$ do total & 5,8 & 9,3 & 15,1 \\
\hline \multicolumn{4}{|l|}{ Total } \\
\hline $\mathrm{n}$ & 154 & 210 & 364 \\
\hline$\%$ & 42,3 & 57,7 & 100,0 \\
\hline$\%$ do total & $+2,3$ & 57,7 & 100,0 \\
\hline
\end{tabular}


Tabela 3

Distribuição das causas de internação de indígenas em hospitais de Porto Velho,

Rondônia, 1998-200, segundo a CID-10.

\begin{tabular}{llc}
\hline Causas de internação & $\mathbf{n}$ & $\%$ \\
\hline Doenças do aparelho respiratório (oap. X) & 102 & 20,4 \\
Doenças infecciosas e parasitárias (cap. I) & 78 & 15,6 \\
Gravidez, parto e puerpério (cap. XV) & 77 & 15,4 \\
Contatos corn serviços de saúde (cap. XXI) & 54 & 10,8 \\
Sintomas e sinais mal definidos (cap. XVIII) & 41 & 8,2 \\
Lesões, envenenamentos e causas externas (caps. XIX e XX)* & 38 & 7,6 \\
Doenças endócrinas, nutricionais e metabólicas (cap. IV) & 26 & 5,2 \\
Doenças do olho e anexos (cap. VII) & 18 & 3,6 \\
Doenças do aparelho digestivo (cap. XI) & 14 & 2,8 \\
Doenças do aparelho geniturinário (cap. XIV) & 09 & 1,8 \\
Doenças do aparelho circulatório (cap. IX) & 08 & 1,6 \\
Doenças da pele (cap. XII) & 06 & 1,2 \\
Doenças do sistema nervoso (cap. VI) & 05 & 1,0 \\
Neoplasias (tumores) (cap. II) & 04 & 0,8 \\
Doenças do sangue (cap. III) & 04 & 0,8 \\
Doenças do sistema osteomuscular (cap. XIII) & 04 & 0,8 \\
Transtornos mentais e comportamentais (cap. V) & 02 & 0,4 \\
Malformações congênitas (cap. XVII) & 02 & 0,4 \\
Afecções perinatais (cap. XVI) & 01 & 0,2 \\
lgnoradas & 06 & 1,2 \\
Total & 499 & 100,0 \\
\hline
\end{tabular}

* Foram agrupados os capítulos XIX e XX da CID-10.

pontos relevantes (Tabela 5). Considerando as seis principais causas de internação para os dois grupos, verifica-se o compartilhamento de quatro delas (doenças infecciosas e parasitárias; doenças do aparelho respiratório; gravidez, parto e puerpério; lesões, envenenamentos e causas externas). Doenças dos olhos e anexos, sintomas e sinais mal-definidos e contatos com serviços de saúde figuram como causas de internação muito mais freqüentes em indígenas que na população geral, da ordem de 6 a 12 doze vezes. Por outro lado, neoplasias, transtornos mentais, doenças dos aparelhos circulatório e geniturinário e afecções perinatais figuram como causas de hospitalização proporcionalmente mais relevantes na população geral. 
Figura 1

Distribuição (\%) das causas de internação de indígenas em hospitais de Porto Velho, Rondônia, 1998-2001, segundo a CID-10.

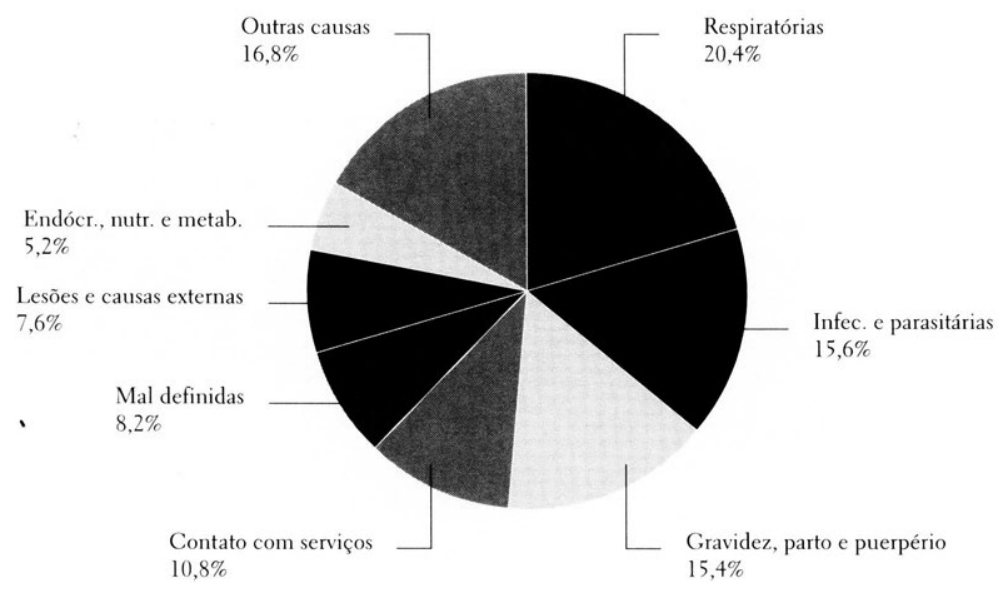

Quanto às internações devido à gravidez, parto e puerpério, nota-se que metade $(48,6 \%)$ das pacientes são da etnia Karitiána. Para o total de mulheres, a idade média das pacientes é de 24,6 anos, variando de 12,3 a 43,4 anos (Tabela 6).

Ao se analisar a distribuição segundo sexo das causas de internação mais freqüentes em indígenas, excetuando aquelas devido à gravidez, parto e puerpério, nota-se predomínio de pacientes do sexo masculino. As diferenças são particularmente pronunciadas para as seguintes causas: sintomas e sinais mal definidos; lesões, envenenamentos e causas externas, e contatos com serviços de saúde (Tabela 7).

Do total de 499 internações, $446(89,4 \%)$ ocorreram em hospitais públicos e $53(10,6 \%)$ em entidades privadas. Os pacientes indígenas foram internados em 14 diferentes hospitais, com a maioria das internações concentradas em três unidades: Hospital Pronto Socorro João Paulo II $(35,1 \%)$, Hospital de Base Ary Pinheiro $(26,7)$ e Hospital Pronto Socorro Infantil Cosme e Damião 
Tabela 4

Distribuição das internações de indígenas em hospitais de Porto Velho, Rondônia, por faixa etária, 1998-2001, excluídas as causas obstétricas, segundo a CID-10.

\begin{tabular}{c} 
Faixa etária (anos) \\
Causas de Internação \\
$00 \vdash 0505 \vdash 1010 \vdash 2020 \vdash 5050 \mathrm{e}+\quad$ Total \\
\hline
\end{tabular}

Doenças infecciosas e parasitárias (cap. I)

n

$\%$

Neoplasias (tumores) (cap. II)

n

$\%$

Doenças do sangue (cap. III)

n

$\%$

Doenças endócr., nutr. e metab. (cap. IV)

n

$\%$

\section{Transtornos mentais}

e comportamentais (cap. V)

n

$\%$

Doenças do sistema nervoso (cap. VI)

n

$\%$

Doenças do olho e anexos (cap. VII)

n

$\%$

Doenças do aparelho circulatório (cap. IX)

n

$\%$

Doenças do aparelho respiratório (cap. $\mathrm{X}$ )

$\mathrm{n}$

$\%$

$\begin{array}{llcccc}31 & 10 & 8 & 9 & 8 & 66 \\ 47,0 & 15,2 & 12,1 & 13,6 & 12,1 & 100,0\end{array}$

$\begin{array}{cccccc}1 & 2 & 1 & - & - & 4 \\ 25,0 & 50,0 & 25,0 & - & - & 100,0\end{array}$

$\begin{array}{cccccc}2 & 2 & - & - & - & 4 \\ 50,0 & 50,0 & - & - & - & 100,0\end{array}$

$\begin{array}{llllll}13 & 4 & 2 & 3 & 1 & 23\end{array}$

$\begin{array}{llllll}56,5 & 17,4 & 8,7 & 13,0 & 4,3 & 100,0\end{array}$

$\begin{array}{cccccc}- & - & 1 & 1 & - & 2 \\ - & - & 50,0 & 50,0 & - & 100,0\end{array}$

$\begin{array}{cccccc}1 & 1 & 1 & 1 & 1 & 5 \\ 20,0 & 20,0 & 20,0 & 20,0 & 20,0 & 100,0\end{array}$

$\begin{array}{llcccc}1 & - & 2 & 2 & 13 & 18 \\ 5,6 & - & 11,1 & 11,1 & 72,2 & 100,0\end{array}$

(continua) 
Tabela 4 (continuação)

\section{Causas de Internação}

Faixa etária (anos)

$00 \vdash 05 \quad 05 \vdash 10 \quad 10 \vdash 2020 \vdash 5050 \mathrm{e}+$ Total

Doenças do aparelho digestivo (cap. XI)

n

$\%$

Doenças da pele (cap. XII)

n

$\%$

Doenças do sistema osteomuscular (cap. XIII)

n

$\%$

Doenças do aparelho geniturinário (cap. XIV)

n

$\%$

Afecções perinatais (cap. XVI)

n

$\%$

Malformações congênitas (cap. XVII)

n

$\%$

Sintomas e sinais mal definidos (cap. XVIII)

n

$\%$

Lesões, envenenamentos e causas

externas (caps. XIX e XX) ${ }^{*}$

n

$\%$

Contatos com serviços de saúde (cap. XXI)

n

$\%$

Total

n

$\%$

* Foram agrupados os capítulos XIX e XX da CID-10

$\begin{array}{cccccc}3 & 1 & 1 & 4 & 5 & 14 \\ 21,4 & 7,1 & 7,1 & 28,6 & 35,7 & 100,0\end{array}$

$\begin{array}{cccccc}- & 3 & 1 & 2 & - & 6 \\ - & 50,0 & 16,7 & 33,3 & - & 100,0\end{array}$

$\begin{array}{cccccc}- & 1 & 1 & 1 & 1 & 4 \\ - & 25,0 & 25,0 & 25,0 & 25,0 & 100,0\end{array}$

$\begin{array}{cccccc}1 & 2 & 4 & - & 1 & 8 \\ 12,5 & 25,0 & 50,0 & - & 12,5 & 100,0\end{array}$

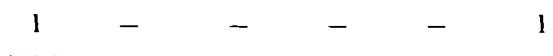

$100.0 \quad-\quad \ldots \quad-\quad-\quad \ldots \quad 100,0$

$\begin{array}{cccccc}2 & - & - & - & - & 2 \\ 100,0 & - & - & - & - & 100,0\end{array}$

$\begin{array}{lccccc}12 & 6 & 3 & 10 & 5 & 36 \\ 33,3 & 16,7 & 8,3 & 27,8 & 13,9 & 100,0\end{array}$


Tabela 5

Distribuição das causas de internação hospitalar, população geral e indígenas, em Porto Velho, Rondônia, 1998-200, segundo a CID-10.

\begin{tabular}{|c|c|c|c|c|c|}
\hline Causas de Internação & Geral & $(\%)$ & Índigenas & $(\%)$ & $\begin{array}{l}\text { Razão } \\
\text { (\%Indígenas/ } \\
\text { \%Geral) }\end{array}$ \\
\hline Doenças infecciosas e parasitárias (cap. l) & 14.691 & 14,1 & 77 & 15,4 & 1,09 \\
\hline Neoplasias (tumores) (cap. II) & 2.509 & 2,4 & 04 & 0,8 & 0,33 \\
\hline Doenças do sangue (cap. III) & 1.057 & 1,0 & 04 & 0,8 & 0,80 \\
\hline $\begin{array}{l}\text { Doenças endócrinas, nutricionais } \\
\text { e metabólicas (cap. IV) }\end{array}$ & 1.902 & 1,8 & 26 & 5,2 & 2,89 \\
\hline $\begin{array}{l}\text { Transtornos mentais } \\
\text { e comportamentais (cap. V) }\end{array}$ & 1.317 & 1,3 & 02 & 0,4 & 0,31 \\
\hline Doenças do sistema nervoso (cap. VI) & 1.874 & 1,8 & 05 & 1,0 & 0,56 \\
\hline Doenças do olho e anexos (cap.VII) & 305 & 0,3 & 18 & 3,6 & 12,0 \\
\hline $\begin{array}{l}\text { Doenças do ouvido e da apófise } \\
\text { mastóide (cap. VIII) }\end{array}$ & 22 & 0,0 & - & - & - \\
\hline Doenças do aparelho circulatório (cap. IX) & 5.262 & 5,0 & 08 & 1,6 & 0,32 \\
\hline Doenças do aparelho respiratório (cap. $\mathrm{X}$ ) & 12.736 & 12,2 & 102 & 20,4 & 1,67 \\
\hline Doenças do aparelho digestivo (cap. XI) & 5.740 & 5,5 & 14 & 2,8 & 0,51 \\
\hline Doenças da pele (cap. XII) & 1.816 & 1,7 & 06 & 1,2 & 0,71 \\
\hline Doenças do sistema osteomuscular (cap. XIII) & 1.158 & 1,1 & 04 & 0,8 & 0,73 \\
\hline Doenças do aparelho geniturinário (cap. XIV) & 5.624 & 5,4 & 09 & 1,8 & 0,33 \\
\hline Gravidez, parto e puerpério (cap. XV) & 32.752 & 31,4 & 77 & 15,4 & 0,49 \\
\hline Afeç̧ões perinatais (cap. XVI) & 2.736 & 2,6 & 01 & 0,2 & 0,08 \\
\hline Malformações congênitas (cap. XVII) & 538 & 0,5 & 02 & 0,4 & 0,80 \\
\hline Sintomas e sinais mal definidos (cap. XVIII) & 1.209 & 1,2 & 41 & 8,2 & 6,83 \\
\hline $\begin{array}{l}\text { Lesões, envenenamentos } \\
\text { e causas externas }{ }^{\text {* }} \text { (cap. XIX e XX) }\end{array}$ & 10.153 & 9,7 & 38 & 7,6 & 0,78 \\
\hline Contatos con serviços de saúde (cap. $\mathrm{XXI}$ ) & 929 & 0,9 & 54 & 10,8 & 12,0 \\
\hline Ignoradas & - & - & 06 & 1,2 & - \\
\hline Total & 104.330 & 100,0 & 499 & 100,0 & 1,0 \\
\hline
\end{tabular}

Fonte: http://tabnet.datasus.gov.br/cgi/tabcgi.exe?sih/cnv/miro.def

* Foram agrupados os capítulos XIX e XX da CID-10. 
Caracterização da idade das mulheres indígenas internadas em hospitais de Porto Velho, Rondônia, por causas obstétricas, 1998-2001.

\begin{tabular}{lccccc}
\hline Etnia & $\mathbf{n}$ & $\begin{array}{c}\text { Média } \\
\text { (anos) }\end{array}$ & $\begin{array}{c}\text { Desvio } \\
\text { padrão }\end{array}$ & Mínima & Máxima \\
\hline Kagwahív & $17(23,6 \%)$ & 24,7 & 9,97 & 14,2 & 41,1 \\
Karitiána & $35(48,6 \%)$ & 24,7 & 8,88 & 12,3 & 43,4 \\
Outras & $20(27,8 \%)$ & 24,3 & 6,62 & 14,0 & 36,3 \\
Total & $72(100 \%)$ & 24,6 & 8,48 & 12,3 & 43,4 \\
\hline
\end{tabular}

$(18,4 \%)$. A distribuição das causas de internação nos hospitais públicos é próxima daquela descrita para o conjunto da população indígena, havendo predominância das doenças respiratórias (22,7\%), infecciosas e parasitárias $(17,0 \%)$ e gravidez, parto e puerpério (14,8\%). Nos hospitais privados, as principais causas de internação foram: contatos com serviços de saúde $(30,2 \%)$, gravidez, parto e puerpério $(22,6 \%)$ e doenças oculares $(22,6 \%)$. O tempo médio de internação nos hospitais públicos foi de 8,5 dias e nos privados de 3,1 dias, com uma média geral de 8,1 dias.

Do total de internações, ocorreram 28 óbitos, dos quais foi possível identificar o motivo da internação, a idade e o sexo de 22 indivíduos. Desses, 12 $(54,6 \%)$ eram crianças menores de cinco anos e a maioria delas faleceu devido a doenças infecciosas e parasitárias, desnutrição ou sintomas e sinais mal definidos. Considerando o número total de óbitos, a principal causa de internação foram doenças respiratórias $(37,0 \%)$, doenças infecciosas e parasitárias $(22,2 \%)$ e doenças endócrinas e nutricionais $(11,1 \%)$.

Ao se estratificar as internações segundo os períodos pré- e pós-distritalização (ou seja, antes e após a FUNASA ter assumido a responsabilidade pelos serviços de saúde dirigidos à população indígena), foram observadas poucas alterações nas proporções de internações pelas causas mais freqüentes (aquelas com mais de 30 ocorrências) (Tabela 8). Não houve diminuição expressiva dos percentuais de internações devido a doenças infecciosas e parasitárias (capítulo I) e àquelas do aparelho respiratório (capítulo $\mathrm{X}$ ) após a distritalização, tampouco de internações devido à gravidez, parto e puerpério (capítulo XV) e sintomas e sinais mal definidos (capítulo XVIII). Por outro lado, verificou-se um decréscimo das internações devido a lesões, envenenamentos e causas externas (capítulos 


\section{Tabela 7}

Distribuição das causas de internação mais frequientes em indígenas, em hospitais de Porto Velho, Rondônia, por sexo, 1998-2001, excluídas as causas obstétricas, segundo a CID-10.

\begin{tabular}{|c|c|c|c|}
\hline \multirow[t]{2}{*}{ Causas de Internação } & \multicolumn{2}{|c|}{ Sexo } & \multirow[t]{2}{*}{ Total } \\
\hline & $\mathrm{F}$ & $\mathbf{M}$ & \\
\hline \multicolumn{4}{|c|}{ Doenças infecciosas e parasitárias (cap. I) } \\
\hline n & 33 & 45 & 78 \\
\hline$\%$ & 42,3 & 57,7 & 100,0 \\
\hline \multicolumn{4}{|c|}{ Doenças endócr., nutr. e metab. (cap. IV) } \\
\hline $\mathrm{n}$ & 13 & 13 & 26 \\
\hline$\%$ & 50,0 & 50,0 & 100,0 \\
\hline \multicolumn{4}{|c|}{ Doenças do aparelho respiratório (cap. X) } \\
\hline $\mathrm{n}$ & 44 & 58 & 102 \\
\hline$\%$ & 43,1 & 56,9 & 100,0 \\
\hline \multicolumn{4}{|c|}{ Sintomas e sinais mal definidos (cap. XVIII) } \\
\hline $\mathbf{n}$ & 12 & 29 & 41 \\
\hline$\%$ & 29,3 & 70,7 & 100,0 \\
\hline \multicolumn{4}{|c|}{$\begin{array}{l}\text { Lesões, envenenamentos e causas } \\
\text { externas (caps. XIX e XX) }\end{array}$} \\
\hline $\mathbf{n}$ & 11 & 27 & 38 \\
\hline$\%$ & 29,0 & 71,0 & 100,0 \\
\hline \multicolumn{4}{|c|}{ Contatos com serviços de saúde (cap. XXI) } \\
\hline $\mathrm{n}$ & 19 & 35 & 54 \\
\hline$\%$ & 35,2 & 64,8 & 100,0 \\
\hline \multicolumn{4}{|l|}{ Total } \\
\hline $\mathrm{n}$ & 132 & 207 & 339 \\
\hline$\%$ & 38,9 & 61,1 & 100,0 \\
\hline
\end{tabular}

* Foram agrupados os capítulos XIX e XX da CID-10. 
Tabela 8

Distribuição das internaçôes de indígenas em hospitais de Porto Velho, Rondônia,

de acordo com o período referente à distritalização ${ }^{*}, 1998-200$, segundo a CID-10.

\begin{tabular}{lll} 
Causas de Internação & $\begin{array}{l}\text { Antes e depois } \\
\text { da distritalização } \\
\text { Antes } \quad \text { Depois }\end{array}$ & $\begin{array}{c}\text { Total e Razão } \\
\text { (\% Depois/\% Antes) }\end{array}$ \\
\hline
\end{tabular}

Doenças infecciosas e parasitárias (cap. I)

n

$\%$

Neoplasias (tumores) (cap. II)

n

$\%$

Doenças do sangue (cap. III)

n

$\%$

Doenças endócrinas, nutricionais e metabólicas (cap. IV)

$n$

$\%$

Transtornos mentais

e comportamentais (cap. V)

n

$\%$

Doenças do sistema nervoso (cap. VI)

n

$\%$

Doenças do olho e anexos (cap. VII)

$\mathrm{n}$

$\%$

Doenças do aparelho circulatório (cap. IX)

$\mathrm{n}$

$\%$

Doenças do aparelho respiratório (cap. X)

n

$\%$

Doenças do aparelho digestivo (cap XI)

$\begin{array}{lll}0,4 & 0,4 & 1,00\end{array}$

\begin{tabular}{cccc}
$\mathrm{n}$ & 9 & 5 & 14 \\
$\%$ & 4,0 & 1,9 & 0,48 \\
\hline
\end{tabular}

(continua) 
Tabela 8 (continuação)

\begin{tabular}{lcc}
\hline Causas de Internação & $\begin{array}{l}\text { Antes e depois } \\
\text { da distritalização } \\
\text { Antes } \quad \text { Depois }\end{array}$ & $\begin{array}{c}\text { Total e Razão } \\
\text { (\% Depois/\% Antes) }\end{array}$
\end{tabular}

Doenças da pele (cap. XII)

$\mathrm{n}$

$\%$

Doenças do sistema osteomuscular (cap. XIII)

$\mathrm{n}$

$\%$

Doenças do aparelho geniturinário (cap. XIV)

n

$\%$

Gravidez, parto e puerpério (cap. XV)

n

$\%$

Afecções perinatais (cap. XVI)

n

$\%$

Malformações congênitas (cap. XVII)

$\mathrm{n}$

$\%$

Sintomas e sinais mal definidos (cap. XVIII)

n

$\%$

Lesões, envenenamentos

e causas externas (caps. XIX e XX)

n

$\%$

Contatos com serviços de saúde (cap. XXI)

n

$\%$

Total

n

$\%$
4

1,8

2

6

0,7

0,39

2

0,9

2

4

0,78

2

0,9

2,6

9

2,89

$34 \quad 43$

77

15,2

15,9

1,05

$\begin{array}{ccc}- & 1 & 1 \\ - & 0,4 & -\end{array}$

2

0,9

20

21

41

$9,0 \quad 7,8$

0,87

21

17

38

9,4

6,3

0,67

$19 \quad 35$

54

8,5

13,0

1,53

223

270

493

100,0

100,0

1,00

* Até julho de 1999, antes da edição da Medida Provisória No. 1911-08, de 29 de julho de 1999, e da promulgação da Lei No. 9836, de 23 de setembro de 1999, a responsabilidade pelos serviços de saúde estava sob a responsabilidade da FUNAI. Desde então, passaram a ser de responsabilidade da FUNASA. 
XIX e XX) e um expressivo aumento daquelas associadas a contatos com serviços de saúde (capítulo XXI).

\section{DISCUSSÃO}

Apesar das limitações devido ao seu caráter seletivo, os registros hospitalares constituem importantes fontes de informações sobre o perfil de morbidade da população brasileira (ver Cesar et al., 2002; Gouvêa et al., 1997; Lebrão, 1999; Rocha \& Simões, 1999, dentre outros). Esse conjunto de informações pode ser útil não somente para avaliar o sistema de assistência à saúde, como para a formulação e o aperfeiçoamento de políticas de saúde e estratégias médico-assistenciais e preventivas. No caso dos povos indígenas no Brasil, as amplas reformas recém verificadas nas políticas e na estrutura dos serviços de saúde requerem a utilização de diferentes abordagens analíticas visando a caracterização de perfis de morbi-mortalidade e a avaliação do modelo assistencial implantado.

A análise dos registros de hospitalização de indígenas em Porto Velho no período de 1998 a 2001 revela diversos pontos significativos. Entre eles, destacam-se: (a) a elevada diversidade étnica dos pacientes, ao mesmo tempo em que a maioria das internações está concentrada em poucas etnias; (b) excluindo-se as causas obstétricas, verifica-se a predominância de homens, que correspondem a 58\% do total das internações; (c) as internações concentraram-se em crianças menores de 10 anos (54\%); (d) as principais causas de internação são devidas às doenças do aparelho respiratório (capítulo $\mathrm{X}$ ) e às infecciosas e parasitárias (capítulo I).

A elevada freqüência de registros incompletos, aliada ao grande número de causas de internação classificadas como sintomas e sinais mal-definidos, compromete sobremaneira a análise e aponta para falhas importantes na qualidade dos registros existentes na Casa de Saúde do Índio de Porto Velho. Aparentemente, as ações desenvolvidas por este tipo de unidade de saúde, que ocupa posição estratégica no atual modelo de atenção à saúde das populações indígenas, não têm merecido a devida consideração pelos diferentes sistemas de informação em saúde disponíveis. Os dados de morbidade indígena têm sido tratados burocraticamente pelo sistema, havendo clara prioridade pelos indicadores de "produção" (número de consultas, procedimentos, medicação dispensada, etc.). Como revela essa análise, há muito a se avançar para garantir uma qualidade dos dados suficiente para que se possa gerar indicadores epidemiológicos confiáveis. Apesar da 
importância dada à implementação de uma sistemática de referência e contrareferência com a rede hospitalar por parte das CASAIs existentes no país, na prática essa dinâmica não foi observada na CASAI de Porto Velho, razão pela qual tantos registros permanecem incompletos.

Os diferenciais de morbidade hospitalar, segundo etnia, possivelmente estão associados não somente à menor ou maior facilidade relativa de acesso das aldeias à cidade de Porto Velho (distância, existência de linhas de ônibus ou veículo nas aldeias, etc.), como também à disponibilidade de serviços de saúde em localidades próximas às aldeias. A comunidade Karitiána é uma das mais próximas de Porto Velho (cerca de $90 \mathrm{~km}$ ) e não há infraestrutura de serviços de saúde em localidades mais próximas. A freqüência relativamente elevada de pacientes de etnias Kagwahív nos registros de atendimentos realizados em Porto Velho (cidade situada à cerca de $250 \mathrm{~km}$ de suas terras) sugere a existência de dificuldades de atendimento na rede hospitalar de Humaitá, que é a cidade mais próxima. Por outro lado, apesar dos Pakaanóva (Wari') constituírem a população indígena mais numerosa em Rondônia, os mesmos respondem por apenas $10,4 \%$ do total de internações na rede hospitalar de Porto Velho, sugerindo que, possivelmente, os serviços disponíveis na cidade mais próxima - Guajará-Mirim - estejam sendo utilizados no atendimento de suas demandas.

Os diagnósticos mais freqüentes na população indígena foram doenças do aparelho respiratório e doenças infecciosas e parasitárias; gravidez, parto e puerpério e lesões, envenenamentos e causas externas, o que corresponde às principais causas de internação também verificadas na população de Rondônia em geral (DATASUS, 2003). Apesar dessas similaridades, quando se analisa o conjunto mais amplo de causas de internação, notam-se diferenças importantes entre indígenas e não-indígenas. Por exemplo, neoplasias, transtornos mentais e doenças do aparelho circulatório constituem causas mais freqüentes de internação em não-indígenas. Em outras palavras, a se julgar pela análise das internações, aparentemente o perfil de morbidade da população indígena é mais influenciado pelas doenças infecciosas e parasitárias do que o que se observa em não-indígenas de Porto Velho, entre os quais o peso das doenças crônicas não transmissíveis é proporcionalmente mais acentuado.

No tocante às doenças infecciosas e parasitárias, as causas mais freqüentes de internação entre os indígenas foram: diarréias (41\%), malária (19\%) e tuberculose $(17 \%)$. As diarréias desempenham importante papel na determinação do perfil de morbi-mortalidade das populações indígenas de Rondônia, em especial entre crianças de 0-5 anos de idade, conforme indicado por Haverroth et al. 
(2003). A malária constitui uma das principais parasitoses endêmicas nas populações indígenas da Amazônia, tendo sido identificadas áreas de médio e de alto risco de infecção malárica entre os indígenas de Rondônia (Escobar \& Coimbra Jr., 1998; Ianelli, 2000; Sá, 2003). O porcentual expressivo de internações devido à tuberculose confirma a importância dessa endemia nas populações indígenas da região, assim como colocam em evidência a existência de sérios problemas associados às ações de diagnóstico e tratamento direcionadas para o seu controle, conforme assinalado por Escobar et al. (2001).

Observou-se diferença expressiva no tempo médio de internação ao se comparar hospitais públicos e privados. Possíveis razões para o diferencial verificado incluem: perfil diferenciado de causas de internação (por exemplo, nota-se alta frequiência de causas oftalmológicas em instituições privadas) e tendência ao encaminhamento de pacientes que apresentam quadros clínicos mais severos para os hospitais públicos. Investigação mais detalhada faz-se necessária para esclarecer esse ponto.

Com a implantação dos DSEIs, foi proposta uma alteração substancial no modelo de atenção à saúde dirigido às populações indígenas. Este passaria a ser centrado na atenção primária e na resolução da maioria dos problemas na própria aldeia, sendo que as equipes de saúde de cada pólo-base seriam incumbidas do treinamento e acompanhamento dos agentes indígenas de saúde. A estes caberia, então, a prestação dos serviços nos postos de saúde nas aldeias. No entanto, o que observamos neste estudo é que aqueles problemas capazes de sofrer maior impacto destas medidas continuam contribuindo sobremaneira para as internações, especialmente as diarréias $e$ as doenças respiratórias. Por outro lado, notou-se um aumento importante da freqüência de contatos com serviços de saúde.

No caso das diarréias, por exemplo, há avaliações muito positivas acerca do impacto da adoção da terapia de reidratação oral na redução da morbi-mortalidade infantil no Brasil e no mundo (Benício \& Monteiro, 2000; Victora et al., 2000). Os resultados da presente análise indicam que não houve uma redução substancial na proporção de causas de internação devido às doenças infecciosas e parasitárias e àquelas do aparelho respiratório quando são comparados os períodos de 1998-1999 (com os serviços administrados pela FUNAI) e de 2000-2001 (sob a gestão da FUNASA). Portanto, até o momento, não foi possível identificar, através do perfil de morbidade hospitalar, impactos positivos das ações norteadas pelo novo modelo de atenção à saúde, principalmente no tocante aos problemas sensíveis à promoção da saúde, saneamento e atenção básica. 
Chama a atenção que a taxa de mortalidade hospitalar entre os indígenas tenha atingido a cifra de 56,1/1000 no período analisado. Ressalte-se que, no país, esta taxa, para o mesmo período, foi de $26,7 / 1000$, variando de 35,7 na região Sudeste a 14,0 na Região Norte (em Rondônia, foi de 12,4/1000). Outro dado que se sobressai entre as internações de pacientes indígenas são as taxas de mortalidade hospitalar por doenças infecciosas e parasitárias e por doenças respiratórias (83,3 e 108,7/1000 internações, respectivamente), enquanto que, para Rondônia, as mesmas taxas foram de 10,7 e 8,8/1000, respectivamente. Os resultados desse trabalho mostram que uma proporção elevada das mortes dos pacientes indígenas internados ocorreu em crianças menores de cinco anos devido, sobretudo, a doenças respiratórias e infecciosas e parasitárias. Esse quadro aponta para a precariedade dos serviços de saúde dirigidos a essas populações, o que sugere que deve haver um redirecionamento das ações de diagnóstico e tratamento à rede hospitalar, em especial para esses grandes grupos de causas que, de acordo com os pressupostos do modelo de distritalização, deveriam estar sendo resolvidos no posto de saúde da própria aldeia. É possível que o atraso no diagnóstico e no tratamento de doenças como diarréia e infecções respiratórias agudas resulte na remoção e internação tardias dos pacientes, muitas vezes com chances de sobrevida diminuídas.

Apesar das conhecidas limitações dos registros hospitalares para delinear perfis de morbi-mortalidade de populações, as informações sobre internações hospitalares na área de abrangência do DSEI Porto Velho mostraram-se úteis para alcançar um melhor entendimento acerca do quadro epidemiológico dos indígenas de Rondônia. Não há estudos semelhantes na bibliografia sobre saúde dos povos indígenas no Brasil - a maioria dos trabalhos é constituída por estudos de prevalência, resultantes de inquéritos populacionais (ver Santos \& Coimbra Jr., neste volume). Espera-se que a abordagem aqui desenvolvida estimule a realização de outros estudos semelhantes, fundamentais para a análise comparada de tendências de morbidade nos vários distritos sanitários indígenas do país.

\section{Agradecimentos}

Às enfermeiras Isabel Araújo, Denise Pereira Ferrari e Armanda Gomes do Nascimento, da Casa de Saúde do Índio de Porto Velho, pela ajuda durante o levantamento dos registros; à Coordenação Regional da Fundação Nacional de Saúde de Rondônia pelo apoio ao projeto; e à Fundação Ford pelo financiamento da pesquisa. 


\section{Referências}

ATHIAS, R. \& MACHADO, M., 2001. A saúde indígena no processo de implantação dos Distritos Sanitários: temas críticos e propostas para um diálogo interdisciplinar. $\mathrm{Ca}$ dernos de Saúde Pública, 17: 425-431.

BENICIO, M. H. A. \& MONTEIRO, C. A., 2000. Tendência secular da doença diarréica na infância na cidade de São Paulo (1984-1996). Revista de Saúde Pública, 34 (6 Supl.): 83-90.

CESAR, J. A.; HORTA, B. L.; GOMES, G.; SHEHADEH, I.; CHITOLINA, J.; RANGEL, L; SARAIVA, A. O. \& OLIVEIRA, A. K., 2002. Utilização de serviços de saúde por menores de cinco anos no extremo Sul do Brasil. Cadernos de Saúde Pública, 18 : 299-305.

COIMBRA JR., C. E. A.; SANTOS, R.V. \& ESCOBAR, A. L., 2000. Saúde indígena em Rondônia na década de 90. In: Povos Indigenas no Brasil, 1996-2000 (C. A. Ricardo, org.), pp. 591-593. São Paulo: Instituto Socioambiental.

ESCOBAR, A. L.; COIMBRA JR., C. E. A.; CAMACHO, L. A. \& PORTELA, M. C., 2001. Tuberculose em populações indígenas de Rondônia, Amazônia, Brasil. Cadernos de Saúde Pública, 17: 285-298.

DATASUS (Departamento de Informática do SUS, Ministério da Saúde), 2003. Morbidade hospitalar do SUS por local de internação - Rondônia. 06 de junho de 2003 $<$ http://tabnet.datasus.gov.br/cgi/tabcgi.exe?sih/cnv/miro.def>.

ESCOBAR, A. L. \& COIMBRA Jr., C. E. A., 1998. Considerações sobre as Condições de Saúde das Populações das Áreas Indígenas Pakaánova (Wari) e do Posto Indígena Guaporé, Rondônia. Documento de Trabalho n. 1, Porto Velho: Centro de Estudos em Saúde do Índio de Rondônia, Universidade Federal de Rondônia. <http://www. cesir.org>.

FUNASA (Fundação Nacional de Saúde), 2002. Distrito Sanitário Especial Indígena de Porto Velho. 20 de agosto de 2002. <http://www.funasa.gov.br/ind/pdfs/dsei25.pdf .

FUNASA (Fundação Nacional de Saúde), 2003. Saúde Indígena. 20 de agosto de 2002 $<\mathrm{http}: / /$ www.funasa.gov. br/ind/ind0l.htm>.

GOUVÊA, C. S. D.; TRAVASSOS, C. \& FERNANDES, C., 1997. Produção de serviços e qualidade assistencial hospitalar no Estado do Rio de Janeiro, Brasil - 1992 a 1995. Revista de Saúde Pública, 31:601-617.

HAVERROTH, M.; ESCOBAR, A. L. \& COIMBRA JR., C. E. A., 2003. Infecções Intestinais em Populações Indígenas de Rondônia (Distrito Sanitário Especial Indígena Porto Velho). Documento de Trabalho ne 8, Porto Velho: Centro de Fistudos em Saúde do Índio, Universidade Federal de Rondônia <http://www.cesir.org>.

IANELLI, R. V., 2000. Epidemiologia da malária em populações indígenas da Amazônia. In: Doenças Endêmicas: Abordagens Sociais, Culturais e Comportamentais (R. B. Barata \& R. Briceño-León, orgs.), pp. 355-374, Rio de Janeiro: Editora Fiocruz.

LANGDON, E. J., 2000. Salud y pueblos indígenas: los desafios en el cambio de siglo. In: Salud y Enfermedad: Uma Mirada desde las Ciencias Sociales (R. Briceño-León, M. C. S. Minayo \& Carlos E. A. Coimbra Jr., orgs.), pp. 107-117. Rio de Janeiro: Editora Fiocruz. 
LEBRÃO, M. L., 1999. Determinantes da morbidade hospitalar em região do Estado de São Paulo (Brasil). Revista de Saúde Pública, 33:55-63.

OMS (Organização Mundial da Saúde), 1995. Classificação Estatística Internacional de Doenças e Problemas Relacionados à Saúde - 10a Revisão. São Paulo: Centro Colaborador da OMS para a Classificação de Doenças em Português, Faculdade de Saúde Pública, Universidade de São Paulo.

PORTELA, M. C.; SCHRAMM, J. M. A.; PEPE, V. L. E.; NORONHA, M. F.; PINTO, C. A. M. \& CIANELI, M.P., 1997. Algoritmo para a composição de dados por internação a partir do sistema de informações hospitalares do sistema único de saúde (SIH/ SUS) - Composição de dados por internação a partir do SIH/SUS. Cadernos de Saúde Pública, 13: 771-774.

ROCHA, J. S. Y. \& SIMÕES, B. J. G., 1999. Estudo da assistência hospitalar pública e privada em bases populacionais, 1986-1996. Revista de Saúde Pública, 33:44-54.

SÁ, D. R., 2003. Malária em Terras Indígenas Habitadas pelos Pakaanova (Wari'), Estado de Rondônia, Brasil. Estudo Epidemiológico e Entomológico. Dissertação de Mestrado, Rio de Janeiro: Escola Nacional de Saúde Pública, Fundação Oswaldo Cruz.

SANTOS, R. V. \& ESCOBAR, A. L., 2001. Saúde dos povos indígenas no Brasil: perspectivas atuais. Cadernos de Saúde Pública, 17(2) (número temático).

VICTORA, C. G.; BRYCE, J.; FONTAINE, O. \& MONASCH, R., 2000. Reducing deaths from diarrhoea through oral rehydration therapy. Bulletin of the World Health Organization, 78: 1246-1255. 



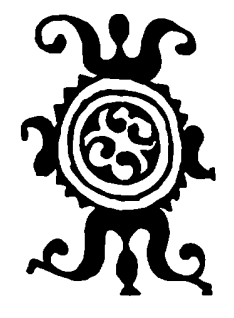

O USO DE BEBIDAS ALCOÓLICAS NAS SOCIEDADES INDÍGENAS: ALGUMAS REFLEXÕES SOBRE OS KAINGÁNG DA BACIA DO RIO TIBAGI, PARANÁ

Juberty Antonio de Souza, Marlene de Oliveira Marilda Kohatsu

Este artigo não tem a intenção de suscitar um debate teórico acerca do alcoolismo, mas apontar para algumas questões referentes ao uso de bebidas alcoólicas no contexto das sociedades indígenas, enfocando principalmente pesquisa realizada entre os Kaingáng da Bacia do Rio Tibagi, no Paraná. Discutir o uso de bebidas alcoólicas e/ou alcoolismo entre este grupo implica desvendar uma longa rede de relações que foram sendo tecidas pelos Kaingáng a partir de uma trajetória estabelecida ao longo do contato com a sociedade nacional. Para compreender este fenômeno, presente na maioria das populações indígenas, faz-se necessário entender as múltiplas causas relacionadas ao processo de alcoolização no interior dessas sociedades.

Nossa análise acerca do fenômeno do alcoolismo não se limita somente aos modelos explicativos da biomedicina, pois esses não têm sido suficientes para compreender o complexo problema do uso de álcool e/ou alcoolismo entre as populações indígenas. As ciências sociais, e antropologia em particular, têm fornecido subsídios importantes para elucidar a diversidade de situações ligadas ao consumo de bebidas alcoólicas, o contexto no qual se aprende a beber, a intensidade do consumo, as representações do beber, as variações nos estilos de beber, etc. Por sua vez, destacamos a importância da epidemiologia, que tem propiciado, por meio de instrumento apropriado, a obtenção de taxas sobre a prevalência do alcoolismo, entre outros aspectos.

Entre os agravos à saúde que acometem os povos indígenas no Brasil, é perceptível que o consumo de bebidas alcoólicas tem se intensificado, ainda que faltem dados precisos para quantificar tendências. No quadro de morbidade ambulatorial, aparece como agravo freqüente, destacando-se como principal causa de mortalidade ligada a fatores externos, tais como acidentes, brigas, quedas, atropelamentos, etc. Doenças como cirrose, diabetes, hipertensão arterial, doenças do coração, do aparelho digestivo, depressão e estresse, entre outras, estão relacionadas ao consumo abusivo de bebidas alcoólicas (Oliveira, 2000b). 
A desnutrição protéico-calórica em crianças aparece de forma bastante significativa nas aldeias indígenas, principalmente na região sul do país, sendo provável que esteja, em parte, ligada ao consumo de bebidas alcoólicas por parte dos pais. As atividades cotidianas, incluindo subsistência e alimentação, podem ser bastante alteradas pelo consumo de bebidas alcoólicas. A síndrome fetal alcoólica, decorrente do consumo de álcool durante a gestação, configura-se como uma realidade perversa que atinge os grupos indígenas. Muitas crianças apresentan problemas de comportamento, deficiências no crescimento, desordem no sistema nervoso central (Siqueira-Duran, 2001), entre outras dificuldades. Nem de longe esses problemas são reconhecidos ou diagnosticados como sendo ligados ao uso de bebidas alcoólicas, ainda que possivelmente estejam en algum grau.

Ainda em relação aos fatores externos ligados ao alcoolismo, têm sido relacionados casos de homicídio, suicídio, violência entre grupos, incestos, abusos sexuais, estupros, que elevam o índice de mortalidade entre os jovens e adultos dentro de áreas indígenas em diferentes estados do Brasil. Esta situação tornouse objeto de preocupação de alguns grupos indígenas, que têm solicitado uma intervenção dos órgãos oficiais para resolver o problema.

Assim, preocupados com a situação sobre uso abusivo de bebidas alcoólicas entre o povo Kaingáng da Bacia do Rio Tibagi e as conseqüências desse processo, foi iniciado um trabalho de pesquisa e intervençãol. Para uma melhor compreensão acerca do uso de bebidas alcoólicas e/ou alcoolismo, ao longo deste texto destacaremos algumas questões ligadas ao beber que têm sido fundamentais para o nosso trabalho. É importante ressaltar que o estabelecimento do debate interdisciplinar tem possibilitado uma melhor compreensão sobre o al-

\footnotetext{
I Este capítulo apresenta dados de uma pesquisa em andamento coletados entre os Kaingáng da T. I. do Apucaraninha da região de Londrina, Paraná. Os Kaingáng são um povo Jê meridional e representam um contingente populacional numericamente importante no sul do país, somando aproximadamente 25 mil pessoas, espalhados pelos Estados de São Paulo, Paraná, Santa Catarina e Rio Grande do Sul. No Paraná, vivem cerca de 7.500 Kaingáng, distribuídos em várias Terras Indígenas. A T. I. Apucaraninha ocupa a porção sudoeste do Município de Londrina, sendo limitada ao norte pelo Rio Apucaraninha, ao sul pelo Rio Apucarana e a leste pelo Rio Tibagi. Os Kaingáng da T. I. Apucaraninha somam aproximadamente 1.300 pessoas, em um total de 250 famílias. A Prefeitura Municipal de Londrina, por intermédio das Secretarias Municipais de Ação Social e Saúde, tem desenvolvido importantes trabalhos junto a esta população.
} 
coolismo nos seus múltiplos fatores. No final do texto apontamos para algumas possibilidades para a implantação de programas, objetivando a redução de danos em relação ao uso de bebidas alcoólicas no contexto dessas sociedades.

\section{REPENSANDO O CONCEITO BIOMÉDICO DO ALCOOLISMO}

É necessário conceituar aqui como o alcoolismo vem sendo definido pelas ciências médicas. Segundo a Organização Mundial da Saúde (OMS), o alcoolismo passou a ser denominado como "Síndrome de Dependência do Álcool" e sua definição enquanto tal é: “...estado psíquico e, também, geralmente físico, resultante da ingestão do álcool, caracterizado por reações de comportamento e outras que sempre incluem uma compulsão para ingerir álcool de modo contínuo ou periódico, a fim de experimentar seus efeitos psíquicos e por vezes evitar o desconforto de sua falta, a tolerancia ao mesmo podendo ou não estar presente" (J.M. Bertolote apud Quilles, 2000:6). Ou ainda, “...uma doença crônica primária, com fatores genéticos, psicossociais e ambientais influenciando seu desenvolvimento e suas manifestações" (Marlatt, 1999).

A síndrome da dependência do álcool é caracterizada como um processo seqüencial, que se inicia com ingestão de bebidas até chegar a uma situação de dependência, num período que varia entre 5 a 10 anos, ligada a fatores cognitivos, comportamentais e fisiológicos. Por outro lado, as incapacidades relacionadas ao álcool consistem em disfunções físicas, psicológicas e sociais que advêm direta ou indiretamente do uso excessivo de bebida e da "dependência" (Souza, 1996).

O conceito biomédico da síndrome de dependência do álcool, caracterizada como universal, tem estabelecido o alcoolismo como doença, cuja causa é sempre a mesma para todas as pessoas em diferentes culturas. Dentro deste conceito, o alcoolismo aparece com conotação física, patológica e individual. No entanto, sabemos da necessidade de relativizar este conceito, visto que diversas culturas têm demonstrado padrões e hábitos de beber bastante específicos (Heath, 1993). Entre os grupos indígenas, a maneira como bebem difere de grupo para grupo, assim como as taxas variam de acordo com as particularidades do contexto sociocultural e histórico de cada povo (Langdon, 2000). Sobre isso, Marlatt (1999:65), cita uma frase bastante pertinente que diz "um só tamanho veste todos”, querendo dizer que: “...pensar desta forma o alcoolismo pode inadvertida- 
mente desencorajar indivíduos com problemas mais leves a participar de serviços de tratamento que trabalhem com propostas de moderação mais apropriados para as suas condições".

Frente a isso, consideramos a necessidade de se repensar o conceito do alcoolismo, elegendo outros fatores que não sejam somente aqueles de ordem biomédica. Para tanto, é importante considerar a contribuição de outras disciplinas, como a antropologia, que parte de outras perspectivas para interpretar o "beber”. Há importantes pesquisas antropológicas que apontaram para maneiras diferentes de se olhar a questão do alcoolismo, demonstrando os vários significados do beber em diferentes povos do mundo (Douglas, 1987; Heath, 1993; Jellinek, 1960; Menéndez, 1990). Estes autores destacam a necessidade de se entender o fenômeno do alcoolismo dentro do contexto sociocultural, sinalizando para a diversidade e as múltiplas representações do "beber" nas diferentes culturas, assim como para as diferentes causas do consumo de bebidas alcoólicas, sua intensidade e estilos de beber (Langdon, no prelo). Segundo Douglas (1987), o uso do álcool não só conduz a um relaxamento dos padrões culturais, mas também a comportamentos altamente padronizados e aprendidos, que diferem de uma cultura para outra. Já Heath (1993), ressalta a diversidade de significados do álcool. Em determinados contextos pode servir de alimento, enquanto que em outros é tido como sagrado. A embriaguez pode ser considerada como um estado religioso, enquanto que em outros grupos, um grande desconforto (D. Heath apud Quilles, 2000).

O consumo excessivo de bebidas alcoólicas e de outras drogas tem se agravado entre várias etnias indígenas no país, o que mostra a situação de vulnerabilidade a que estão expostas. Vários são os fatores que contribuem para o agravamento desta problemática - expropriação, redução e exploração de territórios indígenas, dificuldades de auto-sustentação, moradia nas periferias de grandes cidades, etc. Ao adotarmos uma perspectiva interdisciplinar, buscamos a possibilidade de uma compreensão mais profunda sobre o fenômeno para, assim, podermos (re)orientar e (re)avaliar ações que conduzam à redução do alcoolismo entre esses povos.

\section{DAS BEBIDAS ALCOÓLICAS FERMENTADAS ÀS BEBIDAS ALCOÓLICAS DESTILADAS}

O uso de bebidas fermentadas e de substâncias psicoativas é uma tradição bastante antiga, que por vezes remonta ao período pré-colombiano, e que desempe- 
nha importante papel dentro da estrutura social das diferentes sociedades indígenas do continente sul americano. A maioria dessas sociedades preparava bebidas alcoólicas fermentadas, cujas matérias-primas incluíam seiva da palmeira, mel, frutas, banana, batata doce, milho, mandioca, caju, etc. Eram preparadas e depositadas em cochos de madeira ou em grandes potes de barro, cabendo às mulheres sua produção. $\mathrm{O}$ consumo era coletivo e, em alguns grupos, a beberagem durava dias, até se exaurir o estoque da bebida, e servia para cumprir rituais bem marcados. Outros grupos usavam a bebida fermentada com finalidade terapêutica e em rituais de xamanismo. Outros faziam uso dessas habitualmente, como alimento ou divertimento. A maneira, a finalidade e a ocasião para se fazer uso dessas bebidas diferiam (e continuam a diferir) de um grupo para outro.

Entre os Kaingáng, o uso de bebidas fermentadas restringia-se a rituais, seguindo um calendário bem marcado. Acontecia por ocasião de caçadas, pescarias, colheita, guerra, ritos de nascimento, iniciação, cerimônias fúnebres e celebrações mágico-religiosas. O kiki é uma bebida fermentada feita a base de milho, água e mel, usada durante a festa mais importante dos Kaingáng - o kiki $k o i$, um ritual do culto aos mortos. Sua preparação era marcada por atividades ritualísticas, organizadas pelas metades exogâmicas (kamé e kairu). Os Kaingáng bebiam o kiki até esgotarem os grandes cochos de madeira (Baldus, 1979; Barboza, 1913; Becker, 1976; Borba, 1908; Teschauer, 1905; Veiga, 1994). O kiki koi era um ritual altamente simbólico, no qual transparece a rede social desta sociedade, permitindo aos seus integrantes intensificar suas relações e reafirmar sua identidade grupal.

Segundo Baldus (1979), é possível que o ritual do kiki koi tenha sido realizado em todas as aldeias Kaingáng até o inicio do século XX. Entre os Kaingáng do Apucaraninha, está somente na memória de alguns velhos. Atualmente, os Kaingáng de Chapecó ainda mantêm este rito. Que se saiba, são os únicos que ainda o realizam, preparando a bebida em grandes cochos de madeira, mas adicionando cachaça aos ingredientes tradicionais (Tommasino \& Rezende, 2000).

No Brasil, são vários os grupos indígenas que ainda consomem bebidas alcoólicas fermentadas e, para todos, a bebida possui um significado próprio dentro do contexto na qual é consumida. Entre algumas etnias do Acre, como os Kaxináwa, fabrica-se a caiçuma, feita de batata e de macaxeira, que é consumida durante a festa do mariri. Os Yawanáwa, também fabricantes da caiçuma, costumam encher os cochos de madeira com 200 a 400 litros da bebida "forte", que consomem por ocasião de vários rituais (Oliveira, 2000a). Os Kaxináwa, os Yamináwa e os Kulina, entre outros, têm por costume oferecer às suas crianças a cai- 
çuma. Neste caso, a bebida cumpre a função de alimento e é preparada como "bebida fraca" (Oliveira, 2000a).

Tudo indica que o consumo de bebidas alcoólicas fermentadas entre os grupos indígenas não provocava transtornos de ordem física ou biológica, como acontece em relação ao uso das destiladas no presente. $O$ uso de psicoativos em culturas tradicionais ocorria em contextos ritualizados; sendo assim, raramente apresentava-se como nocivo para os seus participantes, no grau que se vê nos dias atuais. No entanto, pela dinâmica do contato, as bebidas tradicionais fermentadas acabaram sendo substituídas, mesmo que parcialmente, pelas destiladas. Em contextos de uso de bebidas fermentadas, a passagem para os destilados parece ocorrer com maior facilidade.

Em Roraima, o caxiri, o mocororo e o pajuaru são produzidos em grande escala e consumidos por quase todas as etnias. Tradicionalmente, além de distintos significados, a bebida servia também como fonte de alimento. No entanto, o uso dessas bebidas já está sendo problemático na região dos Wapixána e Makuxí, conforme relatos de representantes indígenas. Com a introdução dos destilados, ambos os grupos passaram a utilizar a bebida fermentada de forma descontrolada e com uma fermentação superior, que denominam de "bebida forte", o que tem ocasionado muitas desavenças (Oliveira, 2002a,b). Na falta da cachaça, o caxiri e o pajuaru são fabricados pelos indígenas de forma desordenada, deixando de cumprir funções socialmente definidas e ritualísticas. Eintre os Makuxí, as mulheres estão se recusando a fazer o caxiri por conta das grandes bebedeiras de seus maridos e pelos transtornos decorrentes (Oliveira, 2002a,b).

Além da fermentação visando a obtenção de teor alcoólico mais forte, alguns indígenas costumam adicionar às bebidas o fermento comprado em supermercado, objetivando acelerar o processo de fermentação para que possam consumi-las mais rapidamente. Outras vezes adicionam a própria cachaça. Em vários grupos com os quais tivemos contato, a cachaça foi introduzida e começa a fazer parte do cotidiano, contribuindo para a desagregação social, cultural e ocasionando agravos à saúde. Por exemplo, os Yanomámi, que tradicionalmente não consumiam bebidas fermentadas, tomaram de empréstimo o caxiri dos Makuxí e atualmente estão consumindo cachaça em larga escala (E. Magalhães, 2002, comunicação pessoal).

No caso dos Kaingáng, conforme se dava o processo de pacificação e contato, consta que começaram a substituir as bebidas fermentadas nos cochos pela cachaça, fabricada em alambiques ${ }^{2}$, algo que teve importante papel na estratégia de subjugação desse povo frente à sociedade nacional (Mota, 1998; Oli- 
veira, 2000a). A partir de então, deu-se o uso indiscriminado da bebida destilada. Isso ocorreu concomitantemente à catequização, à desvalorização da cultura indígena, à imposição de novos valores e à perseguição aos kuiã, especialistas tradicionais dos Kaingáng.

Com os Teréna do Mato Grosso do Sul, a situação não foi diferente. O contato prolongado e a convivência com os regionais fizeram com que eles compartilhassem dos mesmos problemas, principalmente em relação ao uso de bebidas. A introdução das bebidas destiladas tornou-se uma constante entre este grupo, registrando uma proporção maior do consumo em relação às populações que vivem no entorno de suas aldeias (Aguiar \& Souza, 1997; Souza \& Aguiar, 2000).

\section{OS DIFERENTES PADRÕES \\ DE COMPORTAMENTO ALCOÓLICO}

Outra questão importante é reconhecer como se dá o uso das bebidas, as diferentes atitudes e os diversos estilos de beber (S. Kunitz, apud Langdon, no prelo; Zinberg apud MacRae, 1992).

Ao estudar os Maxakalí, Minas Gerais, Torreta (1997), encontrou 38\% dos adultos fazendo uso semanal de bebidas alcoólicas. Entre os Boróros, Quilles (2000), refere que o costume de beber se dá de forma generalizada. Homens, mulheres, velhos e jovens bebem ou já beberam em alguma época, "socialmente" ou de forma dependente.

Em uma pesquisa sobre alcoolismo entre os Navajo, foram identificados diferentes estilos de beber, destacando-se o "beber social" e o "beber problemático" (S. Kunitz apud Langdon, no prelo). No primeiro, caracterizado por grupos de homens e pela grande quantidade de bebida que ingeriam por dias seguidos, as pessoas conseguiam passar dias e até semanas sem beber ou tinham bebedeiras episódicas. $\mathrm{O}$ segundo estilo era caracterizado por pessoas que bebiam sozinhas. No caso do estilo de beber social, verificou-se que algumas pessoas conseguiam parar de beber sem ajuda ou sem interferência médica, o que não ocorria com os bebedores solitários. Esses não conseguiam parar e nem di-

\footnotetext{
$2 \mathrm{Na}$ Terra Indígena do Apucaraninha, consta que foram instalados vários alambiques para produzir açúcar e aguardente, com várias consequiências. Há referências sobre estes alambiques ainda na época do Governo de Getúlio Vargas.
} 
minuir o uso das bebidas e muitas vezes morriam por causas relacionadas ao uso de álcool.

Entre os Kaingáng, embora alguns bebam individualmente, a grande maioria costuma beber de forma coletiva. Ou seja, o beber é usualmente compartilhado. $\mathrm{O}$ ato de beber em companhia de outros parece ser um elo importante de ligação social, sempre ligado a contextos de reuniões e festividades. Não se percebe muito o estilo "beber sozinho" entre os Kaingáng, embora ocorra.

Outro aspecto importante refere-se à freqüência, isto é, se o consumo acontece todos os dias, em alguns dias ou somente em finais de semana. Entre os Kaingáng, constatamos uma variação que parece estar ligada a determinados valores, como responsabilidade familiar, dinheiro, emprego, problemas de saúde, disposição para o trabalho, entre outros. Enquanto algumas pessoas bebem somente em finais de semana (quando se verifica o aumento de violência e de prisões), outras bebem durante a semana. Os bebedores de finais de semana costumam dizer que "durante a semana a gente não bebe, pois precisa trabalhar para cuidar da família. Se beber, aí estraga tudo e a gente não consegue trabalhar. Agora no fim de semana ai a gente bebe com os companheiros" (homem Kaingáng, 42 anos). Ou seja, para alguns, a responsabilidade em relação à família é um mecanismo importante que reduz o consumo de bebida durante a semana. Segundo outro informante, “...se tivesse dinheiro bebia todos os dias, mas tenho que economizar para andar certo. Sempre tomo uns goles para matar a vontade. Por causa dos companheiros a gente sempre passa na bebida e sente prejudicado" (homem Kaingáng, 32 anos). É bastante comum ouvir lamentações e acusações por parte dos bebedores em relação aos seus companheiros: “A gente passa na bebida por causa dos companheiros, eles não deixam a gente afastar da bebida" (Kaingáng, 39 anos).

Numa análise sobre o estilo de beber de uma comunidade andina, Heath (1993) referiu-se ao beber compartilhado como sendo um "lubrificante social", um símbolo de unidade. Jellinek (1960) fala da dimensão simbólica que a bebida proporciona e o beber compartilhado como possibilidade de identificação de uns com os outros.

Para os Kaingáng, o ato de beber em companhia de uma ou mais pessoas parece estar fortemente vinculado a aspectos da organizaçĩo sociocultural, no qual laços de reciprocidade são estabelecidos e fortalecidos. Quando tem dinheiro, um companheiro oferece para pagar a bebida dos demais, geralmente um parente. Segundo um informante, "muita gente bebia demais aqui, todo os dias. Se eu acho no meio da semana os meus colegas aí eu bebo. No dia de festa aí 
eu bebo mesmo, são muitos os colegas. Tem outro clima de divertimento" (homem Kaingáng, 36 anos). Disse outro: "Não bebo no meio da semana, só bebo na sexta-feira, no sábado e domingo. Se quiser parar de beber, acho que consigo. Às vezes paro, fico 20 dias sem tomar nada e ai os companheiros oferecem e volto a beber. Sozinho não sinto vontade beber, somente quando estou com os companheiros porque eles animam a gente" (homem Kaingáng, 52 anos). Um outro informante, que se diz bebedor de final de semana, relata: "no tempo que eu tomava, sempre tinha vontade de beber depois do trabalho para tirar a dor do corpo. Agora parei de beber porque estou com uma dor meio esquisita. Os amigos me convidaram pra ir na casa deles beber, aí eu experimentei a bebida e logo começou a dor de novo. Talvez eu fico louco. A bebida é boa, mas encurta a vida da gente. A gente quer ser valentão, bom da boca. Já briguei muito e aí encontra com outro valentão e morre matado. Por isso eu tenho que descansar da bebida. Meu irmão me deu conselho, mas se ele quiser beber eu pago pra ele. Meus amigos estão sabendo que eu parei, mas mesmo assim eles oferecem pra mim e às vezes eu pago pra eles. No domingo me ofereceram e eu disse não. Aí eles falaram que eu queria ser melhor que eles. Aí eu pago para eles ficarem contentes" (homem Kaingáng, 42 anos).

Verificamos que as pessoas que bebem sozinhas são aquelas com maior facilidade de se embriagarem durante a semana, a qualquer hora do dia, sendo discriminadas na aldeia. É comum ouvir pessoas dizendo "lá vem fulano e já esta bêbado" ou "esse aí não tem mais jeito". Uma dessas pessoas revelou-nos em seus momentos de não embriaguez o desejo enorme de parar de beber para não mais sofrer. Segundo esse homem, por mais que se esforce, não tem conseguido deixar a cachaça (Oliveira, 2002a,b). Vale ressaltar que alguns homens que bebiam "sem controle" foram deixados por suas mulheres. A propósito, a proporção de mulheres Kaingáng que fazem uso de bebidas alcoólicas é quase insignificante quando comparada aos homens. Entre os Teréna, Souza \& Aguiar (2000) observaram que as mulheres que residem nas periferias de cidades consomem mais álcool do que as residentes nas aldeias.

A religião atua como fator importante entre os Kaingáng no ato de "parar de beber ou começar a beber". Tanto a igreja católica como as pentecostais (Missão Cristianismo Decidido e Assembléia de Deus) têm exercido um papel neste sentido. Os indivíduos que passam pela conversão religiosa devem seguir regras rígidas de conduta e entre elas está a proibição ao uso de bebidas alcoólicas. Em alguns casos, a conversão com a finalidade de deixar a bebida ocorre em aparência, pois, conforme percebemos, muitas pessoas convertidas continuam a beber, muitas vezes de forma oculta. Outros, já convertidos, voltam a beber de 
repente, às vezes até por motivos "banais", como foi o caso de um homem e sua mulher que, após sete anos convertidos, voltaram a fumar e beber porque ficaram desgostosos com um comentário feito por um "irmão" da Igreja.

Segundo Oliveira (2002a,b), a conversão religiosa tem conseguido restringir o uso de bebidas alcoólicas entre os Kaingáng, apesar da ocorrência de "desvios" (i.e., atos ou atitudes "proibidos" pela religião). Isso também foi observado entre os Teréna (Souza \& Aguiar, 2000). Ou seja, a religiosidade apresentase como fator a ser considerado dentre os mecanismos controladores do uso abusivo de álcool. Por outro lado, diferentes igrejas pentecostais instaladas em aldeias de todo o país pregam como principio básico a "conversão das almas pagãs". Faz-se necessária uma maior reflexão sobre os prejuízos que isto tem provocado para as sociedades indígenas.

A idade é também um fator importante na iniciação do consumo de bebidas alcoólicas, o que tem implicações no estabelecimento de programas de prevenção. Em alguns grupos indígenas, como os Teréna, Gavião, Xavánte, Karajá, Tikúna, Maxakalí, Kayapó, Kaiwá, Xakriabá, Makuxí, entre outros, o início do consumo de bebidas destiladas começa entre 10 e 12 anos de idade, e às vezes até mesmo aos 7 anos (Oliveira, 2000a). Esse padrão é também observado entre os Kaingáng. $O$ fato de começarem a beber com esta idade parece marcar um rito de passagem para a fase adulta, visto que neste ato estão embutidos atributos como coragem, força e valentia, que reforçam a idéia de masculinidade. Ao contrário, se deixa de beber, lembrando sempre que são os companheiros que oferecem a bebida, este indivíduo pode ser taxado como fraco ou covarde. $\mathrm{O}$ início precoce do consumo faz com que jovens Kaingáng, quando atingem seus 2027 anos, comecem a apresentar intensas dores no estômago, às vezes convulsões, sintomas possivelmente causados pela síndrome de abstinência.

Shore et al. (1973) e Walker et al. (1994) apontaram que, além das altas taxas de alcoolismo entre indígenas americanos em relação à população não-indígena, estas são maiores entre os mais jovens. O’Nell \& Mitchell (1996) explicam que as maiores taxas de consumo de álcool entre os jovens ocorre como demonstração de coragem, humor e talvez por estarem mais distantes dos valores tradicionais.

Constatada a diversidade nos padrões do comportamento alcoólico dos Kaingáng, o passo seguinte é apreender o significado que atribuem a "beber problemático", "beber sucessivo", "beber excessivo" ou "abuso episódico do álcool" (Langdon, no prelo; Marlatt, 1999). O reconhecimento de especificidades na variação de estilos de beber dentro de um mesmo grupo é importante para melhor 
compreender o fenômeno do alcoolismo, c ajuda a orientar no tratamento annbulatorial oferecido na aldeia. $\Lambda$ partir do entendimento da existência dos diferentes estilos, exemplificados de acordo com as narrativas de nossos informantes, podemos dizer que os Kaingáng percebem o alcoolismo como um fator negativo, fazendo com que busquem alternativas para minorar a situação.

\section{O USO DE BEBIDAS NO CONTEXTO DAS FESTAS}

As festas, incluindo o Dia do Índio, Natal, Ano Novo, Santo Antônio, São João, São Pedro, Festa do Divino, bem como bailes com conjuntos sertanejos, são ocasiões quando os Kaingáng geralmente fazem uso da bebida em larga escala (Oliveira, 2002a,b). É perceptível a ligação que eles estabelecem com a bebida antes, durante c depois da festa, sendo também vários os significados que atribuem ao fato de beberem nestas ocasiões. As festas muitas vezes proporcionam aos jovens o "primciro gole". F́. comum observar nestas ocasiões rapazes e moças fazendo uso de bebidas, ainda que seja somente um copo de cerveja.

O uso da cachaça no contexto das festas estabelece e intensifica uma rede de relações sociais e de troca, visto ser a cachaça distribuída e compartilhada entre todos, além de ser utilizada como justificativa para elevar o ânimo daqueles envolvidos durante a preparação da atividade. Segundo os Kaingáng, "a gente trabalha muito nestes dias e então temos que beber para tirar a canseira do corpo", ou ainda, "temos que dar uns golinhos para que o corpo fique firme para a gente ter coragem de fazer tudo". Festas, como a do Dia do Índio, podem se estender por vários dias, quando se dança a noite inteira, com uma intensa participação de pessoas da região na confraternização. É notável a alegria dos Kaingáng em receber os fóg (isto é, os brancos) nessas ocasiões. Festas como estas levam os Kaingáng a um estado de embriaguez coletiva, principalmente os homens.

Segundo a Lei 6.001, o chamado Estatuto do Índio, é proibida a venda de bebidas alcoólicas para os indígenas. Contudo, no caso dos Kaingáng, no Dia do Índio, existe uma "liberação" para venda de bebidas alcoólicas dentro da aldeia. F́, comum nesta ocasião encontrar pessoas caídas pelo salão de baile ou no gramado ao redor do barracão onde acontece a festa. No entanto, tal situação não parece constituir em nenhum tipo aparente de constrangimento ou vergonha (korég, que significa feio, ruim), o que fica evidenciado em narrativas como: "ninguém pode falar nada porque hoje é permitido beber". Percebe-se que, nos dias posteriores à festa, pessoas que já haviam deixado a bebida por motivos di- 
versos $^{3}$ voltam a fazer uso do álcool, bebendo por várias semanas. Segundo essas pessoas, os antigos companheiros insistem para que bebam e assim acabam não resistindo e recomeçam a beber.

Assim como no passado, as festas são para os Kaingáng uma forma coletiva de expressão social. É também um espaço onde o beber tem uma função que é levar os indivíduos a expressarem emoções e sentimentos 4 . A bebida propicia um estado de desinibição e alegria, tornando-os mais comunicativos e também muito corajosos, o que às vezes acarreta sérios problemas, deixando vir à tona formas de violência. Sob estado de embriaguez, qualquer ofensa pode ser considerada um bom motivo para brigar. As reuniões sociais muitas vezes findam em discussões e acusações, por vezes evoluindo para brigas com a utilização de faca e foice, que resultam em ferimentos e até em morte. Segundo um informante: "A bebida dá coragem na gente. Quando não toma fica com medo de entrar, de falar. Quando toma dá coragem para falar, fazer senviço. Se outro mexer comigo aí eu tenho que enfrentar" (Kaingáng, 36 anos). Ainda que a violência ocasionada pela bebida não aconteça somente nas festas, é nesse contexto que está mais propensa a emergir. Por isso, nessas ocasiões, algumas pessoas recebem como atribuição do cacique a missão de "controlar" aqueles que "passam" na bebida, na intenção de reprimir atitudes violentas.

Dentro da sociedade Kaingáng existe uma diversidade política caracterizada pela existência de facções. Em situações de uso de álcool pode haver o desencadeamento de tensões entre os grupos. A violência doméstica é tida também como uma das consequiências do uso de bebidas. As mulheres são as maiores vítimas e sempre que podem reclamam da atitude de seus maridos com o cacique. O ciúme é outro sentimento desencadeado pela ingestão de bebidas alcoólicas e acaba sendo o principal motivo da violência doméstica. Violência entre pais e filhos também faz parte desta dolorosa realidade.

Embora não seja uma data festiva no sentido mais amplo, o Dia de Finados é também uma data importante para os Kaingáng. Nos dias que o prece-

\footnotetext{
3 Vários são os motivos que levam a parar de beber, incluindo conversão religiosa e problemas de saúde. Há casos de mulheres Kaingáng que adicionam o medicamento "dissulfiram" à comida de seus maridos, para que passem a rejeitar a bebida. Vale ressaltar que não se recomenda este medicamento pelos efeitos colaterais.

4 São vários os sentimentos expressados pelos Kaingáng após a ingestão de bebidas. Assim, para nossa pesquisa foi importante conhecê-los para a própria adaptação do CAGE instrumento de triagem que utilizamos para obtenção de dados epideniológicos.
} 
dem, confeccionam coroas feitas de papel crepom seguindo o modelo ocidental, para enfeitar o cemitério no "dia das almas". É uma data também marcada pelo consumo de bebidas alcoólicas. Se no passado era o kiki a bebida usada no ritual dos mortos, hoje são a cachaça e o vinho. Segundo eles, os "goles" fazem com que se sintam menos tristes ao visitar seus parentes mortos.

Para um melhor entendimento acerca das representações simbólicas dos Kaingáng acerca dessas celebrações na atualidade, podemos nos remeter a Sahlins (1990), em sua abordagem sobre a relação entre a história e o dinamismo das culturas. Segundo ele, "A história é ordenada culturalmente de diferentes modos nas diversas sociedades, de acordo com os esquemas de significação das coisas. O contrário também é verdadeiro: esquemas culturais são ordenados historicamente porque, em maior ou menor grau, os significados são reavaliados quando realizados na prática. A síntese desses contrários desdobra-se nas ações criativas dos sujeitos históricos, ou seja, as pessoas envolvidas. Porque, por um lado, as pessoas organizam seus projetos e dão sentido aos objetos partindo das compreensões preexistentes da ordem cultural. Nesses termos, a cultura é historicamente reproduzida na ação". No processo de "construção cultural", as festas Kaingáng foram (re)criadas e ganharam um novo sentido dentro da organização social do grupo. O uso de bebidas destiladas, produto do dinamismo histórico-cultural desta sociedade, atrela-se também a estruturas mais antigas. Nesse contexto, os Kaingáng, assim como outros grupos indígenas, criaram uma "cultura do beber" bastante distinta.

\section{ESTUDOS EPIDEMIOLÓGICOS SOBRE O ALCOOLISMO}

O alcoolismo constitui uma das primeiras causas de morte em países latino-americanos como México, Chile e Argentina (Menéndez, 1990). Pesquisa realizada na população norte-americana pelo National Clearinghouse for Alcohol and Drug Information (NCADI), revelou que, em 1993, havia 4,2 milhões de novos usuários de álcool e dentre eles, a taxa na faixa de 12-17 anos aumentou de 125 em 1991 para 172 por mil em 1995 (Marlatt, 1999).

O Centro Brasileiro de Informações Sobre Drogas Psicotrópicas (CEBRID) da Universidade Federal de São Paulo, realizou um extenso levantamento em hospitais psiquiátricos, gerais, clínicas e comunidades terapêuticas em todo o país e concluiu que o álcool foi a principal causa de internações por transtornos mentais, alcançando 90\% dos casos (Cavalieri \& Egypto, 2002). 
Em populações culturalmente diferentes, as taxas apresentadas são diferenciadas, de acordo com maior ou menor permissividade para o uso da bebida (Souza \& Aguiar, 2000). Wanberg et al. (1978) demonstram que, dentre brancos, negros e hispânicos, os indígenas são os que apresentam maiores taxas de alcoolismo, o que os autores associaram à desagregação social e cultural. Também nesta vertente, Young (1988) relacionou problemas de álcool e outras doenças à transição epidemiológica entre povos indígenas no Canadá.

Há teorias que atribuem as altas taxas do alcoolismo entre indígenas a fatores de ordem genética. Alguns autores argumentam ao longo da "teoria da água e do fogo" (fire water theory), segundo a qual os indígenas não conseguem segurar o álcool por serem mais vulneráveis às bebidas alcoólicas (Ferreira, 1998). Entre os Navajo, $94 \%$ dos adultos concordam que os indígenas têm problemas com álcool, sendo que $63 \%$ acreditam que os mesmos apresentam alguma debilidade física em relação ao álcool, debilidade essa que os brancos não apresentam (Ferreira, 1998). Até o presente não há evidências suficientes que comprovem essa teoria.

Inquérito realizado entre os Teréna usando o CAGE5 como instrumento de triagem, encontrou uma taxa de alcoolistas de $10,1 \%$ na população geral (Souza \& Aguiar, 2000). Esse percentual foi semelhante ao obtido em população não-indígena, utilizando metodologia semelhante (Miranda-Sá Jr. et al., 1989; Souza, 1996). Quando considerada a faixa de idade acima de 15 anos, a proporção de alcoolistas foi de $17,6 \%$ nos aldeados e de $19,7 \%$ na população que vive na periferia de Sidrolândia (diferenças estatisticamente não significativas). Em relação ao sexo, os resultados apontaram para $31 \%$ entre homens Teréna aldeados e 22,4\% entre não aldeados. Esses valores foram semelhantes aos verificados na literatura internacional, isto é, $50 \%$ dos prováveis dependentes do sexo masculino apresentavam menos de 30 anos de idade (O’Nell \& Mitchell, 1996; Shore et al., 1973; Walker et al., 1994). Entre as mulheres, a prevalência na população aldeada foi de $1,6 \%$, com concentração de casos nas faixas etárias mais elevadas. No entanto, dentre aquelas que vivem na periferia da cidade, a cifra foi

\footnotetext{
5 CAGE é um instrumento de fácil aplicação e alta especificidade que procura determinar os "bebedores de risco". Amplamente utilizado em muitos países, foi validado no Brasil por Masur \& Monteiro (1983) e seu uso tem sido preconizado pelo Ministério da Saúde. O CAGE em versão na língua portuguesa foi validado para a população Teréna na região de Miranda, Mato Grosso do Sul, por Souza \& Aguiar (2000).
} 
de $17,1 \%$, ou seja, uma porcentagem 10 vezes maior que a de mulheres aldeadas e também superior a de mulheres não-indígenas. Na população aldeada, as mulheres consideradas alcoolistas apresentavam meia idade e muitas cram viúias. $\mathrm{Na}$ periferia da cidade eram mais novas, em geral empregadas domésticas.

Utilizando-se do CACF, numa amostra de 93 famílias Kaingáng entrevistadas, com um total de 672 pessoas, foi verificado que aqueles que fizeram uso de bebidas alcoólicas nos últimos 12 meses constituíram 29,9\% da população: 40,1\% entre os homens e 14,2\% entre as mulheres. Fisses valores são bem superiores aos verificados em populaçõcs não-indígenas (Souza, 1996). Deve-sc observar que as taxas aqui apresentadas não significam que todas as pessoas sejam dependentes do álcool, apenas indicam quem fe uso de bebida durante o período do estudo, não podendo ser necessariamente consideradas "dependentes". Todavia, ć importante ressaltar que estas pessoas estão em situação de risco para desenvolver dependência química ao álcool, o que já se observa em alguns casos. A bebida alcoólica que consomem preferencialmente ć a cachaça. Ainda que alguns façam uso de vinho e de cerveja, mas as consideram "bebida de álcool". Produtos como o "álcool de farmácia”, geralmente misturado com água e limão, e mesmo desodorantes, também podem ser consumidos. Foi também estimada a frequiência de pessoas sob risco de desenvolver dependência química ao álcool, que foi de $10,7 \%$ para a população geral (Figura 1). Ao se considerar somente as pessoas acima de 10 anos, a porcentagem aumentou para $18 \%$, e alcançou $21,3 \%$ no scgmento acima de 15 anos, sempre com as cifras dos homens bastante superiores a das mulheres.

\section{ELEMENTOS PARA PROGRAMAS DE PREVENÇÃO}

Com base na experiência Kaingáng, destacamos a seguir alguns pontos que consideramos importantes para o estabelecimento de programas de prevenção e intervenção sobre o consumo de bebidas alcoólicas entre os povos indígenas:

(1) Identificar e reconhecer como esses grupos se relacionam com as bebidas alcoólicas, que incluem aspectos como: $\mathrm{cm}$ qual contexto se aprende a beber; os estilos de beber; o que se bebe; como as bebidas foram introduzidas, entre outros. F́, importante também conhecer como as bebidas se inserem no cotidiano, como se dá acesso aos destilados, a faixa etária na qual começam a beber, os sentimentos e as atitudes expressos após a ingestão das bebidas e suas conseqüências individuais e sociais, bem como os mecanismos culturais e sociais acionados para enfrentar (ou não) o problema; 
Figura ]

Frcqüência relativa de indivíduos Kaingáng da T.I. Apucaraninha CACE +, Londrina, Paraná, 1999.

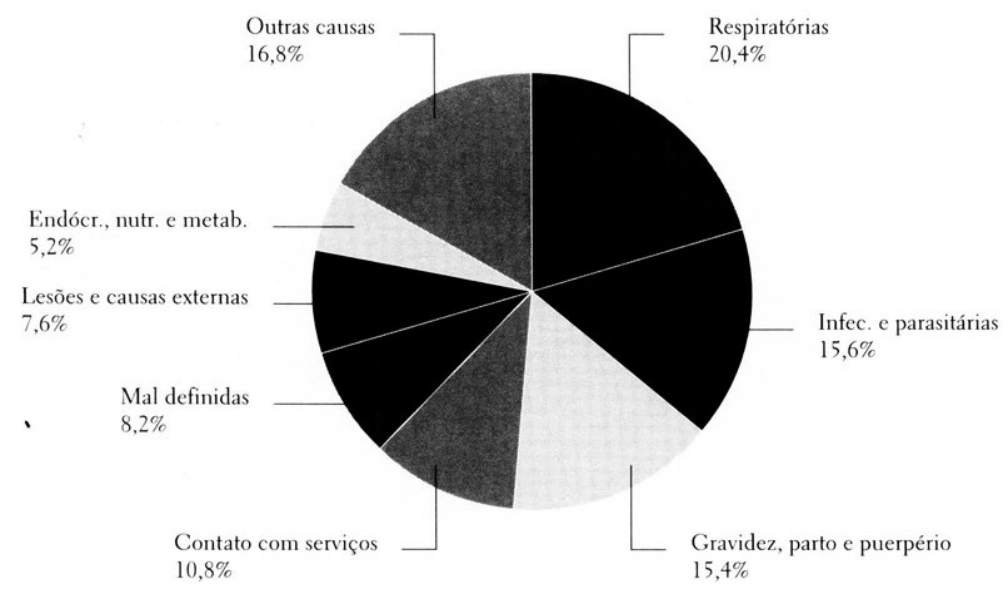

(2) Realizar diagnósticos epidemiológicos que possibilitem conhecer a situação do consumo de álcool e as características sócio-econômicas das famílias daqueles que fazem uso de bebidas. É importante identificar os indivíduos em "situação de risco". Para tal, sugerimos a utilização do CAGE adaptado para aplicação em sociedades indígenas, de acordo com as especificidades culturais de cada grupo. A realização de estudos de prevalência do alcoolismo nas populações indígenas é bastante importante, pois permite a comparação das taxas encontradas com as de outros grupos populacionais, possibilita o reconhecimento dos danos e repercussões dentro do grupo, e pode vir a servir como parâmetro de avaliação de programas;

(3) Envolver a comunidade em questão. É importante direcionar as atividades de prevenção aos mais jovens, enfatizando atividades pedagógicas e desportivas junto àqueles que não são usuários de bebidas alcoólicas ou outras drogas. As orientações e as informações educativas sobre as conseqüências do uso abusivo do álcool são necessárias e essenciais. Sugere-se a realização de oficinas sobre saúde, 
nas quais seja debatido o problema do alcoolismo, suas conseqüências e, principalmente, sua associação com outros agravos, incluindo as doenças sexualmente transmissíveis e AIDS. A participação da comunidade deve incluir lideranças tradicionais e especialistas de cura. A revitalização cultural também é um aspecto que deve ser enfatizado e incentivado. $O$ resgate de práticas tradicionais contribui para o fortalecimento dos indivíduos e das comunidades, fazendo-se refletir em melhoria da qualidade de vida, assim como da saúde de uma forma geral;

(4) Estabelecer e organizar o atendimento às pessoas com problemas com álcool e suas famílias nas unidades de saúde situadas nas próprias áreas indígenas. Para tanto, faz-se necessária a capacitação adequada de profissionais, cujo treinamento deve ser abordar as especificidades sócio/históricas e culturais de cada grupo, visando o melhor reconhecimento das pessoas em relação aos aspectos micro e macrossociais associados ao uso de álcool. Deve-se garantir o acompanhamento contínuo dos casos.

No estabelecimento de programas de prevenção e intervenção sobre o alcoolismo, é imprescindível ter clareza acerca do caráter multidisciplinar e processual que este tema requer. As mudanças em relação ao alcoolismo ocorrerão a médio e a longo prazos. Daí a necessidade de se avaliar continuamente cada atividade implantada no decorrer deste processo. Acima de tudo, uma questão é certa: faz-se necessário e urgente enfrentar o problema.

\section{Referências}

AGUIAR, J. I. \& SOUZA, J. A., 1997. Prevalência de Alcoolismo na População Indígena da Nação Teréna do Complexo Sidrolândia-Colônia Dois Irmãos do Buriti. In: Ministério da Saúde: Anais da I Oficina Macrorregional de Estratégia, Prevenção e Controle das DST/AIDS para as Populações Indígenas das Regiões Sul, Sudeste e do Mato Grosso do Sul. Londrina.

BALDUS, H., 1979. Ensaios de Etnologia Brasileira. 2a Ed. São Paulo: Companhia Editora Nacional.

BARBOZA, L. B. H., 1913. A Pacificação dos Gaingangs Paulistas. Hábitos, Costumes e Instituições Desses Índios. Publicação 88. Rio de Janeiro: Conselho Nacional de Proteção aos Índios.

BECKER, I. B., 1976. O Índio Kaingáng no Rio Grande do Sul. São Leopoldo: Instituto Anchietano de Pesquisas, Universidade do Vale do Rio dos Sinos.

BORBA, 'T., 1908. Atualidade Indígena. Curitiba.

CAVALIERI, A. L. \& EGYPTO, A. C., 2002. Drogas e Prevenção: A Cena e a Reflexão. São Paulo: Editora Saraiva. 
DOUGLAS, M. (ed.), 1987. Constructive Drinking: Perspectives on Drink from Anthropology. Cambridge: Cambridge University Press.

FERREIRA, M. K. L., 1998. Corpo e história do povo yurok. Revista de Antropologia, 41:53-105.

HEATH, D. B., 1993. Borrachera indígena. Cambio de concepciones. In: Borrachera y Memoria: La Experiencia de Lo Sagrado en Los Andes (T. Saignes, comp.), Travaux de l'IFEA Tomo 69, pp. 171-185, Lima: Hisbol/Instituto Francés de Estudios Andinos.

JELLINEK, E. M., 1960. The Disease Concept of Alcoholism. New Haven: Hillhouse Press.

LANGDON, E. J., 2000. O que beber, como beber e quando beber: $\mathrm{O}$ contexto sociocultural do alcoolismo entre as populações indígenas. In: Seminário sobre Alcoolismo e DST/AIDS entre os Povos Indígenas, Anais, pp. 83-97, Brasília: Secretaria de Políticas de Saúde, Ministério da Saúde.

LANGDON, E. J., no prelo. Considerações Antropológicas sobre Programas de Prevenção do Abuso de Álcool e Outras Substâncias. Florianópolis: Editora da Universidade Federal de Santa Catarina.

MacRAE, F., 1992. Guiado pela Lua: Xamanismo e Uso Ritual da Ayahuasca no Culto do Santo Daime. São Paulo: Editora Brasiliense.

MARLATT, G. A., 1999. Redução de Danos: Estratégias Práticas Para Lidar com Comportamentos de Alto Risco. Porto Alegre: Artmed Editora.

MASUR, J. \& MONTEIRO, M. G., 1983. Validation of the "CAGE" alcoholism screening test in a Brazilian psychiatric inpatient hospital setting. Brazilian Journal of Medical and Biological Research, 16:215-218.

MENENDEZ, E., 1990. Morir de Alcohol. México, DF: Alianza Editorial Mexicana.

MIRANDA-SÁ Jr., L. S.; SOUZA, J. A. \& SOUZג, J. C. R. P., 1989. Investigação de Dependência Alcoólica em uma Porção do Bairro Universitário de Campo Grande - MS. Campo Grande, Mato Grosso do Sul, 1989 (inédito).

MON'TEIRO, M. G. \& MASUR, J., 1987. O uso de indicadores biológicos para diagnóstico, avaliação de severidade e seguimento terapêutico do alcoolismo em nosso meio. Revista da Associação Brasileira de Psiquiatria 9:23-28.

MO'TA, L. T., 1998. O Aço, a Cruz e a Terra: Índios e Brancos no Paraná Provincial (1853 1889). Tese de Doutorado, Botucatu: Programa de Pós-Graduação em História, Universidade Estadual Paulista.

OLIVEIRA, M., 2000a. Alcoolismo entre os Kaingáng: Do sagrado e lúdico à dependência. In: Seminário sobre Alcoolismo e DST/AIDS entre os Povos Indígenas, Anais, pp. 99-125, Brasília: Secretaria de Políticas de Saúde, Ministério da Saúde.

OLIVEIRA, M., 2000b. Os efeitos do álcool entre os Jê da Bacia do Rio Tibagi. Trabalho apresentado no I Seminário sobre Saúde, Cultura em Doença, Londrina (inédito).

OLIVEIRA, M., 2000c. Proposta de intervenção e controle do alcoolismo entre os Kaingáng - relato de experiência. Trabalho apresentado no I Seminário sobre Alcoolismo entre os Povos Indígenas no Rio Grande do Sul, Porto Alegre (inédito).

OLIVEIRA, M., 2002a. Curso sobre Uso de Bebidas Alcoólicas e Alcoolismo para a população indígena do DSEI Leste de Roraima. Boa Vista, Roraima (inédito).

OLIVEIRA, M., 2002b. O Uso de Bebidas Alcoólicas e Alcoolismo entre os Kaingáng (Pesquisa em andannento). Londrina, Paraná (inédito). 
O'NELL, T. D. \& MITCHELL, C. M., 1996. Alcohol use among American Indian adolescents: The role of culture in pathological drinking. Social Science and Medicine, 42:565-578.

QUILLES, M., 2000. Mansidão de Fogo: Um Estudo Etnopsicológico do Comportamento entre os Índios Bororo de Meruri, Mato Grosso. Dissertação de Mestrado, Cuiabá: Programa de Pós-Graduação em Saúde e Ambiente, Universidade Federal de Mato Grosso.

SAHLINS, M., 1990. Ilhas de História. Rio de Janeiro: Jorge Zahar.

SHORE, J. H.; KINZIE, J. D.; HAMPSON, J. L. \& PATTISON, E. M., 1973. Psychiatric epidemiology of an Indian village. Psychiatry, 36:70-81.

SIQUEIRA-DURAN, L., 2001. Curso introdutório sobre Síndrome Alcoólica Fetal/Convênio Governo do Canadá/Brasil. Londrina, Paraná (inédito).

SOUZA, J. A., 1996. Estudo Epidemiológico Descritivo de Alcoolismo no Bairro Universitário de Campo Grande - MS. Dissertação de Mestrado, Campo Grande: Programa de Saúde Coletiva, Universidade Federal de Mato Grosso do Sul.

SOUZA, J. A. \& AGUIAR, J. I., 2000. Alcoolismo em população Teréna no Estado do Mato Grosso do Sul - impacto da sociedade envolvente. In: Seminário sobre Alcoolismo e DST/AIDS entre os Povos Indígenas, Anais, pp. 149-165, Brasília: Secretaria de Políticas de Saúde, Ministério da Saúde.

TESCHAUER, C. S. J., 1905. A catequese dos índios coroados de São Pedro do Rio Grande. Contribuição para a História da Civilização da América. Anuário do Estado do Rio Grande do Sul, Porto Alegre.

TOMMASINO, K. \& REZENDE, F. J., 2000. Kikikoi. Ritual dos Kaingáng na Área Indígena de Xapecó/SC. Registro Áudio-Fotográfico do Ritual dos Mortos. Londrina: Midiograf.

TORRETA, O., 1997. Uso e Abuso de Substâncias Alcoólicas ao Interno do Grupo Indígena Maxacali. Belo Horizonte: Universidade Federal de Minas Gerais. (mimeo.)

VEIGA, J., 1994. Organização Social e Cosmovisão Kaingáng: Uma Introdução ao Parentesco, Casamento e Nominação em uma Sociedade lê Meridional. Dissertação de Mestrado, Campinas: Departamento de Antropologia Social, Universidade Estadual de Campinas.

WALKER, R. D.; HOWARD, M. O.; ANDERSON, B. \& LAMBEERT, M. D., 1994. Substance dependent American Indian veterans. A national evaluation. Public Health Reports, 109:235-242.

WANBERG, K.; LEWIS, R. \& FOSTER, F. M., 1978. Alcoholism and ethnicity: A comparative study of alcohol use patterns across ethnic groups. Intermational joumal of the Addictions, 13:1245-1262.

YOUNG, T. K., 1988. Are subartic Indians undergoing the epidemiologic transition? Social Science and Medicine, 26:659-671. 



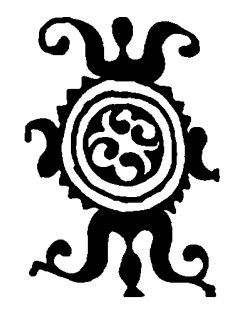

PREVALÊNCIA DE DIABETES MELLITUS E DA SÍNDROME DE RESISTÊNCIA INSULÍNICA NOS ÍNDIOS GUARANÍ DO ESTADO DO RIO DE JANEIRO

\author{
Andrey M. Cardoso, Inês E. Mattos \\ Rosalina J. Koifman
}

Considerável variação geográfica, étnica e sócio-econômica nas prevalências de diabetes mellitus tipo II (DMII) tem sido descrita nas populações ao redor do mundo (Young, 1993). As desigualdades nas prevalências parecem refletir diferenças genéticas quanto à susceptibilidade, graus variados de urbanização e modernização do estilo de vida e níveis de exposição a diversos fatores de risco (Fleming-Moran \& Coimbra Jr., 1990; Hall et al., 1992; Pavan et al., 1999; Santos et al., 2001; Szathmáry, 1994; Welty et al., 1995; Young, 1988).

Vieira Filho (1977) relacionava, já na década de 70, as baixas freqüências de DMII encontradas nos índios Karipúna e Palikúr à predisposição genética, às mudanças alimentares e à obesidade. Pavan et al. (1999) desenvolveram estudo transversal comparando quatro grupos populacionais em diferentes estágios de modernização do estilo de vida. Encontraram reduzidas médias de glicemia nos índios Amondava, de Rondônia ( $55,1 \mathrm{mg} / \mathrm{dl}$ ) e no grupo Mantu, da Tanzânia $(77,4 \mathrm{mg} / \mathrm{dl})$, considerados sob incipiente ocidentalização. King \& Zimmet (1988) ressaltam a forte tendência ao desenvolvimento de DMII em hindus, polinésios, micronésios e aborígenes australianos, quando migram para regiões ocidentalizadas, e nos índios norte-americanos, descendentes de mexicanos e afroamericanos. Elevadas prevalências foram referidas por Zimmet et al. (1977) e Balkau et al. (1985), na população micronésia de Nauru (34,5\%), comparáveis à descrita por Knowler et al. (1978), nos índios Pima (ajustada por idade e sexo: 21,1\%) dos Estados Unidos.

Em relação à determinação da obesidade e conseqüentes distúrbios metabólicos nos índios americanos, foi postulada a ocorrência do chamado thrifty gene, que apresentaria função reguladora no armazenamento de energia sob a forma de gordura em momentos de maior privação alimentar. Corresponderia a uma adaptação que, em tempos de maior fartura, passaria a representar incapacidade de adaptação metabólica do indivíduo aos padrões comportamentais da ocidentalização, contribuindo para o surgimento da obesidade e do descontrole dos níveis glicêmicos (Hall et al., 1991; Neel, 1962; Szathmáry, 1994). Essa pro- 
posição é utilizada hoje como possível explicação da predisposição genética de alguns grupos populacionais ao desenvolvimento da obesidade, da hiperinsulinemia e do DMII, quando submetidos à modernização do estilo de vida tradicional (Sherwin, 2001; Yajnik, 2001).

Contudo, outras teorias foram propostas na tentativa de melhor elucidar divergências nas prevalências de DMII em diferentes populações ameríndias. A síndrome metabólica do Novo Mundo considera a existência de uma condição genética relacionada ao metabolismo dos lipídios e carboidratos, também voltada para a economia energética em tempos de privação alimentar, capaz de agrupar DMII, obesidade e cálculo biliar, sobretudo em mulheres com elevada fecundidade (Weiss et al., 1984). Por sua vez, Szathmáry (1994) postula que os ameríndios que ocuparam as frias regiões do Ártico possuíam condição genética adaptativa que os levaria a intensa contra-regulação da insulina, predispondo ao DMII sob mudanças no estilo de vida.

Diversos estudos apontam, de forma consensual, para a resistência insulínica como base fisiopatológica dos eventos cardiovasculares, evidenciando, entretanto, que a expressão de fatores de risco varia, de grupo para grupo, na dependência de fatores genéticos (Ferranini et al., 1991; Meigs, 2000; Reaven, 1988, Sakkinen et al., 2000). Na última década, tem sido demonstrado que múltiplos fatores de risco ocorrem de forma concomitante nos indivíduos em uma freqüência superior à esperada ao acaso (Erkelens, 2001; Greenlund et al., 1999; Meigs, 2000; Reaven, 1988). Esta tendência de agrupamento de fatores é denominada síndrome de resistência insulínica (SRI) ou síndrome X.

A fisiopatologia da SRI tem sido descrita como decorrente de uma resistência dos tecidos periféricos à insulina e o surgimento de hiperinsulinemia compensatória, acarretando repercussões sobre a distribuição e o acúmulo corporal da gordura, dos níveis glicêmicos, lipêmicos e de pressão arterial. Tais alterações metabólicas estariam relacionadas à predisposição genética e a condições adversas de ocidentalização do estilo de vida, ou ainda à desnutrição intrauterina (Barker et al., 1993, 1989; Reaven, 1988; Yajnik, 2001). Recentemente, alguns estudos vêm levantando a possível participação de outros fatores concorrentes para a SRI, tais como o incremento da fibrinólise, anormalidades da coagulação, disfunção endotelial e inflamação, hiperuricemia e síndrome do ovário policístico (Meigs, 2000; Sakkinen et al., 2000; Vega, 2001; Yajnik, 2001).

Em populações autóctones, como os índios Navajo, Chippewa e Menominee dos Estados Unidos, tem sido observado que mudanças de hábitos alimentares e tendência ao sedentarismo, aliados à predisposição genética, influenciam 
o perfil antropométrico e metabólico dos grupos, acarretando maior incidência e prevalência de obesidade, sobretudo a central, e desordens metabólicas como o DMII de forma isolada ou agrupada sob a forma da SRI (Greenlund, 1999; Hall et al., 1991, 1992).

Os grupos indígenas Guaraní-Mbyá que vivem no litoral do Estado do Rio de Janeiro têm experimentado um profundo contato interétnico e a destruição do ecossistema vem interferindo nos aspectos mais diversos de sua vida ( $\mathrm{Li}$ taiff, 1996). Um estudo sobre saúde cardiovascular realizado nestes grupos identificou prevalências, variando de médias a baixas, de diversos fatores de risco cardiovascular, como hipertensão arterial, dislipidemias e obesidade (Cardoso, 2000; Cardoso et al., 2001). Diante da reconhecida tendência de agrupamento de fatores de risco cardiovasculares em alguns grupos populacionais, aliado ao importante incremento do risco cardiovascular quando ocorre associação dos fatores sob a forma da SRI, decidiu-se investigar o comportamento do conjunto desses fatores e sua relação com a obesidade, objetivando caracterizar a possível ocorrência da SRI entre os Guaraní do Rio de Janeiro.

\section{POPULAÇÃO E MÉTODOS}

Com base em censo populacional, foram identificados 193 indígenas moradores atuais das três aldeias Guaraní-Mbyá do Rio de Janeiro, com idade igual ou superior a 15 anos, segundo os registros de nascimento da FUNAI ou documentos de identidade. Após a obtenção do consentimento informado, os indivíduos foram submetidos a exame físico, a medidas antropométricas e à coleta de material para exames laboratoriais.

Houve 16 recusas de participação $(8,3 \%)$ e 4 indivíduos $(2,1 \%)$ mudaram-se antes de serem avaliados. As 16 gestantes $(18,4 \%)$ foram excluídas da análise. Entre os participantes, $6(3,5 \%)$ foram entrevistados e submetidos à coleta de sangue, mas não quiseram ser examinados. Dos 151 indivíduos que participaram de todas as etapas da avaliação, $15(7,8 \%)$ tiveram algum valor laboratorial referente à SRI perdido, tendo sido incluídos na análise geral das médias e prevalências de fatores individuais, mas excluídos das análises relativas à SRI.

Todos os exames laboratoriais foram realizados no Laboratório de Análises Clínicas do Hospital de Furnas Centrais Elétricas (Usina Nuclear de Angra dos Reis), que pertence ao Programa Nacional de Controle de Qualidade da Sociedade Brasileira de Análises Clínicas. 
A glicemia casual foi aferida pelo método enzimático colorimétrico, em $\mathrm{mg} / \mathrm{dl}$, em sangue venoso periférico colhido em tubo com fluoreto, sendo o valor igual ou superior a $200 \mathrm{mg} / \mathrm{dl}$ indicativo de DMII e entre $140 \mathrm{mg} / \mathrm{dl}$ e $200 \mathrm{mg} / \mathrm{dl}$ indicativo de TDG (Schmidt, 1996). A hemoglobina glicosilada (HbG) foi aferida no sangue venoso periférico, colhido em tubo com EDTA, pelo método de cromatografia, com limites de referência entre $5 \%$ e $8 \%$. Valores de HbG superiores a $8 \%$ foram considerados como indicativos de elevação glicêmica (Schmidt, 1996).

A pressão arterial (PA) foi aferida por meio de método padronizado, sendo os indivíduos classificados como portadores de hipertensão arterial (HA) segundo dois critérios: $\mathrm{PA} \geq 140 \times 90 \mathrm{mmHg}$ (JNC, 1988) e PA $\geq 160 \times 95 \mathrm{mmHg}$ (OMS, 1978). Os dados relativos à PA encontram-se descritos detalhadamente em outra publicação (Cardoso et al., 2001).

Os pontos de corte para risco das variáveis lipídicas foram os valores limítrofes definidos em relatório do segundo painel de especialistas do National Cholesterol Education Program (NCEP, 1993). O ponto de corte do colesterolHDL nas mulheres acima de 50 anos foi igual ao masculino $(35 \mathrm{mg} / \mathrm{dl})$.

O índice de massa corporal (IMC) foi calculado pela fórmula [peso (kg)/ altura $\left.{ }^{2}\left(\mathrm{~m}^{2}\right)\right]$, utilizando-se as medidas obtidas pelos métodos padronizados de aferição previamente descritos (Cardoso et al., 2001). Os critérios de classificação do IMC adotados foram os preconizados pela OMS (WHO, 1995): peso adequado $18,5 \leq$ IMC $<25,0$ e sobrepesos graus I, II e III, respectivamente, 25,0 $\leq$ IMC $<30,0 ; 30,0 \leq \mathrm{IMC}<40,0$ e IMC $\geq 40,0$. As circunferências da cintura e do quadril foram aferidas utilizando-se fita métrica de material sintético não extensível, graduada em milímetros (WHO, 1995). Valores de razão cintura-quadril (RCQ) superiores a 0,95 para homens, 0,80 para mulheres sem sobrepeso e 0,85 para mulheres com sobrepeso foram considerados como de risco (Pereira et al., 1999).

Considerou-se o DMII, a HA, a hipertrigliceridemia e o colesterol-HDL baixo como fatores componentes da SRI (Greenlund et al., 1999; Reaven, 1988). Para efeito de cálculo da prevalência da SRI, indivíduos que apresentaram glicemia elevada ( $\geq 200 \mathrm{md} / \mathrm{dl}$ ), assim como aqueles somente com $\mathrm{HbG}$ acima de $8 \%$, foram classificados como diabéticos. Os indivíduos com dois ou mais fatores acumulados foram considerados portadores da SRI.

A idade foi coletada como variável contínua e optou-se, durante a análise, em categorizá-la em estratos definidos pelos intervalos de classe 15-29 anos, 30-49 e 50 anos e mais.

A análise dos dados consistiu na exploração descritiva dos parâmetros populacionais e no cálculo das prevalências de valores alterados das variáveis de 
interesse do estudo. Efetuou-se o cálculo da prevalência da SRI e avaliou-se a frequiência de acúmulo de fatores da SRI segundo faixa etária e sexo, assim como o gradiente das médias por tercil e prevalências de cada fator individual, nos estratos de 0-1 e acumulado de dois ou mais dos outros fatores. O mesmo procedimento de análise foi utilizado para avaliar o gradiente das médias e prevalências de alteração de IMC e RCQ. Foram calculadas as razões de prevalência brutas e ajustadas (razões de prevalência de Mantel-Haenszel, segundo sexo e faixa etária). O grau de correlação entre as variáveis foi avaliado por meio do coeficiente de correlação de Pearson, testando-se a significância estatística pelo teste t bicaudal. $\mathrm{Na}$ análise estatística, foram utilizados os programas Epi Info versão 6.04a e SPSS for Windows.

\section{RESULTADOS}

A população de estudo é composta por 151 indivíduos, sendo 80 homens (53,0\%) e 71 mulheres (47,0\%). A distribuição por faixa etária mostra 50,3\%, 21,2\% e $28,8 \%$ dos participantes, respectivamente, com 15-29, 30-49 e 50 anos e mais.

A média global de glicemia casual foi de $98,7 \mathrm{mg} / \mathrm{dl}$. A média feminina $(102,1 \mathrm{mg} / \mathrm{dl})$ foi superior à masculina $(95,6 \mathrm{mg} / \mathrm{dl})$, padrão que se manteve na análise por faixa etária, nos grupos de 15-29 anos e de 50 anos e mais. Na faixa etária de 30-49 anos, a média de glicemia foi superior no grupo masculino (M: 95,8mg/dl; F: 92,lmg/dl).

A prevalência de DMII global foi de $0,7 \%$, sendo todos os casos diagnosticados em mulheres acima de 50 anos (Tabela 1). A prevalência global de TDG foi de $3,5 \%$, sendo 4 vezes superior no grupo feminino em comparação com o masculino. A média global de HbG foi 7,1\% e a prevalência global de alteração foi superior à do DMII $(14,1 \%)$. A prevalência feminina foi 2 vezes maior que a masculina.

As médias globais ambulatoriais de PA sistólica (PAS) e diastólica (PAD) foram, respectivamente, $109,3 \mathrm{mmHg}$ e $69,7 \mathrm{mmHg}$. A prevalência de HA foi superior no grupo feminino por qualquer dos critérios utilizados. Nenhum indígena masculino foi classificado como hipertenso pelo critério OMS (Tabela 1).

As médias de triglicerídios (global: 116,0 mg/dl; M: 119,0 mg/dl; F: $113,3 \mathrm{mg} / \mathrm{dl}$ ) foram inferiores aos respectivos valores de referência para ambos os sexos, enquanto as médias de HDL (M: 34,8mg/dl; F: $38,0 \mathrm{mg} / \mathrm{dl}$ ) se incluem na faixa considerada de risco para homens e mulheres. 
Tabela 1

Prevalências globais e por sexo das variáveis analisadas. Guaraní-Mbyá, Rio de Janeiro.

\begin{tabular}{|c|c|c|c|c|c|c|}
\hline \multirow[t]{2}{*}{ Variáveis } & \multicolumn{2}{|c|}{ Masculino } & \multicolumn{2}{|c|}{ Feminino } & \multicolumn{2}{|c|}{ Global } \\
\hline & $\mathrm{n}$ & $\mathrm{P}(\%)$ & $\mathrm{n}$ & $P(\%)$ & $\mathrm{n}$ & $\mathrm{P}(\%)$ \\
\hline Diabetes mellitus tipo II & 0 & 0,0 & 1 & 1,4 & 1 & 0.7 \\
\hline Intolerância à glicose & 1 & 1,4 & 4 & 5,6 & 5 & 3,5 \\
\hline Hemoglobina glicosilada & 6 & 9,0 & 12 & 19,7 & 18 & 14,1 \\
\hline $\begin{array}{l}\text { Síndrome de resistência insulínica } \\
\text { ( } 2 \text { ou } 3 \text { fatores) }\end{array}$ & 6 & 8,5 & 12 & 17,9 & 18 & 13,1 \\
\hline Colesterol & 2 & 2,7 & 2 & 2,9 & 4 & 2,8 \\
\hline HDL & 43 & 58,1 & 46 & 66,7 & 89 & 62,2 \\
\hline $\mathrm{LDL}$ & 2 & 2,7 & 2 & 2,9 & 4 & 2,8 \\
\hline Triglicerídios & 7 & 9,5 & 11 & 15,9 & 18 & 12,6 \\
\hline Sobrepeso I & 12 & 15,6 & 20 & 29,0 & 32 & 21,9 \\
\hline Sobrepeso II & 3 & 3,9 & 4 & 5,8 & 7 & 4,8 \\
\hline Razão cintura-quadril & 5 & 6.5 & 52 & 75,4 & 57 & 39,7 \\
\hline Hipertensão arterial (JNC) & 2 & 2,6 & 5 & 7,4 & 7 & 4,8 \\
\hline Hipertensão arterial (OMS) & 0 & 0,0 & 3 & 4,4 & 3 & 2,1 \\
\hline
\end{tabular}

O grupo feminino apresentou média de IMC superior à do masculino (M: 23,3; F: 24,0). Não foram observados valores compatíveis com sobrepeso grau III. A prevalência global de sobrepeso foi de $26,7 \%$, sendo a do grupo feminino $(34,8 \%)$ quase o dobro da observada no masculino (19,5\%). A média de RCQ feminina foi superior ao valor de referência considerado de risco para doenças crônicas nesse grupo (M: 0,88; F: 0,85). A prevalência feminina de RCQ alterada reduziu de $86,9 \%$ para $75,4 \%$ quando se utilizou 0,85 como ponto de corte para o grupo feminino com sobrepeso. Contudo, a prevalência feminina manteve-se bastante elevada em comparação com a masculina (Tabela 1).

Das variáveis de interesse para a caracterização da SRI, somente o IMC não apresentou elevação significativa com a idade. A PAS não mostrou correlação significativa com as outras variáveis da SRI. As variáveis glicemia, HbG, triglicerídios e HDL mostraram graus variados de correlação significativa entre si, e com o IMC e a RCQ (Tabela 2).

A prevalência global da SRI foi de $13,1 \%$. A prevalência masculina foi inferior à feminina (Tabela 1). A distribuição de frequeiências de fatores acumula- 
Matriz de correlação de Pearson para variáveis analisadas. Guaraní-Mbyá, Rio de Janeiro.

\begin{tabular}{|c|c|c|c|c|c|c|c|c|}
\hline Variáveis & Idade & Glicemia & $\begin{array}{l}\text { Hemo- } \\
\text { globina } \\
\text { glicosilada }\end{array}$ & HDL & $\begin{array}{l}\text { Triglice- } \\
\text { rídios }\end{array}$ & $\begin{array}{l}\text { Índice } \\
\text { de massa } \\
\text { corporal }\end{array}$ & $\begin{array}{l}\text { Razão } \\
\text { cintura- } \\
\text { quadril }\end{array}$ & $\begin{array}{l}\text { Pressão } \\
\text { arterial } \\
\text { sistólica }\end{array}$ \\
\hline Idade & - & & & & & & & \\
\hline Glicemia & 0,261 * & - & & & & & & \\
\hline $\begin{array}{l}\text { Hemoglobina } \\
\text { glicosilada }\end{array}$ & $0,204^{\circ}$ & $0,629^{*}$ & - & & & & & \\
\hline HDL & $0,202^{*}$ & $-0,098$ & $.0,198^{\circ}$ & - & & & & \\
\hline Triglicerídios & $0,238^{*}$ & $0,270^{*}$ & $0,198^{*}$ & $-0,244^{*}$ & - & & & \\
\hline $\begin{array}{l}\text { Indice de massa } \\
\text { corporal }\end{array}$ & 0,041 & 0,108 & $0,199^{*}$ & $-0,207^{\star}$ & $0,318^{* *}$ & - & & \\
\hline $\begin{array}{l}\text { Razão cintura- } \\
\text { quadril }\end{array}$ & 0,273 \# & $-0,007$ & $-0,004$ & $-0,012$ & $0,366^{* *}$ & 0,271 * & - & \\
\hline $\begin{array}{l}\text { Pressão arterial } \\
\text { sistólica }\end{array}$ & $0,194^{*}$ & 0,159 & 0,086 & 0,005 & 0,146 & 0,116 & 0,076 & - \\
\hline $\begin{array}{l}\text { Pressão arterial } \\
\text { diastólica }\end{array}$ & $0,200^{*}$ & 0,129 & $0, \mathrm{i} 73$ & $-0,012$ & $0,193^{\circ}$ & $0,228^{\circ}$ & 0,073 & $0,680^{*}$ \\
\hline
\end{tabular}

${ }^{*}$ P-valor $<0,05$ (Teste t bi-caudal); " $\mathrm{P}$-valor $<0,01$.

dos da SRI segundo faixa etária evidencia uma tendência estatisticamente significativa $(\mathrm{p}<0,01)$ de acúmulo de 2 e 3 fatores da SRI, à medida que aumenta a idade. Essa tendência é evidenciada na análise segundo sexo, para o grupo feminino ( $p<0,05)$, enquanto no grupo masculino, ocorre uma redução na freqüência 2 ou mais fatores acumulados, acima de 50 anos (Tabela 3).

A comparação das médias das variáveis por tercis e das prevalências de cada componente isolado da SRI, segundo os estratos de fatores, encontra-se na Tabela 4. Evidencia-se tendência estatisticamente significativa de elevação das médias de glicemia casual ( $\mathrm{p}<0,01)$, de HbG $(\mathrm{p}<0,05)$ e de triglicerídios $(\mathrm{p}<$ $0,01)$ com o aumento do número de fatores acumulados da SRI. Tendência estatisticamente significativa de incremento das prevalências de elevação glicêmica ( $\mathrm{p}<0,01$ ), de HDL baixo $(\mathrm{p}<0,01)$ e de hipertrigliceridemia $(\mathrm{p}<0,01)$ também foi observada com o acúmulo de fatores da SRI. Apenas a PA não mostrou tendência estatisticamente significativa de elevação das médias e/ou prevalências com a agregação de fatores da SRI.

A comparação das médias por tercis e das prevalências de IMC e de RCQ por sexo, segundo os estratos de acúmulo de fatores da SRI, encontra-se na Tabe- 
Tabela 3

Frequiência de acúmulo de fatores da síndrome de resistência insulínica, segundo sexo e faixa etária. Guaraní-Mbyá, Rio de Janeiro.

\begin{tabular}{|c|c|c|c|c|}
\hline \multirow[t]{2}{*}{ Fatores acumulados } & \multicolumn{4}{|c|}{ Freqüência de fatores por faixa etária (\%) } \\
\hline & $15-29$ & $30-49$ & 50 e mais & Global \\
\hline \multicolumn{5}{|l|}{ Masculino } \\
\hline 0 & 16,2 & $+7,0$ & 64,7 & 35,2 \\
\hline 1 & 75,7 & $+1,2$ & 29,4 & 56,3 \\
\hline 2 & 8,1 & 11,8 & 5,9 & 8,5 \\
\hline 3 & 0.0 & 0,0 & 0,0 & 0,0 \\
\hline \multicolumn{5}{|l|}{ Feminino } \\
\hline 0 & 29,0 & 16,7 & 37,5 & 29.9 \\
\hline 1 & 67.8 & 75.0 & 20,8 & 52,2 \\
\hline 2 & 3,2 & 8.3 & 29,2 & 13,4 \\
\hline 3 & 0,0 & 0.0 & 12,5 & 4.5 \\
\hline \multicolumn{5}{|l|}{ Clobal } \\
\hline 0 & 22.1 & $3+.5$ & 48,8 & 32,6 \\
\hline 1 & 72,0 & 55,2 & 24,4 & 54,3 \\
\hline 2 & 5.9 & 10,3 & 19,5 & 10.9 \\
\hline 3 & 0,0 & 0,0 & 7,3 & 2,2 \\
\hline
\end{tabular}

$\chi^{2}=1,04,2$ gl., $\mathrm{p}<0,01$ (idade $\mathrm{e}$ acúmulo de fatores $(<2 \geq 2)$ ); Teste exato Fischer, 2 gl., $\mathrm{p}<0,05$ (sexo e acúnulo de fatores $(<2 \geq 2)$ - faixa etária de 50 anos $\mathrm{c}$ mais).

la 5. Evidencia-se tendência estatisticamente significativa de elevação da média global de IMC $(\mathrm{p}<0,01)$ e das médias de IMC $(\mathrm{p}<0,01)$ e de RCQ $(\mathrm{p}<0,05)$ para o sexo feminino, com o aumento do número de fatores acumulados da SRI. Tendência estatisticamente significativa de incremento das prevalências de IMC global $(\mathrm{p}<0,01)$ e para o sexo feminino $(\mathrm{p}<0,05)$ também foi observada com o acúmulo de fatores da SRI, o que não foi observado com a RCQ.

As razões de prevalência de Mantel-Haenszel brutas e ajustadas encontram-se na Tabela 6. Os indivíduos obesos, após controle por sexo e idade, mostraram risco 4,1 (IC: 4,36-15,36) veres maior de apresentar a SRI do que aqueles com peso normal, e os com mais de 50 anos, após controle por sexo, mostraram risco 4,58 (IC: 1,78-9,46) vezes maior que os mais jovens (15-29) de apresentar a SRI. 
Tabela 4

Comparação dos tercis e prevalências das variáveis, segundo número de fatores acumulados da síndrome de resistência insulínica. Guaraní-Mbyá, Rio de Janeiro.

\begin{tabular}{|c|c|c|c|c|c|c|}
\hline \multirow[t]{3}{*}{ Variáveis } & \multicolumn{6}{|c|}{ Fatores acumulados } \\
\hline & \multicolumn{3}{|c|}{ Médias } & \multicolumn{3}{|c|}{ Prevalências $(\%)$} \\
\hline & Nenhum & 1 & 2 ou + & Nenhum & 1 & $2 \mathrm{ou}+$ \\
\hline Glicemia & & & & $12,7^{\text {* }}$ & $12,7^{\star * *}$ & $15.4^{* *}$ \\
\hline \multicolumn{7}{|l|}{ Casual } \\
\hline le tercil & 79,2 & 76,0 & 80,0 & & & \\
\hline 30 tercil & $116,2 * *$ & $118,0^{* * *}$ & $172,8^{* *}$ & & & \\
\hline \multicolumn{7}{|c|}{ Hemoglobina glicosilada } \\
\hline le tercil & $6,1^{*}$ & $6,4^{*}$ & $6,1^{*}$ & & & \\
\hline 30 tercil & 8,0 & 8,0 & 8,8 & & & \\
\hline HDL & & & & $59,0^{* 0}$ & $69,7^{\circ \prime}$ & $100,0^{* n}$ \\
\hline le tercil & 27,0 & 26,2 & 26,0 & & & \\
\hline 30 tercil & 48,1 & 43,5 & - & & & \\
\hline Triglicerídios & & & & $6,8^{* *}$ & $15,4^{* *}$ & $21,4^{* a}$ \\
\hline 10 tercil & 59,7 & 61,0 & 58,0 & & & \\
\hline 30 tercil & $157,0^{* *}$ & $216,7^{* *}$ & $234,0^{* n}$ & & & \\
\hline Pressão arterial & & & & 4,9 & 4,2 & 4,8 \\
\hline \multicolumn{7}{|l|}{ Sistólica } \\
\hline 1o tercil & 98,1 & 96,4 & 96,4 & & & \\
\hline 30 tercil & 125,6 & 121,8 & 130,1 & & & \\
\hline \multicolumn{7}{|l|}{ Diastólica } \\
\hline lo tercil & 59,8 & 59,3 & 62,0 & & & \\
\hline 30 tercil & 80,4 & 81,0 & 82,1 & & & \\
\hline
\end{tabular}

' $\mathrm{p}<0,05 ;{ }^{*} \mathrm{p}<0,01$ (gradiente de aumento das médias e prevalências das variáveis com o acúmulo de fatores da síndrome de resistência insulínica). 
Tabela 5

Médias e prevalências de índice de massa corporal (IMC) e razão cintura-quadril (RCQ) por sexo, segundo número de fatores acumulados da síndrome de resistência insulínica. Guaraní-Mbyá, Rio de Janeiro.

\begin{tabular}{|c|c|c|c|c|c|c|c|c|}
\hline \multirow[t]{3}{*}{ Variáveis } & \multicolumn{8}{|c|}{ Fatores acumulados } \\
\hline & \multicolumn{4}{|c|}{ Médias e desvios-padrão } & \multicolumn{4}{|c|}{ Prevalências (\%) } \\
\hline & Nenhum & 1 & 2 & 3 & Nenhum & 1 & 2 & 3 \\
\hline \multicolumn{9}{|l|}{ IMC } \\
\hline \multirow[t]{2}{*}{ Masculino } & 22,9 & 23,2 & 24,6 & - & 13,0 & 21,1 & 40,0 & - \\
\hline & 2,16 & 3,39 & 3,97 & & & & & \\
\hline \multirow[t]{2}{*}{ Feminino } & $22,1^{* *}$ & $23,5^{*}$ & $28,3 *$ & $25,0^{* *}$ & $17,6^{*}$ & $28,1^{*}$ & $61,5^{*}$ & $66,7^{\circ}$ \\
\hline & 2,81 & 3.35 & 3,49 & 0,66 & & & & \\
\hline \multirow[t]{2}{*}{ Global } & $22,6^{* *}$ & $23,4^{* *}$ & $29,9^{*}=$ & $25,0^{* *}$ & $17,6^{* *}$ & $24,3 * \cdots$ & $52,2^{* *}$ & $66,7^{* *}$ \\
\hline & 2,46 & 3.35 & 3,98 & 0,66 & & & & \\
\hline \multicolumn{9}{|l|}{$\mathrm{RCQ}$} \\
\hline \multirow[t]{2}{*}{ Masculino } & 0,86 & 0,88 & 0,91 & -- & 8,7 & 7,9 & 10,0 & - \\
\hline & 0,06 & 0,05 & 0,05 & & & & & \\
\hline \multirow[t]{2}{*}{ Feminino } & $0,84^{*}$ & $0,84^{\circ}$ & $0,88^{*}$ & $0,90^{*}$ & 76,5 & 81,3 & 84,6 & 66,7 \\
\hline & 0,04 & 0,05 & 0,03 & 0,02 & & & & \\
\hline \multirow[t]{2}{*}{ Global } & 0,86 & 0,86 & 0,89 & 0,90 & 37,5 & 41,4 & 52,2 & 66,7 \\
\hline & 0,06 & 0,05 & 0,04 & 0,01 & & & & \\
\hline
\end{tabular}

* $\mathrm{p}<0,05 ; * \mathrm{p}<0,01$ (gradiente de aumento das médias e prevalências de IMC e RCQ com o acúmulo de fatores da síndrome de resistência insulínica).

Tabela 6

Razões de prevalência de Mantel-Haenszel brutas e ajustadas da síndrome de resistência insulínica.

Guaraní-Mbyá, Rio de Janeiro.

\begin{tabular}{|c|c|c|c|c|}
\hline \multirow[t]{2}{*}{ Variáveis } & \multicolumn{2}{|c|}{ RP bruta } & \multicolumn{2}{|c|}{$\mathbf{R P}_{\mathbf{M H}}$ ajustada } \\
\hline & RP & IC (95\%) & RPMH & IC (95\%) \\
\hline \multicolumn{5}{|l|}{ Idade } \\
\hline $50 e+/ 15-29$ & 4,56 & $1,55-13,39$ & 4,58 (sexo) & $4,36-15,36$ \\
\hline \multicolumn{5}{|l|}{ Sexo } \\
\hline Feminino/Masculino & 2,12 & $0,84-5,33$ & 1,90 (iclade) & $0,68-5,30$ \\
\hline \multicolumn{5}{|c|}{ Índice de massa corporal/Obesidade } \\
\hline SPII/p. normal & 7,76 & $2,97-20,24$ & 4,Il (sexo, idade) & $1,78-9,46$ \\
\hline \multicolumn{5}{|l|}{ Razão cintura-quadril } \\
\hline (elevada/normal) & 2,17 & $0,89-5,25$ & 1,91 (sexo, idade) & $0,62-5,85$ \\
\hline
\end{tabular}




\section{DISCUSSÃO}

Não se observaram diferenças marcantes entre as médias de glicemias do conjunto da população Guaraní-Mbyá em relação ao grupo de indivíduos com dados completos da SRI, fazendo supor que as perdas provavelmente não afetaram os resultados. As médias de glicemia casual dos Guaraní (M: 95,5mg/dl; F: $101,4 \mathrm{mg} / \mathrm{dl}$ ) foram superiores às observadas nos índios Amondava, de Rondônia (global: 55,lmg/dl), recentemente contatados (Pavan et al., 1999) e nos Aymara, do Chile (M: 78,8mg/dl; F: 83,4mg/dl), que vivem relativamente isolados em elevadas altitudes e sob intensa atividade física (Santos et al., 2001). Por outro lado, verificaram-se valores inferiores aos encontrados para a população Yanomámi (H: 98,4mg/dl; M: 114,lmg/dl), com baixos níveis de ocidentalização do estilo de vida (Bloch et al., 1993) e, de forma mais marcante, para a grande maioria dos grupos indígenas norte-americanos. Contudo, as mulheres Guaraní, tal como as Yanomámi e Aymara e indígenas norte-americanas (Gray et al., 1998), apresentaram médias superiores às do grupo masculino, contrariando observações feitas em alguns grupos estudados no Sudeste Asiático, Pacífico Ocidental, Austrália, Tunísia e em populações ocidentais de origem caucasiana (Ford et al., 2002; King \& Zimmet, 1988).

A prevalência global de DMII $(0,7 \%)$ nos Guaraní foi superior à observada nos Amondava (Pavan et al., 1999), na população de Togo (África) e em Papua Nova-Guiné (King \& Zimmet, 1988), onde nenhum indivíduo foi classificado como diabético. Valores semelhantes foram observados por Larenas et al. (1985), nos índios Mapuche, do Chile e por Eason et al. (1987), nas populações rural e urbana das Ilhas Salomão (Pacífico Ocidental). Entretanto, essa prevalência foi inferior à encontrada na população urbana brasileira de 30-69 anos (7,6\%) (Malerbi \& Franco, 1992) e àquelas observadas em diferentes grupos indígenas norte-americanos, como os Navajo (Hall et al., 1991; Will et al., 1997) e os Pima (Knowler et al., 1978), que experimentaram grandes mudanças no estilo de vida tradicional. Nos Guaraní, tal como foi relatado em diferentes grupos indígenas (Ford et al., 2002; Gray et al., 1998; Santos et al., 2001; Young, 1993), a prevalência de DMII foi superior no grupo feminino.

A prevalência global de TDG foi mais próxima da observada na população urbana brasileira $(5,6 \%)$, sendo também maior no grupo feminino. A prevalência de elevação da HbG $(14,1 \%)$ foi superior às do DMII e da TDG, sugerindo a possibilidade de uma subestimação dessas, devido ao critério diagnóstico utilizado. Em contrapartida, deve-se considerar que as correlações mostram que 
a HbG explica $62 \%$ da variação da glicemia casual e que a prevalência de HbG elevada poderia estar superestimada em função da alta prevalência de anemia carencial. Sendo assim, as prevalências de DMII e de TDG estariam refletindo aproximadamente o perfil glicêmico do grupo.

Alguns autores consideram que nem todos os fatores descritos na SRI necessitam estar presentes em todos os grupos populacionais (Gray et al., 1998; Meigs, 2000). Gray et al. (1998) avaliaram a participação dos fatores componentes da SRI em grupos indígenas norte-americanos, por meio da análise fatorial. Os resultados demonstraram, diferentemente de outros estudos com populações brancas, que a pressão arterial era um fator de risco isolado dos outros fatores de risco habitualmente associados à SRI, integrando um componente distinto daqueles que continham a glicemia, os lipídios, a insulinemia e a obesidade. A investigação da associação entre fatores de risco demonstrou que as PAS e PAD não estavam significativamente associadas à insulinemia de jejum, após controlado o confundimento, sugerindo haver diferenças na composição da SRI entre populações indígenas e não-indígenas norte-americanas. Os fatores que melhor se agrupavam na SRI nos indígenas diferiam entre indivíduos diabéticos (glicose, triglicerídios e HDL) e não diabéticos (insulina, glicose e IMC).

Nos Guaraní, não se observou associação estatisticamente significativa entre as médias e prevalências de PAS e PAD e o acúmulo de fatores da SRI, tendo sido observada correlação estatisticamente significativa somente entre PAD e triglicerídios, fazendo supor que nestes grupos, a PA é fracamente associada ou não integra a SRI. Além disso, observou-se tendência estatisticamente significativa de elevação das prevalências de hiperglicemia, hipertrigliceridemia e HDL baixo segundo estratos de acúmulo de fatores da SRI, refletindo uma tendência de agrupamento desses fatores de forma idêntica a descrita por (Gray et al. (1998) para indígenas norte-americanos diabéticos.

O acúmulo de fatores de risco componentes da SRI nos Guaraní tende a ocorrer com o aumento da idade, sobretudo nas mulheres. Tal resultado poderia ser explicado pela hipótese de maior exposição do grupo feminino, aliada ao reconhecido aumento do risco cardiovascular na menopausa, quando se reduzem os níveis de estrogênio. A sobreposição do risco feminino ao masculino nas idades mais avançadas é relatada como freqüente nas populações indígenas norte-americanas e canadenses, que têm elevadas prevalências de DCV e de fatores de risco sob a forma da SRI (Szathmáry, 1994). Em um estudo com grupos de índios norte-americanos, Greenlund et al. (1999) observaram que 27,0\% dos homens e $21,3 \%$ das mulheres apresentavam 2 ou mais fatores da SRI. Apesar das 
diferenças metodológicas na classificação de indivíduos diabéticos, nos Guaraní, as prevalências correspondentes foram inferiores.

Somente as mulheres Guaraní apresentaram três fatores acumulados com a prevalência de 4,5\%. Em estudo realizado por Ford et al., (2002), na população norte-americana, os indivíduos brancos (M: 24,8\%; F: 22,8\%), afro-americanos (M: 16,4\%; F: 25,7\%) e mexicano-americanos (M: 28,3\%; 35,6\%) apresentaram prevalências mais elevadas de três fatores da SRI.

Como tem sido observado em diversos estudos com outras populações indígenas e não-indígenas, a média de IMC e a prevalência de sobrepeso das mulheres Guaraní foi superior a dos homens. Em geral, o grupo feminino apresentou aumento do IMC com a idade e o sobrepeso foi mais prevalente na faixa etária de 50 anos e mais, refletindo uma maior proporção de gordura corporal nas mulheres, sobretudo nas de maior idade, o que poderia ser uma explicação para o acúmulo de fatores da SRI nesse grupo.

O comportamento da RCQ foi semelhante ao do IMC, com maior prevalência de alteração no sexo feminino, crescente com a idade, mostrando que as mulheres têm maior concentração abdominal de gordura que os homens, sobretudo as mais velhas. A observação dos resultados excessivamente elevados levanta a hipótese da influência da conformação corporal sobre esse indicador, sugerindo que possa haver um ponto de corte de RCQ mais adequado às características físicas do grupo estudado (Bloch et al., 1993; Pereira et al., 1999). De qualquer modo, a diferença marcante da prevalência de obesidade entre os sexos, sobretudo a central, reforça a importância da obesidade na fisiopatologia da SRI no grupo Guaraní feminino.

Várias condições poderiam estar contribuindo paralelamente para a situação encontrada, tais como transformações no padrão alimentar das mulheres (agora rico em carboidratos refinados e gorduras), considerando que a suposta fase de exposição diferenciada dos sexos à ocidentalização do estilo de vida (Fleming-Moran et al., 1991), pudesse ter sido suplantada. Outra explicação seria a crescente redução da atividade física, sendo o sedentarismo mais pronunciado nas mulheres que, em geral, são responsáveis pelos afazeres domésticos e pelo artesanato, que impõem um período prolongado em posição sentada e curtas caminhadas peri-domiciliares. Os resultados demonstram haver uma confluência de fatores de risco para as doenças crônicas não transmissíveis nesse grupo e que esta tendência pode ser explicada pela obesidade.

Apesar de não possuirmos dados substanciais para discutir a teoria do thrifty gene, o perfil antropométrico observado no grupo, decorrente pelo menos 
em parte, de um maior aporte calórico, sustenta essa hipótese como uma possível responsável pela progressão para um elevado risco cardiovascular. Nesse caso, é possível que a SRI possa ser explicada por algum grau de predisposição genética do grupo à obesidade e à resistência insulínica, com uma capacidade intermediária na secreção de insulina pelas células pancreáticas para compensar tal resistência, conferindo razoável controle glicêmico e prevalências baixas de DMII, mas crescente risco cardiovascular sob efeito da hiperinsulinemia (Reaven, 1988). A hipertrigliceridemia (Erkelens, 2001) e outros fatores, como, por exemplo, o baixo peso ao nascer (Barker et al., 1993), também poderiam ser apontados como possíveis contribuintes da resistência insulínica e do seu grau de expressão.

Os resultados referentes ao perfil glicêmico e às outras variáveis, sobretudo no grupo feminino, permitem supor que as mudanças comportamentais assimiladas pelas mulheres Guaraní possam ser determinantes na expressão de distúrbios metabólicos e das doenças cardiovasculares. Considerando a posição geográfica dos Guaraní do Rio de Janeiro, situados entre os dois maiores centros urbanos do país, poderia se apontar a urbanização do estilo de vida, incluindo o constante estresse social a que são submetidos, além dos outros, como fatores ambientais relacionados à $\mathrm{SRI}$.

\section{COMENTÁRIOS FINAIS}

Os resultados mostram que os Guaraní-Mbyá do Estado do Rio de Janeiro apresentaram prevalências elevadas de sobrepeso, de obesidade central, de hipertrigliceridemia, de HDL-colesterol baixo, sobretudo nas mulheres. Encontram-se em uma situação intermediária entre os grupos populacionais comparados quanto à expressão de fatores de risco cardiovasculares.

Encontrou-se uma tendência de acúmulo dos fatores definidos como integrantes da SRI, e que existe um risco aumentado para a presença da SRI entre os indivíduos acima de 50 anos de idade e obesos. Destaca-se assim a importância da manutenção da assistência regular aos casos prevalentes, minimizando e retardando o agravamento dos mesmos e um planejamento de ações preventivas enfocando o controle do sobrepeso, combate ao sedentarismo, ao tabagismo e ao etilismo e a modificação dos hábitos alimentares. 


\section{Referências}

BALKAU, B.; KING, H.; ZIMMET, P. \& RAPER, R., 1985. Factors associated with the development of diabetes in the Micronesian population of Nauru. American Joumal of Epidemiology, 122:594-605.

BARKER, D. J. P.; HALES, C. N.; FALL, C. H. D.; OSMOND, C.; PHIPPS, K. \& CLARK, P. M. S., 1993. Type 2 (non-insulin-dependent) diabetes mellitus, hypertension and hyperlipidaemia (Syndrome X): relation to reduced fetal growth. Diabetologia, 36:62-67.

BARKER, D. J. P.; WINTER, P. D.; OSMOND, C.; MARGETTS, B. \& SIMMONDS, S. J., 1989. Weight in infancy and death from ischaemic heart disease. Lancet, 2:577-580.

BLOCH, K. V.; COUTINHO, E. S. F.; LÔBO, M. E. C.; OLIVEIRA, J. E. P. \& MILECH, A., 1993. Pressão arterial, glicemia capilar e medidas antropométricas em uma população Yanomámi. Cadernos de Saúde Pública, 9:428-438.

CARDOSO, A. M., 2000. Prevalência de Doenças Crônico-Degenerativas na População Guarani-Mbyá do Estado do Rio de Janeiro. Dissertação de Mestrado, Rio de Janeiro: Escola Nacional de Saúde Pública, Fundação Oswaldo Cruz.

CARDOSO, A. M.; MATTOS, I. E. \& KOIFMAN, R. J., 2001. Prevalência de fatores de risco para doenças cardiovasculares na população Guaraní-Mbyá do Estado do Rio de Janeiro. Cadernos de Saúde Pública, 17:345-354.

EASON, R. J.; PADA, J.; WALLACE, R.; HENRY, A. \& THORNTON, R., 1987. Changing patterns of hypertension, diabetes, obesity and diet among Melanesians and Micronesians in the Solomon Islands. Medical Joumal of Australia, 146:465-473.

ERKELENS, D. W., 2001. Insulin resistance syndrome and type 2 diabetes mellitus. American Journal of Cardiology, 88: 38J-42J.

FERRANNINI, E.; HAFFNER, S. M.; MITCHELL, B. D. \& STERN, M. P., 1991. Hyperinsulinaemia: The key feature of a cardiovascular and metabolic syndrome. Diabetologia, 34:416-422.

FLEMIG-MORAN, M. \& COIMBRA Jr., C. E. A., 1990. Blood pressure studies among Amazonian native populations: A review from an epidemiological perspective. Social Science and Medicine, 31:593-601.

FLEMIG-MORAN, M.; SANTOS, R. V. \& COIMBRA Jr., C. E. A., 1991. Blood pressure levels of the Suruí and Zoró Indians of the Brazilian Amazon: Group- and sex-specific effects resulting from body composition, health status, and age. Human Biology, 63:835-861.

FORD, E. S.; GILES, W. H. \& DIETZ, W. H., 2002. Prevalence of the metabolic syndrome among US adults. Findings from the Third National Health and Nutrition Examination Survey. JAMA, 287:356-359.

GRAY, R. S.; FABSITZ, R. R.; COWAN, L. D.; LEE, E. T.; HOWARD, B. V. \& SAVAGE, P. J., 1998. Risk factor clustering in the insulin resistance syndrome. American Journal of Epidemiology, 148:869-878.

GREENLUND, K. J.; VALDEZ, R.; CASPER, M. L.; RITH-NAJARIAN, S. \& CROFT, J. B., 1999. Prevalence and correlates of the insulin resistance syndrome among native Americans - The Inter-Tribal Heart Project. Diabetes Care, 22:441-447. 
HALL, T. R.; HICKEY, M. E. \& YOUNG, T. B., 1991. The relationship of body fat distribution to non-insulin-dependent diabetes mellitus in a Navajo Community. American Journal of Human Biology, 3:119-126.

HALL, T. R.; HICKEY, M. E. \& YOUNG, T. B., 1992. Evidence for increases in obesity and non-insulin-dependent diabetes mellitus in a Navajo Community. American Joumal of Human Biology, 4:547-553.

JNC (Joint National Committee), 1988. The 1988 Report of the JNC on detection, evaluation, and treatment of high blood pressure. Archives of Internal Medicine, 148:1023. 1038.

KING, H. \& ZIMMET, P., 1988. Trends in the prevalence and incidence of diabetes: Noninsulin-dependent diabetes mellitus. World Health Statistics Quarterly, 41:190-196.

KNOWLER, W. C.; BENNETT, P. H.; HAMMAN, R. F. \& MILLER, M., 1978. Diabetes incidence and prevalence in Pima Indians: A 19-fold greater incidence than in Rochester, Minnesota. American Joumal of Epidemiology, 108:497-505.

LARENAS, G.; ARIAS, G.; ESPINOZA, O.; CHARLES, M.; LANDAETA, O.; VILLANUEVA, S. \& ESPINOZA, A., 1985. Prevalencia de diabetes mellitus en una comunidad Mapuche de la IX Region, Chile. Revista Médica de Chile, 113:1121-1125.

LITAIFF, A., 1996. As Divinas Palavras: Identidade Étnica dos Guarani-Mbyá. Florianópolis: Editora da Universidade Federal de Santa Catarina.

MALERBI, D. A. \& FRANCO, L. J., 1992. Multicenter study of the prevalence of diabetes and impaired glucose tolerance in the urban Brazilian population aged 30-69 yr. Diabetes Care, 15(11): 1509-1516.

MEIGS, J. B., 2000. Invited comentary: Inslin resistance syndrome? Syndrome X? Multiple metabolic syndrome? A syndrome at all? Factor analysis reveals patterns in the fabric of correlated metabolic risk factors. American Journal of Epidemiology, 152:908-911.

NCEP (National Cholesterol Education Program), 1993. Summary of the second report of The National Cholesterol Education Program (NCEP) Expert Panel on Detection, Evolution, and Treatment of High Blood Cholesterol in Adults (adult treatment panel II). JAMA, 269:3015-3023.

NEEL, J. V., 1962. Diabetes mellitus: A “thrifty" genotype rendered detrimental by progress? American Joumal of Human Genetics, 14:353-362.

OMS (Organización Mundial de la Salıd), 1978. Hipertensión Arterial. Serie de Informes Técnicos 628. Geneva: OMS.

PAVAN, L.; CASIGLIA, E.; BRAGA, L. M. C.; WINNICKI, M.; PUATO, M.; PAULETTO, P. \& PESSINA, A. C., 1999. Effects of a traditional lifestyle on the cardiovascular risk profile: The Amondava population of the Brazilian Amazon. Comparison with matched African, Italian and Polish populations. Joumal of Hypertension, 17:749756.

PEREIRA, R. A.; SICHIERI, R. \& MARTINS, V. M. R., 1999. Razão cintura/quadril como preditor de hipertensão arterial. Cadernos de Saúde Pública, 15:333-344.

REAVEN, G. M., 1988. Role of insulin resistance in human disease. Diabetes, 37:15951607.

SAKKINEN, P. A.; WAHL, P.; CUSHMAN, M.; LEWIS, M. R. \& TRACY, R. P., 2000. 
Clustering of procoagulation, inflammation, and fibrinolisis variables with metabolic factors in insulin resistance syndromc. American Journal of Epidemiology, 152:897-907.

SANTOS, J. I.; PERF\%-BRAVO, F.; CARRASCO, E.; CALVILLAN, M. \& AI.BA, C., 2001. Low prevalence of type 2 diabetes despite a high average body mass index in Aymara natives from Chile. Nutrition, 17:305-309.

SCHMII'I', M. I., 1996. Diabetes mellitus. In: Medicina Ambulatorial: Condutas Clínicas em Atenção Primária (B. B. Duncan, M. I. Schmidt \& E. R. J. (jiugliani, org.), pp. 476-490, Porto Alegre: Editora Artes Médicas Sul.

SHERWIN, R. S., 2001. Diabete Melito. In: Cecil - Tratado de Medicina Interna (I.. Goldman \& J. (.. Bennett, org.), pp. 1405-1431, Rio de Janeiro: Editora Guanabara Koogan.

SZATHMÁRY, F.. J. F., 1994. Non-insulin dependent diabetes mellitus among aboriginal North Americans. Annual Review of Anthropology, 23:457-482.

VEGA, C. I., 2001. Obesity, the metabolic syndrome, and cardiovascular discasc. American Heart Joumal, 142:1108-1116.

VIE.IRA FII.HO, J. P. B., 1977. O diabetes mellitus e as glicemias de jejum dos índios Caripuna e Palikur. Revista da Associação Médica Brasileira, 23:175-178.

WEISS, K. M.; FERRELL, R. E. \& HANIS, C. I., 1984. A new world syndrome of metabolic diseases with a genetic and evolutionary basis. Yearbook of Physical Anthropology, 27:153-178.

WHITY, 'I. K.; LEF, LE. 'I.; YHH, J.; COWAN, L. D.; GO, O.; FABSITZ, R. R., LE, N.-A.; OOPIK, $i$. J.; ROBBINS, D. C. \& IIOWARD, B. V., 1995. Cardiovascular discase risk factors among American Indians - The Strong Heart Study. American Journal of Epidemiology, 142:269-287.

WHO (World Health Organization), 1995. Physical Status: The Use and Interpretation of Anthropometry - Report of a WHO Expert Committee. WHO) Technical Report Series 854. (ieneva: WIIO)

WILL, J. C.: SI'RAUSS, K. F.; MF'NDIFIN, J. M.; BALIEW, C.; WHITF, I. I . \& PFTER, D. G., 1997. Diabetes mellitus among Navajo Indians: Findings from Navajo Health and Nutrition Surver. Journal of Nutrition, 127:2106S-2113S.

YAJNIK, C. S., 2001. 'The insulin resistance epidemic in India: Fetal origins, later lifestyle, or both? Nutrition Revieus, 59:1-9.

YOUNG, T. K., 1988. Are subartic Indians undergoing the epidemiologic transition? Social Science and Medicine, 26:659-671.

YOUXG, 'I'. K., 1993. Diabetes mellitus among native Americans in Canada and the United States: An epidemiological review. American Journal of Human Biology, 5:390)-413.

ZINMET, P.; 'TAFT', P.; GUIVHA, A.; COTHRIE, W. \& THOMA, K., 1977. The high prevalence of diabetes mellitus on a central pacific island. Diabetologia, 13:111-115. 



\section{ขै?}

CONTATO INTERÉTNICO, PERFIL

SAÚDE-DOENÇA E MODELOS DE

INTERVENÇÃO EM SAÚDE INDÍGENA:

O CASO ENAWENÊ-NAWÊ, MATO GROSSO

Maria Clara V. Weiss

Nas últimas décadas, o rcconhecimento dos direitos dos povos indígenas e as discussões sobre a democratização do setor saúde propiciaram a abordagem da questão da saúde indígena, no sentido de conhecer os scus determinantes e na adoção de modelos diferenciados de atenção, em oposição ao modelo intervencionista que caracterizou predominantemente a atenção à saúde indígena no Brasil no passado.

Numa reunião de trabalho sobre povos indígenas e saúde, foi recomendado que a Organização Pan-Americana da Saúdcle e os ministérios da saúde dos países membros deveriam assegurar um sistema de vigilância sobre as condições de saúde desses povos. Por intermédio do desenvolvimento de métodos, instrumentos específicos e indicadores epidemiológicos para avaliação contínua e sistemática, deveriam ser estabelecidos mecanismos que permitirian à comunidade indígena participar na definição do tipo de informação e reconhecer o seu uso. Deveria ainda ser garantida a atenção primária à saúde aos povos indígenas num esforço de viabilizar o acesso aos serviços de saúde, a participação da população nas decisões e o respcito à diferenciação étnica (Lightman, 1977; OIT, 1989).

No Brasil, no âmbito das políticas de saúde, a situação dos povos indígenas tem sido discutida em Conferências Nacionais de Saúde (CNS) e de Saúde Indígena (CNSI)2 ${ }^{2}$ Essas discussões têm defendido a proposta da implantação de modelos diferenciados, com base nas diretrizes do Sistema Único de Saúde (SUS)

\footnotetext{
I Vide Reunión de 'Trabajo sobre Pueblos Indigenas y Salud. Anexo 1: Recomicndaciones. Organización Panamericana de la Salud, Wimipeg, Canadá, 1993.

2 Vide I Conferência Nacional de Salide do Índio. Relatório Final, Brasília, 1987; II Conferência Nacional de Proteção à Saúde dos Povos Indigenas. Relatório Final, Luziânia, Coiás, 1993; III Conferência Nacional de Saúde Indigena. Relatório Final, Luziânia, Coiás, 200); IX Conferência Nacional de Saúde. Relatório Final, Brasília, I)F, 1992; X Conferência Nacional de Saúde. Relatório Final, Brasília, 1996; XI Conferência Nacional de Saúde. Relatório Final, Brasília, 2000$).$
} 
e nas peculiaridades das diferentes etnias como: situação de contato, dinâmica do perfil epidemiológico, mudanças das práticas do sistema médico tradicional e o moderno; situação geográfica e sua implicação na continuidade das ações de saúde. Os princípios básicos do SUS são o acesso universal e igualitário às ações e serviços, rede regionalizada e hierarquizada, descentralização, atendimento integral, participação comunitária e respeito às diferenças. Surgem daí a proposta dos Distritos Sanitários Especiais Indígenas (DSEIs), sob a responsabilidade do Ministério da Saúde e gestão da Fundação Nacional de Saúde (FUNASA).

\section{AS ESTRATÉGIAS DE CONTATO}

A Terra Indígena Enawenê-Nawê compreende 742 mil hectares, situada nos municípios de Juína, Sapezal e Comodoro, noroeste do Estado de Mato Grosso. A área foi demarcada em 1995 e homologada em 1996. Em dezembro de 2002, os Enawenê-Nawê somavam 362 pessoas. São assistidos pela Operação Amazônia Nativa (OPAN), que tem procurado garantir a autonomia do grupo nas decisões relativas ao contato com a sociedade envolvente e nas questões relacionadas à atenção à saúde.

Os Enawenê-Nawê foram contatados em 1974 por missionários jesuítas. Contudo, havia informações sobre a existência desse povo desde pelo menos 1908, quando a Comissão de Linhas Telegráficas atravessou a bacia do rio Juruena (Busatto, 1995). Por ocasião do contato, alguns missionários da Missão Anchieta traçaram uma política de manutenção da alimentação tradicional, defesa do espaço territorial e reconhecimento da medicina nativa.

Antes do contato, os Enawenê-Nawê já tinham uma história de fuga do seu território tradicional devido aos ataques dos Cinta-Larga e Rikbaktsá. Após o contato, voltaram à plantação das roças e ao reconhecimento do território que ocupavam, determinando assim a demarcação do mesmo com o apoio da ação missionária e indigenista.

Até 1983, os Enawenê-Nawê eram conhecidos como Salumã, denominação dada pelos Paresí, que julgavam se tratar de um de seus subgrupos dissidente. E.m 1984, foi encaminhada à Fundação Nacional do Índio (FUNAI) a solicitação de renomeação da terra Salumã para Enawenê-Nawê, que é uma autodesignação (Lisboa, 1985).

Em março de 1987, o missionário Vicente Canhas, que prestava assistência aos Enawenê-Nawê, foi brutalmente assassinado em seu acampamento às 
margens do rio Juruena. Após sua morte, saiu a portaria de interdição da Área Indígena Salumã, atingindo quase que plenamente o território Enawenê-Nawê (ficaram de fora o Córrego Pedra de Fogo e as cabeceiras dos rios Preto e Iquê). Em 1987, a OPAN, que já atuava em parceria com a Missão Anchieta, assumiu a assistência ao grupo, respeitando suas características culturais e buscando conhecer melhor seus costumes, a fim de direcionar as intervenções necessárias. A partir de então, ocorreu uma sistematização das informações sobre as ações de saúde desenvolvidas, que até então eram registradas em diários de campo.

\section{COSMOLOGIA E ORGANIZAÇÃO SOCIAL}

Para os Enawenê-Nawê, os rituais yãkwa, lerohi, salumã e kateoku são as formas de manutenção do elo entre a sociedade e o cosmos, por intermédio deles buscando-se a harmonia e a vida plena. Os rituais yãkwa e lerohi envolvem os yakairiti, de formas monstruosas e predadores; os rituais salumã e o kateoku envolvem os enore-nawe. Os Enawenê-Nawê estão num plano intermediário, no "meio", articulando o espaço terrestre dos humanos com o celeste e o subterrâneo (Silva, 1995).

Na morfologia social Enawenê-Nawê, são encontrados clãs e grupos residenciais, domésticos e familiares. O clã é a base do sistema de parentesco e, por conseguinte, da organização social e econômica. O sistema de parentesco assenta-se em relações de consangüinidade (irmãos) e de afinidade (conjugues e irmãos do conjugue). De certa forma, essas relações são estabelecidas pelo regime de trocas matrimoniais definido pelos entrecruzamentos dos clãs. Os clãs têm funções matrimoniais, cerimoniais e econômicas. Esses grupos são compostos pelos descendentes de dezenas de "tribos míticas" que viviam no vale do rio Juruena e regiões adjacentes. No conceito nativo de cultura, essas tribos teriam "culturas incompletas" e ensinaram umas as outras o que sabiam (Silva, 1995).

O grupo residencial corresponde aos residentes de uma mesma casa comunal, na qual se encontram os grupos domésticos e os familiares. O grupo familiar tem como núcleo um casal e seus filhos e filhas solteiros, mas podem incluir pai ou mãe viúvos de um dos conjugues e os filhos das filhas solteiras. Podem ser encontrados grupos familiares independentes, formados por mães viúvas ou mulheres solteiras e seus filhos, quando seus pais não sejam vivos. Ao grupo familiar compete cultivar os pequenos roçados de mandioca próximos à aldeia, extrair lenha, coletar insetos comestíveis e pescar em pequena escala com a participação de todos os membros. O grupo doméstico é constituído de um homem, 
sua esposa, seus filhos(as) solteiros(as) e suas filhas casadas. Cada casa abriga geralmente mais de um grupo doméstico, constituindo o grupo residencial. O grupo doméstico e o residencial são importantes unidades sociais, com base nas quais são definidas várias atividades comunitárias.

\section{PERFIL POPULACIONAL}

Somente a partir de 1979 encontramos informações sistematizadas sobre nascimentos e óbitos. Em diversas ocasiões, nascimentos e óbitos ocorriam nos acampamentos distantes da aldeia, onde os Enawenê-Nawê desenvolvem atividades de subsistência. Na ocasião do contato, em 1974, a população dos Enawenê-Nawê era de 97 pessoas (Lisboa, 1985) e em 1997 totalizavam 287, aumentando em quase $300 \%$ após duas décadas. O crescimento populacional parece ser desejado e esperado, pois os indígenas se referem à existência de uma população maior do que a encontrada por ocasião do contato com a Missão Anchieta, sugerindo a possibilidade de ter havido uma redução da população, anterior ao encontro com os jesuítas.

Nas pirâmides etárias de 1983 e de 1993, foram encontradas características de populações em crescimento, como um grande número de jovens (Figura 1). Em 1997, na distribuição percentual da população por faixa etária e sexo, foi encontrada uma concentração de 35,5\% na faixa etária de 5-14 anos, maior que nos anos anteriores. Tal perfil associa-se à retomada de nascimentos nos últimos anos. Um dado importante a ser considerado é o ressurgimento de indivíduos na faixa etária com mais de 65 anos, o que pode indicar um aumento na esperança de vida.

Os Enawenê-Nawê apresentam uma definição própria de diferentes fases da vida, diferenças que podem ser caracterizadas no vestuário, por meio do uso dos adornos segundo critérios de nascimento, crescimento e desenvolvimento (Sá, 1996). Essas mudanças no vestuário são as manifestações de direitos e obrigações sociais e outras, próprias a cada fase. De maneira geral, podemos definir uma fase infantil até os 14 anos e, a partir dessa idade, uma fase adulta, quando ocorrem os ritos de iniciação masculino e feminino. A partir de então, os Enawenê-Nawê assumem atividades de subsistência e de reprodução sócio-biológica, com a efetivação de casamentos e participação em rituais. 
Fïrura l

Pirâmides etárias dos Enawenế-i Vawê, Mato (irosso, em 1983 e 1993.

pirâmide etária em 1983

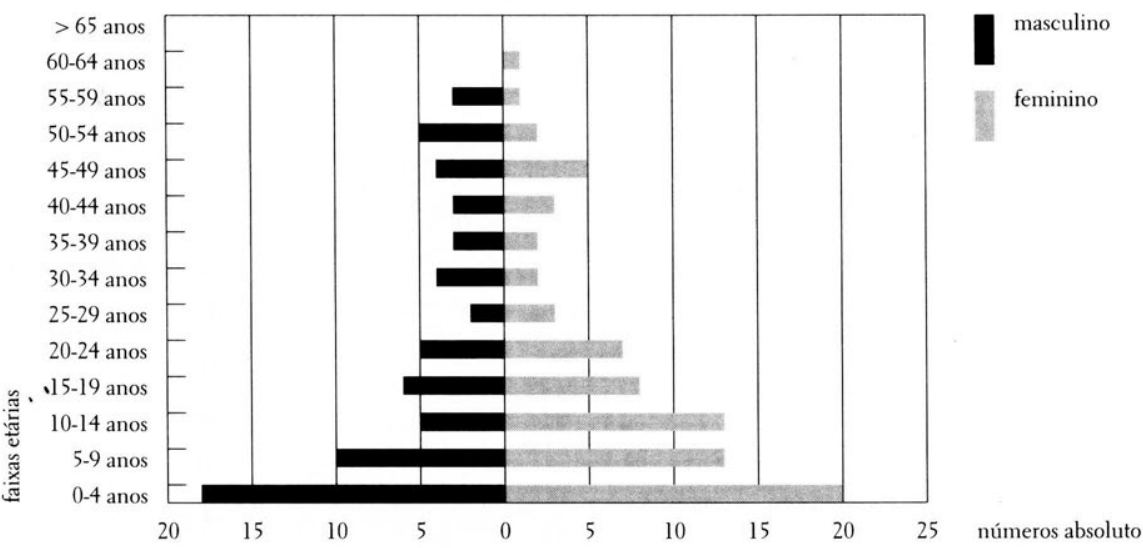

pirâmide etária em 1993

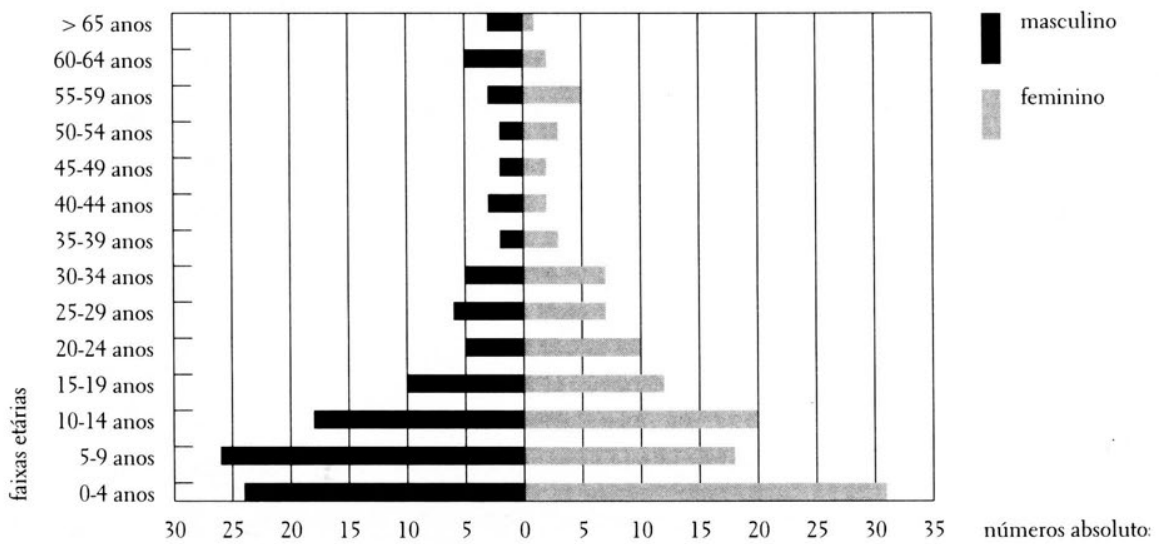




\section{MORBIDADE E MORTALIDADE}

Nos primeiros dez anos de contato encontramos referências constantes às febres, que ocorriam sob a forma de surtos ou como casos isolados, além de gripes, doenças de pele, conjuntivite, diarréias, dores abdominais, reumáticas e de cabeça, vômitos e, alguns casos identificados como leishmaniose tegumentar. Embora a malária tenha sido pouco referida neste período, comumente as febres eram tratadas como tal. As gripes ocorreram sobretudo nos meses de chuva (novembro-janeiro) e nos meses de junho-julho, quando são registradas as temperaturas mais baixas na região. Inquéritos clínicos realizados em diferentes momentos confirmaram a importância das doenças infecciosas e parasitárias como as principais causas de morbidade entre os Enawenê-Nawể $\hat{e}^{3}$ Vale mencionar que não foram encontrados casos de diabetes mellitus e hipertensão arterial. Segundo relatórios produzidos por indigenistas da OPAN cobrindo o período de 1988-1997, há registro de vários surtos de gripe, diarréias e conjuntivite que acometeram os Enawenê-Nawê, destacando-se a malária no período de 1990 a 1995, e a catapora em 1993 e em 1997.

Nos últimos vinte anos, a distribuição dos óbitos evidencia maiores percentuais em menores de um ano (44,2\% do total dos óbitos), o que provavelmente reflete um elevado coeficiente de mortalidade infantil. No total, foram 27 óbitos em menores de um ano, quatro dos quais filhos de uma mesma mãe. $\mathrm{Na}$ faixa etária de $1-5$ anos, o percentual foi de $13,1 \%$ e de $22,9 \%$ ern maiores de 14 anos. Os valores mais baixos foram encontrados nas faixas etárias de 6-13 anos e em maiores de cinqüenta, com $9,8 \%$ dos óbitos.

$\mathrm{Na}$ distribuição da mortalidade por sexo, verificamos que $44,2 \%$ dos óbitos foram do sexo masculino e $37,2 \%$ do feminino (não houve registro de sexo

\footnotetext{
3 Vide relatórios médicos de Maria Stela C. Lobo (Relatório de Viagem a Campo. Projeto de Saúde Enawene-Nawe. Operação Amazônia Nativa/Fundo Nacional de Saúde. Rio de Janeiro: Núcleo de Estudos em Saúde de Povos Indígenas, Escola Nacional de Saúde Pública, Fundação Oswaldo Cruz, 1995, 13 pp.; Relatório de Viagem a Campo. Projeto de Saúde Enawene-Nawe. Operação Amazônia Nativa/Fundo Nacional de Saúde. Rio de Janeiro: Núcleo de Estudos em Saúde de Povos Indígenas, Escola Nacional de Saúde Pública, Fundação Oswaldo Cruz, 1997, 10 pp.) e Rubens V. Ianelli (Relatório de Viagem a Campo. Projeto de Saúde Enawene-Nawe. Operação Amazônia Nativa/Fundo Nacional de Saúde. Rio de Janeiro: Núcleo de Estudos em Saúde de Povos Indígenas, Escola Nacional de Saúde Pública, Fundação Oswaldo Cruz, 1997, 9 pp.).
} 
cm 18,6\% dos óbitos). Todos os óbitos de sexo ignorado foram de recém-nascidos, dificultando a análise da mortalidade por sexo nesta faixa etária.

Na distribuição dos óbitos por faixa ctária e sexo, verificamos que, em todas as faixas ctárias foi maior o número de óbitos no sexo masculino, com exceção daqueles entre 6-13 anos, na qual ocorreu um óbito do sexo masculino e cinco do feminino. Nos maiores de cincüuenta anos, não houve diferença, tendo ocorrido três óbitos em cada sexo no período de 1977-1997.

As principais causas associadas aos óbitos no período de 1977-1997foram: gripe (16,4\%); febre com dores abdominais ( $11,5 \%$ ); paralisia intestinal em recém-nascidos (9,8\%); febre e hemorragia umbilical $(6,5 \%)$; outros (infanticídio, malária, pneumonia, etc.) (3,3\%). Nas causas associadas aos óbitos, encontramos alta frequiência de registros referentes a "outras causas" (18,0\%) e "causa ignorada" $(9,8 \%)$. Tal quadro está relacionado à baixa fidedignidade dos registros existentes nos locais em que se dão os óbitos, sem assistência médicat.

\section{ALIMENTAÇÃO E ESTADO NUTRICIONAL}

A distribuição e o consumo dos alimentos estão relacionados ao calendário dos rituais yãkwa, lerohi, salumã e kateoku, realizados durante os meses do ano, envol-

\footnotetext{
+ Particularmente as febres com dores abdominais preocupavam sobremaneira os Enawenê-Nawê devido aos óbitos associados. Ém janciro de 1988, devido ao número de casos de febres de etiologia não esclarecida, foi realizada uma pesquisa com o apoio do IIospital Pio X, localizado em Ceres, Goiás. Foram colctadas amostras de sangue para diagnóstico de malária, hemograma e sorologia em 13 pessoas. Fin 1989 e 1996, foram realizados inquéritos sorológicos para esclarecincnto dos surtos febris com ênfase nos arbovírus. Os arbovírus são caracterizados como um grupo de vírus transmitidos por artrópodes, principalmente mosquitos, a partir de vertcbrados silvestres. As arboviroses, doenças caulusadas por esses vírus, podem ocorrer de forma esporádica, endêmica ou epidêmica, podendo estar associada a alterações ambientais (Tsai, 1991). Em julho de 1995, um surto de febre de etiologia não esclarecida provocou cuuatro óbitos. No incuérito sorológico realizado em 1996 contra 19 tipos de arbovírus, foram obtidas quatro reaçoes positivas para Alphavírus (família Togaviridac), nove para Flavivírus (família Flaviridac), cinco para Bunyavírus (família Bunyariridae). Dentre os Alphavírus, o Mayaro foi o mais frequiente, seguido pelo Nucambo (complexo WH.E.). Vide Weiss (1998) e relatórios de A. P. A. Travassos da Rosa: (1) Soros de Índios da Tribo Finawene-Nawe MT. Pesquisa de Anticorpos III para Arborirus. Instituto liandro (Shagas, Belém, 1989 e (2) Índios Finawene-Nawe (Noroeste de Mato (Grosso). Pesquisa de anticorpos para arbovínes. Instituto Fiandro Chagas, Belém, 1997.
} 
vendo a pesca, a plantação e a coleta. Esses rituais são determinados pelo ciclo hidrológico da região, como as estações de seca, enchente e vazante dos rios. A subsistência do grupo ainda está diretamente relacionada à utilização de alimentos silvestres, obtidos por meio da coleta em ecossistemas de cerrado e de transição para a floresta (insetos, mel, frutos, etc.), além de peixe, mandioca e milho.

Segundo inquérito antropométrico realizado na década de 1990, que incluiu setenta crianças Enawenê-Nawê entre 0-6 anos de idade (Weiss, 1998), foram encontradas $5,6 \%$ abaixo do percentil 3 e 5,6\% abaixo de -2 escores-z para o indicador peso/estatura, tendo como referência as curvas do National Center for Health Statistics (NCHS). Esse resultado indica condições atuais de nutrição satisfatórias. Quanto ao indicador estatura/idade, foram encontradas $53,8 \%$ das crianças abaixo do percentil 3 e 50,0\% abaixo de -2 escores-z, demonstrando déficit de crescimento. Na avaliação nutricional de populações, prevalências acima de $25 \%$ indicam uma situação grave de carência alimentar e condições precárias de vida, que determinam a falta de condições adequadas ao crescimento e desenvolvimento, sendo necessário intervenção. No caso das populações indígenas, a interpretação de resultados de investigações em antropometria nutricional é particularmente complexa devido ao debate acerca da validade de se utilizar curvas de crescimento internacionais, como as do NCHS (Santos, 1993)5.

A avaliação do estado nutricional dos Enawenê-Nawê maiores de 18 anos revelou valores normais do índice de massa corporal (IMC) em 31,2\% dos homens e $38,4 \%$ das mulheres (Tabela 1). A maior freqüência de baixo peso foi observada em mulheres $(13,1 \%)$ e de sobrepeso em homens $(11,1 \%)$. Foi também observado que $26,6 \%$ dos homens apresentaram uma razão cintura-quadril (RCQ) superior a 0,95 e em 40,0\% das mulheres foi superior a 0,80 . Esses resultados apontam para o risco maior de desenvolver doenças cardiovasculares devido à concentração de gordura na região abdominal. Entretanto, com base no IMC (valores > 30), não há indicação da ocorrência de obesidade no grupo. É importante que, no futuro, esses dados sejan considerados em associação com investigações sobre o surgimento de doenças cardiovasculares e diabetes mellitus, embora a mudança neste quadro pareça remoto enquanto os Enawenê-Nawê mantiverem a alimentação tradicional.

\footnotetext{
5 'lanto nos relatórios dos indigenistas (referentes a 1989-1996) como no das equipes médicas (1993-1997), não foram referidos casos de desnutrição, com exceção do caso de um menino de $1 \mathrm{l}$ anos coin malária e lcishmaniose, e de uma mulher idosa.
} 
Distribuição percentual da classificação segundo o índice de massa corporal em 86 adultos Enawenê-Nawê (42 homens e 44 mulheres). Julho, 1997.

\begin{tabular}{|c|c|c|c|c|c|c|}
\hline \multirow[t]{3}{*}{ Idades } & \multicolumn{6}{|c|}{ Índice de Massa Corporal } \\
\hline & \multicolumn{2}{|c|}{$<18,5$} & \multicolumn{2}{|c|}{$18,5-25$} & \multicolumn{2}{|c|}{$>25$} \\
\hline & Homens & Mulheres & Homens & Mulheres & Homens & Mulheres \\
\hline $18-60$ anos $(n=75)$ & 3,1 & 11,1 & 23,2 & 35,3 & 11,1 & 3,1 \\
\hline$>60$ anos $(n=11)$ & 0,0 & 2,0 & 8,0 & 3,1 & 0,0 & 0,0 \\
\hline Total & 3,1 & 13,1 & 31,2 & 38,4 & 11,1 & 3,1 \\
\hline
\end{tabular}

\section{CONSIDERAÇÕES FINAIS}

A atenção à saúde, desenvolvida por meio de uma intervenção mínima de recursos da medicina moderna para controle e tratamento das doenças que acometem os Enawenê-Nawê, a adoção de uma "estratégia de convivência pacífica" e a garantia do território tradicional desde o contato têm pautado os trabalhos realizados pela OPAN. Para tanto, são mantidos indigenistas na aldeia, que prestam assistência, garantem a continuidade do registro de dados e o desenvolvimento das ações básicas de saúde, assim como a viabilização do conhecimento e respeito ao modo de vida do grupo. Os casos mais graves são removidos para diagnóstico e tratamento, sempre com a permissão da comunidade e o acompanhamento de parentes. Exames complementares são realizados em centros hospitalares nos municípios de Brasnorte e Cuiabá, no Estado de Mato Grosso, e Ceres, em Goiás.

As ações de saúde foram sendo introduzidas gradualmente desde o contato, intensificando-se nos últimos anos. No início da década de 1990, houve uma implementação de ações para o controle da malária e, a partir de 1995, por intermédio de convênio com a FUNASA, foi implementado o Projeto de Saúde Enawenê-Nawê, por meio do qual foram realizados inquéritos epidemiológicos $\mathrm{e}$ visitas médicas e odontológicas. Esses inquéritos evidenciaram a necessidade do acompanhamento de gestantes e de recém-nascidos, devido à elevada mortalidade infantil. Também foi identificada a necessidade de tratamentos odontológicos devido à precária situação de saúde bucal.

Como enfatizado, na implementação das ações de saúde deve ser considerada a complementariedade do conhecimento sobre as relações simbólicas 
que envolvem o processo de adoecer e morrer entre os Enawenê-Nawê, e o aprofundamento sobre os determinantes ambientais neste processo.

Atualmente, no âmbito da política de saúde indígena, a OPAN como ONG indigenista tem atuado com profissionais de saúde na atenção básica e procurado garantir o acesso aos níveis secundário e terciário por meio dos DSEIs, viabilizando assim a integralidade do modelo de intervenção.

Essse modelo de atenção à saúde indígena pauta-se no reconhecimento dos direitos de cidadania dos povos indígenas, que devem ser considerados nos níveis municipal, estadual e nacional. A consolidação desse modelo supõe uma lógica na intervenção que possibilite aos povos indígenas reafirmarem seus direitos à diferenciação étnica e à autonomia, mediante a participação no controle social das ações que afetem suas vidas nas aldeias e no contato com a sociedade envolvente.

\section{Referências}

BUSATTO, I., 1995. Os Enawene-Nawe, contato e indigenismo. In: Estudo das Potencialidades e do Manejo dos Recursos Naturais na A. I. Enawene-Nawe (G. M. Santos, M. F. Silva \& P. Costa Jr., orgs.), Relatório inédito. Cuiabá: Operação Amazônia Nativa/Núcleo de Estudos e Pesquisas do Pantanal, Amazônia e Cerrado, Universidade Federal de Mato Grosso.

LIGHTMAN, S., 1977. The responsibilities of intervention in isolated societies. In: Health and Disease in Tribal Societies. CIBA Foundation Symposia 49. Anssterdam: Elsevier. LISBOA, T. A., 1985. Os Enawene-Nawe: Primeiros Contatos. São Paulo: Ediçōes Loyola. OI'T (Organização Internacional do Trabalho), 1989. Convenção 169 sobre Povos Indígenas e Tribais em Países Independentes e Resolução sobre a Ação da Organização Internacional do Trabalho Concernente aos Povos Indígenas e Tribais. Brasília/Genebra: Organização Internacional do Trabalho.

SÁ, C., 1996. As Fases da Vida: Categorias de Idade Enawene (ru)-nawee. Cuiabá: Operação Amazônia Nativa.

SANTOS, R. V., 1993. Crescimento físico e estado nutricional das populações indígenas brasileiras. Cadernos de Saúde Pública, 9(Sup.):46-57.

SILVA, M., 1995. Estrutura social Enawene-Nawe: Um rápido esboço. In: Estudos das Potencialidades e do Manejo dos Recursos Naturais na Área Indígena Enawene-Nawe (G. M. Santos, M. F. Silva \& P. Costa Jr., org.), pp. 19-32, Cuiabá: Operação Amazônia Nativa/Núcleo de Esstudos e Pesquisas do Pantanal, Amazônia e Cerrado, Universidade Federal de Mato Grosso.

TSAI, T. F., 1991. Infecções por arbovírus nos Estados Unidos. In: Infeç̧ões Humanas Associadas a Animais (R. C. Moelling, org.), pp. 75-106, Rio de Janeiro: Interlivros.

WEISS, M. C. V., 1998. Contato Interétnico, Perfil Saúde - Doença e Modelos de Intervenção Mínima: O Caso Enawene-Nawe em Mato Grosso. Tese de Doutorado, Rio de Janeiro: Escola Nacional de Saúde Pública, Fundação Oswaldo Cruz. 


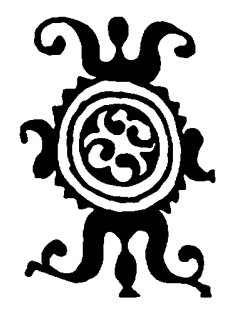

\section{A FORMAÇÃO DO AGENTE DE SAÚDE INDÍGENA TIKÚNA NO ALTO SOLIMÕES: UMA AVALIAÇÃO CRÍTICA}

Regina M. de Carvalho Erthal

A estratégia de formação de agentes comunitários para que sua atuação venha a significar uma ampliação da cobertura dos serviços de saúde por meio da atenção primária à saúde é uma indicação básica da Organização Mundial da Saúde, e vem sendo amplamente defendida e utilizada por organizações governamentais e não-governamentais (ONGs) com atuação nesta área.

A Conferência Internacional sobre Atenção Primária à Saúde, realizada em Alma-Ata (União Soviética/1978), definiu o agente comunitário de saúde como o ator principal da proposta de fazer com que o objetivo de "saúde para todos no ano 2000" pudesse ser alcançado.

Em termos de conceituação mais geral, o trabalho do agente comunitário de saúde tem sido definido como um canal de comunicação entre a população e os serviços de saúde, sendo portanto uma recomendação fundamental o seu pertencimento à comunidade com a qual trabalha, pressupondo nessa relação a possibilidade de um trabalho integrado (trabalho de equipe e recursos da comunidade). Nesse sentido, o papel dos agentes de saúde no sistema deve ser estabelecido em cada comunidade com base nas necessidades específicas e dos recursos disponíveis, dando-se destaque dentro das tarefas de promoção, prevenção e cura à sua função de educador. $O$ trabalho do agente comunitário deve estar integrado com as atividades em todos os níveis do sistema de saúde, sendo tarefa dos demais membros da equipe de saúde a capacitação, apoio e supervisão dos agentes, sem o que a sua atividade corre o risco de se tornar uma atuação paralela e/ou substituição "desqualificada" do sistema de atenção oficial.

Essas definições básicas colocam o agente de saúde como sendo mais do que apenas um recurso humano para a atenção primária e, nesse sentido, a exigência de agentes/atores dá um destaque especial para a discussão da participação comunitária em níveis diversos.

Apesar das exigências colocadas aos profissionais de saúde no sentido da formação e supervisão do agente comunitário, a sua atuação tem sido vista, de modo geral, como uma solução para aquelas populações na qual a ausência de 
informações e de acesso aos serviços de saúde, desemboca em alt as taxas de morbi-mortalidade por doenças infecciosas de fácil prevenção e tratamento valendose de procedimentos relativamente simples. A estratégia de incorporação do trabalho do agente de sande deve ser realizada de modo qualificado para que não se torne apenas em mais una forma de discriminação e assistência desigual, na qual o modelo epidemiológico signifique apenas restriçóes de recursos e profissionais de sande qualificados.

\section{O AGENTE DE SAÚDE INDÍGENA TIKÚNA}

Com relação às commuidades indígenas, a implementação da estratégia de formação de "agentes indígenals de saúde" (AISs), como forma de ampliação da assistência à salúde tem se pautado, quase que inteiramente, pelia adoção de um modelo que, a par da sobrevalorização de conhecimentos e recursos externos a essas commidades, desconhece os modelos locais e recursos internos que podem ser acionados para a resolução de problemas específicos de saúde/doença, vinculados a modelos culturalmente diferenciados de entendimento dos processos de adoecimento/sofrimento e cura.

No caso específico do processo de constituição dos AIS 'Jikúna enquanto "(ategoria profissional", as iniciativas foram formalnente descncadeadas no final da década de 80, valendo-se de un processo então considerado pionciro, já que tinha como base unna crítica articulada pelas lideranças indígenas a um sistema de assistência deficitário e excludente, oferecido pela Fundação N'acional do Índio ( $\mathrm{F}(\mathrm{N}$ NI), e a reivindicação de que a base do modelo assistencial deveria se constituir de indígenas, preparados para atuar nas suas comunidades de origem.

() modelo de assistência ao qual tinham acesso os Tikúna por intermédio da FUNAI se pautou, nas três últtimas décadas, pelas ações de saúde executadas nas alcleias (com a remoção de casos mais graves), por auxiliares de enfermagem c/ou chefes de postos com cursos técnicos em saúde ou sancamento, capalcitados para a realização de procedimentos curativos emergenciais, com uma utilização exacerbada e muitas veres fora de controle de medicannentos c, principalmente, vendo nos investimentos natives de tratamento c cura apenas o reflevo do estágio primitivo de seus conluecimentos.

A partir da década de 60, pastores americanos vinculados a Association of Baptists for World Fivangelism, com sede em Benjamin Constant, passaram a se envolver com os problemas de saúde das comunidades formadas em torno das 
missões (Campo Alegre e Betânia), atuando na obtenção de vacinas ou, eventualmente, na remoção de casos mais graves usando-se o avião da Associação. Os remédios eram vendidos aos índios pelos pastores, que viam nessa forma de relação uma proposta educativa do indígena, pautada pela concepção de integração do indígena à sociedade nacional formulada pela missão. Também a Igreja Católica organizou os moradores da comunidade de Belém do Solimões em torno de uma cooperativa, onde a contribuição financeira, por família indígena, permitia o fornecimento gratuito de medicamentos aos índios católicos (Oliveira Filho, 1977).

Um outro tipo de atendimento foi ainda disponibilizado, nas décadas de 70 e 80, por intermédio da ação campanhista do Projeto Rondon ou pelo atendimento esporádico fornecido pela unidade do Exército localizada na fronteira Brasil-Colômbia, percorrendo com um barco as aldeias do beiradão. Deve-se chamar a atenção ainda para a total desvinculação da ação do Exército com os programas oficiais de assistência à saúde realizados na área.

A primeira iniciativa de formulação de uma proposta de prestação de serviços assistenciais em moldes adequados à população Tikúna, realizou-se por meio do Projeto Tukuna, na década de 70. A falta de verbas do Programa de Integração Nacional (PIN), que financiava o trabalho de uma equipe interdisciplinar, que já na época juntava antropólogos, médicos e técnicos da FUNAI, abortou o que poderia ter sido o primeiro projeto diferenciado de assistência à população Tikúna.

Na segunda metade da década de 80, por recomendação do Grupo de Estudos sobre os Tikúna, a FUNAI contratou uma equipe de saúde para atuar com base em uma Unidade de Saúde Móvel que realizou apenas uma viagem e, ao final de dois anos de total falta de investimento da FUNAI, foi desmobilizadal.

O modelo oficial de assistência implementado serviu, então, como ponto de partida para o desencadeamento das reivindicações dos indígenas por uma melhor qualidade no atendimento às suas questões de saúde/doença. No entanto, a atuação do agente de saúde era percebida como uma tentativa de assegurar uma presença constante dos recursos que poderiam ser oferecidos pela medicina ocidental, por meio de uma mediação indígena.

1 O Projeto Tukuna, coordenado pelo antropólogo João Pacheco de Oliveira Filho, reunia uma equipe composta de técnicos indigenistas da FUNAI e médicos do Hospital de Moléstias Tropicais de Manaus (Marcus L. B. Barros, Marli Barreto e Marcus Guerra), além do médico José Alfredo Guimarães, da Equipe Volante de Saúde da FUNAI. 
As mudanças ocorridas em seu meio ambiente, resultado de um processo histórico de ocupação e exploração de seu território, imposto aos Tikúna pelos diferentes formatos que assumiram suas relações com a sociedade nacional nas diversas situações históricas (Oliveira Filho, 1977), alteraram progressivamente o quadro epidemiológico nas Terras Indígenas do Alto Solimões, com a introdução de novas doenças e a ocorrência de epidemias para os quais as terapias tradicionais passaram a não demonstrar as condições de resolutividade necessárias.

Todos esses fatores, com destaque para o processo mais amplo de desqualificação de sua cultura tradicional (Oliveira Filho, 1988), determinaram uma percepção pragmática dos Tikúna em relação à atuação do agente indígena de saúde como espelho/cópia dos procedimentos técnicos utilizados pelos profissionais de saúde (o que não permite inferir a sua adesão às lógicas que presidem tais atos), fator de aproximação com um sistema de atenção oficial que, via de regra, cria dificuldades ao acesso da população indígena nos seus vários níveis.

Além disso, a percepção que as instituições prestadoras de assistência à saúde têm da "participação popular", e particularmente da "participação indígena" no processo de ampliação dos cuidados básicos à saúde das populações pobres e/ou culturalmente diferenciadas, tem contribuído sobremaneira para que a questão da "participação comunitária", embutida no debate que presidiu a década de 80 em torno da implantação do SUS, seja definida enquanto "ferramenta neutra", elemento "facilitador" da entrada dessas populações no sistema de saúde².

O entendimento acerca do trabalho dos AISs, de modo geral, tem se pautado pela sua inserção nos programas e sistemas locais de saúde, restringindo-se à "participação da comunidade" (na prática, sua adesão a um modelo de atenção definido em fóruns aos quais não tiveram acesso). Nesse contexto, a participação indígena pode ser avaliada como um "meio técnico" (Bronfman \& Gleizer, 1994), um modo dos programas de saúde e as suas estratégias de funcionamento se fazerem aceitos pelas comunidades.

Nesta mesma linha, as recomendações para que o desenvolvimento de estratégias de atenção primária no nível local respeite as especificidades de cada povo indígena foi, muitas vezes, traduzida por um discurso que atribui à antropologia médica o papel de tradutora dos princípios e práticas do sistema médico oficial para essas comunidades, controlando um processo de "integração" entre o

2 Para uma discussão sobre a relação entre a constituição dos papéis de liderança e a capacidade de intermediação com os brancos ver Macedo (1996). 
sistema médico ocidental e as práticas tradicionais de cura. Parece claro que apesar de se buscar um discurso democrático de participação, garantia de igualdade e eqüidade no atendimento, os critérios e conceitos do paradigma médico ocidental presidem efetivamente essa "integração".

\section{O PROJETO DE SAÚDE TIKÚNA: DA REIVINDICAÇÃO DE AUTONOMIA AO "MODELO OFICIAL"}

Os primeiros treinamentos para $\mathrm{AIS}$ s 'l'ikúna foram elaborados no sentido de prover, para algums indivíduos apontados pelas lideranças de suas comunidades, os conceitos básicos sobre as causas das doenças e suas formas de prevenção, assim como capacitá-los na identificação daqueles agravos mais importantes para a área, formas de tratamento simplificado e/ou encaminhamento de casos mais graves.

Apesar do seu curto espaço de implementação sob a coordenação da equipe do Consclho Geral das Tribos 'l'ikúna (CG'I"l) (1989/1990), e das críticas cabíveis ao estágio de cvolução desta experiência, os cursos e treinamentos realizados por meio de convênios que envolveram as lideranças indígenas do C.GI'T', a Faculdade de Medicina da Universidade Federal do Rio de Janeiro e o Núcleo de listudos em Saúde dos Povos Indígenas (NFSPI) da Fundação Oswaldo Cruz (FIOCRI\%), capacitaram os indígenas no sentido da realização de tarefas básicas de identificação das doenças de maior ocorrência e resolução de um encaminhamento adequado, assim como na sua organização em uma entidade represcntativa, instrumentalizando-os ao mesmo tempo para a intermediação necessária entre as comunidades $c$ as autoridades locais nas questões de saúde.

A Organização dos Monitores de Saúde do Povo 'Tlikúna (OMSP'I'), deu um peso especial às suas reivindicações junto ao órgão tutor e ao Ministério da Saúde (MS), no sentido de que fosse preparada uma estrutura capaz de enfrentar o problema do cólera, que chegou ao Brasil através da região do Alto Solimões, em 1991. No início da epidemia, os AISs Tikúna, formados com o apoio do CG'T"I', se constitúram no único grupo preparado para, mediante um rápido treinamento, atuar nos atendimentos aos casos de cólera, incluindo as ocorrências em commidades não-índias mais próximas (Confalonieri \& Verani, 1993).

A chegada do cólera no Brasil pôs em evidência, por um lado, a fragilidade do sistema de saúde local e, de outro, a capacidade de mobilização do povo Tikúna para o enfrentamento do problema sob a liderança de seus $\mathrm{AIS}$ s, que se 
mostraram aptos ao desenvolvimento de ações preventivas e curativas. O resultado prático foi o reduzido número de casos de cólera observados nas comunidades indígenas e o baixo índice de mortalidade por esta causa.

Dentro desse quadro específico, mediante Decreto Presidencial no 23 (fevereiro de 1991), passou-se para a recém-criada Fundação Nacional de Saúde (FUNASA), a responsabilidade de, junto com a FUNAI, operacionalizar a atenção à saúde indígena por meio de projetos de saúde específicos c de caráter estratégico.

Nesse momento, a ação de formação dos AISs Tikúna passou a ser marcada pela questão do cólera, produzindo-se un quadro de novos agentes de saúde, com formação bastante limitada. Havia a emergência de atender a maior parte do território indígena com agentes que, com noções mínimas, pudessem atuar na defesa contra essa epidemia. Dentro de uma perspectiva da necessidade de criação das condições necessárias para barrar a entrada do cólera no Brasil através do território Tikúna, o Programa de Agentes Comunitários de Saúde (PACS) do MS, ofereceu contratação para alguns agentes de saúde, criando uma situação en que se passou de uma atuação eminentemente voluntária e de apoio de base comunitária, para a criação de uma nova categoria assalariada. $O$ fato da maioria dos agentes ter sido excluída do benefício, criou uma nova base de conflito entre as diferentes facções que caracterizam a sociedade Tikúna, já que os critérios de contratação foram formulados sem a participação da comunidade, ou mesmo da OMSPT.

Os cursos de formação e reciclagem para AISs no Alto Solimões já se encontravam, então, sob a responsabilidade exclusiva da FUNASA, com apoio estratégico (salas de aula, convocação e apoio político, mão-de-obra, etc.) do CGITT por intermédio da OMSPT. Os cursos que se seguiram (até 1994), ampliaram sobremaneira a base numérica sobre a qual se assentava o projeto inicial de formação de AISs, sem articular as possibilidades reais de um acompanhamento e avaliação continuada do trabalho dos agentes. Os cursus se tornaram fonte contínua de busca de afirmação de prestígio por parte dos capitães de aldeias, na medida em que passaram a significar uma possibilidade de acesso a mais una categoria de trabalho remunerado para aqueles aliados que se valiam de suas indicações. Mesmo as tentativas de implantação de cursos de reciclagem (1993/1994), tiveram de ser reavaliadas durante sua execução dada a demanda exacerbada pela formação de novos agentes, dentro de uma expectativa de contratação, já bastante prejudicada neste momento, quando o alarde do cólera diminuíra e, conseqüentemente, os investimentos emergenciais dirigidos à área. 
Como conseqüência do contínuo confronto entre FUNAI e FUNASA, em maio de 1994 um novo decreto presidencial voltou a alterar o quadro da saúde indígena, com a atribuição das responsabilidades do cuidado à saúde retornando para a FUNAI. A Comissão Intersetorial de Saúde Indígena (CISI), também criada por esse decreto, em sua Resolução 2/1994, definiu como de atribuição da FUNAI a assistência curativa aos índios, ficando com a FUNASA o encargo de prevenção de doenças e controle de endemias.

Em junho de 1995, a FUNAI, por meio de seu Departamento de Saúde, apresentou a proposta de contratação de uma equipe de médicos, enfermeiros e odontólogos para realização de trabalho na área Tikúna. A OMSPT se colocou disponível para definir a forma de atuação dessa equipe e exigiu, por intermédio de uma proposta de pauta para discussão em assembléia geral, a definição de um trabalho conjunto entre FUNAI, OMSPT e FUNASA. As negociações se desenvolveram no sentido de agregar à contratação de uma equipe médica mais sete AISs, a serem localizados em aldeias estratégicas dentro da área, atuando como elementos de referência e supervisão do trabalho dos demais agentes 3 .

As negociações em torno da contratação de AISs desencadearam uma luta de poder dentro da OMSPT, vista então, dentro de um quadro mais amplo de ausência de novos investimentos em projetos de desenvolvimento ou nas estruturas organizacionais indígenas já existentes, como um locus privilegiado de acesso a cargos remunerados e de grande prestígio junto às comunidades indígenas, que "garantiriam" um amplo trânsito junto a diversas instituições da sociedade nacional. A mudança de coordenação da organização indígena de saúde foi colocada em pauta ao final de um novo curso para AISs, em setembro de 1995, sem que houvesse uma convocação prévia nesse sentido, mas com ampla presença dos agentes aliados da faç̧ão proponente. Nessa mesma reunião, adotou-se um novo nome para a organização (Organização de Saúde do Povo Tikúna do Alto Solimões - OSPTAS), com um novo estatuto, e foi encaminhada proposta de que as sete vagas fossem ocupadas pelos sete membros da nova diretoria (na qual se incluía um assessor indígena sem formação na área da saúde).

\footnotetext{
3 Verani (1999), chama a atenção para o fato de que as várias fases do confronto entre FUNASA e FUNAI pela hegemonia no controle da saúde do índio recobritu-se de um caráter eminentemente corporativista, impondo retrocessos ao processo de construção de um modelo de atenção diferenciado para as populações indígenas.
} 
O impasse colocado pela Diretoria da OSPTAS foi resolvido por um acordo em que os contratados seriam escolhidos por meio de prova classificatória. Como não houve a possibilidade de se convocar AISs representantes de cada município para a seleção realizada sob pressão da OSPTAS, alguns indígenas classificados foram remanejados para áreas distantes de seu local de moradia, o que criou atritos e resistências nas comunidades que os receberam, assim como alto índice de faltas e abandono de trabalho. A experiência de contratação realizada pelo período de seis meses em 1996, não mais se repetiu.

Durante o ano de 1996, a OSPTAS encaminhou ainda pequenos projetos de manutenção da organização, elaborou projeto para a construção de uma escola de formação de AISs na comunidade de Filadélfia, que também deveria abrigar a diretoria da Organização. Esse último projeto não foi aprovado e a Organização passou a funcionar nas dependências da FUNAI em Tabatinga, contando com a infra-estrutura do órgão governamental, gerando atritos constantes.

No decorrer dos últimos anos, o aprofundamento do isolamento que a diretoria da OSPTAS tem imposto aos grupos representativos diversos (agentes de saúde de comunidades vinculadas ao CGTT, grupos de mulheres, agentes de desenvolvimento, etc.), dificultando sobremaneira a comunicação das reivindicações de suas comunidades e o exercício pleno de suas atividades, praticando um controle total sobre o acesso a cursos, eventos e canais de diálogo com as instituições promotoras de ações de saúde na área, deu origem à necessidade de criação de uma nova Organização de Agentes Indígenas de Saúde (Organização de Agentes de Saúde do Povo Tikúna - OASPT), apoiada e referendada pela Assembléia Geral dos Capitães do CGTT, realizada esn dezembro de 19984. Essa nova organização, além de pretender garantir canais de comunicação das reivindicações de suas comunidades, tem colocado como elemento diferenciador de sua proposta a percepção da necessidade de um trabalho integrado com as lideranças tradicionais das comunidades, o (re)conhecimento dos modos tradicionais de tratamento da população Tikúna, assim como a proteção a certas áreas do conhecimento indígena que são referidas a profissionais espe-

\footnotetext{
4 Apesar da proximidade das siglas das duas organizações, os agentes de saúde da OSPT decidiram manter um nome que reafirme sua identidade com a proposta inicial de organização de agentes sob a sigla OMSPT, onde iniciaram seus trabalhos mediante uma participação voluntária por melhores condições de saúde de suas comunidades.
} 
cíficos e não devem ser tornadas públicas. A OASPT tem tentado se apresentar como alternativa ao trabalho eminentemente corporativista que vem sendo praticado pela diretoria da OSPTAS, que nem sempre conta com o apoio do conjunto dos AISs, reconhecendo a necessidade de um trabalho integrado com outras organizações representativas existentes entre os Tikúna, com destaque para o CGTT, a Organização das Mulheres Indígenas Tikúna (AMIT), a Organização dos Estudantes Indígenas (AEITAS) e a incipiente Organização dos Agentes de Desenvolvimento, vinculando desse modo, saúde, educação, desenvolvimento e participação comunitária.

A falta de uma real discussão com os AISs e seus órgãos representativos sobre o modelo assistencial pretendido para a área do Alto Solimões, pode expressar a marginalidade do projeto governamental de atendimento à saúde do índio em relação aos serviços oficiais de saúde. $\mathrm{Na}$ área Tikúna, a assistência aos índios, apesar de ter estado marcada, em alguns períodos, pelo discurso da proposta de um "projeto diferenciado", estruturou-se pela exclusão e descontinuidade entre o saber científico e os saberes locais. Os órgãos oficiais encarregados da assistência à saúde dos índios, seja a FUNAI ou a FUNASA, estiveram sempre pouco dispostos a se dobrar às determinações do grupo; quando muito, avançando na discussão da participação dos índios no sistema apenas na sua condição de "usuário".

$\mathrm{Na}$ verdade, a formação dos AISs foi concretizada apenas no sentido de sua participação enquanto elementos de ligação entre os serviços e as comunidades onde vivem, como parte de programas e sistemas locais de saúde já anteriormente estruturados dentro de uma lógica em que a participação da comunidade e a incorporação de práticas de cura tradicionais não ultrapassaram o nível da retórica avalizadora da continuidade de determinados modelos de intervenção, marcados por uma visão clínica e que se localizam no espaço de atenção às pessoas.

O que se tem visto, principalmente para a área indígena Tikúna, onde o difícil relacionamento com um conjunto diversificado de agentes tradicionais (curadores, feiticeiros, parteiras, pajés, rezadores, etc.) impede uma instrumentalização imediatista dos chamados "saberes populares", é uma redução da contribuição dos conhecimentos tradicionais àqueles saberes e práticas que se assemelham aos da biomedicina (saberes botânicos, por exemplo), com o descarte do que é considerada a sua face "mágico-religiosa" e, portanto, irracional e pré-científica.

Do mesmo modo que a articulação da biomedicina com os saberes terapêuticos de cada população tem sido realizada baseando-se nos parâmetros de 
eficácia estabelecidos pela biomedicina (Buchillet, 1991), também a concepção da participação popular como ferramenta pensada como neutra do ponto de vista social e político tem desencadeado resultados inesperados para as equipes de saúde que vêm se recusando a encarar a tarefa de trabalhar não apenas com o lado confortável da participação, no sentido do seu caráter legitimador das políticas de Estado frente às populações, mas também com a possibilidade de sua utilização pelos índios, enquanto canal legítimo de disputa de poder político, ou mesmo o controle do destino de verbas públicas.

Apesar de num certo sentido a existência e atuação do AIS, nos moldes acima traçados, se configurar numa espécie de enclave dentro da comunidade indígena, atuando com base em um conjunto de conhecimentos e técnicas, instrumentos, remédios, etc., que vêm "de fora", tanto a vitalidade de sua organização social quanto de seu sistema médico tem se apresentado por meio de: (1) disputas faccionais atualizadas nos esquemas de alianças e poder dentro das organizações indígenas de saúde (para o desespero do pessoal médico que tenta enquadrá-los dentro de seus parâmetros organizacionais e hierárquicos) ou (2) do vigor e importância do sistema xamânico, dentro das diversas alternativas de tratamento que se colocam à "disposição" da comunidade Tikúna, mesmo que em relação ao "público externo" o mesmo possa ser tratado de maneira bastante ambígua, ora sendo negado (principalmente pelos adeptos das religiões da Cruz e Batista), ora fazendo parte de um "discurso tradicional”, manipulado por algumas lideranças que têm uma percepção bastante aguçada em relação ao valor que é dado às "questões tradicionais" pelas ONGs e certos segmentos das instituições governamentais, isso podendo se reverter em financiamentos e reforço interno de suas posições de poder.

\section{O DELINEAMENTO DE UM MODELO ASSISTENCIAL E SEUS REFLEXOS CONCRETOS NA ATENÇÃO À SAÚDE INDÍGENA NO ALTO SOLIMÕES}

A proposta de implantação de um sistema de assistência à saúde no Alto Solimões, pela recém-criada FUNASA, supunha a possibilidade de uma real eficiência da atuação de AISs, valendo-se de um esquema periódico de reciclagem e revisão dos conhecimentos adquiridos e, principalmente, supervisão permanente dos trabalhos executados pelos mesmos. Os AISs passaram a ser a única base de atividade regular de atendimento à saúde dentro das aldeias, assim como os pre- 
sumíveis elos de ligação entre as comunidades e as unidades de referência implantadas nas sedes municipais.

A par de um processo burocrático impeditivo do definitivo estabelecimento de profissionais supervisores na área (ausência de concursos públicos, recursos para contratações de profissionais apenas por tempo limitado, etc.), tanto a formação dos AISs quanto a implantação de um esquema de supervisão, acabaram por se perder em meio a uma ausência de real co-participação da comunidade Tikúna na formulação de um projeto de saúde diferenciado.

Ponto chave do sistema, a presença constante de supervisores nos pólos estratégicos de referência mostrou-se descontínua. A falta de profissionais de saúde em campo, controlando a ação do AISs e sendo a base do encaminhamento dos acometimentos de maior importância, teve como resultado a baixa efetividade da ação e o desencantamento e desamparo daqueles envolvidos no projeto, seja como agentes, seja como clientela.

Dentro da logística de supervisão, o trabalho dos AISs deveria ser registrado em uma ficha de Registro de Atividade Diária do Agente, por meio da qual se daria a aferição de sua produção mensal. Os atendimentos e respectivos procedimentos também seriam registrados, com a função de propiciar a reavaliação constante do aprendizado e da prática do agente. Na maioria das vezes, a percepção que o indígena conseguia ter dessa mecânica não ia além da vinculação realizada entre a entrega de sua "produção" e a liberação de seu salário, juntamente com a possibilidade de reposição de seu estoque de remédios, reivindicação básica de sua comunidade.

A continuidade do trabalho dos agentes nos períodos de ausência dos supervisores (nos quais os salários não eram pagos) viabilizava-se por intermédio da negociação de uma menor regularidade na realização das tarefas, que possibilitasse um investimento maior de trabalho nas roças, pesca, etc. Esse esquema gerou um nível considerável de abandono do trabalho nesses períodos e um alto grau de insatisfação da população, que passou a classificar o agente como "preguiçoso" e faltoso com os seus compromissos.

A enorme rotatividade de profissionais de saúde nos postos de supervisão também se refletiu na impossibilidade concreta de viabilizar cursos de qualificação para o trabalho com uma população indígena. Os prazos de contratação praticados pela FUNASA (em média de seis meses) eram curtos o suficiente para tornar inviável um maior investimento na formação interdisciplinar deste profissional. Os supervisores deveriam estar preparados para lidar constantemente não só com questões técnicas referentes a diagnósticos, prescrições de medicamen- 
tos, campanhas de vacinação, etc., mas com o conteúdo específico de determinadas práticas terapêuticas definidas com base em representações indígenas sobre a doença, o sofrimento, a melhora, a cura, a morte.

Profissionais de saúde, em sua grande maioria despreparados para perceber a necessidade de uma atuação específica junto aos AISs, viam naqueles índios que falavam o português como sua segunda língua e tinhanı um certo nível de instrução formal que lhes permitia ler e escrever (uma fonte de reafirmação do estereótipo do "índio integrado" não muito diferente do agente comunitário de saúde das comunidades ribeirinhas), sua principal clientela para a qual normalmente dirigem suas atividades.

De modo geral, esses profissionais não estão abertos a entender e aceitar os itinerários terapêuticos utilizados pelos indígenas (curadores, pajés, feiticeiros, rezadores), permitindo a incorporação das práticas da medicina tradicional apenas na medida em que estas se aproximem da utilização, pela população nacional, de chás e benzeduras para doenças consideradas de menor importância. A condicionante colocada por alguns curadores de que o paciente só deve sair da aldeia após o processo de "cura", que em geral dura três dias, e a obediência às suas prescrições, é vista como demonstração de uma mentalidade primitiva e atrasada, que só vem a atrapalhar os casos em que haja necessidade de remoção.

Nesse sentido, com relação ao atendimento nas unidades de referência, o quadro torna-se ainda mais complicado. Os atendimentos referenciados deveriam ser realizados nas sedes municipais ou em Manaus, na rede do SUS, onde não se constituiu uma política específica para populações indígenas. Tanto o pessoal administrativo quanto as equipes de saúde ocultam (mas revelam) uma visão etnocêntrica que, informa as suas relações com a população indígena sob o discurso da "igualdade". Sob a capa de um discurso "democrático" de acesso indiferenciado às unidades de atendimento médico, tanto para a população branca quanto para os indígenas, são eliminadas as interferências das especificidades culturais que indicam a necessidade de um atendimento realmente "integral" e "diferenciado".

Dentro desses limites, a formação dos AISs Tikúna tern se afastado, na sua prática, de uma concepção ampliada do processo saúde/doença e pautado seus esforços na direção de uma lógica tecno-assistencial, baseada na doença e nas intervenções por meio de processos de trabalho informados pela clínica. Os índios têm tido a sua formação baseada numa lógica assistencial que privilegia o indivíduo como objeto de atenção, exclui práticas alternativas e, principalmente, dá ênfase a uma medicina curativa que tem por conseqüência a necessidade cres- 
cente de incorporação de tecnologia, criando maiores descompassos com a sua realidade e as possibilidades reais das próprias instituições formadoras em suprir essas novas demandas, por elas mesmas exacerbadas (remédios, internações, etc.).

Por fim, e como conseqüência, há que se ressaltar os marcos específicos com base nos quais se configura a produção de dados de saúde no Alto Solimões, que servem de base para as análises oficiais da situação de saúde local e valendose dos quais são construídas as "propostas de intervenção". Todo o sistema de informação de saúde no Alto Solimões foi pensado tendo por base o trabalho dos AISs e deve ser avaliado baseando-se nas condições efetivas de realização do mesmo, traçadas anteriormente.

Os agentes foram orientados a encaminhar suas anotações de atendimentos, remoções e eventos vitais aos respectivos supervisores da FUNASA, localizados nas unidades de referência. A orientação elimina a possibilidade da criação, junto a cada comunidade/conjunto de agentes, de um processo educativo mais amplo de percepção do valor e utilidade da acumulação de dados no delineamento e negociação de um projeto de saúde diferenciado. As tarefas de anotação se tornaram, na maioria dos casos, um processo mecânico, cujo objetivo maior seria a comprovação de uma "produção" que lhes daria direito a receber um "salário". Mais que isso, um processo confuso de sucessivas mudanças das instituições governamentais encarregadas de coordenar a prestação de assistência à saúde da população indígena a partir de 1990, terminou por desembocar num processo de "desmonte" (arquivos esvaziados, anotações e fichas destruídas) sistemático de uma "história da saúde" dessa população.

$\mathrm{Na}$ ausência de um médico, única fonte de legitimidade de um diagnóstico de causa de morte, vem se registrando no Alto Solimões, para mortes ocorridas nas comunidades distantes dos centros de referência, basicamente apenas dois grandes grupos de causa: morte por causas externas (acidentes, homicídios e suicídio) e S.A.M. (sem assistência médica). A orientação dada pelos profissionais de saúde que desembocou nesse tipo de anotação, denuncia claramente não só a grave situação de ausência destes profissionais nas áreas indígenas, mas também a sua grande dificuldade em lidar com os saberes e entendimentos diferenciados das populações indígenas sobre seus processos de adoecimento e morte. Como conseqüência, são eliminadas as possíveis colaborações dos AISs na construção de um modelo de assistência realmente diferenciado.

Esta postura, comum às instituições governamentais de assistência à saúde, vincula-se a uma percepção universalista dos fenômenos, onde as categorias ocidentais de classificação de desordens têm uma validade pan-humana. De modo 
geral, os fenômenos expressos com base em entendimentos das populações indígenas, que não são facilmente assimilados a categorias ocidentais, são tratados como pertencentes ao nível "mágico", "irracional”, ou são simplesmente ignorados.

O efeito da proposta de se criar meios de avaliação de fenômenos, que passam normalmente despercebidos pelos métodos clássicos de medida de morbi-mortalidade (já que baseados apenas no diagnóstico médico i, ocasionaria um "alargamento" do campo da saúde com a "abolição do monopólio médico sobre a apreciação dos problemas de saúde”, permitindo que aflorem categorias próprias da população estudada e a incorporação de outras "fontes idôneas de julgamento" (Goldberg, 1990; Pacqué-Margolis et al., 1990).

() encaminhamento desse tipo de proposta não deve ter, de forma alguma, o sentido de referendar um quadro de desassistência à saúde (quase que institucionalizado), como o encontrado na área Tikúna, minimizando a participação de profissionais de saúde na busca por registros de doenças e agravos mais confiáveis, mas problematizar a percepção do que possa ser definido como "problema de saúde" para uma determinada população, levando em conta o contexto sociocultural, ideológico e mesmo profissional em que esses "problemas" ocorrem.

As referências e interpretações que os indígenas fazem de seus processos de adoecimento e morte são essenciais na superação de tipologias e interpretações etnocêntricas, realizadas pela sociedade nacional, e que não passam de superposições e atribuições de entendimentos realizados valendo-se de parâmetros ocidentais (entendimento da construção e fisiologia do corpo, doença, sofrimento e morte, etc.) para as ocorrências de doença e morte na sociedade Tikúna.

Uma qualificação sistemática das mortes, despersonalizadas e desqualificadas pela ausência de assistência médica, poderia apontar para uma vinculação entre os processos de adoecimento e os prováveis desdobramentos em termos de acusações de enfeitiçamentos, contra-feitiços, mortes violentas, suicídios, e para o que Taussig (1993) denominou de "relações sociais incrustadas na feitiçaria".

A listagem de óbitos ocorridos no Alto Solimões, disponibilizada pela FUNAI em Brasília, cobrindo o período de 1993-1995, confirma o quadro de desassistência na área. Do total de 132 casos anotados, $16 \%$ são de suicídios e, subtraídos os casos de mortes por causas externas, dos 101 eventos restantes, $62 \%$ ocorreram sem que houvesse assistência médica. Desses últimos, $43 \%$ correspondem a mortes de crianças na faixa de $0-5$ anos.

De modo mais imediato, e baseando-se em sua própria condição de precariedade, esses dados podem apresentar um quadro de mortalidade que levante a possibilidade de uma discussão mais conseqüente sobre a ocorrência de epide- 
mias de coqueluche, malária, diarréia e falta de assistência, que vêm sistematicamente assolando a população Tikúna'.

A partir de 1995, é flagrante o agravamento do estado da saúde da população Tikúna, quando a FUNASA passou a manter na área apenas os recursos humanos para a realização de uma cobertura vacinal vacilante (vejam as estatísticas das próprias instituições, FUNAI e FUNASA, em relação à ocorrência significativa de casos de coqueluche e tétano neonatal). A FUNAI, já desde 1994 com a responsabilidade das ações de caráter curativo, atua na área de maneira pífia, apenas realizando ações de remoção em situações de caráter mais emergencial. Até 1998, o atendimento era ainda realizado por AISs que, novamente de forma voluntária, tomaram a si a responsabilidade do atendimento possível, numa situação de ausência quase total de medicamentos e de supervisão de seu trabalho ${ }^{6}$.

\section{OBSERVAÇÕES SOBRE O PROCESSO DE CONSTRUÇÃO DE UM MODELO DE ATENÇÃO À SAÚDE DO ÍNDIO}

Durante a XXXIII Reunião da Organização Pan-Americana da Saúde, realizada em Washington, Estados Unidos, em setembro de 1988, ficou aprovada pelo voto de todos os ministros da saúde das Américas, inclusive o do Brasil, a reorganização dos Sistemas Nacionais de Saúde por intermédio dos Sistemas Locais de Saúde (SILOS). Em nosso país, tal sistema aproxima-se da idéia de "distritos sanitários”, implantados pela Lei no 8.080, de 19 de setembro de 1990.

Como consequiência dos atos formais, a estratégia de implantação de distritos sanitários implicou, em um primeiro momento (1988-1989), na construção e difusão da idéia do distrito enquanto "processo social de mudança das práticas sanitárias" (Mendes, 1993:94), e a necessidade de um debate teórico-metodológico em torno da formatação de sua conceituação com base nas experiências nacio-

\footnotetext{
5 O CGTT e a OASPT vêm sistematicamente denunciando pelos jornais locais a ocorrência de mortes por diarréia e cólera, decorrentes do total abandono a que está submetida a população Tikúna nos últimos três anos.

6 Nas eleições de 1998, por exemplo, voltaram a ocorrer, sem qualquer possibilidade de controle pela FUNASA ou FUNAI, as “colaborações" de candidatos na forma de medicamentos, sem que os índios tenham sido treinados no seu uso, ou que se possa ter algum nível de segurança quanto à sua procedência ou qualidade.
} 
nais. Esse debate articulou campos diferenciados, entrelaçando conceitos da nova geografia de Milton Santos (território-processo), do planejamento estratégico-situacional de Carlos Matus e um conceito holístico do processo de saúde/doença.

Refletindo o debate nacional em torno dessas novas formulações de políticas de saúde, no VI Simpósio sobre Política Nacional de Saúde, da Câmara dos Deputados (maio de 1989), veio a público a figura dos Distritos Sanitários Especiais Indígenas (DSEI). A partir de então, vários eventos vêm alterando o panorama institucional no campo da saúde indígena. Em 1991, o Decreto Presidencial ne 23 (4 de fevereiro), entregou a coordenação dos projetos de saúde para populações indígenas para a Fundação Serviços de Saúde Pública (FSESP), que logo em seguida teve seus recursos reunidos aos da ex-SUCAM e ex-DATAPREV e passou a se denominar Fundação Nacional de Saúde. A então recémcriada fundação albergou a Coordenação de Saúde do Índio (COSAI), no âmbito do seu Departamento de Operações. Em 1992, foi criada a CISI, subordinada ao Conselho Nacional de Saúde.

Em 1991, foi criado o Distrito Sanitário Yanomami e, em 1992, o Distrito Sanitário dos Povos Indígenas de São Paulo e Rio de Janeiro. Na avaliação do I Fórum Nacional de Saúde Indígena (abril de 1993), o modelo de atuação entre FUNASA e FUNAI não chegou sequer a formular um plano conjunto de trabalho e cooperação. No que diz respeito à implantação dos distritos sanitários indígenas, afirmou-se: "carro chefe da primeira gestão da COSAI, ainda não apresenta resultados objetivos do ponto de vista institucional"7. Apesar disso, o DSEI se constituiu como a base do modelo assistencial para atenção à saúde indígena, conforme definido no documento final da II Conferência Nacional de Saúde para os Povos Indígenas 8 .

Desse modo, dando continuidade ao debate, há que se levar em conta uma perspectiva onde se concretize a possibilidade real de trabalho com novos recortes conceituais, mais adaptados ao encaminhamento da construção dos DSEIs. Mendes (1993), indica que o Distrito Sanitário deve ser reconhecido não por um caráter burocrático de redivisão topográfica-administrativa, mas sim por se constituir de três dimensões. A primeira delas, política, no sentido de que é um espaço em construção onde se expressam atores sociais, portadores de diferentes projetos 9 . A dimensão ideológica deriva da opção por uma concepção ampla do processo saúde/doença e sua conseqüente estruturação na lógica da atenção às necessidades específicas de saúde da população. Como conseqüência, as definições anteriores exigem a redefinição de uma dimensão tecnológica (conhecimentos, métodos e técnicas), coerente com estes referenciais políticos e ideológicos. 
Nesse sentido, alguns autores propõem que se fale de "processo de distritalização" onde se teria, como produto de uma dinâmica social, um "territórioprocesso" com "problemas" de saúde, cuja identificação, descrição e explicação não independem daquele que a faz e de que posição os percebe. O enfrentamento dos problemas de saúde dá origem a um processo de transformação das práticas sanitárias, ou seja, a proposta de distritalização implica o redirecionar e modificar a forma de organização e o conteúdo das ações e serviços de saúde, de modo a se responder às demandas da população, atender às necessidades de saúde e, fundamentalmente, contribuir para a solução dos problemas de saúde da população que vive e trabalha no espaço territorial e social do distrito sanitário (Mendes et al., 1993).

Para os DSEIs, a proposta é que se avance na definição de problemas e na participação da construção de um novo modelo assistencial, no sentido de se pensar a "integralidade" também como espaço de negociação, para onde possam realmente afluir novas racionalidades, códigos e lógicas de conhecimento.

Trabalhar com lógicas e racionalidades diversas da medicina ocidental implica investir em pesquisa antropológica que sirva de base para a formatação de um modelo assistencial diferenciado, adequado para a população Tikúna do Alto Solimões, com o conhecimento e a valorização efetiva dos modelos da medicina tradicional indígena. A pesquisa antropológica deverá buscar o conhecimento e a compreensão das representações e práticas da medicina tradicional Tikúna, não com o sentido da tentativa de uma incorporação mecânica desses saberes, o que pode desencadear, para algumas categorias de profissionais nativos, na inviabilização do seu próprio trabalho ou ainda significar grandes interferências na prestação de um serviço organizado em bases de relações de reciprocidade, compadrio, ou até mesmo alianças políticas diversas 10 .

\footnotetext{
7 Seminário Nacional de Saúde Indígena - I Fórum Nacional de Saúde Indígena. Ministério da Saúde, Brasília, 22 a 26 de abril de 1993.

8 II Conferência Nacional de Saúde para os Povos Indígenas. Luziânia, Goiás, 25 a 27 de outubro de 1993.

9 Nesta dimensão existe a necessidade de se superar uma construção mitificada de uma unidade na sociedade Tikúna, reconhecendo com base no trabalho com escalas menores de observação, diferentes modos de sociabilidade tradicional, ficando explicitadas mesmo, em determinados momentos, disputas de "tradições".

10 Lobo-Guerrero (1991) alerta para a tendência de alguns programas em medicalizar e institucionalizar as medicinas indígenas.
} 
A explicitação de categorias explicativas de práticas cotidianas deve fazer surgir o conjunto de problemas de saúde e ações preventivas e curativas utilizadas no presente: o que de "medicina indígena" persiste (uso de ervas medicinais, benzeduras, rituais religiosos de cura, ação de pajés e feiticeiros, trabalho das parteiras), quais as formas de utilização da medicina ocidental e quais as outras soluções que são buscadas pela população indígena para resolver os seus problemas. Baseando-se nesses dados, será possível levantar os principais itinerários terapêuticos presentes nas escolhas cotidianas e como estes se elaboram com base em vivências particulares sobre a doença, a melhora ou a cura. Tais itinerários deverão ocorrer de forma dinâmica, como conseqüência das múltiplas interpretações e "julgamentos" acerca da eficácia dos diversos tratamentos colocados à disposição. Fssa dinâmica, por outro lado, deverá estar informando (re)interpretações sobre doenças e doentes, curas e curadores, que serão expressas simbolicamente no decorrer do processo da doença e da busca de resoluções.

Nesse sentido, é bom reafirmar que, apesar das propostas de implantação de modelos de assistência diferenciados virem envoltas em discursos democráticos de participação das comunidades, sua prática autoritária pode ser percebida por meio de projetos que delimitam a participação indígena à condição de usuário do sistema, e supõe que a proposta de uma "gestão participativa" pode realmente ser implementada onde não se busca na população indígena uma parceria efetiva no delineamento de um modelo realmente diferenciado de atenção à saúde.

No caso Tikúna, é necessário que se faça uma avaliação criteriosa dos impactos das propostas de participação comunitária que vêm sendo implementadas, tanto no sentido da melhoria das condições de saúde da população, como de seus reflexos na sua cultura e organização social e política. Na implantação do DSEI Alto Solimões, é preciso que se possa suplantar as polarizações faccionais, sem a pretensão etnocêntrica de eliminar a diversidade ou os diferentes projctos políticos formulados no interior da sociedade Tikúna.

\section{Agradecimentos}

Estc trabalho foi claborado no âmbito do projeto Universo Ticuna: Território, Saúde e Meio Ambiente (PPD/PPG'T/FINEP/MC'T, 1998). 


\section{Referências}

BRONFMAN, M. \& GLEIZER, M., 1994. Participación conunitaria: Necesidad, cxcusa o estrategia? O de qué hablamos cuando hablamos de participación comunitaria. Cadernos de Saúde Pública, 10:111-122.

BUCHILLET, D., 1991. A questão da integração dos sistemas médicos: Problemas e perspectivas. In: Medicinas Tradicionais e Medicina Ocidental na Amazônia (D. Buchillet, org.), pp. 243-246, Belém: Museu Paraense Emílio Goeldi/Editora Cejup.

CONFALONIERI, U. E. \& VERANI, C. L., 1993. Agentes indígenas de saúde. In: Saúde de Populações Indigenas. Uma Introdução para Profissionais de Saúde (U. E. Confalonieri, org.), pp. 45-51, Rio de Janeiro: Escola Nacional de Saúde Pública, Fundação Oswaldo Cruz.

GOLDBERG, M., 1990. Este obscuro objeto da epidemiologia. In: Epidemiologia. Teoria $e$ Objeto (D. C. Costa, org.), pp. 87-136, Saúde em Debate 32, São Paulo: Editora Hucitec/Rio de Janeiro: ABRASCO.

LOBO-GUERRERO, M., 1991. Incorporación del shaman indígena en los programas de salud: Reflexiones sobre algunas experiencias en Colombia. In: Medicinas Tradicionais e Medicina Ocidental na Amazônia (D. Buchillet, org.), pp. 267-279, Belém: Museu Paraense Emílio Goeldi/Editora Cejup.

MACEDO, G. M., 1996. Negociando a Identidade com os Brancos: Religião e Política em um Núcleo Urbano Ticuna. Dissertação de Mestrado, Rio de Janeiro: Programa de Pós-Graduação em Antropologia Social, Museu Nacional do Rio de Janeiro.

MENDES, E. V., 1993. O processo social de distritalização da saúde. In: Distrito Sanitário: O Processo Social de Mudança das Práticas Sanitárias do Sistema Único de Saúde (E. V. Mendes, org.), pp. 93-158, São Paulo: Editora Hucitec/Rio de Janeiro: ABRASCO.

MENDES, E. V.; TEIXEIRA, C. F.; ARAUJO, E. C. \& CARDOSO, M. R. L., 1993. Distritos sanitários: Conceitos-chave. In: Distrito Sanitário: O Processo Social de Mudança das Práticas Sanitárias do Sistema Único de Saúde (E. V. Mendes, org.), pp. 159185, São Paulo: Editora Hucitec/Rio de Janeiro: ABRASCO.

OLIVEIRA FILHO, J. P., 1977. As Faç̧ões e a Ordem Política em uma Reserva Tükuna. Dissertação de Mestrado, Brasilia: Universidade de Brasília.

OLIVEIRA FILHO, J. P., 1988. "O Nosso Govermo": Os Ticuna e o Regime Tutelar. São Paulo: Marco Zero/Brasília: Ministério da Ciência e 'Tecnologia/Conselho Nacional de Desenvolvimento Científico e Tecnológico.

PACQUÉ-MARGOLIS, S.; PACQUÉ, M.; DUKULY, Z.; BOATENG, J. \& TAYLOR, H. R., 1990. Application of the verbal autopsy during a clinical trial. Social Science and Medicine, 31:585-591.

TAUSSIG, M., 1993. Xamanismo, Colonialismo e o Homem Selvagem. Um Estudo sobre o Terror e a Cura. São Paulo: Editora Paz e Terra.

VERANI, C. B. L., 1999. A política de saúde do índio e a organização dos serviços no Brasil. Boletim do Museu Paraense Emílio Goeldi, 15:171-192. 



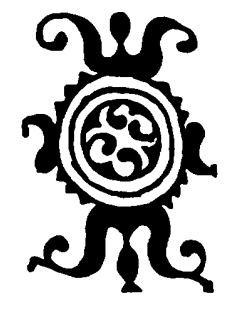

FINANCIAMENTO E ATENÇÃO

À SAÚDE NO DISTRITO SANITÁRIO

ESPECIAL INDÍGENA INTERIOR SUL

\author{
Eliana E. Diehl, Maria de Lourdes Drachler, \\ Ivone Menegolla, Inajara Rodrigues
}

Nas últimas décadas, movimentos indígenas de afirmação étnica cresceram na América Latina, incentivados por diversos setores da sociedade, como intelectuais, religiosos e organizações não-governamentais (ONGs). Para Langdon (2000), o surgimento da identificação e resistência étnica na América Latina tem alcançado uma dimensão política importante pois, ao confrontar os governos nacionais, obriga seus governantes a reformularem políticas públicas. $\mathrm{Na}$ área da saúde, uma das principais reivindicações foi o desenvolvimento de modelos diferenciados de atenção à saúde indígena, construídos com participação dessas populações, considerando a organização social e política, crenças, costumes e tradições de cada povo.

Em 1986 e 1993, a I Conferência Nacional de Proteção à Saúde do Índio e a II Conferência Nacional de Saúde para os Povos Indígenas, respectivamente, por indicação da VIII e IX Conferências Nacionais de Saúde, propuseram a estruturação de um modelo de atenção diferenciada no Brasil, baseado na estratégia de Distritos Sanitários Especiais Indígenas (DSEIs), como forma de garantir a esses povos o direito ao acesso universal e integral à saúde, respeitando suas especificidades. Apenas em 1999 o Governo Federal regulamentou o Subsistema de Atenção à Saúde Indígena (Brasil, 1999a), como parte integrante do Sistema Único de Saúde (SUS), definiu as diretrizes básicas para a implantação dos DSEIs e designou a Fundação Nacional de Saúde (FUNASA) como gestora das questões relacionadas à saúde indígena. No final de 1999, foram implantados 34 DSEIs, abrangendo a maioria das terras indígẹnas do território nacional, com cerca de 351 mil índios (FUNASA, 2000).

A provisão de atenção diferenciada pelo Subsistema de Saúde Indígena requer aporte financeiro suplementar aos já definidos no SUS, como o Piso de Atenção Básica (PAB) e as Autorizações de Internação Hospitalar (AIHs), que consideram a população total dos municípios e, portanto, incluem a população indígena. Assim, o financiamento específico do Subsistema não é a única fonte de recursos financeiros, mas suplemento para garantir a diferenciação da atenção aos indígenas. 
As três principais formas do financiamento suplementar são: (1) convênios celebrados por estados, municípios e/ou ONGs com a FUNASA para o financiamento da atenção básica; (2) transferências fundo a fundo da Secretaria de Políticas de Saúde do Ministério da Saúde (SPS/MS) aos fundos municipais e estaduais de saúde, autorizadas pela FUNASA, recursos conhecidos como Fator de Incentivo de Atenção Básica aos Povos Indígenas e destinados ao pagamento de pessoal das Equipes Multiprofissionais de Saúde Indígena (EMSI), conforme Portaria 1163/GM/MS/1999 (Brasil, 1999b) e (3) transferências da SPS/MS aos hospitais de referência, denominadas Incentivo para Assistência Ambulatorial, Hospitalar e de Apoio Diagnóstico à População Indígena (Brasil, 1999b), também conhecido como Apoio de Média e Alta Complexidade (MAC) à População Indígena.

Este artigo analisa os repasses financeiros ao DSEI Interior Sul e apresenta alguns indicadores da atenção à saúde em parte desse DSEI, referente ao Rio Grande do Sul. Salientamos que o objetivo não é detalhar as contas e os gastos de cada município e/ou ONG desde a implantação desse DSEI, visto que ainda não há uma efetiva e regular prestação de contas. Tambénı não são avaliados os recursos advindos de outras vias, como do VIGISUS e da FUNASA, que também têm sido utilizados para a atenção à saúde indígena.

\section{METODOLOGIA}

Os dados financeiros do DSEI Interior Sul foram obtidos nas páginas eletrônicas do DATASUS e da Secretaria Federal de Controle Interno (SIAFI) e nas Portarias Conjuntas (SPS/MS e Secretaria Executiva do MS) 125/2001 (Brasil, 2001) e 167/2002 (Brasil, 2002), que tratam da habilitação de municípios para o recebimento dos incentivos da SPS/MS.

A atenção à saúde no DSEI lnterior Sul/Rio Grande do Sul (DSEI Interior Sul/RS) foi indicada pela: (1) cobertura de profissionais de saúde; (2) cobertura de consultas médicas e de internações hospitalares e (3) taxas de mortalidade geral, infantil e de menores de cinco anos em 2001. A estimativa de profissionais de saúde baseou-se no número de profissionais das EMSIs descrito na Portaria Conjunta 167/2002 (Brasil, 2002). Para a cobertura de serviços hospitalares, foran utilizadas informações do Banco de Autorizações de Internações Hospitalares (SIH-RS) referentes aos hospitais que recebem incentivo específico para atendimento de indígenas, obtido na Secretaria de Estado da Saúde (SES/RS). 
Como as AIHs não contemplam a cor ou etnia dos indivíduos, as internações de índios foram identificadas com base no sobrenome e endereço dos indivíduos. A identificação foi feita pela Equipe de Coordenação de Saúde Indígena da SES/RS, auxiliados por um indigenista da Secretaria Estadual de Educação do Rio Grande do Sul e, quando necessário, por lideranças indígenas da área de residência do indivíduo hospitalizado. Em casos de dúvida, o indivíduo era considerado não-índio. Assim, embora internações de pessoas de outras raças/etnias possam ter sido identificadas como internações de índios, é mais provável que índios tenham deixado de ser identificados por usarem sobrenomes incomuns, morarem fora de terras indígenas, ou por erros no preenchimento da $\mathrm{AIH}$, levando à subestimação das taxas de internação hospitalar. A idade no dia da internação foi calculada com base nas datas de nascimento e de internação hospitalar. O número de nascimentos em 2001 de crianças índias, cujas mães residiam no DSEI Interior Sul/RS, foi obtido do Sistema de Informações de Nascidos Vivos (SINASCRS); os dados sobre os óbitos foram buscados no Sistema de Informação de Mortalidade (SIM-RS). Outra fonte de dados sobre internações hospitalares, mortes e nascimentos de índios foi o relatório apresentado pela FUNASA/RS em reunião do Conselho Distrital do DSEI Interior Sul, realizada em Florianópolis em junho de 2002.

\section{O DSEI INTERIOR SUL E OS RECURSOS FINANCEIROS}

O DSEI Interior Sul abrange os Estados do Rio Grande do Sul, Santa Catarina, Paraná e São Paulo, em suas porções mais a oeste, contemplando a atenção à saúde Kaingáng, Guaraní, Xokléng, Krenák e Teréna. Estima-se que o DSEI Interior Sul inclua cerca de 30.860 índios, sendo a terceira maior população entre todos os 34 DSEIs. O maior grupo é o Kaingáng, com $61 \%$ da população do DSEI (FUNASA, 2000). O DSEI é coordenado por uma funcionária da Coordenação Regional da FUNASA/SC (CORE/SC) e a sede, prevista para Chapecó, ainda permanece nas instalações da CORE/SC em Florianópolis. Os pólos-base estão localizados em Bauru (São Paulo), Londrina (Paraná), Guarapuava (Paraná), Chapecó (Santa Catarina), José Boiteux (Santa Catarina) e Passo Fundo (Rio Grande do Sul).

Enı setembro de 1999, foram iniciadas as negociações dos municípios e da ONG Projeto Rondon (pertencente à Associação Estadual dos Rondonistas de Santa Catarina, fundada em 1999) com a FUNASA, visando a atenção bási- 
ca. É importante salientar que a ONG Projeto Rondon também exerce os mesmos tipos de funções no DSEI Litoral Sul, que abrange os Estados do Rio Grande do Sul, Santa Catarina, Paraná, São Paulo e Rio de Janeiro, com uma população estimada em 4.776 índios Guaraní (Associação Estadual dos Rondonistas de Santa Catarina, 2002).

Os hospitais que tradicionalmente atendiam aos índios também participaram de negociações com a FUNASA, visando o recebimento do Apoio MAC à População Indígena, sendo esse adicional ao valor já pago pelo SUS por cada internação.

As negociações resultaram em diferentes modos de financiamento da atenção básica no DSEI Interior Sul. Em alguns locais foi implantada uma forma mista, em que as prefeituras passaram a receber os recursos da SPS/MS para a contratação das EMSIs e a ONG Projeto Rondon, via convênio com a FUNASA, ficou responsável pela aquisição de insumos (como medicamentos, combustível e próteses) e pela contratação de outros serviços (como, por exemplo, de consultas e exames especializados e de saneamento). Em outros locais, a ONG assumiu todo o financiamento. Houve ainda casos em que os nunicípios passaram a receber os repasses da SPS/MS para a contratação das EMSIs e também assinaram convênios com a FUNASA para a aquisição de insumos e serviços, ou seja, também se responsabilizaram pelo financiamento da atenção básica.

Em 29 de dezembro de 1999, foi firmado o primeiro convênio entre a FUNASA e a Associação Estadual dos Rondonistas de Santa Catarina 1, cujo objeto era o programa de promoção, prevenção e assistência primária à saúde de populações indígenas, com recursos da FUNASA, no valor de $\mathrm{R} \$ 4.906 .577,44$ (Tabela 1). Além de convênios para a atenção básica, essa ONG tem firmado outros para a viabilização de obras de saneamento e de construção de unidades de saúde (Tabela 1). Os valores de todos esses convênios totalizam R \$ 19.847.751,71, já tendo sido pagos $\mathrm{R} \$ 16.990 .648,99$. Esses convênios possibilitaram à ONG Projeto Rondon, inicialmente, o financiamento total da atenção básica no DSEI Interior Sul para todas as terras indígenas de São Paulo, Paraná e de parte das de Santa Catarina.

Somente os municípios de Ipuaçu e Entre Rios, ambos em Santa Catarina, se encarregaram da responsabilidade total pelo financiamento da atenção

I Publicado no Diário Oficial da União em 10 de janeiro de 2000. 
Repasses (em R\$) à ONG Projeto Rondon conveniada com a FUNASA, no período 1999-2002.

\begin{tabular}{|c|c|c|c|}
\hline $\begin{array}{l}\text { Número } \\
\text { do convênio }\end{array}$ & Objeto do convênio & Valor do convênio $(R \$)$ & Valor liberado (R\$) \\
\hline CV $1718 / 99$ & $\begin{array}{l}\text { Promoção, prevenção e assistência } \\
\text { primária à saúde do índio }\end{array}$ & $4.906 .577,44$ & $4.883 .708,88$ \\
\hline CV $22 / 01$ & $\begin{array}{l}\text { Promover melhoria das condições } \\
\text { de saúde das populações indigenas }\end{array}$ & $6.181 .015,18$ & $6.181 .015,18$ \\
\hline CV $247 / 01$ & $\begin{array}{l}\text { Projeto Alvorada (água) - } 11 \\
\text { municípios do Rio Grande do Sul } \\
\text { (19 localidades indígenas) }\end{array}$ & $450.000,00$ & $450.000,00$ \\
\hline CV 858/01 & $\begin{array}{l}\text { Promoção, prevenção e assistência } \\
\text { primária à saúde do índio }\end{array}$ & $35.496,62$ & $35.496,62$ \\
\hline CV 1023/01 & $\begin{array}{l}\text { Promoção, prevenção e assistência } \\
\text { primária à saúde do índio - Santa Catarina }\end{array}$ & $940.428,31$ & $940.428,31$ \\
\hline CV 66/02 & $\begin{array}{l}\text { Ações básicas de prevenção de doenças, } \\
\text { promoção e recuperação da saúde }\end{array}$ & $7.334 .234,16$ & $4.500 .000,00$ \\
\hline Total & & $19.847 .751,71$ & $16.990 .648,99$ \\
\hline
\end{tabular}

* A descrição do convênio (CV) aqui apresentada foi resumida com base nas informações contidas na fonte de pesquisa.

Fonte: (http://www.sfc.fazenda.gov.br), acesso em 3 de setembro de 2002 (dados de 31 de agosto de 2002 da Secretaria Federal de Controle Interno - SIAFI - do Ministério da Fazenda).

básica desde 1999, recebendo recursos da SPS/MS (Figuras l e 2) para a contratação das EMSIs e de convênios com a FUNASA (Tabela 2) para a aquisição de insumos e serviços. José Boiteux (Santa Catarina) também assinou convênio em 1999, o qual vigorou por pouco mais de um ano (Tabela 2); o Município de Chapecó (Santa Catarina) assinou convênio em 2001 (Tabela 2). Até o momento, o total de recursos repassados a estes municípios por meio de convênio com a FUNASA foi de R $\$ 1.457 .026,00$.

No Rio Grande do Sul, inicialmente, não houve qualquer convênio e somente alguns municípios que contam com população indígena passaram a receber o Fator de Incentivo de Atenção Básica aos Povos Indígenas (Figura 1), visando a contratação das EMSIs. A aquisição de insumos e serviços ficava a cargo da Coordenação Regional da FUNASA/RS, passando posteriormente à ONG Projeto Rondon.

Outros municípios do Rio Grande do Sul passaram a contar com as transferências fundo a fundo da SPS/MS a partir de 2000 (Figura 2) ou 2001 (Figura 3). Em 2001, vários municípios do Paraná, além de Chapecó e José Boi- 
Figura 1

Percentual dos recursos financeiros repassados de 1999 a junho de 2002, pela Secretari. de Políticas de Saúcle/Ministério da Saúde a municípios do Rio Grande do Sul e de Santa Catarina para a atenção básica à saúde indígena, área de abrangência Distrito Sanitário Especial Indígena Interior Sul.

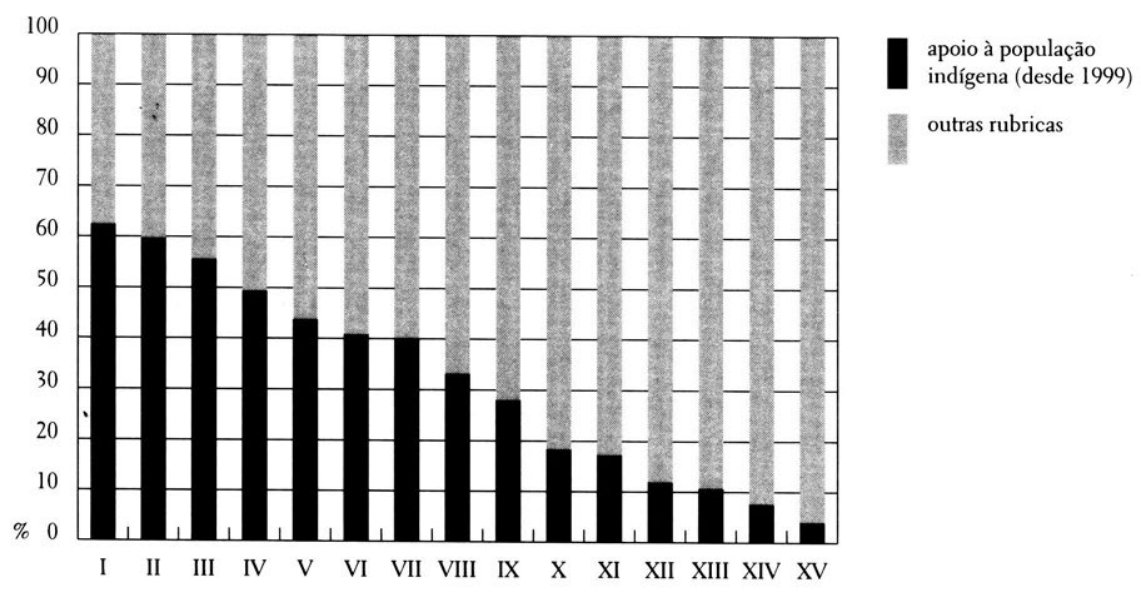

Municípios: I - Redentora (RS); II - Benjamin Constant (RS); III - Charrua (RS); IV - Ipuaçu (SC); V - Tenente Portela (RS); VI - Planalto (RS); VII - Nonoai (RS); VIII - Cacique Doble (RS); IX - Irai (RS); X - Rodeio Bonito (RS); XI - Salto do Jacuí (RS). XIl - Água Santa (RS); XIII - Ronda Alta (RS); XIV - Ibiraiaras (RS); XV - Passo Fundo (RS).

teux, passaram a receber os repasses da SPS/MS (Figura 3), assuınindo as contratações das equipes.

Os valores das transferências da SPS/MS aos vários municípios do Rio Grande do Sul, Paraná e Santa Catarina desde 1999 até junho de 2002 totalizaranı $R \$ 9.635 .030,00$, senclo que a somatória dos PABs (fixo e variável) desses mesmos municípios, para o mesmo período, foi igual a $\mathrm{R} \$ 55.724 .564,65$. Considerando somente os 23 municípios do Rio Grande do Sul que estão na abrangência do DSEI Interior Sul e que contan com uma população indígena estimada em 13.214 índios (Associação Fistadual dos Rondonistas de Santa Catarina, 2002), o Fator de Incentivo à Atenção Básica aos Povos Indígenas representa 22,8\% de todos os seus PABs somados. Aos quatro municípios de Santa Catarina, que têm em suas áreas territoriais em torno de 7.142 índios, foram repassados $\mathrm{R} \$$ 1.596.420,00, significando $23,8 \%$ da soma dos PABs no mesmo período. Os re- 
Percentual dos recursos financeiros repassados de 2000 a junho de 2002, pela Secretaria de Políticas de Saúde/Ministério da Saúde a municípios do Rio Grande do Sul e de Santa Catarina para a atenção básica à saúde indigena, área de abrangência Distrito Sanitário Especial Indígena Interior Sul.

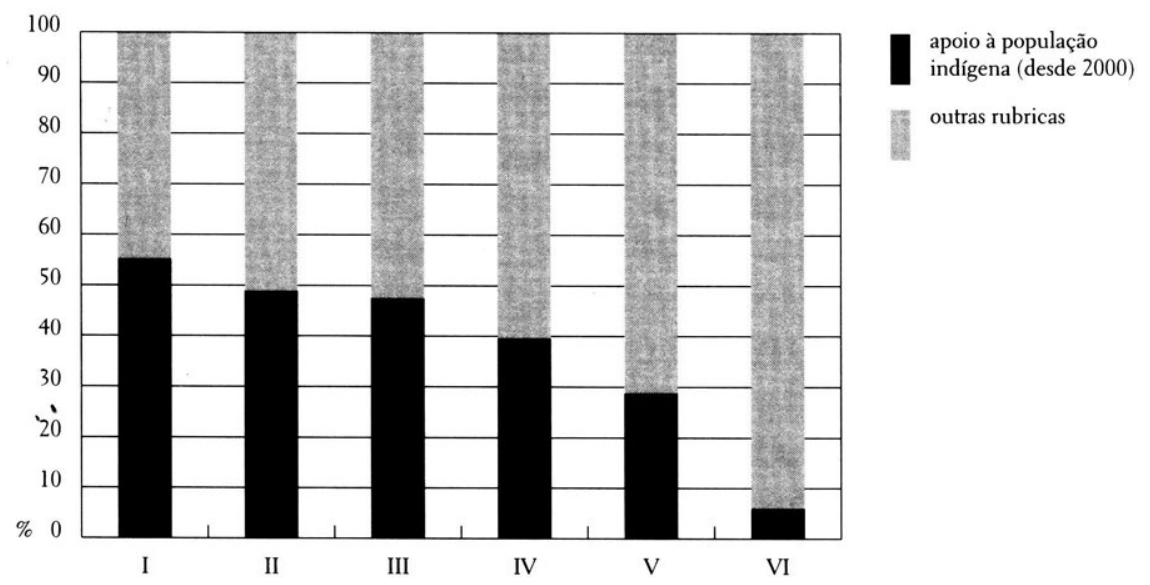

Municípios: I - Entre Rios (SC); 11 - São Valério do Sul (RS); IIl - Muliterno (RS); IV - Engenho Velho (RS); V - Constantina (RS); VI - Três Palmeiras (RS).

cursos da SPS/MS que foram destinados a 17 municípios do Paraná que têm aproximadamente 10.991 índios, representam $12,0 \%$ da soma dos respectivos PABs no período analisado.

Avaliando cada um dos municípios, é possível observar que o Fator de Incentivo à Atenção Básica para os Povos Indígenas varia muito de um para outro (Figuras 1, 2 e 3). A Portaria 1.163/GM/1999 (Brasil, 1999b) e as várias portarias conjuntas não especificam quais são os critérios que definem os valores por município. Se tomarmos como critério a população indígena de cada município, vamos notar que para Redentora (Rio Grande do Sul), por exemplo, que tem uma população indígena em torno de $39 \%$ da sua população total (FUNASA, 2000), o Fator de Incentivo representou 62,4\% do seu PAB (fixo e variável) no período analisado (Figura 1); Ipuaçu (Santa Catarina), com aproximadamente $41 \%$ de população indígena (FUNASA, 2000), recebeu $\mathrm{R} \$ 654.880,00$ 
Tabela 2

Repasses (em R\$) aos municípios conveniados com a FUNASA, no período 1999-2002, área de abrangência DSEI Interior Sul.

\begin{tabular}{|c|c|c|c|c|}
\hline Municípios & $\begin{array}{l}\text { Número } \\
\text { do convênio }\end{array}$ & Objeto do convênio & $\begin{array}{l}\text { Valor do } \\
\text { convênio }(\mathbf{R} \$)\end{array}$ & $\begin{array}{l}\text { Valor } \\
\text { liberado (R\$) }\end{array}$ \\
\hline \multirow[t]{4}{*}{ Ipuaçu } & CV $1.677 / 99$ & $\begin{array}{l}\text { Implantar o programa de promoção } \\
\text { e assistência integral da saúde } \\
\text { na reserva indígena T.I. Xapecó }\end{array}$ & $259.000,00$ & $259.000,00$ \\
\hline & CV 03/01 & $\begin{array}{l}\text { Pronover a melhoria das condições } \\
\text { de saúde da população indígena }\end{array}$ & $369.735,05$ & $369.735,00$ \\
\hline & CV $76 / 02$ & $\begin{array}{l}\text { Ações básicas de prevenção de doenças, } \\
\text { promoção e recuperação da saúde indigena }\end{array}$ & $312.607,50$ & $230.000,00$ \\
\hline & Subtotal & & $941.342,55$ & $858.735,00$ \\
\hline \multirow[t]{4}{*}{ Entre Rios } & CV $1.570 / 99$ & $\begin{array}{l}\text { Implantar o programa de promoção } \\
\text { e assistência integral da saúde } \\
\text { na reserva indígena T.1. Xapecó }\end{array}$ & $78.000,00$ & $78.000,00$ \\
\hline & CV 07/01 & $\begin{array}{l}\text { Promover a melhoria das condições } \\
\text { de saúde da população indígena }\end{array}$ & $102.261,92$ & $102.261,00$ \\
\hline & CV $77 / 02$ & $\begin{array}{l}\text { Ações básicas de prevenção de doenças, } \\
\text { promoção e recuperação da saúde indígena }\end{array}$ & $101.340,00$ & $85.000,00$ \\
\hline & Subtotal & & $281.601,92$ & $265.261,00$ \\
\hline \multirow[t]{2}{*}{ José Boiteux } & CV 1.948/99 & $\begin{array}{l}\text { Implantar o programa de promoção } \\
\text { e assistência integrada à saúde } \\
\text { nas comunidades Xokléng }\end{array}$ & $277.308,00$ & $277.308,00$ \\
\hline & Subtotal & & $277.308,00$ & $277.308,00$ \\
\hline \multirow[t]{3}{*}{ Chapecó } & CV 04/01 & $\begin{array}{l}\text { Promover a melhoria das condições } \\
\text { de saúde das populações indígenas }\end{array}$ & $55.722,00$ & $55.722,00$ \\
\hline & Subtotal & & $55.722,00$ & $55.722,00$ \\
\hline & Total & & $1.555 .974,47$ & $1.457 .026,00$ \\
\hline
\end{tabular}

\footnotetext{
"A descrição do convênio (CV) aqui apresentada foi resuınida com base nas informações contidas na fonte de pesquisa.

Fonte: (http://www.sfc.fazenda.gov.br), acesso em 28 de outubro de 2002 (dados de 26 de outubro de 2002 da Secretaria Federal de Controle Interno - SIAFI - do Ministério da Fazenda).
} 
Percentual dos recursos financeiros repassados de 2001 a junho de 2002, pela Secretaria de Políticas de Saúde/Ministério da Saúde a municípios do Rio Grande do Sul, de Santa Catarina e do Paraná para a atenção básica à saúde indígena, área de abrangência Distrito Sanitário Especial Indígena Interior Sul.

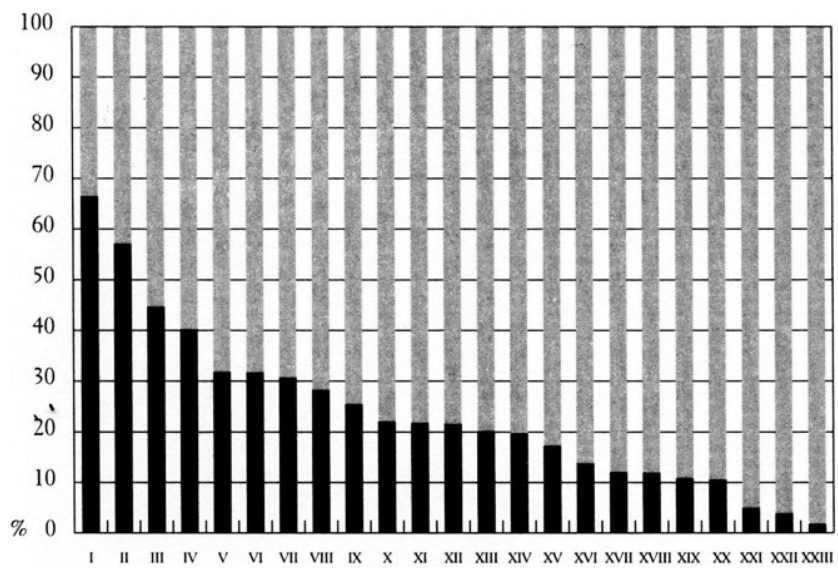

Municípios: I - José Boiteux (SC); II - Nova Laranjeiras (PR); III - São Jerônimo da Serra (PR); IV - Diamante d'Oeste (PR); V - Mangueirinha (PR); VI - Espigão Alto do Iguaçu (PR);

VII - Manoel Ribas (PR); VIII - São Miguel do Iguaçu (PR); IX - Turvo (PR); X - Santa Amélia (PR);

XI - Chopinzinlıo (PR); XII - Cândido de Abreu (PR); XIII - Ortigueira (PR); XIV - São Miguel da Missões (RS); XV - Inácio Martins (PR); XVI - Tomazina (PR); XVII - Palmas (PR); XVIII - Coronel Vivida (PR); XIX - Vicente Dutra (RS); XX - Erebango (RS); XXI - Chapecó (SC); XXII - Riozinho (RS); XXIII - Londrina (PR).

de incentivo, o que significou 49,4\% do seu PAB total no período (Figura 1); para Tenente Portela (Rio Grande do Sul), com população indígena estimada em 14,5\% (FUNASA, 2000), o Fator de Incentivo representou 43,8\% do teto financeiro do município desde 1999 (Figura 1); Entre Rios (Santa Catarina), com mais ou menos 20\% de índios em seu território (FUNASA, 2000), recebeu repasses desde o início de 2000 que significaram 55,2\% do seu PAB total (Figura 2); São Jerônimo da Serra (Paraná), com população indígena aproximada de $7,7 \%$ (FUNASA, 2000), recebeu recursos que corresponderam a 44,7\% do seu PAB total (Figura 3). Essas discrepâncias sugerem uma provável não proporcionalidade entre a população indígena e os recursos financeiros repassados fundo a fundo. 
De acordo com o funcionamento dos DSEIs, os recursos obtidos via SPS/MS ou por convênios com a FUNASA devem ser utilizados para garantir a atenção básica diferenciada nas próprias comunidades ou nos pólos-base. Visando o atendimento hospitalar, o MS criou o Fator de Incentivo para a Assistência Ambulatorial, Hospitalar e de Apoio Diagnóstico à População Indígena (Brasil, 1999b). Cada DSEI, quando de sua implantação, indicou os hospitais de primeira, segunda e terceira referência, bem como a população a ser referenciada para cada um. Assim, cada hospital recebe mensalmente, além do pagamento das $\mathrm{AIHs}$, o valor do incentivo em sua conta corrente cadastrada entre os estabelecimentos de saúde do SUS. Os valores destinados aos hospitais localizados em 47 municípios dos quatro estados para o Apoio MAC à População Indígena, publicados pelo DATASUS, totalizam R $\$ 716.585,00$. Essa quantia, porém, refere-se apenas a sete meses de 2001, não incluindo, portanto, todos os pagamentos, iniciados em maio de 2000.

\section{ATENÇÃO À SAÚDE NO DSEI INTERIOR SUL/RS}

A Tabela 3 mostra a cobertura de recursos e serviços de saúde no DSEI Interior Sul/RS em 2001. A Tabela 4 apresenta as taxas de mortalidade geral, infantil e de menores de cinco anos naquele ano. Quando estimada com base nas informações da FUNASA, a mortalidade geral foi $57 \%$ maior e a infantil e de menores de cinco anos foram o dobro das estimadas usando o SIM e o SINASC. Isso ocorreu porque nesses bancos o número de mortos foi menor e o de nascimentos maior do que os registrados pela FUNASA.

\section{DISCUSSÃO}

\section{Financiamento}

A regulamentação do Subsistema de Atenção à Saúde Indígena é importante conquista de movimentos indígenas de afirmação étnica iniciados há pelos menos duas décadas (Brasil, 1999a). Pela primeira vez no país, foram destinados aos povos indígenas recursos financeiros específicos para implementar e manter ações e serviços de saúde. Os índios, constituindo uma população de alto risco sob o ponto de vista da saúde pública e quase sempre tratados com preconceito 
Tabela 3

Cobertura de recursos e serviços de saúde no Distrito Sanitário Especial Indígena Interior Sul, no âmbito do Rio Grande do Sul em 2001.

\begin{tabular}{lc}
\hline Recursos e serviços & Taxas \\
\hline Profissional nédicol $^{1}$ & 1,1 \\
Profissional enfermeiro $^{1}$ & 1,5 \\
Profissional odontólogo $^{1}$ & 0,8 \\
Auxiliar técnico de enfermagem! $^{1}$ & 5,2 \\
Agente de saúde indígenal $^{1}$ & 7,8 \\
Consultas mnédicas $^{2}$ & 2,4 \\
Consultas enfermeiro $^{2}$ & 3,4 \\
Consultas por especialista2 $^{2}$ & 0,1 \\
Hospitalização, dados FUNASA $^{3}$ & 20,2 \\
Hospitalizações, dados AIHs $^{3}$ & 16,3 \\
Hospitalização, média e alta complexidade, dados AIHs $^{3}$ & 2,5 \\
\hline
\end{tabular}

1 por 1.000 habitantes.

2 por habitante.

${ }^{3}$ por 100 habitantes.

Obs.: população indígena no Rio Grande do Sul na abrangência do DSEI Interior Sul: 13.214.

(Fonte: Associação Estadual dos Rondonistas de Santa Catarina, 2002).

'labela 4

Mortalidade no Distrito Sanitário Especial Indígena Interior Sul, no âmbito do Rio Grande do Sul em 2001.

\begin{tabular}{llclc}
\hline & \multicolumn{4}{c}{ Mortalidade conforme fonte dos dados } \\
& \multicolumn{2}{c}{ SIM/SINASC } & FUNASA \\
& $\mathrm{n}$ & Taxa & $\mathrm{n}$ & 'laxa \\
\hline Mortalidade infantill & 17 & 26,4 & 29 & 56,5 \\
Mortalidade de menores de 5 anos $^{1}$ & 30 & 46,5 & 50 & 97,5 \\
Mortalidade geral? & 60 & 4,5 & 94 & 7,1 \\
\hline
\end{tabular}

Nascidos vivos registrados: SINASC-RS 200] $=645$ e FUNASA $=513$.

1 por 1.000 nascidos vivos.

2 por 1.000 habitantes. 
até mesmo dentro do SUS, finalmente passam a contar com uma política específica que pretende diminuir o enorme abismo criado pela dificuldade de acesso às ações para a saúde e pela falta de eqüidade a que estão mais sujeitos, mesmo quando comparados a outros segmentos populacionais tradicionalmente desfavorecidos.

O DSEI Interior Sul, localizado no sul do país, abrange dezenas de comunidades indígenas, de diferentes etnias, com população estimada em torno de 31 mil índios. Desde a implantação desse DSEI, no final de 1999, o Governo Federal tem investido valores consideráveis para a atenção à saúde indígena, seja por meio das transferências fundo a fundo (SPS/MS) aos municípios, como por intermédio de convênios com a FUNASA. A somatória dos recursos obtidos utilizando-se essas duas vias, já pagos até meados de 2002, foi igual a $R \$ 28.082 .704,99$, sendo que o repassado aos conveniados com a FUNASA soma $R \$ 18.447 .674,99$, ou seja, $65,7 \%$ desses pagamentos. Ainda há que se considerar o incentivo financeiro para o atendimento ambulatorial e hospitalar dos índios, recebido por hospitais referência nos quatro estados, cujos valores pagos durante sete meses de 2001 somaram $R \$ 716.585,00$ (os valores obtidos desde maio de 2000 não estão disponíveis, até o momento, na página eletrônica do DATASUS).

\section{Atenção à saúde}

Após quase três anos de implantação dos DSEIs, é difícil medir o impacto dos recursos financeiros disponibilizados à saúde indígena, já que a variável etnia ou cor da pele não está incluída nos sistemas de informação SIH/SIA e no SIM, SINASC e SINAM, estima-se que o sub-registro para essa variável seja grande. O descumprimento da obrigatoriedade de atestados de óbito para a população indígena contribui para o sub-registro de mortes nos sistemas oficiais de notificação. Isso produz "embaçamento" epidemiológico que pode estar mascarando a precariedade da situação de saúde dessas populações. Um exemplo disso é o Município de Redentora (Rio Grande do Sul), cuja mortalidade infantil era praticamente zero nos bancos de dados oficiais, mas quando foi realizada investigação específica (Menegolla et al., 2002), evidenciou-se taxas entre 47 a 190 óbitos por mil nascidos vivos em indígenas. O Sistema de Informações de Saúde Indígena (SIASI), ainda em fase de implantação, criado para gerar dados que possam servir de subsídios para a construção de indicadores de saúde indígena e para a avaliação da qualidade da atenção dispensada, pode ser um importante aliado na avaliação e no planejamento de ações, mas corre o risco de colocar os índios à 
margem dos bancos de dados da população geral, produzindo um "gueto epidemiológico", cujos dados paralelos poderão inviabilizar a contextualização das condições de saúde indígena em relação à população envolvente.

Essa situação tem sido debatida por diferentes autores, como Peterson (2002), que diz que a falta de identificação racial/étnica em prontuários não permite avaliar o acesso diferencial (ou discriminação) no atendimento à saúde, o que “...produz uma espécie de daltonismo - a desigualdade racial é presidencialmente decretável, porém, cientificamente indizivel" (Peterson, 2002:43). A “danosa invisibilidade demográfica e epidemiológica" dos povos indígenas no Brasil, apontada por Coimbra Jr. \& Santos (2000:131), parece resultar da falta de informações nos bancos de dados oficiais. As categorias utilizadas pelos censos nacionais até 1980 não permitiram que os índios fossem considerados enquanto grupos étnicos diferenciados (Oliveira, 1997).

Superando a falta da variável etnia e o senso comum no meio indigenista de dados inexistentes ou não fidedignos, foi possível detectar que a cobertura de profissionais médicos no DSEI Interior Sul/RS no ano de 2001 foi a metade da taxa estadual, enquanto a taxa de consultas médicas por habitante foi semelhante à estadual (MS, 2002), indicando que o número de consultas por médico é o dobro da média estadual. Esses resultados indicam falha nos objetivos de atenção básica à saúde, pois houve, em média, cinco atendimentos por médicos ou enfermeiros por habitante/ano e ainda assim as internações hospitalares foram o dobro da média estadual (MS, 2002). O risco de uma criança indígena do DSEI Interior Sul/RS morrer antes dos cinco anos de idade, estimada com dados da FUNASA, foi mais de cinco vezes a média estadual (MS, 2002), levantando a possibilidade de falhas também na atenção hospitalar. Essas taxas de mortalidade foram bem menores quando estimadas com dados do SIM e SINASC. Embora seja possível que alguns nascimentos não tenham sido registrados pela FUNASA, a maior parte das diferenças entre as fontes de dados provavelmente reflete sub-registro de óbitos de índios no sistema oficial (SIM), devido a não exigência de atestado de óbito para índios, sepultados em cemitérios indígenas, onde não há necessidade de apresentação de registro de óbito. A possibilidade de sub-registro de óbitos indígenas no SIM é reforçada pela maior mortalidade geral medida com dados da FUNASA.

É preciso investigar os determinantes da alta mortalidade e das altas taxas de internação hospitalar na população indígena no DSEI Interior Sul/RS, que provavelmente incluem moradias precárias, falta de saneamento básico, pobreza e problemas de planejamento e execução das ações de saúde (supervi- 
são/capacitação das EMSIs, capacitação dos consclhciros, incexistência de contratos claros com os municípios e hospitais, entre outros).

\section{O controle social}

Io I)Sial Interior Sul, o Conselho Distrital (CONI)ISI-INSUL) e os Comselhos I ocais de Saude, instâncias de controle social que devem participar do plancjamento e da araliação das ações, bem como apreciar as prestações de contas dos órgàos e instituições executoras das mesmas (Brasil, 1999c), enfrentam dificuldades para desemolver essals atribuições.

Vo que se refere à araliação das prestações de contas, a situação é agravada porcue são muitas as fontes a serem verificadas para checagem do acordado e clos recursos repassados, além de serem de difícil compreensióo para o público leigo. Soma-se a isso a existência no DStil Interior Sul de um número considerável de municípios envolvidos na atenção à saúde indígena, cada um com suas peculiaridades políticas, econômicas e de relação histórica com os povos indígenas, o que permite que cada prefeitura decida como e quando empregar os recursos, bem como se irá ou não prestar contas dos mesmos.

Him remião de junho de 20(02, o C(O)NI)ISI-INSUL solicitou oficialmente aos municípios que recebem recursos da SPS/MS para contratação das W.M.Sls, a prestação de contas detalhada descle o primeiro repasse realizado. Não foi atendido, com execção de duas prefeituras de Santa Catarina que as apresentaram parcialmente em remião do Conselho realizada em outubro de 200 ?. I ma das prefeituras, inclusive, relatou a realização de obras e aquisição de bens com o "saldo" deste recurso. A plenária do Consclho deliberou por solicitar novamente a prestação de contas detalhada aos municípios. Parece-nos que boa parte dessas dificuldades poderia ser resolvida com o estabelecimento, pela FUIAS 1 de contratos que apresentem as formas de descrição da aplicação e prestação de contas dos recursos financeiros recebidos pelos municípios e a sua periodicidade, facilitando assim a avaliação.

Voltando nosso ollar para os comênios com a FUNAS. I, há outros questionamentos que poden ser levantados. No caso da ONC: Projeto Rondon, que conta com recursos financeiros para atuar em dois DSFis (Interior Sul c Litoral Sul) ('labela 1), o CON'DISI-INSSUI, não tem recebido com detalhes, por abrangência de cada IDSEI, o planejannento orçamentário e alguns itens da stla execu(aĩo, como, por exemplo, a apuisição de medicamentos classificados por grupos terapêuticos (tanto de medicanentos básicos quanto aqueles de nso excepcio- 
nal) e a previsão das respectivas quantidades por aldeia. Isso é importante não só porque o montante financeiro destinado ao item "medicamento" é um dos maiores, mas também porque essas informações tornariam possível a necessária avaliação para o estabelecimento de planejamentos futuros, com base em indicadores epidemiológicos mais claros e condizentes com cada contexto local. Cabe lembrar que parcela significativa do gasto com medicamentos pode ser resultado de excesso de "sintomatoterapia", decorrente de consultas médicas-relâmpago, com prescrição de medicamento para alívio dos sintomas, sem preocupação diagnóstica, o que é sinal de baixa eficiência do serviço.

A prestação de contas mais minuciosa feita pela ONG foi exibida na reunião de outubro de 2002, trazendo os gastos efetuados por itens gerais (por exemplo, "combustível e lubrificante", "medicamentos básicos", "medicamentos não básicos", "exames especializados", etc.) e por aldeia do DSEI Interior Sul no período de lo de abril a 21 de outubro de 2002. Essa prestação se referiu somente aos insumos e alguns serviços (consultas especializadas e exames, sem especificálos), não sendo apresentadas as planilhas de gastos com recursos humanos, o que prejudicou sobremaneira a avaliação da aplicação financeira e de seu impacto sobre as ações de saúde. Some-se a isso os fatos de que: (1) não foi feita uma comparação entre as ações planejadas no plano distrital para o período e o que foi efetivamente realizado; (2) não houve tempo para uma apreciação mais profunda dos gastos, já que as prestações estavam sendo mostradas pela primeira vez durante a reunião e (3) não foi apresentado um detalhamento por aldeia, ou mesmo por estado, dos motivos que justificaram os gastos em alguns dos itens, o que possibilitaria, por exemplo, inferir informações sobre as doenças mais freqüentes.

Quanto aos municípios conveniados com a FUNASA (Entre Rios e Ipuaçu desde 1999, José Boiteux em 1999 e Chapecó em 2001), o conjunto do CONDISI-INSUL não tem recebido qualquer prestação de contas, apesar dos altos valores repassados, como demonstra a Tabela 2. Mais uma vez, o acompanhamento da aplicação de recursos e a medida do impacto sobre a atenção à saúde indígena estão dificultados.

No que se refere ao Fator de Incentivo para a Assistência Ambulatorial, Hospitalar e de Apoio Diagnóstico à População Indígena (Brasil, 1999b), até o momento não há clareza a respeito dos objetivos desse recurso, prejudicando o controle social. Isso tem gerado situações como a relatada na reunião do Conselho (outubro de 2002) por um representante índio de un município de Santa Catarina. Segundo ele, o hospital referência para a população indígena de seu município não tem dado uma atenção diferenciada à comunidade. $\mathrm{O}$ represen- 
tante também questionou o fato de não receberem prestações de contas, o que para ele compromete a avaliação das reais necessidades de recursos para esse hospital. Além das dificuldades de acompanhar a aplicação desses recursos, outras indefinições colocam em discussão o Apoio MAC à População Indígena, como a falta de modelos para a avaliação, qual é o papel da FUNASA e quem deve fiscalizar.

\section{CONSIDERAÇÕES FINAIS}

O paradigma de saúde que permeia o Subsistema de Saúde Indígena no SUS contempla o que foi recomendado pela Organização Pan-Americana da Saúde na Resolução V sobre saúde para os povos indígenas (OPS, 2002). A implantação efetiva deste modelo é um processo que vem sendo construído por vários atores ao longo dos últimos dez anos e que certamente ainda tern uma longa jornada. Muito se avançou nestes anos, mas a análise que apresentamos sinaliza que outros avanços são urgentes se desejamos alcançar impactos positivos, diminuindo as desigualdades as quais os povos indígenas estão sendo submetidos.

Em recente entrevista ao Jornal do Brasil (Garda, 2002), o coordenador nacional do Departamento de Saúde Indígena da FUNASA (DESAI/FUNASA) referiu que, de 2000 a 2001, a mortalidade infantil em indígenas diminuiu de 74 para 56 por mil nascidos vivos, associando o fato aos investimentos realizados pela FUNASA. Citou também que as maiores causas de morte foram diarréias e infecções respiratórias, evitáveis com atenção básica. Dados da ONG URIHI, responsável pela atenção básica em quase todo o território Yanomámi (12.765 índios), sugerem que é possível mudar o quadro epidemiológico desastroso freqüentemente encontrado entre as populações indígenas. Entre os Yanomámi, a mortalidade infantil foi reduzida de 197 por mil em 1998, para 38,4 por mil nascidos vivos em 2002 (até setembro), com redução da mortalidade geral $\mathrm{em} \mathrm{50 \%} \mathrm{(Comis-}$ são Pró-Yanomámi, 2002), com gastos semelhantes aos do DSEI Interior Sul. Isso reforça que o caminho para superar a desigualdade em saúde dos povos indígenas está aberto. A criação do subsistema e o financiamento estão sendo implementados, apesar da gerência conflitante entre a SPS/MS e a FUNASA. Agora devem ser priorizados a qualificação dos recursos humanos, os mecanismos de avaliação e fiscalização e, principalmente, a promoção do controle social na gestão de saúde.

Soluções para os problemas levantados neste texto, que se baseou em análises dos repasses financeiros ao DSEI Interior Sul e da cobertura de serviços 
de saúde e mortalidade nesse DSEI no Rio Grande do Sul, requerem, entre outras, a melhoria na qualidade dos serviços, desde a captação, capacitação e supervisão dos recursos humanos até a fiscalização continuada e a avaliação sistemática de custos e benefícios dos programas e ações de saúde, com participação ativa dos povos indígenas. Além disso, devem ser implementadas outras medidas que têm impacto positivo sobre a saúde, como saneamento básico, estímulo e subsídios à agricultura indígena, ações in loco de combate à desnutrição, sempre respeitando as especificidades locais e construindo-as coletivamente.

Considerando as instâncias deliberativas fiscalizadoras e de pactuação nas três esferas de governo (Conselhos Municipais de Saúde, Conselhos Estaduais de Saúde, Conselho Nacional de Saúde, Comissões Intergestores Bipartite e Tripartite), vê-se também como importante a realização de amplos debates que reforcem aos municípios o fato de que esses recursos financeiros são suplementares aos já existentes para o gerenciamento do sistema municipal de saúde, nos quais os povos indígenas também estão incluídos.

\section{Referências}

ASSOCIAÇÃO ESTADUAL DOS RONDONISTAS DE SANTA CATARINA, 2002. Plano Distrital de Saúde 2002 - Distritos Sanitários Especiais Indígenas Interior e Litoral Sul. Florianópolis: Fundação Nacional de Saúde/ONG Projeto Rondon.

BRASIL, 1999a. Lei n. 9.836 de 23 de setembro de 1999. Acrescenta Dispositivos à Lei $n$. 8.080, de 19 de setembro de 1990, que "Dispõe sobre as Condições para a Promoção, Proteção e Recuperação da Saúde, a Organização e o Funcionamento dos Serviços Correspondentes e dá Outras Providências", Instituindo o Subsistema de Atenção à Saúde Indigena. 11 julho $2000<$ http://www.planalto.gov.br>.

BRASIL, 1999b. Portaria n. 1.163 de 14 de setembro de 1999. Dispõe sobre as responsabilidades na prestação de assistência à saúde dos povos indígenas, no Ministério da Saúde e dá outras providências. Diário Oficial da União, 15 set.

BRASIL, 1999c. Decreto n. 3.156 de 27 de agosto de 1999. Dispõe sobre as condições para a prestação de assistência à saúde dos povos indígenas, no âmbito do Sistema Único de Saúde, pelo Ministério da Saúde. Diário Oficial da União, Edição Extra, 28 ago.

BRASIL, 2001. Portaria Conjunta n. 125 de 21 de novembro de 2001. Altera os valores do incentivo de atenção básica aos povos indígenas dos Municípios constantes do anexo desta Portaria, destinados às Equipes Multidisciplinares de Saúde Indígenas e Agentes Indígenas de Saúde. Diário Oficial da União, $10 \mathrm{dez}$.

BRASIL, 2002. Portaria Conjunta n. 167 de 01 de agosto de 2002. Altera os valores do incentivo de atenção básica aos povos indígenas dos Municípios constantes do anexo 
desta Portaria, destinados às Equipes Multidisciplinares de Saúde Indígenas e Agentes Indígenas de Saúde. Diário Oficial da União, 2 ago.

COIMBRA Jr., C. E. A. \& SAN'TOS, R. V., 2000. Saúde, minorias e desigualdades: Algumas teias de inter-relações, com ênfase nos povos indígenas no Brasil. Ciência $\sigma$ Saúde Coletiva, 5:125-132.

COMISSÃO PRÓ-YANOMÁMI, 2002. Ação de ONGs Baixa Mortalidade de Índios. 10 outubro $2002<$ http://www.proyanomami.org.br>.

FUNASA (Fundação Nacional de Saúde), 2000. Saúde Indígena. 5 fevereiro $2000<$ http:// www.fns.gov.br/ind.htm>.

GARDA, C., 2002. Brasil tem dívida com seus índios. Jomal do Brasil, 25 ago.

LANGDON, E. J., 2000. Salud y pueblos indígenas: Los desafíos en el cambio del siglo. In: Salud y Equidad: Una Mirada desde las Ciencias Sociales (R. Briceño-León; M. C. S. Minayo \& C. E. A. Coimbra Jr., org.), pp. 107-117, Rio de Janeiro: Editora Fiocruz.

MENEGOLLA, I. A.; FUKUOKA, E. \& RODRÍGUEZ, I. H., 2002. Investigação de óbitos de crianças menores de 5 anos na Terra Indígena Guarita, Município de Redento$\mathrm{ra} /$ RS. Revista Brasileira de Epidemiologia, Suplemento Especial:229.

MS (Ministério da Saúde), 2002. Indicadores e Dados Básicos para a Saúde 2001 Brasil. Rede Interagencial de Informações para a Saúde, Ministério da Saúde. 29 novernbro $2002<$ http://tabnet.datasus.gov.br/cgi/idb2001/matriz.htm>.

OLIVEIRA, J. P., 1997. Pardos, mestiços ou caboclos: Os índios nos cénsos nacionais no Brasil (1872-1980). Horizontes Antropológicos, 6:60-83.

OPS (Organización Panamericana de la Salud), 2002. Resolución V - Salud de los Pueblos Indigenas. 19 Junio $2002<\mathrm{http}: / / \mathrm{www}$.paho.org>.

PETERSON, C., 2002. Trambiclínicas, Pilantrópicas, Embromeds: Um Ensaio sobre Gíria Médica. Rio de Janeiro: Editora Fiocruz. 


\title{
or \\ (웅 \\ AVALIAÇÃO PRELIMINAR DO PROCESSO DE DISTRITALIZAÇÃO SANITÁRIA INDÍGENA NO ESTADO DO AMAZONAS
}

Sर

\author{
Luiza Garnelo, Luiz Carlos Brandão
}

A saúde indígena no Brasil, configurada como um subsistema do Sistema Único de Saúde (SUS), assume diversas peculiaridades em relação às formas próprias de operar do SUS. Uma delas se refere à responsabilidade de gestão, que cabe, por designação constitucional, ao Governo Federal. Esssa disposição jurídica confere à saúde indígena uma movimentação oposta à trajetória de descentralização percorrida pelo SUS, pois nela o poder decisório deve permanecer concentrado no âmbito de órgãos federais encarregados de prover atenção à saúde dos povos indígenas.

Nos últimos anos, a responsabilidade pela prestação de cuidados de saúde aos povos indígenas se alternou entre a Fundação Nacional do Índio (FUNAI), órgão do Ministério da Justiça, e a Fundação Nacional de Saúde (FUNASA), do Ministério da Saúde (MS). Nos períodos gerenciados pelo SUS, seus dirigentes preconizaram a adoção de sistemas locais de saúde - na forma de distritos sanitários - como o modelo assistencial prioritário para a prestação de cuidados à população aldeada.

A implantação dos distritos foi iniciada em 1991, com o Decreto no 23 do governo Collor, que transferiu a responsabilidade da saúde indígena da FUNAI para o MS e criou o primeiro distrito sanitário, dirigido ao povo Yanomámi. Com o retorno da saúde indígena para a FUNAI em 1994, o processo foi interrompido, sendo retomado apenas em 1999, novamente pela FUNASA. Esta manteve o modelo de distritalização, mas optou pela renúncia à execução direta das ações, adotando a proposta de terceirizaçãol das ações de saúde a serem desenvolvidas em áreas indígenas.

\footnotetext{
1 Fernandes (1994:21), caracteriza o terceiro setor como "um conjunto de organizações e iniciativas privadas que visam à produção de bens e serviços públicos". No campo da saúde, a recente política neoliberal vem investindo progressivamente na utilização dessas instituições para o desenvolvimento de políticas públicas, reproduzindo num espaço setorial o processo mais amplo de terceirização de funções do Estado.
} 
A terceirização em saúde indígena assume dimensões que são também diferenciadas em relação àquelas que se processam no restante do SUS. Por exemplo, neste existe a compra de serviços de empresas ou outras instituições de direito privado, mas sem renúncia ao desenvolvimento da assistência à saúde pelo próprio poder público. Na saúde indígena, por sua vez, as ações têm sido integralınente terceirizadas, mantendo-se a responsabilidade de gestão no órgão de governo, ao qual caberia normatizar, acompanhar e avaliar os serviços prestados pelas entidades executoras.

$\mathrm{Na}$ saúde indígena, a pactuação entre governo e prestadoras de serviços vem sendo viabilizada por meio de convênios com prefeituras e com entidades não-governamentais, as quais competiria, mediante a utilização de recursos oriundos do SUS, executar atividades preventivas e curativas. O planejamento das atividades é ordenado por intermédio de plano distrital, anualmente renovado - da mesma forma que o convênio - e aprovado no Conselho Distrital. No Amazonas, foram implementados sete distritos, todos por meio de convênios firmados com organizações não-governamentais $(\mathrm{ONGs})^{2}$, seis das quais organizações indígenas.

Este texto propõe uma avaliação de atividades desenvolvidas pelas entidades conveniadas com a FUNASA para os Distritos Sanitários Especiais Indígenas (DSEIs) Rio Negro, Médio Solimões, Alto Solimões, Manaus, Parintins, Médio Purús e Javari, Estado do Amazonas, para os anos de 2000 e 2001. Não foi possível coletar dados para 1999, pois no ano de implantação dos distritos houve carência de informações que viabilizassem a análise proposta.

\section{METODOLOGIA}

Este trabalho constitui um esforço de apreender os modos de articulação entre os conhecimentos científicos - que fornecem orientação epidemiológica para a detecção de necessidades de saúde, adoção de normas técnicas e de modelos assistenciais propostos pelo SUS e por seu subsistema de saúde indígena - e as programações e práticas desenvolvidas pelas equipes distritais.

Para fins desta análise foi adotado o conceito de avaliação normativa expresso por Contandriopoulos et al. (2000:34), que a caracterizam como uma

\footnotetext{
2 A única exceção é a de um convênio firmado com a Prefeitura de Barcelos, destinado ao atendimento de uma pequena fração da população indígena do DSEI Rio Negro.
} 
“... atividade que consiste em fazer um julgamento sobre uma intervenção, comparando os recursos empregados e sua organização (estrutura), os serviços ou os bens produzidos (processos), e os resultados obtidos, com critérios e normas". Dentro dos processos de avaliação normativa propostos pelos autores, foi priorizada a apreciação da estrutura e do processo da distritalização, com a preocupação em perceber se ambos são favorecedores da continuidade das ações, se oferecem recursos suficientes e corretamente alocados, capazes de viabilizar cobertura, qualidade técnica e adequação dos serviços às necessidades dos usuários indígenas. A dimensão organizacional também foi explorada, buscando apreender a continuidade, globalidade, resolutividade e intersetorialidade dos cuidados oferecidos e, dentro do possível, apreciação de seus resultados.

Se, por um lado, a avaliação foi de tipo normativo, buscando analisar os componentes da intervenção distrital em contraponto às normas e critérios já estabelecidos pelos avanços do sanitarismo brasileiro e pela experiência institucionalizada nas ações programáticas de saúde, por outro, buscamos agregar à análise alguns aspectos de pesquisa avaliativa, conceituada pelos autores supracitados como uma forma de "... analisar a pertinência, os fundamentos teóricos, a produtividade, os efeitos e o rendimento de uma intervenção, assim como a relação existente entre a intervenção e o contexto no qual ela se situa, geralmente com o objetivo de ajudar na tomada de decisões" (Contandriopoulos et al., 2000:37). Um dos principais elementos explorados na pesquisa avaliativa, foi a análise dos sentidos atribuídos ao processo de distritalização pelos atores-chave entrevistados durante a investigação.

As variáveis priorizadas foram: alocação de recursos financeiros e humanos; oferta de rede física; cumprimento de metas de produção de serviços (consultas médicas, odontológicas, de enfermagem e encaminhamento de casos para a rede de referência); análise de notificação de agravos e de óbitos; análise da implantação de ações programáticas de prevenção e controle de agravos na atenção básica executada nos distritos sanitários.

Os dados foram coletados em fontes secundárias ${ }^{3}$, com base nas quais foi conduzida análise documental dos planos distritais, relatórios de atividades dos DSEIs, Relatório de Acompanhamento do Plano Anual de Trabalho da Coordenação Regional do Amazonas/2001, Relatório de Gestão da Coordenação Regional Amazonas $/ 2000$ e estatísticas oficiais contidas nos sites da FUNASA (http:// www.funasa.gov.br) e do DATASUS (http://www.datasus.gov.br). Essas informações foram complementadas com entrevistas realizadas com atores-chave no processo, tais como servidores da FUNASA e membros de ONGs convenentes. 
No primeiro grupo, foram entrevistados o coordenador regional da FUNASA no Amazonas, dois gerentes distritais e dois técnicos da divisão de vigilância cpidemiológica da Coordenação Regional. No âmbito dals ONGs, foram entrevistados gerentes técnicos de convênios dos DSEIL Rio Negro, Médio Solimões e Manaus, além de gerentes e dirigentes indígenas de conselhos de saúde dos DSFils Alto Solimões, Médio Purús, Manaus, Médio Solimões e Rio Negro.

Os dados da obserração participante de encontros e reuniões de avalia(ção promoridos pela Coordenação Regional do Amazonas da f'UNASA e pelas cntidades indígenas foram utilizados secundariamente neste trabalho, mas vêm sendo analisados de forma mais detallhada cm outros textos (Carnelo, 200)2; Gar-

¿ Documentos consultados: COLAB (Coordenação das Organizações Indígenas da Amaaônia Brasileira), 2001. Relatório Final do Encontro Macrorregional Preparatório para a III Conferência Nacional de Saúde Indigena. Manaus, 51 pp.; COLAB (Coordenação das (Organizações Indígenas da Amazônia Brasilcira), 2002. Relatório Analítico Descritivo do Comênio (OLAB-FUNASA, Manaus; (C)IAB (Coordenação das Organizações Indígenas da Amazônia Brasileira), 2001. Relatório do Encontro das Organizaçoes Indigenas Comeniadas com a FUNASA: Resultados e Desafios do Programa dos Distritos Sanitários Lispeciais Indígenas no Atendimento da Saude dos Povos Indígenas. Manaus, 24 pp.; Conselho Distrital de Manaus, 2(0)2. Ata da X Reumião Ordinária. Manaus, 12 pp.; Conselho Distrital do I)SEI Rio Negro, 20(01. Ata da VIII Reuniào Ordinária. São Cabriel da Cachocira, 23 pp.; Distrito Sanitário Médio Purús, 2001 . Relatório de Atividades de 200) 1. I ábrea, 11 pp.; Distrito Sanitário Médio Solimões, 2001. Relatório de Atividades de 2000. 'Iéfé; I Distrito Sanitário Médio Solimões, 20022. Relatório de Atividades de 2001. 'Tefé. 38 pp.; F UNASA (Fundação Nacional de Saúde), 2001/2002. Plano Distrital do DSFi Rio Negro para os anos de 2000 e 2001. São (iabriel da Cachocira; FUNASA (Fundação Nacional de Saúde), 2001/2002. Plano Distrital do DSFI Manaus para os anos de 2000 e 2001. Manaus; FUNASA (Fundação Nacional de Saúde), 2001/20)2. Plano Distrital do ISSEI Médio Solimões para os anos de 2000 e 2001. 'Tefé; FUNiSA (Fundação Nacional de Saúde), 2001/2002. Plano Distrital do ISSEI Alto Solimöes para os anos de 2000 e 2001. Benjamin Constant; FUNASA (Fundação Nacional de Saúde), 2001/2002. Plano Distrital do DSEI Médio Purús para os anos de 2001 e 2002. I ábrea; FUNASA (Fundação Nacional de Saúde), 20(01/20(02. Plano Distrital do DSSEI Parintins para os anos de 2001 e 2002. Parintins; F'INASA (Fundação Nacional de Saúde), 200) l. Plano Distrital do DSEI Javari para o ano 2000. Atalaia do Norte; FUNASA (Fundação Nacional de Saúde)/Coordenação Regional Amazonas. Relatório de Gestão 2000. Manaus; FuNASA (Fundação Nacional de Saúde)/Coordenação Regional Amazonas. Relatório de Acompanhamento do Plano Anual de Trabalho - PAT 2001. Manaus; FUNASA (Fundação Nacional de Saúde)/Coordenação Regional Amazonas. Relatório de Supenisão T'écnica do Convênio FL'NASA/INI-Tefé. ISSFI Médio Solimóes. Periodo de janciro a junho de 2001, elaborado pela equipe técrnica do IDIVH.P (Divisão de Vigilância Epidemiológica). 'Tefé, setembro de 200)1, 27 pp. 
nelo \& Sampaio, 2001, 2002). Neles, exploramos o ponto de vista do usuário indígena, seja em contextos políticos mais amplos como assembléias regionais do movimento indígena, grandes reuniões nacionais como a III Conferência Nacional de Saúde Indígena, ou ainda em fóruns sanitários de âmbito mais restrito, como as reuniões de conselhos locais e distritais de saúde indígena.

\section{RESULTADOS}

\section{Aplicação de recursos}

A análise da aplicação de recursos demonstra um significativo incremento no financiamento da saúde indígena no Amazonas, que atingiu um valor total de $\mathrm{R} \$ 29.627 .938,38$ em 2000, sofrendo uma pequena retração em 2001, com a aplicação de $R \$ 24.655 .549,08$ (Tabelas 1 e 2). Tais cifras mostram-se mais significativas quando comparadas aos investimentos anuais da FUNASA nos anos de 1993 e 1994, período em que a mesma esteve responsável pela gestão da saúde indígena no estado. Naqueles anos, a instituição investiu na saúde indígena apenas $\mathrm{R} \$ 4.036,93$ e $\mathrm{R} \$ 3.775 .003,28$, respectivamente. Nota-se que o direcionamento exclusivo de recursos para as ONGs, feito em 2000, não se repetiu em 2001. Nesse ano iniciou-se uma diversificação de investimentos, parte dos quais foram aplicados em prefeituras e em atividades desenvolvidas pela própria Coordenação Regional da FUNASA no Amazonas.

As entrevistas com servidores da FUNASA mostraram que tal decisão decorreu da constatação de uma baixa capacidade resolutiva das ONGs, que tiveram dificuldade em alocar a mão-de-obra necessária para as atividades distritais. Tentando amenizar tais problemas, a entidade governamental efetuou um repasse fundo-a-fundo para sistemas municipais de saúde, buscando intensificar a alocação dos recursos humanos necessários. Por outro lado, os recursos financeiros mantidos para aplicação direta pela FUNASA se destinaram à execução de ações de saneamento e de controle de endemias, como a malária, atividades com as quais as ONGs não se mostravam tecnicamente familiarizadas. Seja como for, o resultado final dessa decisão foi uma retração no investimento de recursos destinados às ONGs, com uma queda de mais de $\mathrm{R} \$ 11.412 .841$,38, de um ano para o outro.

A comparação entre os recursos alocados nos distritos e nos municípios que lhes oferecem rede de referência indica que o montante total de recursos 
Tabela 1

Comparativo de recursos aplicados em saúde indígena no Estado do Amazonas em 2000 e 2001 (por R\$1,00), segundo Distrito Sanitário Especial Indígena (DSEI).

\begin{tabular}{lccc}
\hline DSEI & $\begin{array}{c}\text { Transferência para } \\
\text { ONGs em 2000 }\end{array}$ & $\begin{array}{l}\text { Transferência para } \\
\text { ONGs em 2001 }\end{array}$ & $\begin{array}{c}\text { Aplicado em 2001 (ONGs + } \\
\text { FUNASA + prefeituras) }\end{array}$ \\
\hline Alto Solimões & $6.163 .436,89$ & $2.600 .000,00$ & $4.026 .972,69$ \\
Alto Rio Negro & $8.463 .911,70$ & $5.677 .559,00$ & $7.742 .160,24$ \\
Javari & $2.666 .656,00$ & $1.490 .000,00$ & $1.801 .579,69$ \\
Parintins & $2.443 .991,75$ & $2.887 .491,00$ & $3.567 .127,06$ \\
Médio Purús & $2.047 .094,12$ & $1.160 .047,00$ & $2.106 .281,75$ \\
Médio Solimões & $4.385 .841,00$ & $2.200 .000,00$ & $2.783 .756,90$ \\
Manaus & $3.457 .006,92$ & $2.200 .000,00$ & $2.627 .715,75$ \\
Total & $29.627 .938,38$ & $18.215 .097,00$ & $24.655 .594,08$ \\
\hline
\end{tabular}

Fonte: SIAFI - FUNASA/Amazonas.

Tabela 2

Demonstrativo de gasto federal com saúde indígena até novembro de 2001 (por $R \$ 1,00$ ), segundo Distrito Sanitário Especial Indígena (DSEI).

\begin{tabular}{lcccc}
\hline DSEI & $\begin{array}{c}\text { Aplicação direta } \\
\text { (FUNASA) }\end{array}$ & $\begin{array}{l}\text { Transferência } \\
\text { a municípios }\end{array}$ & $\begin{array}{l}\text { Transferência } \\
\text { a ONGs }\end{array}$ & Total geral \\
\hline Alto Solimões & $375.672,69$ & $1.051 .300,00$ & $2.600 .000,00$ & $4.026 .972,69$ \\
Alto Rio Negro & $397.261,2+$ & $1.667 .340,00$ & $5.677 .559,00$ & $7.742 .160,24$ \\
Javari & $225.579,69$ & $86.000,00$ & $1.490 .000,00$ & $1.801 .579,69$ \\
Manaus & $298.136,06$ & $381.500,00$ & $2.887 .491,00$ & $3.567 .127,06$ \\
Médio Purús & $340.659,75$ & $605.575,00$ & $1.160 .047,00$ & $2.106 .281,75$ \\
Médio Solimões & $326.756,90$ & $257.000,00$ & $2.200 .000,00$ & $2.783 .756,90$ \\
Parintins & $427.715,75$ & & $2.200 .000,00$ & $2.627 .715,75$ \\
Total & $2.391 .782,08$ & $4.048 .715,00$ & $18.215 .097,00$ & $24.655 .594,08$ \\
\hline
\end{tabular}

1 Dados até dezembro/200l.

Fontc: SIAFI - FUNASA/Amazonas. 
aplicados é relativamente similar. Porén, como a população indígena sob a responsabilidade distrital é muito menor que aquela atendida pelos municípios, quando se aplica o cálculo de gastos per capita/ano, observa-se uma considerável diferença a favor dos IDSFIs.

A escassez de recursos financeiros alocados nos sistemas municipais de saúde tem reflexos na qualidade da atenção dos DSFis. Isso porque, no modelo assistencial adotado, os casos de doença que ultrapassem a resolutividade dos DSEIs devem ser referidos para a rede de serviços localizada nas sedes dos municípios que abrigam a população adscrita a cada DSFI.

Essa comparação foi organizada apenas para os DSFis Médio Solimões e Parintins (Tabelas 3 e 4), porque os municípios à volta dos outros distritos não constavam, na época da pesquisa, no site do DATASUS como receptores de recursos do governo federal que sustentam, no Amazonas, boa parte dos gastos com saúde. Assim, é válido inferir que uos municípios onde se situam os outros distritos, a aplicação de recursos nos sistemas municipais de saúde foi ainda mais reduzida do que naqueles supracitados. Entretanto, embora os DSEIs contenn com recursos bem acima daqueles disponíveis para as populações não-indígenas dos municípios onde se localizam, não há uma regularidade adequada na disponibilização dos mesmos. Segundo os entrevistados, existem frequientes atrasos no repasse de recursos pela FUNASA, inviabilizando o cumprimento das metas pactuadas e deixando a população indígena sem cobertura assistencial adcquada por longos períodos.

As razões dos atrasos se devem a dois fatos principais, que se retroalimentam. Inicialmente, não há repasse mensal automático de recursos, como ocorre no sistema fundo-a-fundo do SUS. No caso de convênios, a legislação prevê que, após o repasse de duas parcelas do total dos recursos pactuados para o ano, deve ser feita a prestação de contas do montante já aplicado, a fim de fazer jus à nova parcela de recursos. Como fato adicional, não apenas as ONGs encontram dificuldades em organizar prestações de contas de forma ágil e precisa, mas também a própria FUNASA se mostra morosa cm analisar c aprovar (ou reprovar) as contas enviadas e liberar as parcelas subseqüentes. A conjunção desses fatores gera uma crônica dificuldade em manter a continuidade das ações. Tais eventos são bastante conhecidos en celebração de convênios, e se constituíram em motores importantes para instituir o repasse fundo-a-fundo entre governo federal e sistemas municipalizados de saúde no SUS, superando as anteriores relações nos convênios entre o MS e prefeituras. Atrasos dessa natureza são increntes ao modelo de convênio e impedem a adequada continuidade das atividades, comprometendo a eficiência e cficácia do sistema. 
'Tabela 3

Comparativo de alocação de recursos em saúde na região do Distrito Sanitário Especial lndígena (DSEI) Médio Solimões, para populações indígena e não-indígena em 2001.

\section{População}

1.1. Indígena : 7.841

1.2. Não-indígenas nos municípios próximos ao DSEI: 176.673

\section{Recursos alocados}

2.1. FUNASA + ONG: R\$2.526.756,90

2.2. Municípios: R\$2.703.396.06

\section{Gasto per capitalano}

3.1. Indígena: $R \$ 322,24$

3.2. Municípios: $R \$ 15,30$

Fonte: SIAFI - DATASUS.

Tabela 4

Comparativo de alocação de recursos em saúde na região do Distrito Sanitário Especial Indígena (DSEI) Parintins, para populações indigena e não-indígena em 2001.

\section{População}

1.1. Indígena: 8.417

1.2. Não-indlígenas nos municípios próximos ao DSEI: 152.765

2. Recursos alocados

2.1. FUNASA + ONG: R\$2.627.715.75

2.2. Municipios: RS $3.036 .754,13$

3. Gasto per capitalano

3.1. Indígena: $R \$ 312,19$

3.2. Municipios: R\$19,87

Fonte: SIAFI - DATASUS. 
Por outro lado, a análise da proposta de alocação de recursos contida nos planos distritais evidencia uma alta concentração de recursos destinados a atividades meio, quando comparados a investimentos em atividades fins dos distritos. 'lál afirmação pode ser exemplificada na programação do DSEI Mćdio Solimões para 2000 , em cujo plano distrital estava prevista a alocação dc R\$ 2.948.700,00 para atividades de infra-estrutura e logística, supervisão c capacitação de recursos humanos e pagamento de pessoal, ao passo que programava destinar apenas $\mathrm{R} \$ 651.300,00$, ou seja, $18 \%$ do total de recursos previstos no ano, para o desenvolvimento das ações básicas c de controle social.

Em 2001 foi possívcl encontrar tambćm distorções similares, pois o plano de trabalho do DSEI Parintins, aqui usado como exemplo, previa o valor de $\mathrm{R} \$ 2.650 .303,00$ (ou seja, 75,7\% do total de recursos previstos em seu convênio) para "aprimorar as ações técnicas-administrativas através de pesquisas operacionais, visando a promoção, recuperação e manutenção da saúde das populações indígenas", ao passo que o mesmo documento previa o dispêndio de $\mathrm{R} \$ 732.797,00$ (20,9\%) para "reduzir a mortalidade infantil, implantar os programas de doenças crônico-degenerativas, combate a carências nutricionais, DST/AIDS, saúde bucal, implementar o SIASI e o mapeamento geográfico da área". O plano destinava ainda o montante de $\mathrm{R} \$ 83.900,00$ para a manutenção de sistemas simplificados de captação de água e $\mathrm{R} \$ 33.000,00$ para a construção de cinco postos de saúde, dando uma média de $\mathrm{R} \$ 6.600,00$ por posto ${ }^{\dagger}$.

$\mathrm{Na}$ época da coleta das informações aqui descritas, não foi possível analisar a prestação de contas de $200 \mathrm{l}$ dos referidos DSF.Is, de modo que se tornou impossível saber se a aplicação dos recursos ocorreu exatamente como planejado. Porém, a pactuação com as ONGs evidencia a já citada priorização de atividades meio, em detrimento dos recursos a serem alocados para as ações básicas que constituem as atividades fim do DSFI, contempladas com médias de 20\% do montante de recursos programado. Sem nos alongarmos excessivamente, é possível dizer que é uma situação semelhante àquela encontrada nos outros distritos.

\section{Recursos humanos e rede física}

A alocação de recursos humanos, implantação de rede física e aquisição de equipamentos mostra uma real extensão de cobertura, com a contratação de 1.151

\footnotetext{
+ Fonte: Plano de Trabalho de 2001 do DSEI Parintins. Anexo X.
} 
profissionais, num sistema que nunca contou com mais de uma vintena de técnicos de nível superior - seja na FUNAI ou na FUNASA - nos anos anteriores (Tabelas 5 e 6 ).

Apesar de favorável, o quadro de recursos humanos retrata uma realidade cstática, que não expressa a alta rotatividade de profissionais, algo inerente ao modelo de terceirização. A cada final de convênio, a ONG contratante deve rescindir as contratações até que o próximo acordo seja firmado, sob pena de acumular dívidas trabalhistas cujo pagamento não está previsto no orçamento pactuado. As rescisões acarretam desestímulo à manutenção dos profissionais e uma crônica tendência a iniciar cada novo convênio com pessoal inexperiente. Além disso, as entrevistas demonstram que há escassez de recursos humanos capacitados e motivados para atuar em área indígena, havendo dificuldade de captar profissionais de nível superior, pois os salários oferecidos pelos DSEIs não supcram aqueles praticados nos municípios vizinhos.

As metas referentes à rede física também foram em boa parte cumpridas, suprindo uma importante lacuna na oferta de suporte à prestação de cuidados à população aldeada.

Os instrumentos de planejamento das atividades utilizados pela IUNASA são de dois tipos e contam com seus respectivos indicadores de avaliação. $O$ primeiro deles é o plano de trabalho, utilizado para formalizar a relação de convênio com a terceirizada; o segundo é o plano distrital, onde são detalhadas as minúcias da programação estabelecida para cada ano de convênio. Na Coordenação Regional do Amazonas adotou-se ainda o chamado Relatório de Acompanhamento do Plano Anual de Trabalho, buscando avaliar as atividades específicas da instituição no estado. (O) plano de trabalho é um instrumento que prevê basicamente o cumprimento quantitativo de metas de execução de serviços, como consultas médicas, de enfermagem c odontológicas. Conforme se pode observar nos formulários de prestação de contas de convênio utilizados pela FUNASA, o mesmo não prevê formas de avaliação da qualidade da atenção, nem do descnvolvimento de ações de promoção à saúde e de prevenção de agravos

\section{Produção de serviços}

A Tabela 7 apresenta uma síntese dos resultados obtidos pelas convenentes no Amazonas, em relação às metas pactuadas em seus planos de trabalho de $2000 \mathrm{e}$ 2001. Os dados mostram, por um lado, um baixo cumprimento de metas de consultas médicas e de enfermagem, calculadas na base de 2 e 4 consultas por habi- 
Tabela 5

Distribuição dos recursos humanos no Distrito Sanitário Especial Indigena (DSEI)

Amazonas, para o ano de referência 2000.

\begin{tabular}{lrrrrr}
\hline Profissionais & \multicolumn{2}{c}{ Meta } & Contratado & \multicolumn{2}{c}{ \% } \\
& 2002 & 2000 & & Meta-2002 & Meta-2000 \\
\hline Médico & 24 & 26 & 17 & 70,8 & 65,4 \\
Dentista & 29 & 30 & 28 & 96,6 & 93,3 \\
Enfermeiro & 34 & 49 & 47 & 138,2 & 95,9 \\
Auxiliar de enfermagem & 135 & 184 & 166 & 123,0 & 90,2 \\
Agente indígena de saúde & 593 & 663 & 635 & 107,1 & 95,8 \\
Agente indígena de saneamento & 34 & 15 & 0 & 0,0 & 0,0 \\
Outros & 202 & 274 & 258 & 127,7 & 94,2 \\
Total & 1.051 & 1.241 & 1.151 & & \\
\hline
\end{tabular}

Fonte: FUNASA/Regional Amazonas, Relatório de Gestão 2000.

Tabela 6

Distribuição dos equipamentos no Distrito Sanitário Especial Indígena (DSEI) Amazonas, para o ano de referência 2000 .

\begin{tabular}{lrrrrr}
\hline Especificação & \multicolumn{2}{c}{ Meta } & Adquirido & \multicolumn{2}{c}{ \% } \\
& 2002 & 2000 & & Meta-2002 & Meta-2000 \\
\hline Barcos & 201 & 225 & 181 & 90,0 & 80,4 \\
Veículos & 34 & 44 & 28 & 82,4 & 63,6 \\
Rádios & 368 & 247 & 178 & 48,4 & 72,1 \\
Computador & 77 & 72 & 68 & 88,3 & 94,4 \\
Posto de Saúde & 320 & 229 & 115 & 35,9 & 50,2 \\
Pólo Base & 56 & 59 & 49 & 87,5 & 83,1 \\
Casa de Saúde do Índio & 10 & 10 & 8 & 80,0 & 80,0 \\
\hline
\end{tabular}

Fonte: FUNASA/Regional Amazonas, Relatório de Gestão 2000. 


\section{Tabela 7}

Produção de serviços nos diversos Distritos Sanitários Especiais Indígenas (DSEIs), para os anos de 2000 e 2001 .

\begin{tabular}{|c|c|c|c|c|c|c|c|}
\hline DSEI & $\begin{array}{l}\text { Açōes Pro- } \\
\text { gramadas }\end{array}$ & $\begin{array}{l}\text { Programado } \\
\text { para } 2000\end{array}$ & $\begin{array}{l}\text { Executado } \\
\text { em } 2000\end{array}$ & Cobertura & $\begin{array}{l}\text { Programado } \\
\text { para } 2001\end{array}$ & $\begin{array}{l}\text { Executado } \\
\text { em } 2001\end{array}$ & Cobertura \\
\hline \multirow{4}{*}{$\begin{array}{l}\text { Médio } \\
\text { Solimões } \\
\text { (População: } \\
7.697 / 2000 ; \\
7.697 / 2001 \text { ) }\end{array}$} & $\begin{array}{l}\text { Consulta } \\
\text { Médica }\end{array}$ & 15.394 & 4.379 & $28,4 \%$ & 10.000 & 2.863 & $28 \%$ \\
\hline & $\begin{array}{l}\text { Consulta } \\
\text { Odontológica }\end{array}$ & 3.849 & 4.161 & $108,1 \%$ & 20.000 & 36.886 & $184 \%$ \\
\hline & $\begin{array}{l}\text { Consulta de } \\
\text { Enfermagem }\end{array}$ & 30.788 & 3.308 & $10,7 \%$ & 8.000 & 4.441 & $55,5 \%$ \\
\hline & Referências & $\begin{array}{l}\text { Sell pro- } \\
\text { gramação }\end{array}$ & 3.089 & $70,5 \%$ & 30 & 110 & $3,8 \% *$ \\
\hline \multirow{6}{*}{$\begin{array}{l}\text { Javari } \\
\text { (População: } \\
2.467 / 2000 ; \\
2.585 / 2001 \text { ) }\end{array}$} & Consulta & 4.934 & 493 & $10,0 \%$ & \multicolumn{3}{|c|}{ Sem Informação } \\
\hline & Médica & & & & \\
\hline & Consulta & 1.234 & 867 & $70,2 \%$ & \multicolumn{3}{|c|}{ Sem Informação } \\
\hline & Consulta de & 9.869 & 502 & $5,1 \%$ & \multirow{2}{*}{\multicolumn{3}{|c|}{ Sem Informação }} \\
\hline & Enfermagem & & & & & & \\
\hline & Referências & 21 & 88 & $17,8 \% *$ & \multicolumn{3}{|c|}{ Sem lnformaçâo } \\
\hline \multirow{5}{*}{$\begin{array}{l}\text { Manaus } \\
\text { (População: } \\
11.913 / 2000 \text {; } \\
11.913 / 2001 \text { ) }\end{array}$} & Consulta & 23.420 & 5.936 & $25,3 \%$ & \multicolumn{3}{|c|}{7.044} \\
\hline & Viedica & 5855 & 0 & & \multirow{2}{*}{\multicolumn{3}{|c|}{10.870}} \\
\hline & $\begin{array}{l}\text { Consulta } \\
\text { Odontológica }\end{array}$ & 3.855 & 9.215 & $154,4 \%$ & & & \\
\hline & $\begin{array}{l}\text { Consulta de } \\
\text { Enfermagem }\end{array}$ & 46.840 & 16.580 & $35,4 \%$ & \multicolumn{3}{|c|}{12.238} \\
\hline & Referências & 215 & 1.815 & $30,5 \%$ & & 4.182 & $59,3 \%$ \\
\hline \multirow{4}{*}{$\begin{array}{l}\text { Médio Purús } \\
\text { (População: } \\
3.243 / 2000 ; \\
3.414 / 2001 \text { ) }\end{array}$} & $\begin{array}{l}\text { Consulta } \\
\text { Médica }\end{array}$ & 6.846 & 3.543 & $51,7 \%$ & 6.846 & 6.183 & $90,3 \%$ \\
\hline & $\begin{array}{l}\text { Consulta } \\
\text { Odontológica }\end{array}$ & 6.846 & 3.908 & $57,1 \%$ & 1.712 & 4.796 & $2 \% 80$ \\
\hline & $\begin{array}{l}\text { Consulta de } \\
\text { Enfermagem }\end{array}$ & 13.692 & 2.047 & $17,6 \%$ & 13.692 & 4.547 & $33,2 \%$ \\
\hline & Referências & $\begin{array}{l}\text { Sem pro- } \\
\text { gramação }\end{array}$ & 70 & $1,9 \% *$ & $\begin{array}{l}\text { Sem pro- } \\
\text { gramação }\end{array}$ & 30 & $8,9 \%$ \\
\hline $\begin{array}{l}\text { Alto Solimões } \\
\text { (População: }\end{array}$ & $\begin{array}{l}\text { Consulta } \\
\text { Médica }\end{array}$ & 57.124 & 30.883 & $54,1 \%$ & \multicolumn{3}{|c|}{ Sem Informaçầo na Regional } \\
\hline \multirow[t]{3}{*}{$\begin{array}{l}28.582 / 2000 \\
24.684 / 2001)\end{array}$} & $\begin{array}{l}\text { Consulta } \\
\text { Odontológica }\end{array}$ & 14.261 & 3.428 & $24,0 \%$ & \multicolumn{2}{|c|}{ Sem Informaçâo na Regional } & nal \\
\hline & $\begin{array}{l}\text { Consulta de } \\
\text { Enfermagem }\end{array}$ & 114.248 & $\begin{array}{l}\text { Sem } \\
\text { Informação }\end{array}$ & & \multicolumn{3}{|c|}{ Sem Informaçào na Regional } \\
\hline & Referências & 21 & 88 & $0,2 \%$ & \multicolumn{3}{|c|}{ Sem Informaçào na Regional } \\
\hline
\end{tabular}

(continua) 
Tabela ; (continuaço)

\begin{tabular}{|c|c|c|c|c|c|}
\hline DSEI & $\begin{array}{l}\text { Ações Pro- } \\
\text { gramadas }\end{array}$ & $\begin{array}{l}\text { Programado } \\
\text { para } 2000\end{array}$ & $\begin{array}{l}\text { Fxecutado } \\
\text { em } 2000\end{array}$ & Cobertura & $\begin{array}{ll}\text { Programado Fiecutado Cobertura } \\
\text { para } 2001 \text { em } 20001\end{array}$ \\
\hline \multirow{4}{*}{$\begin{array}{l}\text { Parintins } \\
\text { População: } \\
3.30(0 / 200) \text { : } \\
9.248 / 2001 \text {; }\end{array}$} & $\begin{array}{l}\text { Consulta } \\
\text { Mćdica }\end{array}$ & 16.578 & 102 & \multicolumn{2}{|c|}{$0,6 \%$ Sem Informaça na Regional } \\
\hline & $\begin{array}{l}\text { Consultal } \\
\text { Odontológica }\end{array}$ & +220 & 115 & $2,70 \%$ & Sem Informação na Regional \\
\hline & $\begin{array}{l}\text { Consulta de } \\
\text { Enfermagem }\end{array}$ & 33.756 & 151 & $0 .+0 \%$ & Sem Informaçāo na Regional \\
\hline & Reterências & $\begin{array}{l}\text { Sem pro- } \\
\text { gramação }\end{array}$ & 584 & $572 \% *$ & Sem Informação na Regional \\
\hline \multirow{4}{*}{$\begin{array}{l}\text { Alto Rio } \\
\text { Negro } \\
\text { (População: } \\
27.32+/ 2000) \\
27.32+/ 2001)\end{array}$} & $\begin{array}{l}\text { Comsultal } \\
\text { Médica }\end{array}$ & 56.528 & +058 & $7.2 \%$ & Sem Informação na Regional \\
\hline & $\begin{array}{l}\text { Comsulta } \\
\text { Odontological }\end{array}$ & $1+.157$ & $9 .+27$ & $66.6 \%$ & Sem Informaçăo na Regionial \\
\hline & $\begin{array}{l}\text { Comsulta de } \\
\text { Finfermagem }\end{array}$ & 113.256 & 10.564 & $9.3 \%$ & Sem Informação na Regional \\
\hline & Referencias & $\begin{array}{l}\text { Sem pro- } \\
\text { gramação }\end{array}$ & 589 & $14.5 \%$ & Sem Informą̧ăos na Regional \\
\hline
\end{tabular}

Porcentual de referéncias calculado em relaçào ao munero de consultas médicas realizadas Parâmetros utilizados: Consulta Médica: 2 por hab./ano; Consulta de Finfermagem:

4 por hab./ano: Consulta Odontológica: 0.5 cons./hab./ano.

Fonte: FIIVAS.V/Amazonas, Relatório de (xestão em 2000 e relatorios de atividades dos I)SEI em 2001

tante/ano, respectivamente. Por outro lado, chamia a atenção a falta de informação da produção de $2001 \mathrm{~cm}$ quatro dos sete distritos, numa coleta de dados que foi fcita cm abril de 2002. Ou seja, quatro meses após o término do cexcrcício fiscal de 2001, quatro convenentes, que receberam um montante total de recursos da ordem de R\$ 1 1.967.559,00, ainda não tinham informado à Coordenação Regional da FUNASA no Amazonas sua produção de serviços no ano anterior.

Nota-se ainda que a média das consultas odontológicas ultrapassou o programado. A explicação para of fato foi de que muitos distritos estariam somando os procedimentos odontológicos com as consultas odontológicas nas suas estatísticas de produção de serviços, gerando esse aparente superávit de consultas.

Nas entrcvistas interrogou-se a razão para un cumprimento tão baixo de metas, obtendo-se as seguintes respostas: dificuldade de captar médicos para trabalhar nos DSFIs; alta rotatividade de pessoal; interrupções prolongadas por atraso no recebimento dos recursos das atividades no período de vigência do convênio e cálculos de metas inadequados às condiçôes locais. Dentre esses argumentos, a alegada carência de profissionais não parece convincente, pois o quadro de alocação de recursos humanos ('labela 5) mostra que houve mais contra- 
tações de enfermeiros que o inicialmente previsto, e um alcance de $70,8 \%$ nas metas de contratação de médicos, em relação à previsão inicial.

A Tabela 7 mostra também lacunas na programação de metas de produção de serviços em alguns distritos e problemas no cálculo da população alvo para cada ano. Por exemplo, existem distritos, como os DSEIs Rio Negro e Manaus, que mantiveram fixa sua população alvo para 2000 e 2001 (27.324 e 11.913, respectivamente), algo demograficamente impossível. Além disso, nesses dois anos, ambos promoveram a extensão de cobertura de suas ações, passando a englobar população indígena de municípios que não constavam de suas programações em 2000. Ainda assim, os dados disponíveis mostram que o cumprimento de metas foi sofrível. Infelizmente, devido às lacunas de informação de ambos os distritos, não foi possível avaliar se a tendência se consolidou.

Calculou-se o percentual de pacientes referidos em relação ao número de consultas médicas prestadas ('Tabela 7), encontrando-se resultados muito contraditórios. Existem distritos, como o de Parintins, no qual em 2000 foram prestadas apenas 102 consultas médicas e 584 doentes foram referidos para as sedes municipais, incluindo-se Manaus. Outros, como o Médio Solimões, prestaram em 2000 um total de 4.379 consultas e referiram 3.089 casos, ou seja, $70 \%$ das consultas médicas terminaram em referência, indicando baixa resolutividade, tanto no âmbito do próprio distrito como nas unidades de referência dos SUS local. Em 2001, o mesmo DSEI prestou 2.863 consultas e referiu apenas 110 casos (ou seja, 3,8\% das consultas resultaram em referência), numa performance difícil de explicar apenas pela melhoria de resolutividade em espaço tão curto de tempo. No DSEI Manaus, por sua vez, ocorreu o oposto: em 2000 foram prestadas 5.936 consultas e houve 1.815 referências ( $30,5 \%$ das consultas resultando em referência), ao passo que em 2001 o número de consultas aumentou para 7.044, elevando igualmente o número de referências para 4.182 (59,3\%).

Os entrevistados foram unânimes em atribuir o alto índice de encaminhamentos à baixa capacidade resolutiva da rede municipal ou estadual de saúde que opera como referência distrital. Porém, essa justificativa não é capaz de explicar os dados oriundos do DSEI Médio Purús, que referiu apenas 1,9\% e 8,9\% dos atendimentos médicos para 2000 e 2001, respectivamente (Tabela 7). De modo análogo, o DSEI Alto Solimões referiu em 2000 apenas $0,2 \%$ dos 30.883 atendimentos (a falta de dados para 2001 não permitiu verificar se a baixa tendência de encaminhamentos se manteria). Ocorre que as regiões onde se assentam tais distritos são áreas que também contam com redes de serviços de baixa resolutividade, ficando inexplicada a razão de uma proporção tão reduzida de encaminhamentos. 


\section{Dados epidemiológicos}

Nos planos distritais de 2000 e 200l, encontramos quadros de monitoramento e avaliação de atividades ordenados segundo uma lógica epidemiológica como, por exemplo, a previsão de se avaliar o índice de mortalidade infantil, mortalidade materna, percentual de nascidos vivos de baixo peso, incidência de tuberculose, etc. Entretanto, nos relatórios das conveniadas enviados à Coordenação Regional do Amazonas não encontramos informações sobre o desempenho obtido em relação a estes indicadores de avaliação. Tal situação parece indicar que, embora previstos, não existem mecanismos ativos de avaliação do desempenho das convenentes nessa dimensão da programação. Tal indicativo se confirma pelo fato de que o sistema de informação em saúde indígena (SIASI) não está operante e em condições de oferecer, até o momento, dados epidemiológicos que subsidiem a elaboração de indicadores de avaliação e propiciem uma análise de resultados.

A notificação de agravos que vem sendo feita pelas equipes dos DSEIs tem consistido apenas no registro de número absoluto de casos de doenças, sem a construção dos indicadores que permitam uma adequada expressão do perfil epidemiológico da população indígena sob sua responsabilidade. A notificação é feita por pólo-base5, não havendo agregação dos dados no plano distrital. Os dados são enviados de forma bruta para o nível central da FUNASA em Brasília, configurando uma centralização da informação que dificulta análises regionais e inviabiliza seu retorno em tempo hábil para subsidiar as programações de atividades nos distritos. Além disso, muitos desses diagnósticos são notavelmente imprecisos. A leitura dos relatórios de atividades permite que encontremos notificações como as que se seguem:

- Exemplo 1. Principais doenças encontradas: gripe (549), pneumonia (71), tosse crônica (121), diarréia (351), verminoses (1.316), dor nas costas (152)6. - Exemplo 2. Total de casos notificados de doenças de maior incidência por pólo-base: verminose: Barreira das Missões (71)7, Marajaí (203), Morada No-

\footnotetext{
5 No subsistema de saúde indígena, pólo-base é a denominação de um tipo de unidade de saúde que comporta ações mais complexas que aquelas disponíveis no posto indígena de saúde, ofertando atendimento médico, de enfermagem e alguns recursos laboratoriais. 6 Fonte: Relatório de Atividades do DSEI Rio Negro. 2000.

7 O número entre parênteses corresponde ao número absoluto de casos notificados no pólo base, cuja identificação está à esquerda do parêntese.
} 
va (135), Kumarú (187); IRA: Barreira das Missões (74), Marajaí (229), Morada Nova (160); DST: Barreira das Missões (0), Marajaí (12), Morada Nova (0), Eirunepé (12); cefaléia: Kumarú (87)8.

Os dados acima, oriundos de documentos oficiais, não permitem análises epidemiológicas consistentes, pois não estão notificados por grupo etário e não seguem a CID-10, não havendo caracterização precisa do tipo de agravo, em geral designado por um termo genérico como "DST" ou "verminose".

Não encontramos na Coordenação Regional do Amazonas notificações de mortalidade. No entanto, uma rápida consulta aos arquivos da FUNASA, em Brasília, permitiu observar que a informação disponível no nível central do órgão é um pouco mais detalhada, comportando a distribuição do número absoluto de casos e óbitos por grupo etário, ainda que os diagnósticos permaneçam imprecisos.

De acordo com os dirigentes da FUNASA em Brasília, o órgão está consolidando a informação do número absoluto de óbitos e casos de doença por DSEI, embora a análise dos indicadores pertinentes não esteja ainda disponível no SIASI. Da consulta feita nesses arquivos, foi possível observar que, para o ano de 2000, foram notificados 1.823 óbitos de indígenas para todo o Brasil, em todas as faixas etárias. Desses, 1.541 ocorreram na faixa de $0-4$ anos, ou seja $84,5 \%$ dos óbitos. Para 2001, os dados só estavam consolidados de janeiro a junho, período quando foram notificados 1.268 óbitos, dos quais $587(46,2 \%)$ em crianças de 0 4 anos. Apesar de incompletos, os dados disponíveis sugerem que a mortalidade em crianças desponta como um grave problema a ser equacionado pelo subsistema de saúde indígena.

Para os DSEIs do Amazonas somente foi possível obter informações sobre os óbitos ocorridos em 2000, num total de 24l. Desses, 106 (43,9\%) derivavam do grupo etário de 0-4 anos. A análise da proporção de óbitos infantis por distrito mostra que no DSEI Parintins 63,8\% do total de óbitos notificados em 2000 foram de crianças de 0-4 anos, ao passo que os DSEIs Médio Purús, Médio Solimões e Rio Negro ficaram na faixa dos $45 \%$ do total das notificações. A menor proporção ocorreu no DSEI Alto Solimões, onde os óbitos infantis notificados corresponderam a $29,7 \%$ do total. No caso do DSEI Manaus, o porcentual foi de $33,3 \%$.

\section{Ações programáticas}

Dentre os instrumentos analisados, o Relatório de Acompanhamento do Plano Anual de Trabalho, um documento de âmbito nacional da FUNASA, já imple- 
mentado na Coordenação Regional do Amazonas, é o único que permite auferir em algum detalhe as atividades dos DSEIs dirigidas às ações de promoção e prevenção. A análise dos dados registrados nesse relatório demonstrou um franco desconhecimento das normas técnicas de controles de agravos. Assim, foi possível encontrar descrições de metas de programa como as abaixo registradas9:

- Reduzir em $50 \%$ os casos de IRA - índice atual: 1568; índice esperado: 723;

- Reduzir em $50 \%$ os casos de malária - índice atual: 198; índice esperado: 195;

- Reduzir em $100 \%$ os casos de tuberculose notificados - índice atual: 28; índice esperado: 0;

- Atingir $100 \%$ das aldeias com cobertura vacinal adequada em menores de 1 ano: BCG, poliomielite, DTP, sarampo, febre amarela - índice atual: $4,5 \%$; índice esperado: $100 \%$;

- Reduzir em $50 \%$ a incidência de doenças endêmicas - índice atual: $20 \%$; índice esperado: $50 \%$;

- Reduzir em $15 \%$ os casos de malária - índice atual: $85 \%$; índice esperado: $15 \%$;

As frases acima foram literalmente transcritas do documento citado, $\mathrm{e}$ nelas se evidencia o não seguimento de normas técnicas adotadas no país pelos programas de controle de agravos, os quais têm formas sistemáticas de calcular suas metas e adotam índices definidos de avaliação de impacto, que não aparecem no documento. Nele também se observa a persistência do registro de número absoluto de casos, em campos onde são pedidos os indicadores. Os registros passam a impressão geral de que os profissionais envolvidos com as ações de gerenciamento nas entidades terceirizadas têm pouca experiência com a saúde pública. Tal impressão foi confirmada por meio das entrevistas realizadas. Concordando com Rattner (1996), diríamos que normas técnicas podem ser seguidas ou contestadas, mas elas representam informações científicas testadas e validadas,

\footnotetext{
8 Fonte: Relatório e Supervisão Técnica do Convênio FUNASA/UNI-Tefé, DSEI Médio Solimões, janeiro-junho de 2001. O relatório foi elaborado por técnicos da Divisão de Vigilância Epidemiológica da Coordenação Regional da FUNASA, Amazonas.

9 Fonte: Quadros de Acompanhamento do Plano Anual de Trabalho - PAT 2001, da Coordenação Regional do Amazonas. Dados referentes à atuação dos DSEI Médio Solimões, Rio Negro, Médio Purús, Javari, Alto Solimões.
} 
reconhecidas como capazes de viabilizar comparações entre diferentes realidades. Portanto, não deveriam ser pura e simplesmente ignoradas por dirigentes e executores de ações básicas de saúde.

Dentre os entrevistados encontramos algumas pessoas responsáveis pelo fornecimento das informações contidas no Relatório de Acompanhamento do Plano Anual de Trabalho, que alegaram não ter recebido treinamento para o manejo adequado do instrumento, adotado pela Coordenação Regional para avaliar seu desempenho anual. Tal explicação, porém, não parece capaz de explicar o registro de metas tão vagas, como a proposta de redução de $50 \%$ da incidência de doenças endêmicas, ou aquelas baseadas em percentuais ou números absolutos de casos, sem especificação de grupos etários a serem atingidos, tal como é exigido no Programa de Imunização, ou ainda o não uso de indicadores largamente conhecidos como é o IPA (índice parasitário anual), usado no controle da malária.

Em relação à malária cabe ressalvar a existência de um sistema de registro paralelo, o SISMAL, manejado pela FUNASA, que tem fornecido dados epidemiologicamente adequados sobre a situação da endemia no subsistema de saúde indígena. Em contrapartida, apesar da existência de informações acumuladas desde 1992 sobre a situação vacinal das populações indígenas no Amazonas, não encontramos o uso delas pelas equipes dos DSEIs.

A reprodução de uma página do Relatório de Acompanhamento do Plano Anual de Trabalho para 2001 permite observar que o instrumento prevê um campo intitulado Situação, onde deveriam ser descritas as situações epidemiológicas e operacionais das ações programáticas em pauta (Figura 1). Não apenas nesse caso, mas também em todo o relatório, esses campos foram preenchidos com descrições vagas de atividades realizadas, não havendo referência às metas programadas, nem à caracterização de problemas e necessidades de saúde ou a uma avaliação de ações implementadas ao longo do ano.

Por meio do mesmo exemplo é possível questionar ainda sobre a previsão/programação das etapas de implantação do programa de doenças crônico-degenerativas, que não são congruentes com as ações previstas pclo MS. Aliás, a ausência de dados torna impossível saber se esse tipo de agravo tem relevância epidemiológica, capaz de defini-lo como uma prioridade a ser contemplada no plano distrital.

Não existem dados sistemáticos sobre os níveis de satisfação dos usuários indígenas, mas a observação participante em reuniões de conselhos de saúde e em fóruns e reuniões de controle social promovido pela FUNASA e pelas entidades do movimento indígena mostra que as lideranças das entidades etnopolíticas 
Figura 1

Reprodução de uma página do Relatório de Acompanhamento do Plano Anual de Trabalho para 2001/Coordenação Regional do Amazonas.

Comitê Regional de Planejamento - COREPLAN Quadro de Acompanhamento do Plano Anual de Trabalho - PAT/2001.

Programa de Prevenção e Controle de Doenças e outros Agravos à Saúde

Ação - Implantar o programa de controle de doenças crônico-degenerativas.

Objetivos Específicos

\begin{tabular}{l|l} 
Atores: FUNASA, ONGs, Prefeitura, DSEI. & Responsável: DSEI Médio Purús
\end{tabular}

\begin{tabular}{|c|c|c|c|}
\hline Meta & : : & Indice Atual & $\begin{array}{l}\text { Indice } \\
\text { Esperado }\end{array}$ \\
\hline $\begin{array}{l}\text { Realizar diagnósticos situacionais dos casos } \\
\text { de hipertensão arterial e diabetes entre os índios. }\end{array}$ & $\begin{array}{l}\text { Diagnósticos } \\
\text { realizados }\end{array}$ & - & - \\
\hline
\end{tabular}

\begin{tabular}{|c|c|c|c|}
\hline Etapas & Início & Final & Situação \\
\hline $\begin{array}{l}\text { - Realizar supervisão em loco } \\
\text { para verificação de índices } \\
\text { a serem estabelecidos; } \\
\text { - Realizar busca ativa de } \\
\text { hipertensão arterial e diabetes; } \\
\text { - Realizar controle e tratamento } \\
\text { dos casos diagnosticados. }\end{array}$ & $10 / 2001$ & $12 / 2001$ & $\begin{array}{l}\text { Quando a equipe de saúde vai para } \\
\text { a aldeia é realizada busca ativa de } \\
\text { casos de hipertensão, realizamos } \\
\text { tratamento dos casos diagnosticados. } \\
\text { Fazemos orientações aos hipertensos } \\
\text { nas visitas domiciliares. Os casos mais } \\
\text { graves são referenciados para CASAI. } \\
\text { Não dispomos de dados quantitativos. }\end{array}$ \\
\hline
\end{tabular}

Fonte: Relatório de Acompanhamento 2001 do Plano Anual de Trabalho, p. 40, Coordenação Regional do Amazonas/FUNASA. 
demonstraram, ao longo de 2002 e 2001, um alto grau de satisfação com a política de distritalização 10 . Tal satisfação decorre principalmente da participação das organizações indígenas como executoras de uma política pública destinada aos seus representados, e da alocação de recursos materiais que concretizam a implantação dos distritos sanitários na forma de equipamentos, como barcos, motores, rede de radiofonia, medicamentos e pagamento regular de salários aos agentes de saúde. Contudo, a observação de reuniões de conselhos locais e distritais realizadas ao longo de 2002 permitiu ouvir uma espiral crescente de reclamações, feitas por comunitários e conselheiros locais de saúde, incomodados com a freqüente interrupção e/ou descumprimento das atividades previstas nos planos distritais.

\section{COMENTÁRIOS FINAIS}

Os dados apresentados neste capítulo são eloqüentes por si próprios, cabendonos apenas sintetizar algumas das questões mais candentes do terna tratado.

A primeira delas refere-se à constatação de que o processo de distritalização viabilizou uma real extensão de cobertura da atenção à saúde da população indígena aldeada, tendo registrado um significativo incremento na alocação de recursos humanos e materiais, que representam - pelo menos no caso do Amazonas - um montante proporcionalmente superior àquele disponível nos outros níveis de referência do SUS. A incorporação da saúde indígena pelo MS constituiu um importante passo para a integração das iniciativas sanitárias destinadas a essas sociedades, e para o avanço da política nacional de saúde com suas propostas de universalização, eqüidade, participação, democratização e controle social, superando o modelo campanhista praticado pela FUNAI. Viabilizou também a chamada das organizações indígenas para exercer uma parceria com as instituições governamentais, inaugurando um protagonismo até então desconhecido na política indigenista brasileira.

Entretanto, o modelo demonstra um alto grau de centralização de poder de decisão e de controle dos recursos, exemplificado pela peregrinação periódica das convenentes ao nível central da FUNASA em Brasília, onde são efetuadas as negociações anuais de cada convênio. A centralização contribui para um insuficiente acompanhamento técnico das ações terceirizadas, algo que se faz bastante necessário face à verificada inexperiência das ONC;s convenentes com temas e programas da área da saúde pública. 
Após quase quatro anos de distritalização, o sistema de informações sobre saúde indígena permanece operando apenas com um módulo de demografia e não vem produzindo informações epideniológicas c operacionais capazes de subsidiar as programiações. Vale ressaltar que nem mesmo os dados demográficos estão disponibilizados e acessíveis aos interessados. A alimentação manual do registro de agravos, aliada à remessa de dados epidemiológicos direto para Brasília, sem a passagem pela instância regional, retarda ou mesmo impede o uso da informação nos espaços locais de atuaçãoll. Tais trâmites reduzem a já pouca participação das coordenações regionais da FUNASA na programação e avaliação das ações pactuadas.

() atraso ou descumprimento das obrigações de envio de informações pelas convenentes dificulta o acompanhamento técnico das ações, sobrecarregando a gerência técnica de Brasília com problemas oriundos de l)SFis de todo Brasil. Por outro lado, a mão-de-obra das coordenações regionais permanece subutilizada, sem um envolvimento efetivo no gerenciamento regular das ações distritais.

Cabe ressaltar que a multiplicidade atual de instrumentos de coleta de dados, não raro contraditórios, sobrecarrega os gerentes distritais e entidades conveniadas, encarregados de produzir diversos relatórios repetitivos que não vêm encontrando aplicação prática no sistema. A informação disponivel não permite que se tenha idéia do impacto e efetividade das atividades desenvolvidas, ou da adequação ou inadequação da relação custo-benefício, pois os dados expressam mais os problemas e distorções atuais do subsistema de saúde indígena do que a situlação sanitária da população alcançada pelos DSFis.

Apesar da explicitada prioridade de ações programáticas, voltadas para a prevenção de agravos e promoção à saúde, a análise documental e os depoimentos dos cntrevistados comprovam que os ISSFils não lograram superar a pressão

11) A esse respeito, pode-se consultar os relatórios do encontro Macrorregional Preparatório para a III Conferência Nacional de Satide, o relatório do encontro de avaliação dos DSEls organizado pela COIAB e o texto de (arnelo \& Sampaio (2001).

11 Da mesma forma, foi possível observar a insatisfação dos dirigentes dos sistemas municipais de saúde que servem de referência para os DSFI, pelo não recebimento de dados gerados pelas equipes de saúde do índio; tal fato gera um paralelismo de informações, compronete o cumprimento de metas previstas na PPI e o registro das docnças de notificação compulsória (ue ocorrem no município, além de fragilizar o papel do gestor municipal, responsável legal pelas condiçôes sanitárias do município. 
da demanda espontânea, voltada para procedimentos curativo-individuais, resultando em uma baixa resolutividade, ilustrada pelos altos índices de referência para fora do sistema distrital.

Percebe-se também que existe um fraco nível de articulação e integração com os níveis de referência do SUS, que no Amazonas também apresentam graves dificuldades estruturais, com importante comprometimento de sua capacidade resolutiva. Igualmente não encontramos, seja nos planos distritais ou nos relatórios analisados, ações intersetoriais capazes de encaminhar ou equacionar os graves problemas de geração de renda e de acesso aos alimentos, enfrentados pelas populações indígenas.

A presente análise não é exaustiva. Contudo, consideramos que fornece indícios que apontam para a necessidade de melhorar a qualidade do trabalho desenvolvido nos DSEIs, corrigir distorções técnico-operacionais, promover um gerenciamento mais racional dos recursos e buscar um aprimoramento dos instrumentos de pactuação com as terceirizadas. Com isso, será possível contornar ou reduzir dificuldades inerentes ao modelo e garantir qualidade e continuidade das ações distritais de saúde.

A proposta da distritalização é inovadora e carrega, em si própria, o mérito de redimensionar - por intermédio de uma política setorial como a saúde as relações do Estado brasileiro com as sociedades indígenas. Ao pactuar com as entidades etnopolíticas, o MS abre um novo capítulo nas relações do Estado com a sociedade civil, invertendo uma tendência histórica da política indigenista marcada por um etnocentrismo desenvolvimentista pouco sensível às necessidades e peculiaridades das sociedades indígenas.

\section{Agradecimentos}

Os autores agradecem aos técnicos da Coordenação Regional do Amazonas, do Departamento de Saúde Indígena/DESAI da Fundação Nacional de Saúde e aos entrevistados das organizações não-governamentais que atuam nos DSEIs, não apenas por terem propiciado o acesso aos dados, mas também pelas estimulantes discussões que viabilizaram as análises contidas no texto. 


\section{Referências}

CONTANDRIOPOULOS, A.; CHAMPGNE, F.; DENIS, J.-L. \& PINEAULT, R. A., 2000. Avaliação na Área de Saúde: conceitos e métodos. In: Avaliação em Saúde. Dos Modelos Conceituais à Prática na Análise da Implantą̧ão de Programas (Z. M. A. Hartz, org.), pp. 29-48, Rio de Janeiro: Editora Fiocruz.

FERNANDES, R., 1994. Privado Porém Público: O Terceiro Setor na América Latina. Rio de Janeiro: Relume-Dumará.

GARNELO, L., 2002. Organizações indígenas e distritalização sanitária: Os riscos de fazer ver e fazer crer nas políticas públicas de saúde. Trabalho apresentado na 23a Reunião Brasileira de Antropologia, Gramado: Associação Brasileira de Antropologia.

GARNELO, L. \& SAMPAIO, S., 2001. Bases socioculturais do controle social em saúde indígena: Problemas e questões na região norte do Brasil. Trabalho apresentado no VII Encontro de Antropólogos do Norte e Nordeste, Recife: Associação Brasileira de Antropologia.

GARNELO, L. \& SAMPAIO, S., 2002. Controle social em saúde indígena - Reflexões sobre a III Conferência de Saúde Indígena. Trabalho apresentado na 23a Reunião Brasileira de Antropologia, Gramado: Associação Brasileira de Antropologia.

RATTNER, D., 1996. A Epidemiologia na avaliação da qualidade: Uma proposta. Cadernos de Saúde Pública, 12(Sup. 2):21-32. 
impresso nas oficinas

da Imprinta Gráfica e Editora Ltda. .

à Rua João Romariz, 285 - Rio de Janeiro. 